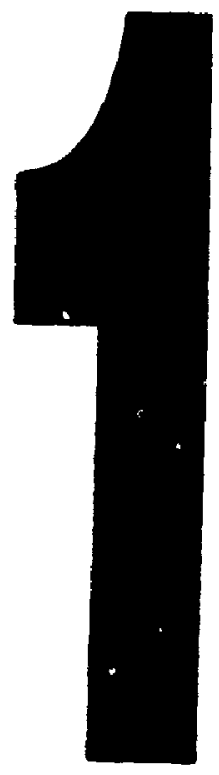

PM-1 31/2" $x$ 4" PHOTOGRAPHIC MICROCOPY TARGET NBS 1010a ANSIIISO \#2 EQUIVALENT

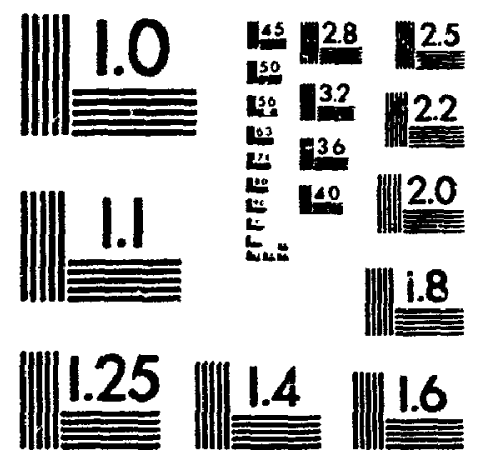

PRECISIONSM RESOLUTION TARGETS 
National Library

of Canada

Acquisitions and

Bibliogranhic Services Branch

395 Wellington Street

Ottawa. Ontaro

K1A ON4
Bibliothequ !e naticnale

du Canar' 1

Directir., des acquisitions et

des services biblingraphiques

395. rue Wellington

Ottawa (Ontano)

Kisin4
Yau the volte refe ence

Our the Novren coterence

NOTICE

AVIS

The quality of this microform is heavily dependent upon the quality of the original thesis submitted for microfilming. Every effort has been made to ensure the highest quality of reprosustion possible.

If pages are missing, contact the university which granted the degree.

Some pages may have indistinct print especially if the original pages were typed with a poor typewriter ribbon or if the university sent us an inferior photocopy.
La qualité de cette microforme dépend grandement de la qualité de la 'hèse soumise au microfilmage. Nous avons tout fait pour assurer une qualité supérieure de reproductior

S'il manque des pages, veuillez communiquer avec l'université qui a conféré le: grade.

La qualité d'impression de certaines pages peut laisser à désirer, surtout si les pages originales ont été dactylographiées à l'aide d'un ruban usé ou si l'université nous a fait parvenir une photocopie de qualité inférieure.

La reproduction, même partielle, de cette microforms est soumise à la Loi canadienne sur le droit d'auteur, SRC 1970, c. C-30, et ses amendements subséquents.
Reproduction in full or in part of this microform is governed by the Canadian Copyright Act,

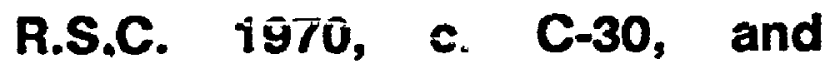
subsequent amendments. 


\title{
Ramp Metering Methodology: The Ottawa-Carleton Case.
}

\author{
By \\ Richard Atta - Armah, BSc (Civil) \\ University of Science \& Technology, \\ Kumasi, Ghana.
}

\begin{abstract}
A Thesis Submitted to the Faculty of Graduate Studies \& Research in Partial Fulfilment of The Requirements For The Degree of
\end{abstract}

\author{
Master of Enginetring \\ Department of Civil and Environmental Engineering, \\ Carleton University \\ Ottawa, Canada \\ October 1994
}

The Master of Engineering in Civil and Environmental Engineering Program is a Joint Program with the University of Ottawa, Adminisitered by the Ottawa Carleton-Institute of Civil Engineering

C Atta-Armah, R 1994 
National Library

of Canada

Acquisitions and

Bibliographic Services Branch

395 Wellington Street

Otlawa, Ontario

K1A ON4
Bibliotheque nationale

du Canada

Direction des acquisitions of

des services bibliographiques

395, rue Wellington

Ottawa (Ontario)

KIA ON4
Your the Votre nenerence

Our niv Notre cettenence
THE AUTHOR HAS GRANTED AN IRREVOCABLE NON-EXCLUSIVE LICENCE ALLOWING THE NATIONAL LIBRARY OF CANADA TO REPRODUCE, LOAN, DISTRIBUTE OR SELL COPIES OF HIS/HER THESIS BY ANY MEANS AND IN ANY FORM OR FORMAT, MAKING THIS : HESIS AVAILABLE TO INTERESTED PERSONS.
L'AUTEUR A ACCORDE UNE LICENCE IRREVOCABLE ET NON EXCLUSIVE PERMETTANT A LA BIBLIOTHEQUE NATIONALE DU CANADA DE REPRODUIRE, PRETER, DISTRIBUER OU VENDRE DES COPIES DE SA THESE DE QUELQUE MANIERE ET SOUS QUELQUF. FORME QUE CE SOIT POUR METTRE DES EXEMPLAIRES DE CETTE THESE A LA DISPOSITION DES PERSONNE INTERESSEES.
THE AUTHOR RETAINS OWNERSHIP OF THE COPYRIGHT IN HIS/HER THESIS. NEITHER THE THESIS NOR SUBSTANTIAL EXTRACTS FROM IT MAY BE PRINTED OR OTHERWISE REPRODUCED WITHOUT HIS/HER PERMISSION.
L'AUTEUR CONSERVE LA PROPRIETE DU DROIT D'AUTEUR QUI PROTEGE SA THESE. NI LA THESE NI DES EXTRAITS SUBSTANTIELS DE CELLECI NE DOIVENT ETRE IMPRIMES OU AUTREMENT REPRODUITS SANS SON AUTORISATION.

ISBN $\quad 0-315-98570-4$ 
Name RICHARD ATTA-ARMAH

Dissertation Abstracts International is arranged by broad, ganeral subject categories. Please select the cne subject which most nearly describes the content of your dissertation. Enter the corresponding four-digit code in the spaces provided.

CIVIL ENGINEERING

\section{SUSUECT TERM}

$01514[3] \mathrm{U} \cdot \mathrm{M} \cdot \mathrm{I}$ SUDUET CODE

\section{Subjoct Casegories}

\section{THE HUMaNmins AND social scInNCIS}

COMnuHKatons AND THE ARTS

Archilucture ............................0729

Ant History ............................0377

Clinma .................................0900

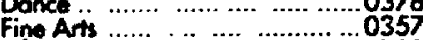

Journalism ...........................0391

Librar Science ........................0399

Speoch Communicotion .............0459

Speoch Communication ............0465

EDUCArion

Administration …........................5515

Adult and Continuing -...............0516

Agricultural .........................0517

Bilingual and Mulficultural ........ 0282

Business ..........................0688

Community Cailoge.................0275

Eorly Childhood ....................0518

Finance ............................. 0277

Guidence and Counseling ........ 0519

Hoolth . and Co ................. . 0680

Higher .................................0745

History of .. …..................... 0520

Industrial .

language and literature ........... 0279

Mothematics .................... 0280

Music ................................... 0522

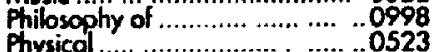

information Science ......................0723

Mass Cortmunicstions ............ 0708

Elementary .......................0524
Psychology .............................. 0525

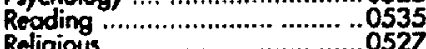

Religious ................................ 0527

Sociol Sciences ...........................0534

Sociology of ........................... 0340

Socioulogy of ............................0529

Special Training .............................0530

Tochnology ............................0710

Vocationol ................................0747

\section{UACUAGE, UTEZATURE ANO} UnCUISTICS

Languay:

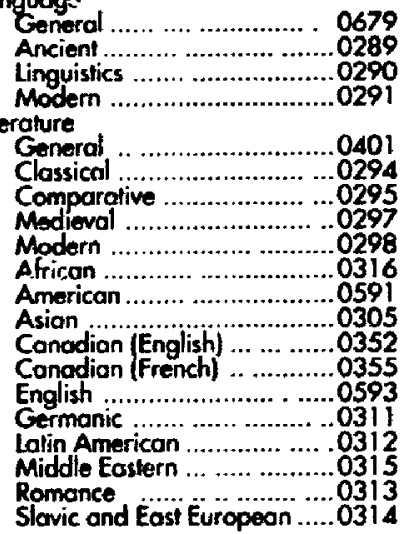

Sciences ............................. 0714

\section{FHLOSOPHY, RELGLN AND}

\section{THFOLOCY}

Philosophy ............................0422

Religion

General ..........................0318

Biblical Studies ……............0321

Clergy .............................. 0319

Philosophy of .......................0322

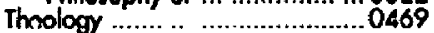

\section{socinl salences}

American Studies ......................0323

Anthropology

Archoeology .....................0324

Cultural .............................. 0326

usiness Administration

General ..........................0310

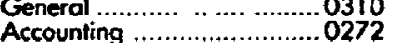

Bonking ................................ 0770

Management ................... 0454

Canadion Studies ........................0385

Economics

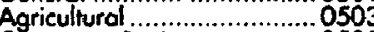

Commerce-Business …….... 0505

Finnence .........................0508

History .......................... 0509

Theory ………..............................

Folklore ……............................0358

Geography............................0366

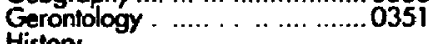

History

General

.0578
Generol ......... 050

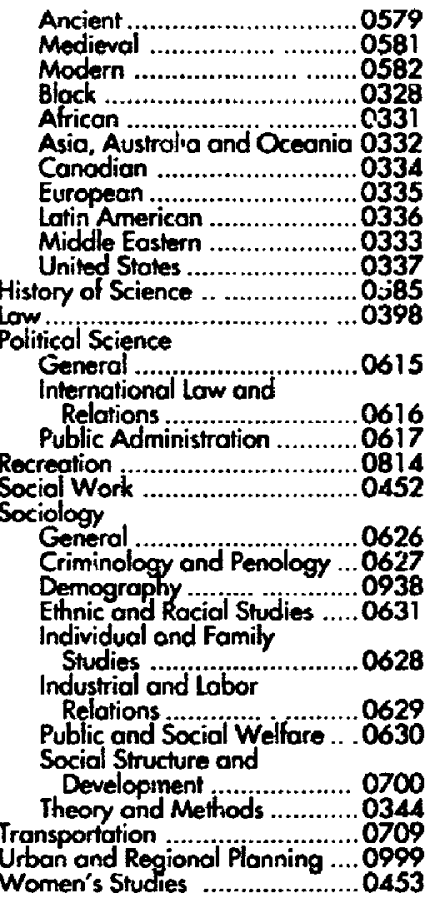

Speech Potholo, 1 ..........0460

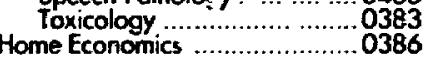

Geodesy .................................037

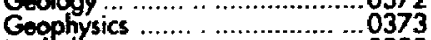

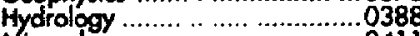

Mineralogy ............................0411

Paleoecology ........................ 0426

Paleontology ……..................0985

Poleozoology …................0985

Polynotoly ........................ 0427

Physical Oceonography........0415

\section{HEATH AMD ENVIRONMENTAL}

\section{SCENCS}

Ronge Manogement ...........0746

- $\log y$

General .....0306

Anatomy ........................... 0289

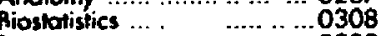

Bofony .... .. .............. 0309

Ecology ... ....... .... ..0329

Eniomology ......... . ...... 0353

Genetics.................. . . . 0369

Limnology ...... ..... .0793

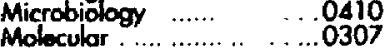

Neuroscience.................. . . 317

Oceanography .........0416

Physiology . ............ 0433

Rodiotion.

Zoology . .................0472

Biophysics

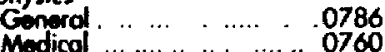

MTH Saydes

Biogechemistry

.0425
.0996
Environmental Sciences .............0768 Hoolth Sciences

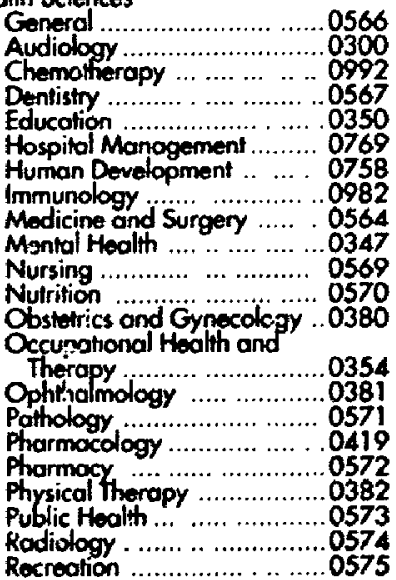

\section{PHYSICAL SCIEWEES}

\section{Pure Sciences}

Chemistry

General ..........................0485

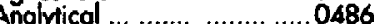

Biochemistry ..................0487

inorganic .............................0488

Organic .............................0490

Physical ................................0494

Polymer … ...................0495

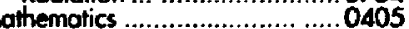

Physics

Generd ........................0605

Acoustics ........

Astrophysics .....................0606

Almospheric Science ............0608

Alomic ...........................0748

Electronics and Electricily ... 0607

Elementory Particles and

High Energy ......................0798

flutd and Plasma .................... 0759

Mustecular ...........................0609

Nuclear ................................0610

Optics ...............................0752

Rodialion .......................... 075

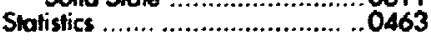

Applied Sciences

Applied Mochanics

Computer Science

.0346
Nuclear ..........................0738

\section{Engineering}

Women's Studies

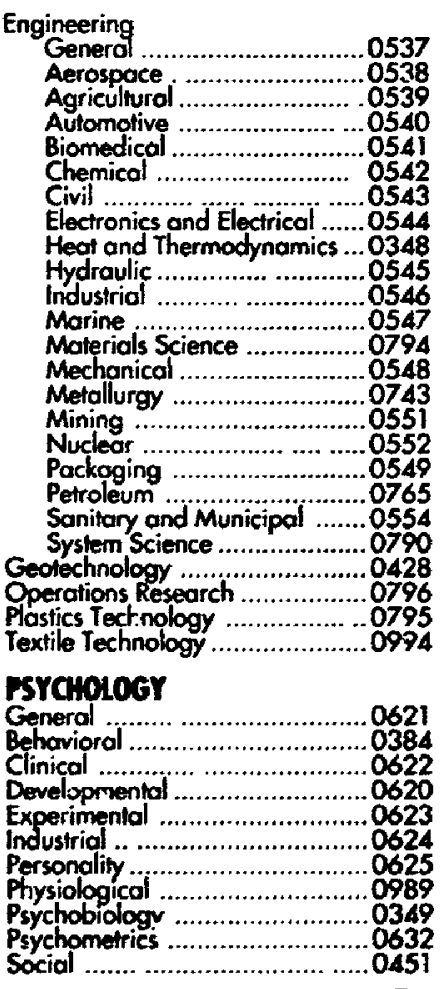

Agricultural .......

Automotive ….................. 0540

0542

Coctronies and Electrical 0544

Heot and Thermodynamics ...0348

Hydraulic ...........................0545

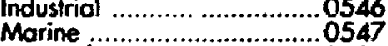

Materials Science ...............0794

Mining

Nucte........................ 0552

Packoging ….....................0549

Petroleum and Municipal ........0565

System Science....

Geotechnology ..........................0428

Plastics Tect nology .......................0795

Textile Technology 


\section{Carieton University Ottawa, Canada K1S5J7}

Thesis contains black and white and/or coloured graphs/tables/photographss which when microfilmed may lose their significance. The hardcopy of the thosis is available upon request from Carleton University tibrary. 
Department of Civil and Environmental Engineering

The undersigned recommends to the Faculty of Graduate Studies and Research acceptance of the thesis

"Ramp Metering Methodology: The Ottawa-Carieton Case" by

Richard Atta- Armah, BSc. (Civil).

in partial fulfilment of the requirements for the degree of Master of Engineering

A. on - Khan

Thesis Supervisor

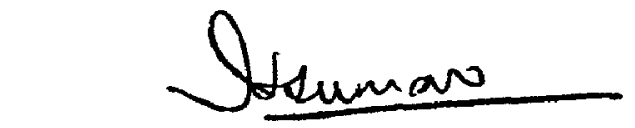

Chairman, Dept of Civt Engineering

Carleton University

Ottawa Canada

October 1994 
Dedicated to my parents Mr \& Mrs JEK Armah 


\section{ABSTRACT}

Many large cities are using or planning to use advanced traffic control systems to improve the efficiency of traffic movement in their travel corridors. Ramp metering is a very effective technique, which releases traffic volume entering urban freeways, especially at peak periods, in measured quantities, such that stop and go, and erratic traffic conditions are eliminated and freeway travel times are reasonably predictable. Although its success in most cities where it has been used has resulted in its increasing use, the benefits have been limited to the freeway users, due to lack of co-ordination, co-operation \& communication of metering strategies with area-wide traffic management activities in the travel corridor.

This thesis presents a ramp metering methodology, evaluates its impacts in the corridor, and ensures that all intersection approaches on alternate routes and its crossing streets operate at selected levels of ayerage stopped delay or better.

The methodology was demonstrated in the Ottawa Queensway freeway corridor. using optimization and simulation techniques. Finally, guidelines for the implementation of the methodology through an advanced traffic management system are described. 


\section{ACKNOWLEDGEMENTS}

I wish to express my sincere gratitude to, Professor A.M. Khan, my thesis supervisor, for his help, encouragement, guidance and support throughout my thesis.

I also wish to thank the Natura' Sciences and Engineering Research Council (NSERC) for the research grant provided through Pinfessor Khan.

I am very grateful to the staff of the Freeway Traffic Management Department, Ministry of Transportation of Ontario (MTO) Kingston and Toronto, especially Bert Knight who was always ready and available for discussions, and suggestions.

My deep gratitude to R.J. Wilson of Bell Northern Research (BNR) and William AttaArmah for their support in many diverse ways through my entire studies.

I also wish to acknowledge llyas Choudry for his assistance during the travel time studies.

Finally I rvish to express my sincere appreciation to Greg Kent, RMOC planning department; Greg Sergeant and John Fraser RMOC signals department; Ken Vallier and Bill Brannen, MTO Ottawa; and Stanley Conley, Civil Engineering Department, Carleton University for their generous co-operation during this research. 


\section{TABLE OF CONTENTS}

Acceptance Sheet. ...................... ii

Abstract .......................... $\ldots \ldots$ iv

Acknowledgements $\ldots \ldots \ldots \ldots \ldots \ldots \ldots \ldots \ldots \ldots \ldots$

Table of Contents $\ldots \ldots \ldots \ldots \ldots \ldots \ldots \ldots \ldots \ldots \ldots \ldots$

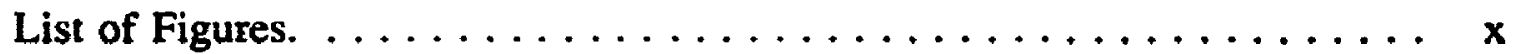

List of Tables $\ldots \ldots \ldots \ldots \ldots \ldots \ldots \ldots \ldots \ldots \ldots \ldots \ldots \ldots$

Glossary and Atoreviations $\ldots \ldots \ldots \ldots \ldots \ldots \ldots \ldots \ldots$

\section{CHAPTER 1}

INTRODUCTION

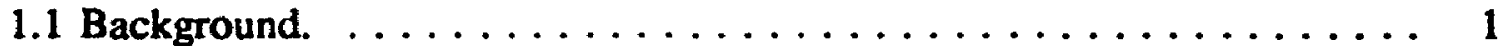

1.2 What is ramp metering? . . . . . . . . . . . . . . . . 6

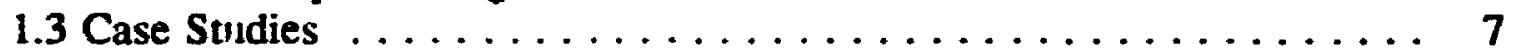

1.4 Problem Definition . . . . . . . . . . . . . . . . . . 11

1.5 Research Objectives and Scope. . . . . . . . . . . . . . . 12

1.6 Thesis Outline: $\ldots \ldots \ldots \ldots \ldots \ldots \ldots$

\section{CHAPTER 2}

\section{RESEARCH FRAMEWORK}

2.1 Research Need . . . . . . . . . . . . . . . . . . . 15

2.2 Measurement of Effectiveness .................. 18

2.3 Research Approach . . . . . . . . . . . . . . . . . . . . . . 19

2.3.1 Capacity Analysis Module ................ 20

2.3.2 Freeway Control module ................. 23

2.3.3 Surface Street module . . . . . . . . . . . . . . . 23

2.3.4 Effectiveness Module . . . . . . . . . . . . . . . . 24

2.4 Current Models Available . . . . . . . . . . . . . . . . . 24

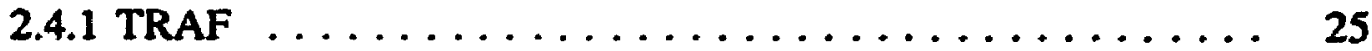

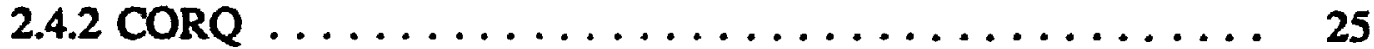

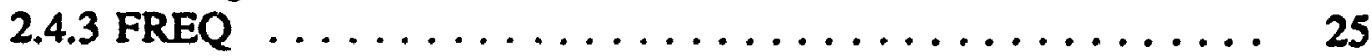

2.4 .4 INTRAS . . . . . . . . . . . . . . . . 26

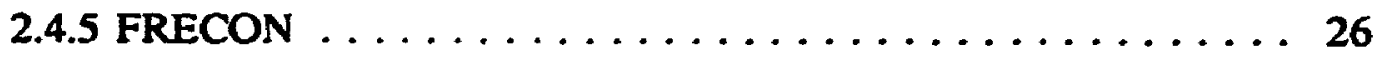

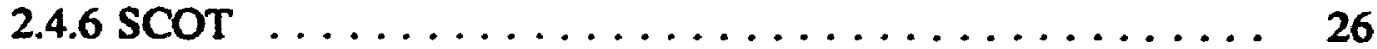

2.4 .7 INTEGRATION $\ldots \ldots \ldots \ldots \ldots \ldots \ldots \ldots \ldots \ldots$

2.4 Why Simulation? ... . . . . . . . . . . . . . . . 30 


\section{CHAPTER 3}

FREEWAY TRAFFIC: CONTROL \& FLOW

3.1 Ramp Metering and IVHS . . . . . . . . . $\ldots \ldots \ldots$

3.2 Advanced Traveller Informution . . . . . . . . . . . 34

3.3 Advanced Fleet Management Systems $\ldots \ldots \ldots \ldots \ldots \ldots \ldots . \ldots 35$

3.4 Advanced Transportation Management Systems . . . . . . . . 36

$3.5 \wedge$ dvanced Vehicle Control Systems $\ldots \ldots \ldots \ldots \ldots \ldots \ldots \ldots . \ldots 37$

3.6 Freeway Traffic Management Systems $\ldots \ldots \ldots \ldots \ldots \ldots \ldots \ldots 38$

3.7 Types of Metering $\ldots \ldots \ldots \ldots \ldots \ldots \ldots \ldots \ldots \ldots \ldots$

3.7.1 Ramp Closure .................... 41

3.7.2 Pretimed Metering $\ldots \ldots \ldots \ldots \ldots \ldots \ldots \ldots \ldots \ldots, 42$

3.7.3 Traffic Responsive Metering ............. 44

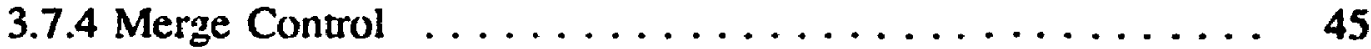

3.7.4.1 Gap Acceptance Merging $\ldots \ldots \ldots \ldots \ldots \ldots 45$

3.7.4.2 Moving Merge (Pacer System) $\ldots \ldots \ldots \ldots \ldots 46$

3.7.5 Integrated Ramp Control $\ldots \ldots \ldots \ldots \ldots \ldots \ldots \ldots .47$

3.8 Components of Freeway Traffic Management System: . . . . . . 48

3.8.1 Control Hardware: . . . . . . . . . . . . . 49

3.8.1.1 Controllers ................ 52

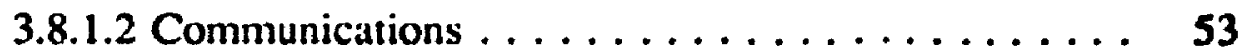

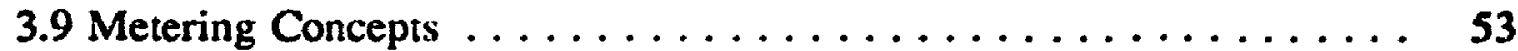

3.10 Coutrol Strategies $\ldots \ldots \ldots \ldots \ldots \ldots \ldots \ldots \ldots \ldots \ldots \ldots$

\section{CHAPTER 4 \\ RAMP CONTROL STRATEGIES \& TACTICS: CAPACITY ANALYSIS}

4.1 The Ottawa Queensway: Introduction and Need . . . . . . . . 61

4.2 Capacity Analysis Module. . . . . . . . . . . . . . 62

4.2.1 Capacity Analysis: Highway $417 \ldots \ldots \ldots \ldots \ldots \ldots \ldots 63$

4.3 Capacity Analysis on Carling Avenue $\ldots \ldots \ldots \ldots \ldots \ldots$

4.3.1 The TRAF-NETSIM Software $\ldots \ldots \ldots \ldots \ldots \ldots \ldots$

4.3.2 Why Traf Netsim . . . . . . . . . . . . 81

4.3.3 Case Studies of NETSIM applications: . . . . . . . 81

4.3.4 Data Sources . . . . . . . . . . . . . 82

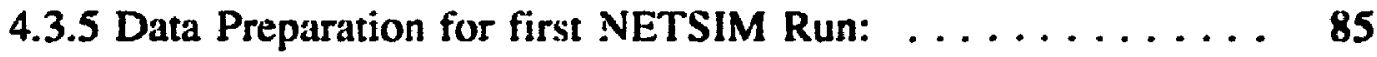

4.3.6 Output From Netsin $\ldots \ldots \ldots \ldots \ldots \ldots \ldots \ldots 2$

CHAPTER 5

RAMP CONTROL STRATEGIES \& TACTICS: CORRIDOR ANALYSIS

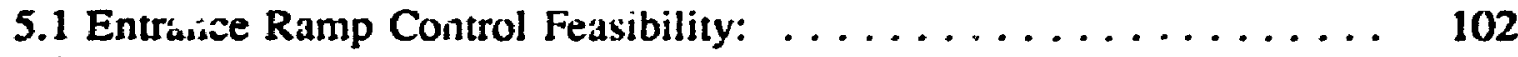

5.2 Metering Alternatives: $\ldots \ldots \ldots \ldots \ldots \ldots \ldots \ldots \ldots \ldots \ldots$

5.3 Metering rates $\ldots \ldots \ldots \ldots \ldots \ldots \ldots \ldots \ldots \ldots \ldots \ldots$

5.4 Control Strategies . . . . . . . . . . . . . . . 105 
5.5 Experiment Set Up: $\ldots \ldots \ldots \ldots \ldots \ldots \ldots \ldots \ldots \ldots \ldots \ldots$

5.5.1 FREFLO Model $\ldots \ldots \ldots \ldots \ldots \ldots \ldots \ldots \ldots \ldots 108$

5.5.2 Model Calibration: $\ldots \ldots \ldots \ldots \ldots \ldots \ldots \ldots \ldots \ldots 110$

5.6 PASSER $11-87 \ldots \ldots \ldots \ldots \ldots \ldots \ldots \ldots \ldots \ldots \ldots \ldots \ldots$

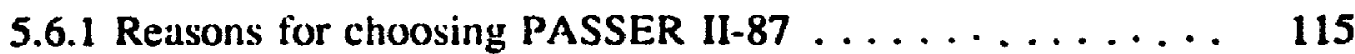

5.7 Freeway Traffic Optimization $\ldots \ldots \ldots \ldots \ldots \ldots \ldots \ldots \ldots \ldots, 115$

5.7.1 Traffic Optimization Using Linear Programming ....... 115

5.7.2 Origin Destination Information . . . . . . . . . 121

5.7.3 Ramp Metering Optimization (See Figure 5.7a). . . . . 121

5.7.4 Priority Ramp Optimization. . . . . . . . . . . . 124

5.7.4.1 Priority Metering With Exclusive Lanes ...... 124

5.8 Application of Ramp Optimization to the Queensway. . . . . . 126

5.8.1 FREFLO First Run: . . . . . . . . . . . . . 130

\section{CHAPTER 6 \\ RESULTS FROM SIMULATION}

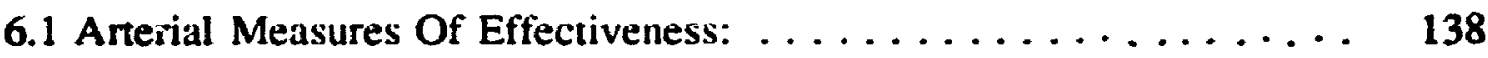

6.1.1 Eastbound Carling Avenue . . . . . . . . . . . 139

6.1.2 Westbound Carling Ave. . . . . . . . . . . . . 144

6.1.3 Southbound \& Northbound Approaches: . . . . . . . . 148

6.2 Freeway Measures of Effectiventss $\ldots \ldots \ldots \ldots \ldots \ldots \ldots \ldots 148$

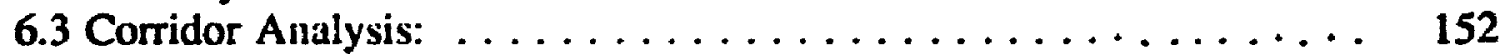

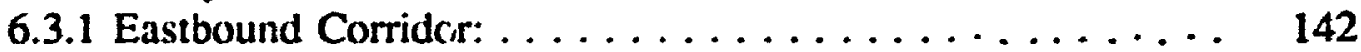

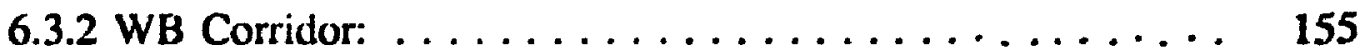

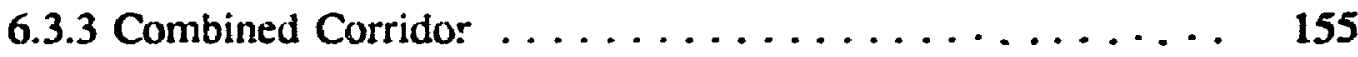

6.4 Disadvantages of "Optinized Metering Rates" . . . . . . . . . 160

6.5 Suggested Alternative Method . . . . . . . . . . . . . 160

6.5.1 Comparism of the "Best" with "Optimized" Rates. . .... 161

6.5.2 Limitations. . . . . . . . . . . . . . . . 166

\section{CHAPTER 7 \\ VERIFICATION OF SIMULATION MODELS}

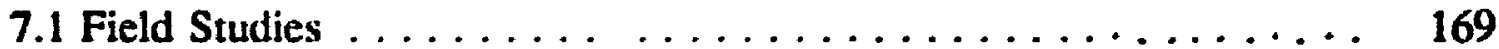

7.2 Procedure $\ldots \ldots \ldots \ldots \ldots \ldots \ldots \ldots \ldots \ldots \ldots \ldots \ldots$

7.3 Results From Field Studies $\ldots \ldots \ldots \ldots \ldots \ldots \ldots \ldots \ldots \ldots$

7.3 Comparism of Simulation and Field Results: . . . . . . . . 176

7.3.1 FREFLO Model $\ldots \ldots \ldots \ldots \ldots \ldots \ldots \ldots \ldots \ldots . \ldots$

7.3.2 NETSIM Moder. . . . . . . . . . . . . . . . . . . 179 
CHAPTER 8 IMPLENENTATION

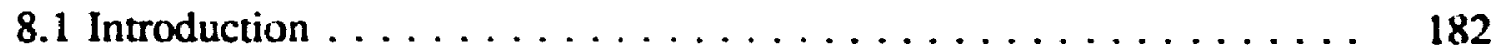

8.2 System Integration $\ldots \ldots \ldots \ldots \ldots \ldots \ldots \ldots \ldots \ldots \ldots \ldots$

8.3 Methodology Application $\ldots \ldots \ldots \ldots \ldots \ldots \ldots \ldots \ldots \ldots$

8.3.1 Freeway Links $\ldots \ldots \ldots \ldots \ldots \ldots \ldots \ldots \ldots \ldots, 184$

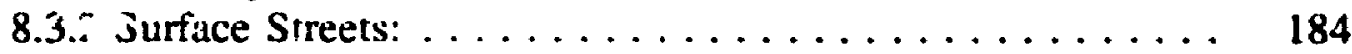

8.3.3 The Algorithm $\ldots \ldots \ldots \ldots \ldots \ldots \ldots \ldots \ldots \ldots . \ldots \ldots$

8.3.4 Limitations $\ldots \ldots \ldots \ldots \ldots \ldots \ldots \ldots \ldots \ldots \ldots 189$

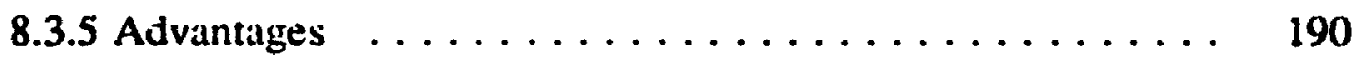

8.4 Application To The Ottawa-Carleton Region .......... 191

CHAPTER 9

CONCLUSIONS \& RECOMMENDATIONS

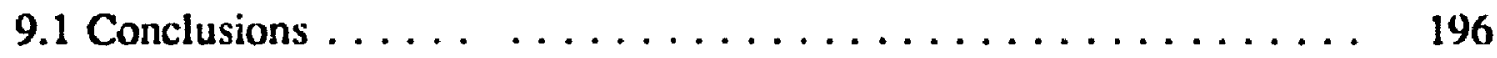

9.2 Recommendations $\ldots \ldots \ldots \ldots \ldots \ldots \ldots \ldots \ldots \ldots \ldots$

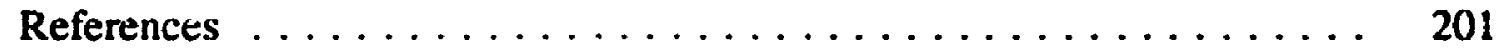

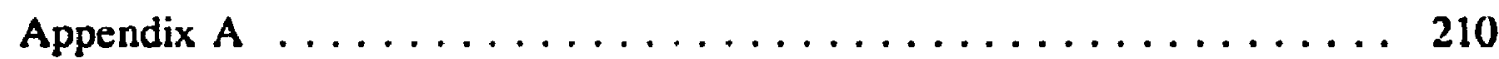

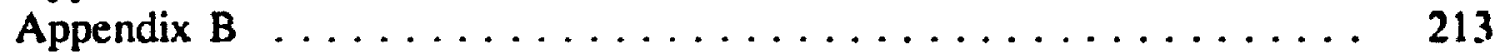




\section{LIST OF FIGURES}

Figure 1.1 Ramp Metering Systems in North America. . . . . . . . . . . 8

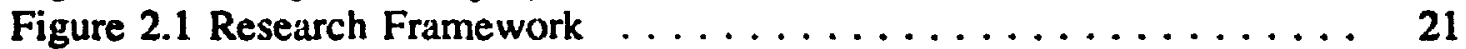

Figure 2.2 Methodology For Establishing Best Metering Rates . . . . . . 22

Figure 3.1 IVHS \& FTMS . . . . . . . . . . . . . . . . 33

Figure 3.2 Pretimed Metering. . . . . . . . . . . . . . . . 43

Figure 3.3 Local Responsive Metering . . . . . . . . . . . . . . 43

Figure 3.4 Proposed FTMS For Ottawa-Carleton . . . . . . . . . . . 50

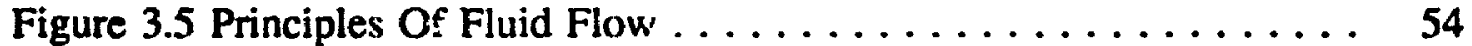

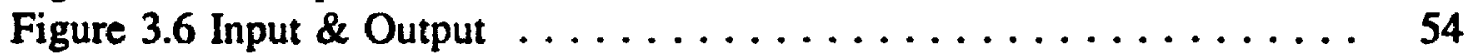

Figure 3.7 Volume Occupancy Plot . . . . . . . . . . . . . . 57

Fijoure 3.8 Flow, Speed \& Density Relationship . . . . . . . . . . . . 58

Figure 4.1 Capacity Analysis Module . . . . . . . . . . . . . . . . 64

Figure 4.2 Highway 417 EB Traffic Volumes 07:00 to 08:00 . . . . . . 69

Figure 4.3 Highway 417 EB Traffic Volumes $17: 00$ to $18: 00 \ldots \ldots$

Figure $4.4 \mathrm{LOS}$ un Basic Freeway Sections for EB am Peak . . . . . . 72

Figure 4.5 LOS on Basic Freeway Sections for EB pm Peak . . . . . . 73

Figure 4.6 LOS on Basic Freeway Sections for WB am Peak . . . . . . . 74

Figure 4.7 LOS on Basic Freeway Sections for WB pm Peak . . . . . . 75

Figure 4.8 Map of The Study Section $\ldots \ldots \ldots \ldots \ldots \ldots \ldots$

Figure 4.9 NETSIM Network Configuration $\ldots \ldots \ldots \ldots \ldots \ldots$

Figure 4.10 Main NETSIM Input Screen $\ldots \ldots \ldots \ldots \ldots \ldots \ldots$

Figure 4.11 Input Data For Run Control Card . . . . . . . . . . . . . 86

Figure 412 Time Period Input Specifications . . . . . . . . . . . . 87

Figure 4.13 NETSIM Input Data For Link $1-2 \ldots \ldots \ldots \ldots \ldots$

Figure 4.14 Typical Input Data For Turning Movement Traffic . . . . . . 89

Figure . '5 Signal Timing for Carling/Alpine Intersection . . . . . . . . . 90

Figure 4.16 Sample Entry Link Volume Entered Into NETSIM . . . . . . . 91

Figure 4.17 NETSIM Output for Existing Conditions . . . . . . . . . . . . . . 94

Figure 4.18 Average Intersection Stopped Delay-Eb Carling . . . . . . . 96

Figure 4.19 EB Link Travel Speed ... . . . . . . . . . . . . . . . . 97

Figure 4.20 Cumulative Travel Time, EB Carling . . . . . . . . . . . . 98

Figure 4.21 Average Stopped Delay, WB Carling . . . . . . . . . . . . . . 99

Figure 4.22 Cumulative Travel Time, Westbound Carling . . . . . . . . . . 101

Figure 5.1 Flow Chart For FREFLO Runs . . . . . . . . . . . . . . 107

Figure 5.2 Typical Speed Density Relations Used By FREFLO . . . . . 112

Figure 5.3 NEMA Movement Designation . . . . . . . . . . . . . 116

Figure 5.4 PASSER II-87 Volume Input Screen $\ldots \ldots \ldots \ldots \ldots \ldots$

Figure 5.5 Sample Of Passer $11-87$ Best Timing Plans . . . . . . . . . 117

Figure 5.6 a Traffic Volume Versus Travel Time . . . . . . . . . . . . 119 
Figure 5.6b Input Output Tratic $\ldots \ldots \ldots \ldots \ldots \ldots \ldots \ldots \ldots \ldots$

Figure 5.7a \& b Non Priority \& Priority Metering . . . . . . . . 122

Figure 5.8 The Ottawa Queensway Study Section ............ 129

Figure $5.9 \mathrm{a} \& \mathrm{~b}$ Existing and Optimised Metering ........... 132

Figure 5.10 FREFLO Network Configuration $\ldots \ldots \ldots \ldots \ldots \ldots \ldots 134$

Figure 5.11 Signal Optimisation Flow Chart $\ldots \ldots \ldots \ldots \ldots \ldots \ldots 136$

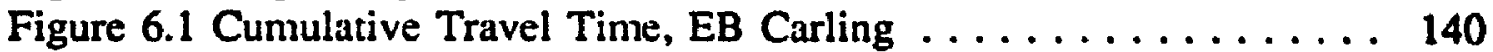

Figure 6.2 EB Intersection Stopped Delays $\ldots \ldots \ldots \ldots \ldots \ldots \ldots 141$

Figure 6.3 EB Link Travel Speeds $\ldots \ldots \ldots \ldots \ldots \ldots \ldots \ldots \ldots, 142$

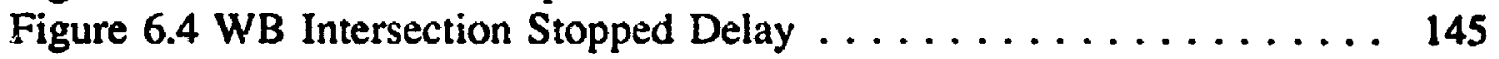

Figure 6.5 WB Link Travel Speed $\ldots \ldots \ldots \ldots \ldots \ldots \ldots \ldots \ldots \ldots$

Figure 6.6 WB Total Travel . . . . . . . . . . . . . . . 147

Figure 6.7 SB Intersecrion Approach Delay $\ldots \ldots \ldots \ldots \ldots \ldots \ldots 149$

Figure 6.8 SB Link Travel Speed $\ldots \ldots \ldots \ldots \ldots \ldots \ldots \ldots \ldots \ldots 150$

Figure 6.9 Northbound Intersection Stopped Delay $\ldots \ldots \ldots \ldots \ldots \ldots 151$

Figure 6.10 EB Corridor Total Travel $\ldots \ldots \ldots \ldots \ldots \ldots \ldots \ldots \ldots 153$

Figure 6.11 EB Corridor Total Travel Time $\ldots \ldots \ldots \ldots \ldots \ldots \ldots 154$

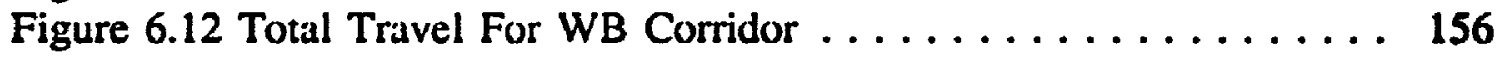

Figure 6.13 Total Travel Time For WB Corridor . . . . . . . . . 157

Figure 6.14 Corridor Total Travel . . . . . . . . . . . . 158

Figure 6.15 Corridor Total Trave Time . . . . . . . . . . . 159

Figure 6.i6 Comparism of Cunulative Travel Time: EB Corridor . . . 163

Fig are 6.17 Comparism of Corridor Total Travel . . . . . . . . . . 164

Figure 6.18 Comparism of Corridor Total Travel Time ........... 165

Figure 7.1 Comparism of Observed \& Simulated Values:WB

Queensway ...................... 177

Figure 7.2 Comparism of Simulated \& Observed values: EB Queensway 178

Figure 7.3 Comparism of Simulated \& Observed Values: EB Carling . . 180

Figure 7.4 Comparism of Simulated \& Observed values: WB Carling . . 181

Figure 8.1 Detector Layout on a network $\ldots \ldots \ldots \ldots \ldots \ldots \ldots \ldots 186$

Figure 8.2 The SCOOT Traffic Model $\ldots \ldots \ldots \ldots \ldots \ldots \ldots \ldots \ldots 186$

Figure 8.3 Algorithm Flow Chart . . . . . . . . . . . . 188

Figure 8.4 Major Components of UTCS in the Ottawa-Carleton Region .. 192

Figure 8.5 Proposed system Integration For the Ottawa-Carleton Region 194 


\section{List of Tables}

Table

Description

Page

2.1 Comparism of Integrated Models. $\ldots \ldots \ldots \ldots \ldots \ldots \ldots \ldots$

3.1 Evalu ttion of Strategies. . . . . . . . . . . . . . . . 39

3.2 Evaluation of Total Strategy Effectiveness: QEW Westbound ..... 40

4.1 Estimated Highway 417 WB Traffic Volumes $\ldots \ldots \ldots \ldots \ldots 6$

4.2 Estimated Highway 417 EB Traffic Volumes $\ldots \ldots \ldots \ldots \ldots . \ldots 67$

4.3 Comparism of TRAF-NETSIM \& other Traffic Engineering Programs ..................... 82

4.4 Vehicle Specifications Used For TRAF-NETSIM . . . . . . . 83

4.5 LOS Criteria For Signalised Intersections . . . . . . . . . 95

4.6 LOS Criteria For Arterial Class $11 \ldots \ldots \ldots \ldots \ldots \ldots \ldots . \ldots 9$

5.1a Origin Destination Surveys In Percentage Terms $\ldots \ldots \ldots \ldots \ldots 127$

5.1b Percentage Traftic Going Past Various Sections . . . . . . . . 127

5.2 Initial Simplex Tableau . . . . . . . . . . . . . . . . 131

5.3 Freeway Simulation Runs . . . . . . . . . . . . . . 137

6.1 Effect of Optimised Metering Rates on EB Carling . . . . . . . . 143

6.2 Effect of Optimised Metering Rates On Westbound Carling ...... 148

6.3 Effect of Optimised Metering Rates on Eastibound Queensway . . . 152

6.4 Comparism of Optimised \& Best Metering Rates ........... 162

6.5 Measures of Effectiveness for Optimised \& Best Metering Rates: EB

Carling . . . . . . . . . . . . . . 162

7.1 Travel Time Runs For Highway $417 \ldots \ldots \ldots \ldots \ldots \ldots \ldots \ldots$

7.2 Travel Time Runs For Carling Avenue . . . . . . . . . . 170

7.3 Sample Travel Time Run For Eastbound Carling Avenue . . . . . 172

7.4 Sample Travel Time R.un For Westbound Carling Avenue ...... 173

7.5 Sample Travel Time Run For Eastbound Queensway ......... 174

7.6 Selected Travel Time R.ıns . . . . . . . . . . . . . . . 176 


\section{Glossary \& Abbreviations}

\section{Glossary}

Average Stopped Delay The total number of stopped vehicles at an intersection approach for a time period divided by the total number of vehicles crossing the same intersection approach for the same time period.

Average Travel Speed

Average Travel Time

Best Metering Rates

Corridor

Latent Demand

Mainline

Mainline Lane 1

Measures of Effectiveness

Occupancy
The total distance, divided by the average travel time of a given road network.

The total time taken to move from one point to another, including stops, and all delays encountered.

A term used by the author for the maximum metering rate which minimises corridor travel time and, at the same time not violating established threshold capacities for all intersection approaches.

An uninterrupted access controlled facility (i.e., a freeway) and all other surface routes in its vicinity affected by the freeway.

The number of vehicles desiring to use a road facility.

A controlled access facility (same as freeway).

The freeway lane adjacent to the right shoulder.

Parameters like average stopped delay, corridor total travel, etc used to describe the service quality of a facility.

Occupancy as used in this thesis refers to detector occupancy: It is the percentage of time a loop detector is turned on

Optimised Metering Rates In this study, it means metering plan based solely on linear programming method.

Metering rates based on historical traffic conditions. 
On Line Metering

Platoon

Ramp Gore

Threshold Capacity/delay

Total Travel Time

ACS

AFMS

ATCS

ATIS

ATMS

AVI

AVL

EB

CBD

CCTV

CMS

FTMS

IVHS

LCS

LT

MTO

NB
Metering rates based on real time traffic conditions.

A moving queue of vehicles or pedestrians.

The intersection between the left edge of a ramp pavement and the right edge of a freeway pavement.

An established capacity/delay value usually lower than its maximum capacity/delay value.

The sum of the trave' times of all vehicles in a given section of a road network, measured in vehicle-minutes or vehicle hours.

\section{Abbreviations}

Advanced Control Systems

Advanced Fleet Management System

Advanced Traffic Control System

Advanced Traveller Information System

Advanced Traffic Management Systems

Automatic Vehicle Identification

Automatic Vehicle Location

Eastbound

Central Business District

Closed Circuit Television system

Changeable Message Signs

Freeway Traffic Management System

Intelligent Vehicle Highway System

Lane Control System

Left Turn

Ministry of Transportation of Ontario

Northbound 
NEMA

RMOC

RT

SB

ST

TAC

TCS

UTCS

VDS

VMS

WB
National Electrical Manufacturers Association

Regional Municipality of Ottawa Carleton

Right Turn

Southbound

Straight Through

Transportation Association of Canada

Traffic Control System

Urban Traffic Control System

Vehicle Detection System

Variable Message Signs

Westbound 


\section{CHAPTER 1}

\section{INTRODUCTION}

\subsection{Background.}

Urban and suburban development and land use patterns have induced numerous vehicle trips, which use major arterials, highways \& freeways. Convenience, privacy, comfort, freedom and flexibility, offered by the private automobile, have encouraged automobile use despite rising costs of ownership and maintenance. In many North American cities, peak perind congestion, and its undesirable social and economic repercussions are already felt. In the Los Angeles region for instance, $\$ 3$ billion / year is estimated to be caused by congestion, of which $63 \%$ occurs on freeways [Johnston et al, 1990]. In a study by Hawks \& Lomax, about 1.2 billion hours of delay, 1.3 billion gallons of wasted fuel and more than $\$ 9$ billion in road user costs, in the U.S.A, are caused by congestion annually [Hawks \& Lomax, 1989]. Another estimate by the same author, indicates that the yearly cost of congestion for some 39 selected cities in the US was $\$ 41$ billion. A report from the US Secretary of Transportation to Congress revealed that the yearly cost of congestion is over $\$ 100$ billion in lost productivity alone, 40,000 fatal accidents and over 5 million injuries [US DOT, 1992]. Urban congestion is therefore socially, economically and politically undesirable and all efforts to improve it are desirable. 
There are three main ways to relieve congestion.

- Increase road capacity by adding more lanes (supply side measure).

- Manage the existing capacity more efficiently (traffic management).

- $\quad$ Reduce demand (demand management)

Stipply management measures have been used for many decades. When more lanes are added, in many cases in a few months, if not weeks or days, the facility returns to its former state of congestion mainly because of the increased number of vehicles desiring to use the facility. This is due to latent demand, and diversion from other routes. The end result is that increasing volume of traffic is attracted to the improved facility. Every city has its own acceptable congestion level. If a facility is improvid to offer a level of service better than this level, attraction of more vehicles returns it to its original state of congestion [Spielberg, 1982]. The degree of congestion in any city depends on a number of factors including the type of transportation system, population, car ownership, land use patterns, income, the quality of public transit, etc. Right of way constraints in major urban areas and recent emphasis on environmental quality are diminishing the opportunity to add supply in an urban area. For a new project or facility expansion to take place, the following factors have to be studied [Morlok, 1978; US Army Corps of Engineers, 1992; IBI Group, 1993]:

- displacement of households, families, industries and businesses;

- land use Patterns: whether the facility will affect land development in terms of increasing imbalance in urban growth or cause an increase or decrease in property values; 
- historic, monumental, and aesthetic losses;

- air Quality: $\mathrm{CO}, \mathrm{CO}_{2} \mathrm{HC}, \mathrm{NO}_{\mathrm{x}}$, and particulate matter produced before and after construction;

- noise levels before, during and after construction; its impacts on residential, commercial, recreational, educational, religious \& other facilities;

- impact on wild life migration, aquatic and terrestrial plant species;

- effects on ground water, wells, aquifers, surface water elevations, catchment areas, ponds, etc;

- effects of facility construction on temporary road diversion, noise, air pollution, fuel and oil spills to adjacent waters; sedimentation \& erosion caused by vibrations from machines and all other waste produced during construction activities.

To make matters worse, in spite of the escalating of the already prohibitive cost of capacity expansion, budget allocation to transportation agencies is decreasing. Even if supply management solutions are affordable and right-of-way is not a problem, should enough freeways be built to completely eliminate congestion? If for argument's sake the answer is a yes, can enough freeways be built to eliminate congestion? It appears that a better solution to congestion is through efficient management of existing facilities and modal shifts to public transit.

Urban streets, designed as interrupted flow facilities, are controlled by stop signs, yield signs, signalised intersections, etc, for an orderly movement of traffic. Freeways, on the other hand, are designed for uninterrupted traffic flow, with limited access/egress 
points to serve high speed traffic between major locations with the hope that traffic would operate efficiently. Increased inter and or intra-urban trips have made vehicles seeking reduced travel times converge onto freeway entrance ramps and compete for downstream mainline lane $1^{1}$ gaps in a disorderly manner with the result that there is a breakdown of the free flowing upstream traffic [Wainright, et. al. 1972]. Unlike arterials, where there could be alternative routes to use, forced flow freeway condition lends itself to no route choice until the next exit.

Intelligent Vehicle Highway System (IVHS) technology, which features application of advanced sensors, computers and communication technologies to get a reliable and real time information on vehicle and roadway conditions, seems to be a very promising technique to improve the efficiency of surface transportation. Apart from being in its carly stages of technical development, non technical issues need to be resolved before IVHS can be fully implemented [US DOT, 1993; Chen, et. al. 1990].

- IVHS technologies in North America will require the participation and partnership ot both private and public organisations in terms of capital and technical expertise. For thesi organisations to be comfortable and make maximum contributions without any reservations, the level of protection from tort, liability claims and damages should be clearly defined rather than the present "Rule of Reason" to settle disputes.

- IVHS technologies will take over some of the driving tasks: In the advanced vehicle control mode for instance, vehicle headways, gaps, side clearance between

- Mainline lane 1 refers to the freeway lane adjacent to the right shoulder. 
cars, braking etc will be out of the driver's control. If a collision occurs who will be responsible, the driver, the vehicle manufacturers, or the transportation agency? Will private agencies get involved in such an uncertain technology with costly risks? If they do, can they afford to pay for the sky rocketing insurance premiums?

- The success of IVHS technologies requires developers and manufacturers to work hand in hand to install and operate such systems. By involving a lot of participants with varying degrees of technical expertise it is not clear how copyright and other intellectual rights of these professionals will be resolved, when part of the project is financed by a public agency.

- Industry standards will have to be resolved internationally such that an European or a Japanese vehicle can be used in a North American environment and vice versa. This will prevent the proliferation of different technologies performing the same functions, such as the Beta and VHS video cassette recorders, when finally the former dropped out of the market.

- Technologies like the Automatic Vehicle Identification, where movements of all vehicles will be well gocumented and inonitored, are likely to raise motorist concerns about their privacy. Such information, on each motorist's day to day activities may be abused (i.e., accessed by other organisations and used for other undesirable purposes).

- Are College and University graduate students being prepared to meet the challenges of these complicated and advanced technologies which require the full 
understanding of their technical aspects?

In view of the above issues which are yet to be resolved, the full realization of IVHS technologies to cope with urban and suburban congestion is premature. It is expected that a significant time lag will occur (most likely by the turn of the century) before all IVHS technologiv : way be implemented. Meanwhile urban corridor congestion will have to be dealt with. Urban \& suburban freeways in concentrated populated regions are increasingly using advanced detection, surveillance, control $\&$ advisory measures to reduce congesti.on. These methods are popularly known as Freeway Traffic Management System (FTMS), or urban traffic control systems. Unlike the more advanced forms of IVHS, these strategies are one way "on line" or "off line" communications between the transportation system and the driver. Given stitable alternate routes, ramp metering is a very effective straiegy to maintain an efficient movement of traffic on freeways [Jacobson et al, 1989; McCormick Rankin, 1986; Bluementritt et al, 1981; US DOT 1976; Cocoran et. al., 19911.

\subsection{What is ramp metering?}

The Oxford Reference Dictionary defines metering as an instrument for measuring the amount of a substance supplied or used, time spent, distance travelled etc. Ramp metering can therefore be explained simply as device for recording and controlling the amount of vehicles passing through a ramp. Metering is usually undertaken with a purpose: to know if the amount of a measured substance is sufficient or not. If required quantities are obtained, the logical decision is to shut it off. Ramp metering therefore is a means of 
measuring and controlling the amount of traffic entering the freeway using a ramp traffic signal. Metering is undertaken to maintain a stable and steady traffic flow rate of the downstream traffic at all times. A successful metering strategy max:mizes throughput, reduces side swipe and rear end collisions, improves travel time predictabiiity, and discourages short trips from using the freeway. It also breaks up platoons of vehicles discharged from a nearby surface street traffic signal and allows vehicles to merge onto the freeway in an orderly manner. [Wainright, 1972 et al; Bluementritt, et al 1981; US DOT, 1976; Robinson \& Doctor, 1989].

\subsection{Case Studies}

Ramp meters are in use in more than 20 cities in North America, Japan, Britain, Germany, and some other European cities. Fig 1-1 indicates cities in North America implementing some form of metering. Ramp metering in some locations are not easy to evaluate because they form an integral part of other freeway management activities such as driver information systems, changeable message signs, incident management programs etc. These case studies were carefully selected at locations where ramp metering alone was installed at the time. Where other freeway improvements were installed, they are mentioned.

- In Portland, Oregon, metering 16 ramps in fixed time mode in 1981 increased average freeway speed during peak periods from $26 \mathrm{~km} / \mathrm{h}$ to $72 \mathrm{~km} / \mathrm{h}$; travel time reduced from 20 to 9 minutes. Fuel consumption, reduced by 2077 litres of gasoline per weekday. 


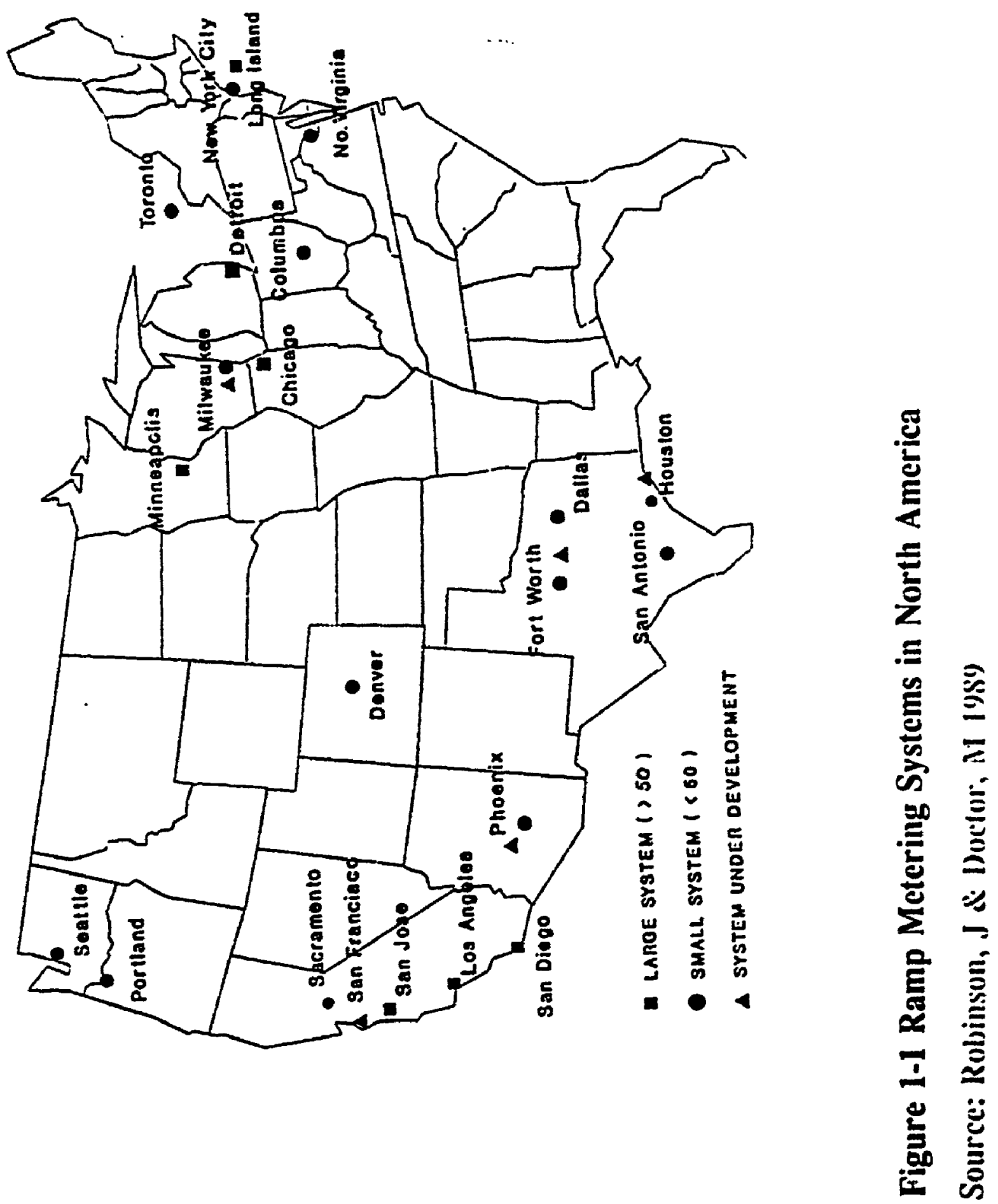


Side swipes and rear end collisions reduced by $43 \%$ [Robinson \& Doctor, 1989]

- In St Paul, Minnesota, 6 metered ramps, installed in 1971 in traffic responsive mode on a 5 mile section of $\mathrm{I}-35 \mathrm{E}$, after 14 years of installation, increased peak hour speeds, from 60 to $69 \mathrm{~km} / \mathrm{h}$ and reduced peak period collisions from 24 to $38 \%$ whilst peak period volumes increased by $24 \%$. [Robinson \& Doctor 1989].

- In Seattle, Washington, metering I-5, north of CBD (17 SB AM ramps and 5 NB PM ramps) was undertaken in 1981. After six years, mainline volumes during peak periods increased $86 \% \mathrm{NB}$ and $62 \% \mathrm{SB}$. Travel time reduced on the six mile section from 22 to 11 minutes and peak period collisions reduced by $39 \%$ [Robinson \& Doctor, 1989].

- In Denver, Colorado, a pilot program was conducted in 1981 on NB I-25. After 18 months metering 5 ramps on 4.7 kilometre section in local traffic responsive mode, travel speeds increased $57 \%$, travel time reduced $37 \%$ and side swipe and collisions declined 5\%. These positive results led the transpurtation agency to meter more ramps and install a centralised computer to control and coordinate all metered rarnps. Ev:luation in 1989 indicated that speeds were lower than the 1983 condition (traffic responsive metering) but higher than 1981 conditions (pre metering). Although collisions were not much different and speeds reduced, the central computer control indicated significant benefits because the NB I-25 increased from $6200 \mathrm{vph}$ in 1981 to $7350 \mathrm{vph}$ in 1989. On one occasion in 1987, when the central metering system was turned on an hour later, traffic was the worst than it had been for years [Cocoran \& Hickman, 1991]. 
- In Detroit, Michigan, metering 28 ramps on I-94 in 1982 increased speeds by $8 \%$, reduced collisions by almost $50 \%$, and typical peak volumes on the three EB lanes increased from 5600 to $6400 \mathrm{vph}$ in 1985 [Robinson \& Doctor, 1989].

- In Austin, Texas, Local traffic responsive strategies on 3 ramps along a 4.2 kilometre segment of NB I-35 on am peak increased vehicle throughput by $7.9 \%$ and a $60 \%$ increase in mainline speeds [Mardsen, 1981].

- In Atlanta, Georgia, installation of ramp signals on the Tenth street northbound on ramp of the I-75 in 1967, reduced rear end collisions by about $90 \%$ over a 12 month evaluation period [Thomas, 1969].

- In Canada, the first Freeway traffic control was implemented in 1974, by MTO along a $16 \mathrm{~km}$ stretch of Queen Elizabeth Way (QEW), Mississauga. The system included loop detectors, incident confirmation by Closed Circuit Television (CCTV) system with remote cameras with pan and zoom capabilities and ramp metering. It yielded [MTO, 1991]:

$$
\begin{aligned}
& \text { - } 22 \% \text { reduction in collisions; } \\
& \text { - } \quad 45 \% \text { increase in average speeds; } \\
& \text { - } \quad 21 \% \text { reduction in overall delay. }
\end{aligned}
$$

Increasing traffic on other urban/suburban freeways and the encouraging results of the system, led to the inituation of the FTMS program in the early 80's which promoted designs and implementation of the Burlington Skyway FTMS and Highway 401 FTMS popularly known as COMPASS. Completed feasibility studies on the Gardiner Lakeshore Corridor and expansion of the Skyway are al! 
clear evidence of th: past and present successes of freeway traffic control [MTO, 1991; IRI Group, 1991].

- In Montreal, freeway traffic control has been recommended for the Bonaventure/Champlain Bridge Corridors \& the A25/Mietropolitaine/Decarie/Ville Marie Corridor [SNC/DELUC, 1988].

- In the Ottawa Carleton Region, two consultant studies done for MTO in August 1987 and 1993 recommended freeway traffic control to ease peak period congestion in the most heavily travelled sections. Ramp metering was recommended for eastbound Richmond, Pinecrest, Woodroffe and Maitland onramps; and westbound p.m. St Laurent, Alta Vista and Nicholas on-ramps [IBI, 1987 \& 1993; MTO 1990].

\subsection{Probiem Definition}

There have been many studies done on ramp metering methodologies. The concept of metering is to improve the function of the freeway by restricting on ramp volumes at peak periods and allowing these vehicles to :nter at a rate which the facility can handle. It smooths the on ramp merge into the freway allowing vehicles to enter the freeway in an orderly function.

Most metering strategies have been implemented with varying degrees of success through surveillance and control, with the sole objective of improving the mainline traffic stream. There is however a general lack of study on its effect on the surface streets in terms of arterial travel time. All the case studies just discussed quantified improved 
freeway flows, decreased freeway travel times, etc, but very few quantified its impacts on alternative routes. The response from the public to metering therefore varies from totally acceptable, where in some cases the public actually requested more ramps to be metered, to highly unacceptable where in an extreme case these metered signals were shot by a gun [Robinson \& Doctor, 1989; Spielberg, 1982].

Furthermore, although ramp controls have improved traffic in almost all areas used, single and multi occupant vehicles are equally delayed. To maintain a stable traffic flow as well as meet another objective of encouraging car pools and other Higher Occupancy Vehicle (HOV) plans and programmes, HOV's should be given priority treatment where feasible. Such innovations have been identified by a growing number of municipalities and other jurisdictions, including the Regional Municipality of OttawaCarleton (RMOC).

The key to successful metering is a detailed analysis of freeways as well as all adjacent road retwork which diverted traffic will use. To do this, a careful identification of goals and objectives is needed. To increase acceptability of metering, control strategies should promote an efficient movement of traffic in the corridor as well as minimize excessive delays to any intersection approach.

\subsection{Research Objectives and Scope}

This study included a detailed analysis of both Highway 417 , a freeway, and its adjacent surface streets, to determine the optimal ramp metering strategy. The purpose of this research was to 
- develop a methodology for optimal ramp metering from a corridor-wide perspective,

- determine the impacts of metering on the corridor, and

- describe the conceptual and system aspects of implementing the methodology for ramp metering from a corridor-wide perspective.

\subsection{Thesis Outline:}

The thesis is divided into eight chapters and two appendixes. Following this introductory chapter, chapter 2 describes the framework of research. The structure of research and a brief overview of existing methodologies are discussed.

Chapter 3 provides a brief introduction to IVHS, FTMS, and a detailed treatment of ramp metering. The inter - relationship between these elements of traffic management and control are discussed. The purpose of the chapter is to acquaint the readers who may be unfamiliar with the present state-or-the-art.

Chapter 4 begins with a detailed treatment of the methodology and its application to the Ottawa Queensway. The chapter mainly deals with Corridor Control Module.

Chapter 5 deals with Freeway and Arterial Control Modules. Ramp metering strategies, arterial signal optimisation to cater for increased traffic on alternate routes are treated. TRAF-NETSIM and other computer simulation models are also discussed including data sources, and analysis.

Effects of traffic on the freeway and surface routes are discussed in Chapter 6.

Chapter 7 deals with verification of simulation models through field studies. Travel time 
studies were carried out and compared to simulated results to check their accuracy.

In Chapter 8, system implementation is discussed. Conclusions and recommendations can be found in chapter 9 , followed by references and Appendixes. 


\section{CHAPTER 2}

\section{RESEARCH FRAMEWORK}

From the case studies in the previous Chapter, it could be seen that most ramp metering evaluations did not cover any detailed studies of adjacent surface strests. They were mainly based on the assumption that the diverted traffic would not adversely affect traffic on these routes. This chapter is devoted to evidence of research need, and an outline of research methodology.

\subsection{Research Need}

In a feasibility study conducted on the Ottawa Queensway in 1987, it was mentioned that "...From a total of 3100 ons ${ }^{t}$ distributed across the 7 ramp locations, 230 diversions represent a total diversion of approximately 7\% of on ramp traffic. It was determined after discussion with RMOC that these volumes were not large enough to significantly change the operation of arterial roadways" [IBI 1987]. Vehicle delays were estimated for interchanges such as Richmond, Pinecrest, Woodroffe and Maitland.

1 3100 ons, stands for 3100 on ramp tralfic. 
Evaluation of metering was based on freeway and arterial travel time studies, O.D. data and forecasted ramp queueing delay.

The question is how much is this going to affect the eastbound, westbound. northbound and southbound approach traffic on surface streets, does it minimise corridor total travel time?

In the Denver case, benefits to ramp metering were analyzed for local responsive and system coordination ramp metering by measuring freeway traffic speeds and volumes before and after implementation, but its impacts on alternate routes were not assessed [Cocoran \& Hickman, 1991].

In a real time metering algorithm developed for the Seattle area, it included a ramp queue adjustment logic as the main restriction on its impacts on alternate routes. Before and after studies were conducted with respect to ramp delays, ramp signal violations, freeway yolumes, freeway travel time studies, and freeway accidents [Jacobson et al 1989].

Existing ramp metering strategies are mainly based on providing a stable flow on the mainline; satisfying the minimum and maximum metering rates; and satisfying the maximum queue length criteria.

Pretimed metering strategies for instance, are developed using historical demand /capacity volumes to establish metering rates or by optimization through Linear Programming [Bluementrit, 1981; Masher et. al., 1975; Institute of Transportation Engineers, 1992; Wattleworth, 1967; Wang, 1972; Pignataro, 1973; May, 1974]. 
Wattleworth, for example, developed pretimed metering strategies using linear programming by maximising total freeway traffic subject to volumes of each section operating at threshold capacities but did not study impacts on surface routes [Wattleworth, 1967].

Wang, used a strategy similar to Wattleworth except that he used a dynamic programming strategy, with a non-linear objective function to minimise delays, queue times for each vehicle, and average travel time, at peak period [Wang, 1972].

Yuan used a quadratic programming method with linear constraints and a linear objective function to maximize mainline flows at or below capacity and to increase metering rates if the rate of change of entrance ramp queue length is positive. Where increased rates will create forced flow conditions on the mainline, metering rates are selected to minimise ramp queue lengths, and upstream metering rates are reduced to avoid freeway congestion [Yuan, et. al., 1971].

Local responsive control strategies are based on local volume / capacity ratio or occupancy strategies, with a queue detector option to limit ramp queues. The microprocessor based controller is fed with user input control iogic, which control "on line" metering rates.

Integrated or segment-wide iraffic responsive metering strategies are similar to the locally responsive strategies except that all locally responsive controllers are coordinated through a central computer controller which determines the metering rate of each location or a system-wide basis. In the Denver case, for example, all the algorithms were aimed at improving mainline congestion and minimising ramp queues [Ayland, et. al., 1991; 
Cocoran \& Hickman, 19911.

From all these methodologies and strategies, although freeway traffic improved, very little documentation on its effects on alternate routes exists. This means that if entrance ramp queues were within certain limits, metering rates were assumed to be adequate. Every solution has its own merits and demerits; therefore to evaluate the benefits of metering, it is very important to consider the diversion routes as well as all their connecting streets. Because diverted traffic will likely require fine tuning of traffic signals, traffic moving in the opposite direction must also be examined.

A successful metering strategy is the one that maximizes mainline traffic throughrut and also prevents negative impar's on alternate routes. The need to develop a methodology to analyze the impacts of metering on a corridor-wide basis has been identified by a number of transportation agencies and professionals including Transportation Research Circular's Research Statements, Dunn et. al., \& May. et. al. [Dunn et al 1992; Transportation Research Circular, 1990, \& 1983; May, et. al., 1982]. This study introduces a methodology to address these issues.

\subsection{Measures of Effectiveness:}

The research is intended:

- to reduce travel time in the corridor, and

- to suggest means to attain an efficient movement of traffic in the corridor;

Based on the above objectives, the following performance measures were used: 


\begin{tabular}{|l|l|}
\hline \multicolumn{1}{|c|}{ Objective } & Performance Measure \\
\hline Travel time & $\begin{array}{l}\text { Vehicle minutes } \\
\text { Seconds per vehicle } \\
\text { Efficient movement of traffic in the Corridor }\end{array}$ \\
$\begin{array}{l}\text { Vehicle kilometres of travel at an acceptable } \\
\text { Level of Service. }\end{array}$ \\
\hline
\end{tabular}

\subsection{Research Approach}

Two studies have been conducted by other researchers on the most travelled section of Highway 417 (Moodie Drive to Walkley Rd \& Highway 417/17 interchange to Champlain Street) to see if the introduction of freeway traffic management strategies is feasible. Both reports recommended ramp metering [IBI 1993; IBI Group, 1987]. This study is not intended to replicate such studies from a benefit cost analysis perspective. It is aimed at developing a methodology for optimal metering, and establishing its feasibility from an operational analysis point of view, by taking into consideration all alternative routes and connecting roads. It is intended to address some of the issues that the two previous studies did not cover. For practical analysis, the Highway 417 corridor was selected as a case study. The intention of the Ministry of Transportation of Ontario (MTO) to meter some ramps on the mainline, makes it suitable for such analysis [IBI Group, 1987 \& 1993; MTO, 1990]. In order to achieve the purpose of the study, a research framework was developed and used, as shown in Figure 2-1. The problem definition, covered in Chapter 1 , is followed by the concepts of ramp metering technology and operational factors. The present state-of-the-art is described and the interrelationship of ramp metering and other IVHS technologies are defined. At the next stage, a methodology was developed for 
establishing the best metering plan.

The developed methodology was tested, using Highway 417 as a case study. For simulations and analyses, FREFLO, NETSIM, \& PASSER-II-87 computer models were used. To verify the accuracy of these models, and to illustrate the application of the methodology, simulated results were compared with field studies. In the final stage. recommendations and conclusions were compiled. This thesis document, reports all parts of the research framework.

Figure 2.2 is a flow chart to illustrate the procedures involved in establishing "best metering plans". The methodology for this purpose is formulated in a logical onder that a transportation agency could follow. The following are major activities that form a part of the overall research methodology. These are:

- Capacity Analysis Module;

- Freeway Control Module;

- Surface Street Control Module;

- Effecriveness Module;

\subsubsection{Capacity Analysis Module}

To determine if metering will be feasible, the present traffic condition in the corridor should be known. Capacity analysis was therefore conducted on the Queensway from Highway \#7 \& 17 interchange to highway 417 \& Walkley interchange by using 1992 traffic volumes. Sections experiencing congestion at peak periods were identified and a detailed analysis was undertaken to see if metering was feasible. 


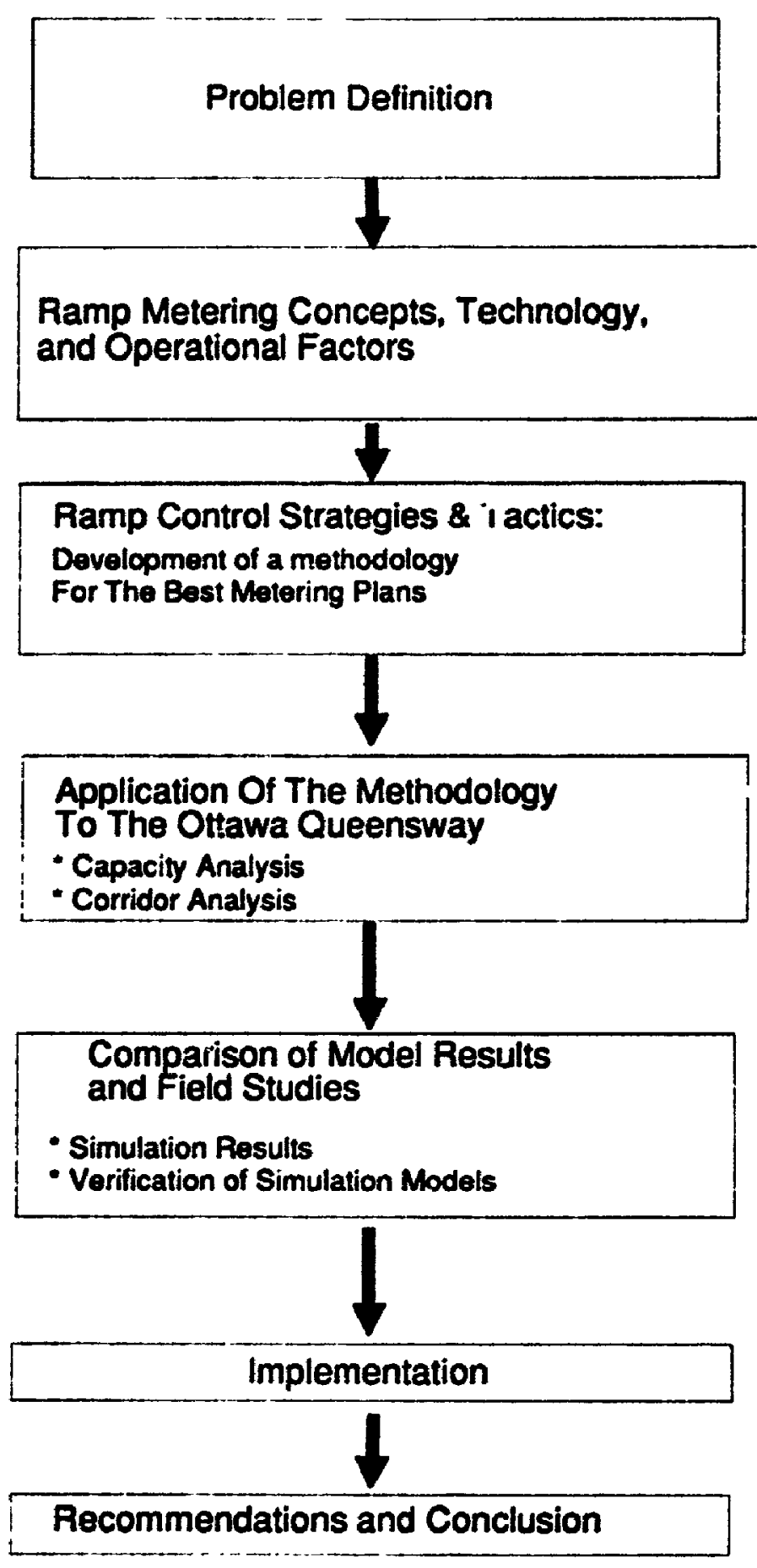

Figure 2-1 Research Framework 


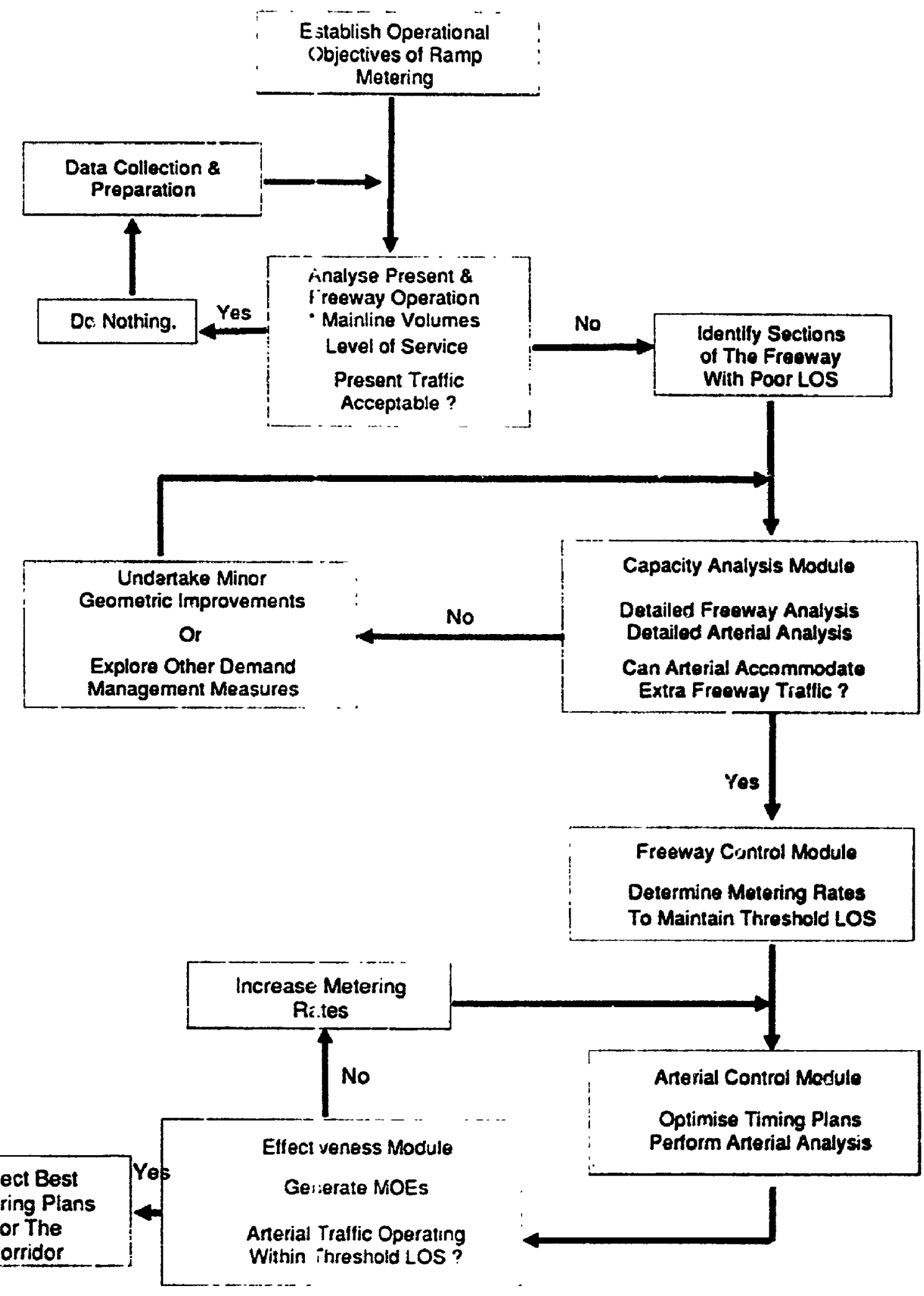

\section{Figure 2-2 Methodology For Establishing Best Metering Plans.}


Traffic congestion can be mitigated through a number of solutions; when these solutions complement each other, benefits are maximised. In view of this, the concepts and methodologies have been formulated to reinforce ride share and increased use of the public transit, using ramp metering and HOV by-pass lanes.

Capacity analysis of alternate routes was also conducted to determine whether these could hanc:e any extra traffic. Based on both analyses, a decision is taken to control or not to control freeway ramps. If surface routes are operating close to capacity, either minor geometric moxlifications can be undertaken to accomnodate anticipated diverted traffic, or other transportation system management strategies are to be explored.

\subsubsection{Freeway Control module}

Freeway control module is activated only if there is residual capacity on surface streets. The procedure involves formulation of metering strategies to suit the problem at hand. Initial metering rates are carried out to minimise freeway travel time.

\subsubsection{Surface Street module :}

After initial metering of traffic entering the freeway, surface street control module comes into play. Cycle lengths, phase timing and sequence, and offsets are all revised for all signalised intersections to optinize increased traffic in the network, using PASSER 2-87 software package. Capacity analysis is undertaken on the alternate routes, to examine the impacts of metering plans. If the anterial threshold level of service is not satisfied for any 
intersection approach, "optimised inetering rates" 2 are increased in small amounts. The procedure is repeated a number of times until all approach threshold LOS are satisfied.

\subsubsection{Effectiveness Module}

For each metering rate, arterial, freeway and corridor performance measures were obtained. Corridor performance measures were obtained by adding freeway and arterial travel times, total travel times and vehicle throughput, etc.

The metering plan which minimised corridor travel time, as well as satisfied the threshold LOS for all approaches was considered to be the best metering strategy.

\subsection{Current Models Available:}

Having defined research objectives and scope, existing models were reviewed to determine their suitability. Review of past and present simulation models have been done by some researchers including Yagar, Aerde, May and Leiman [Aerde \& Yagar, 1988a, 1988b, 1987a \& 1987b; May, 1987; Leiman et. al., 1991]. These revealed a number of freeway and corridor models including the TRAF, CORQ, FREQ, INTRAS, FRECON, SCOT, MACK, KRONOS, TRAFFICQ, DYNEV, CONTRAM, SATURN, and MICRO-ASSIGNMENT models. Following is a brief discussion and critique of integrated models.

2. "Optimised Metering Rates" in this study refer to initial metering rates obtained using linear programming approach with an objective function of maximising freeway traffic input. 


\subsubsection{TRAF}

TRAF is a family of simulation models integrated to represent the traffic environment. The main components are NETSIM, FREFLO, NETFLO 1, NETFLO 2, FRESIM, and ROADSIM. Out of these, NETFLO 1, NETFLO 2, and FREFLO (known as CORFLO) are combined to simulate traffic in a r,orridor.

These models, however don't completely replicate the corridor traffic conditions because they don't fully interact with each other: vehicles are stored in a vehicle holding area, which is demarcated artificially, from one sub-network to the other. Traffic spillback from one sub-network to the other are not modelled on a continuous basis [US DOT April, 1993; Aerde and Yagar, 1987 \& 1988]

\subsubsection{CORQ}

CORQ simulates a corridor network using O.D. data to estimate traffic queues on freeways to determine ramp metering rates and their impacts on surface streets. Its major weaknesses are that, it is not user friendly, traffic assignment is directional, and traffic signals on surface streets are not modelled.

\subsubsection{FREQ}

FREQ simulates freeways and an alternate street using O.D. data from ramps. Metering rates are determined using a linear programming technique. Both priority and non priority freeway traffic could be modelled. The main disadvantages are that uninterrupted traffic environment are modelled very approximately and signals are not optimized. Furthermore 
the model diverts traffic to only one alternate route and therefore traffic assignment is not undertaken. Based on the model's assessment, Aerde and Yagar had this to say [Aerde \& Yagar, 1987a]:

"Finally it appears that FREQ consists of a collection of a highly detailed extensions which have been added to a fundamentally weak base. consequently. many of these extensions provide only marginal or insignificant overall contributions as they are based on a modelling structure which inherently has a large error component already built in".

\subsubsection{INTRAS}

INTRAS stands for INtegrated TRAffic Simulation model. It is a micro-stochastic model mainly used to simulate freeway incidents. Vehicles are modelled individually to respond to freeway and alternate surface street environment, using a time-stepping procedure It does not model traft $c$ signals, no traffic assignment is undertaken and diversion techniques are not bused on O.D. data [Aerde \& Yagar, 1987b].

\subsubsection{FRECON}

FRECON is a corridor traffic model based on a modified FREFLO model. Alternate routes are simulated using simple travel time analysis.

\subsubsection{SCOT}

The SCOT is a corridor traffic model with two main composite models: the DAFT which is based on micro-modelling of vehicle platouns, and the UTCS-1 micro-model which uses a car following analogy.

Its major weaknesses are similar to that of other composite models such as CORFLO, described earlier. The model is no longer supported. 


\subsubsection{INTEGRATION}

The INTEGRATION model simulates corridor traffic, taking into consideration interactions between freeway and arterial traffic, dynamic traffic assignment, and the changing route selections due to congestion. The entire corridor is considered as one system [Aerde \& Yagar, 1988b]. A summary of some integrated models is provided in Table 2.1.

Some of the strengths of these integrated models have not been mentioned. : Ite author has no intentions to be biased in its discussion but to emphasize the point that all existing integrated models cannot replicate a continuous dynamic equilibrium within the corridor. Each has its own strengths and weaknesses. The reasons are mainly due to the fact that:

- corridor models have been developed to meet the needs of an urban traffic system. That is most urban traffic control strategies are localised and operate in isolation. Consequently these models have been developed to simulate local conditions without the thought of a system integration,

- most integrated models, which include the SCOT, TRAF and TRAFLO have been developed and combined together.

For similar reasons, Reiss et al performed traffic simulation in the Long Island corridor in New York, using the SCOT model. Because the model could not optimize traffic signals, signal timing plans were carried out using the TRANSYT model [Reiss et. al., 1991].

For a successful integrated model, a common modelling approach to both interrupted and uninterrupted traffic, taking into consideration traffic diversion and 


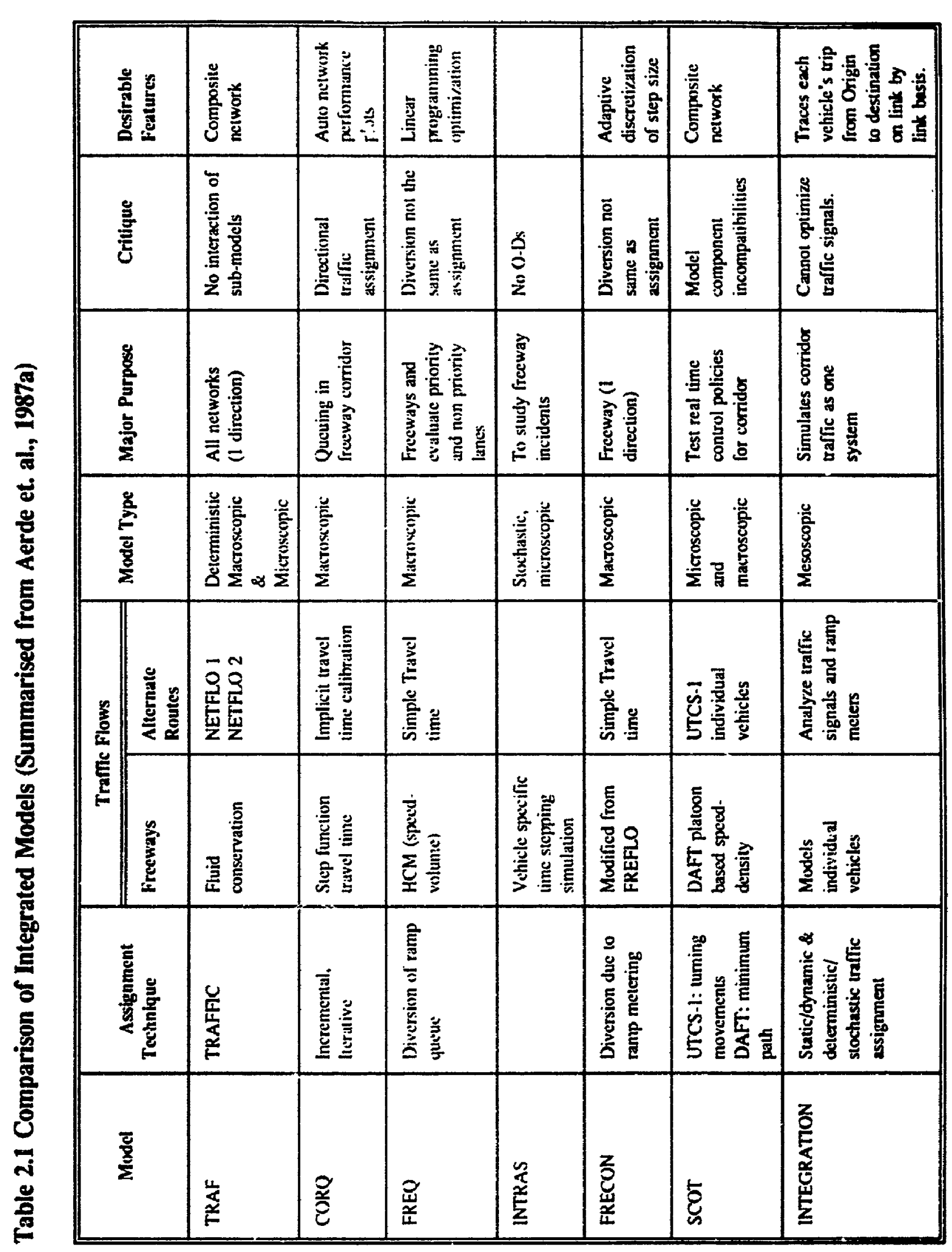


congestion is required. Aerde et. al. suggested that true integrated models required the optimization of the entire system, not individual subsystem: therefore adaptation and combination of contemporary models do not dynamically simulate such systems [Aerde \& Yagar, 1988b].

Although the INTEGRATION model dynamically simulates traffic in the corridor, it was not selected because the intention of the author is to select models such that a reasonable control of stopped delays at all signalized intersection approaches and a conservative traffic assignment is acheived.

For this research, the following computer simulation models were used:

- TRAF NETSIM, for arterial analysis,

- FREFLO for freeway simulation,

- PASSER II-87 for signal progression and optimisation, and

- LP-88, to optimize ramp metering $r$ stes.

These models were combined to,

口 conduct a detailed simulation of the alternate route vith the view to satisfying threshold delays for all signalized approaches,

D optimize traffic signals to respond to diverted traffic in both directions, and simulate freeway traffic conditions, and

口 determine metering rates on a system wide basis, taking into consideration its impacts on all signalised intersection approaches.

Because the combination of these models cannot accurately replicate real traffic conditions in the corridor, a limited and conservative approach have been adopted. A brief 
introduction to TRAF-NETSIM can be found in chapter 4, page 78 whereas FREFLO \& PASSER II-87 are described in chapter 5, page 108

\subsection{Why Simulation?}

Computer simulation was chosen for the following reasons: ${ }^{3}$

- Testing various traffic scenarios with combinations of different timing plans, variable metering rates, \& amount of traffic diversion, is not practical in the field. This activity would disrupt traffic and require enormous time, money and effort. By using : real freeway for such studies would also cause intolerable levels of celay, and decrease vehicular and pedestrian safety. The impact of such experiments in the field with indiscriminate testing of scenarios would be totally rejected by the public.

- By using sirnulation, a number of scenarios are tested and evaluated; hence only the most promising ones are tested in the field. This eliminates the need to test undesirable scenarios in the field.

- It is inexpensive and some Measures of Effectiveness (MOE) that would have been very difficult to obtain in the field (e.g., average stopped delays, density, occupancy, total travel time, in vehicle hours etc) are easily obtained.

If traffic diversion studies were conducted in the field, it is easy to imagine what would happen: police officers required to divert traffic, the number of field staff required to carry out speed, density, delay and other intersection studies, fine tuning of signals, data 
reduction from all these studies etc. Apart from cost, time and effort, will it be acceptable to create such scenarios? With the use of simulation, field conditions were created in the laboratory and a number of scenarios were tested.

To verify the level of accuracy of simul.tion models, travel time studies were performed on both the Ottawa Queensway and Carling Avenue. 


\section{CHAPTER 3}

\section{FREEWAY TRAFFIC: CONTROL \& FLOW}

Previous chapters made mention of IVHS, FTMS, and ramp metering. The purpose of this chapter is to give a brief overview of IVHS, a detailed description of the current meiering strategies, concepts and philosophies, and their interrelationship.

\subsection{Ramp Metering and IVHS}

Freeway traffic management makes effective use of tive freeway through advanced traffic control systems and driver information means. It is a step in the right direction towards Intelligent Vehicle Highway Systems (IVHS). IVHS systems use advanced sensors, computers and communications to get reliable, precise, and real time information on vehicle and road conditions. Thus they provide accurate advisory, guidance and control strategies to manage traffic [Transportation Association of Canada, 1992; Roos, 1991]. Th: concept is to integrate the driver with smart cars and smart transportation systems to 


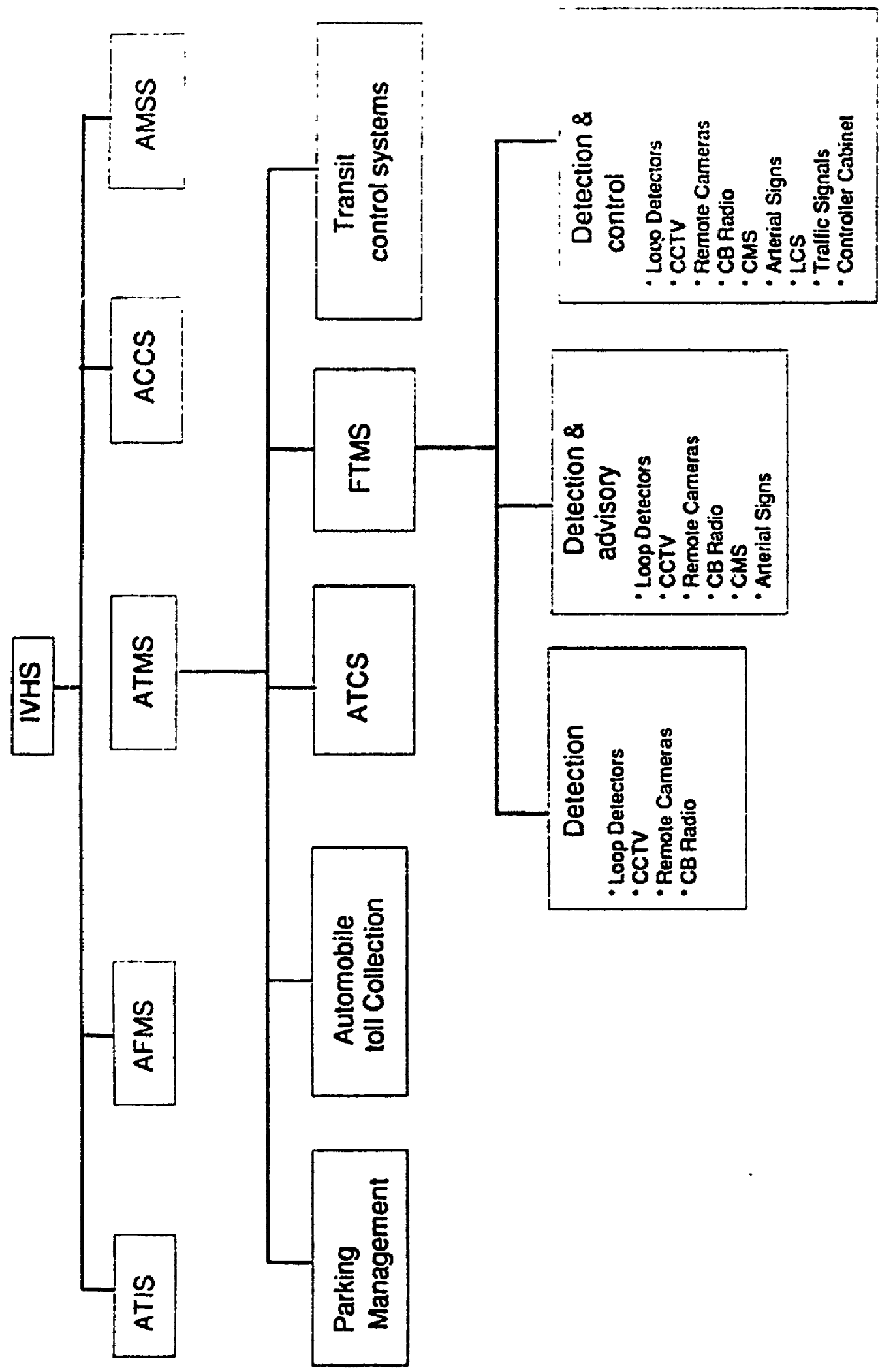

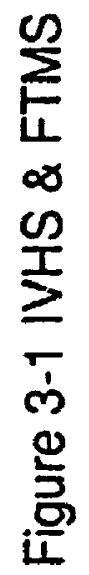


foster a more efficient pertormance. Figure $3-1$ is a flow chan showing how ramp metering and freeway traftic management system is tied into the IVHS. The major types of IVHS are

Advanced Traveller Information Systems (ATIS)

Advanced Fleet Management Systems (AFMS)

Advanced Traffic Management System (ATMS)

Advanced Command and Control Systems (ACS)

Advanced Public Transportation Systems (APTS,

Advanced Rural Transportation Systems (ARTS)

\subsection{Advanced Traveller Information Systems.}

Advanced traveller information systems will provide travellers and drivers with precise information on traffic, roadway conditions, route sequence, schedules, and transportation modes before and during the course of travel in real time, through a broadcast media in vehicles or buildings. Travellers will know the best, safest, and fastest routes; the most convenient mode; and will be able to predict their travel time. Motorists will also know the condition of their route choices, and other valuable information in real time required to select the best route, time and mode of travel. Vehicles will receive dynamic route guidance from their origins to destinations. Components of the system include variable message signs, electronic maps, in-vehicle route guidance system. bus stop displays, and an in- vehicle hazard warning systems (e.g., for slippery roads) [Transportation Association of Canada, 1992; Roos, 1991 ]. 
An example of such a system is TRAVTEK, a three year test project by the American Automohile Association, FHWA, Florida Department of Transportation, General Motors, and the city of Orlando. The system provides:

- information on traffic congestion, motorist services ("electronic yellow pages"), tourist information, and route guidance to 100 vehicles which were equipped with in vehicle navigation equipment.

\subsection{Advanced Fleet Management Systems}

Advanced fleet management systems will be mainly used by trucking and emergency vehicles. With such technologies as Automatic Vehicle Location (AVL), Automatic Vehicle Identification (AVI), Weigh in Motion (WIM), Automatic Vehicle Classification, Automatic Clearance Sensing (ACS), two way communications between fleet operator and vehicles will be possible. Vehicles can be located and monitored through satellite communications or roadside communications via beacons used in conjunction with infrared or microwave transmissions. Parcels will be traced and monitored continuously whilst pick up and delivery times will be reduced. Truck inspection, axle weights, taxation, safety standards, customs clearance and sther vehicle inspection will be transpa.ent and effectively enforced with little or no delays.

An example of such a system is the Advantage I-75 demonstration project, currently under construction, which will improve the efficiency of motor carrier operations 
from Florida to Michigan with minimum stops at inspection and weigh-in-stations. The system will eventually be linked to the AVION project.

AVION is the Canadian couaterpart of Advantage 1-75, which would use similar technologies such as weigh-in-motion, electronic data document processing, etc to keep a close watch on truck movements, and strict enforcement of standards and regulations, on Highway 401, from Windsor to Montreal.

\subsection{Advanced Transportation Management Systems}

The ATMS is the advanced form of the present Freeway Traffic Management System with the following capabilities:

- Effective and efficient response to incidents with very little or no false alarms,

- Traffic in the entire urban area will be effectively and efficiently monitored,

- Coordination and integration of urban traffic cortiol signals, freeway ramp metering, transit control systems, traffic and travel information systems and all other transportation related actions,

- Transportation agencies and $z$ insportation related organisations will operate in harmony, with common goals and objectives without fragmentation or duplication of control and management strategies,

- It wil' be able to predict where and when congestion will occur, hence execution of dynamic traffic assignment based on aggregate origin and 
destination information supplied by all motorists at the beginning of their trips will be possible.

The AVI, AVL, \& advanced incident detection using image processing technologies will be featured prominently. Dynamic traffic assignment models, automatic toll collection and parking management will significantly increase efficiency in the transportation system. It could be inferred that if a full scale implementation of IVHS technologies takes place, then a number of transportation policies and strategies such as road pricing. (e.g., peak period pricing), enforcement of HCV lanes, a better traffic control on a corridor-wide basis, etc, can be implemented with very little and sometimes no obstacles.

\subsection{Advanced Vehicle Control Systems}

This is the most advanced form of technology, where some driving tasks such as collision and skid avoidance, vehicle headways, lane changes, vehicle warnings, adaptive cruise control and other safe manoeuvres are partially or fully executed by the vehicle, with the help of sensors. Shorter headways, closer lateral lane clearance, and speed controls are possible through either vehicle transponders buric ' in the pavement or radar transmitters. In the advanced mode, automated lanes on freeways characterised by high speeds, shorter headways and automatic braking, will increase capacity. According to Johnston et. al., vehicle headways of 0.3 secs and operating speeds of $160 \mathrm{~km} / \mathrm{h}$, resulting in 12000 vehicles per hour per lane (vphpl) will be possin.". As compared with existing capacity of 1800 vphpl, this represents a very high increase in capacity [Johnston et al, 1990]. 


\subsection{Freeway Traffic Management Systems}

The lower order of ATMS includes Advanced Traffic Control Systems (ATCS) \& Freeway Traffic Management Systems (FTMS). A number of strategies have evolved from FTMS but the major ones are detection, detection and advisory, and detection and control systems. Table 3.1 shows components, merits and demerits of each strategy. Specific components of exch depend on a number of factors including traffic characteristics and pattern, geometry and network configuration, objectives and policies of the transportation agency, the nature of the problem, and the last but not the least, available funds. Of all the freeway traffic management strategies, ramp metering was chosen for research because studies done confirm that it has yielded the most positive results [McCormick Rankin, 1986; Bluementritt, 1981; Masher et. al., 1975; Robinson \& Doctor, 1989]. Table 3-2 is a summarised form of a study done on the QEW to evaluate the total effectiveness of various strategies on all sections of the freeway from Ford drive to Humber River Road. The parimeters measured were reduced accidents, reduced weaving intensity, safe merging, improved Level of Service, and increased speeds (see Table 3-2). It confirms the accepted fact that ramp metering is an important technique of FTMS.

\subsection{Types of Metering}

There are five major types of metering

- Ramp Closure

- Pretimed Metering 


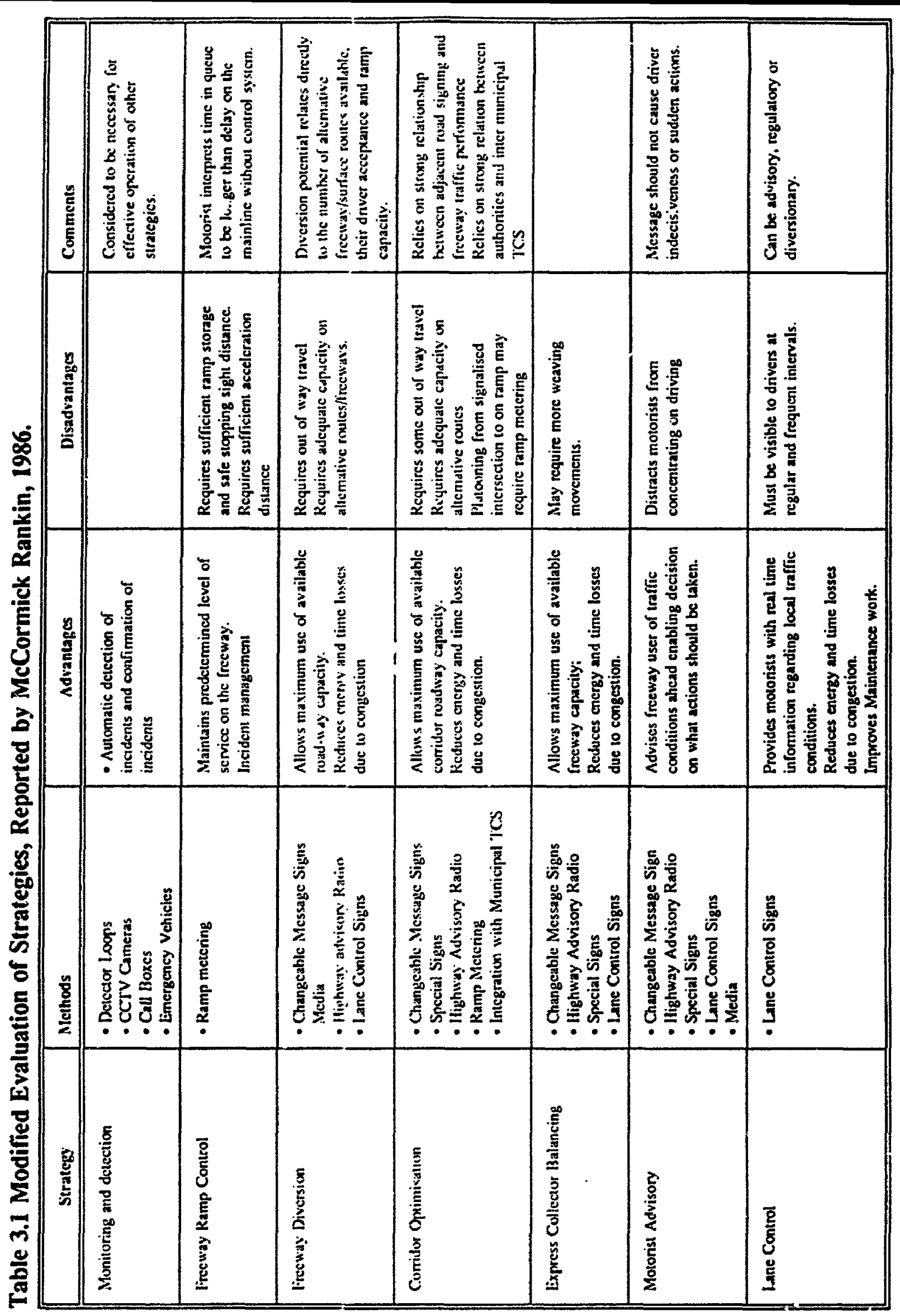




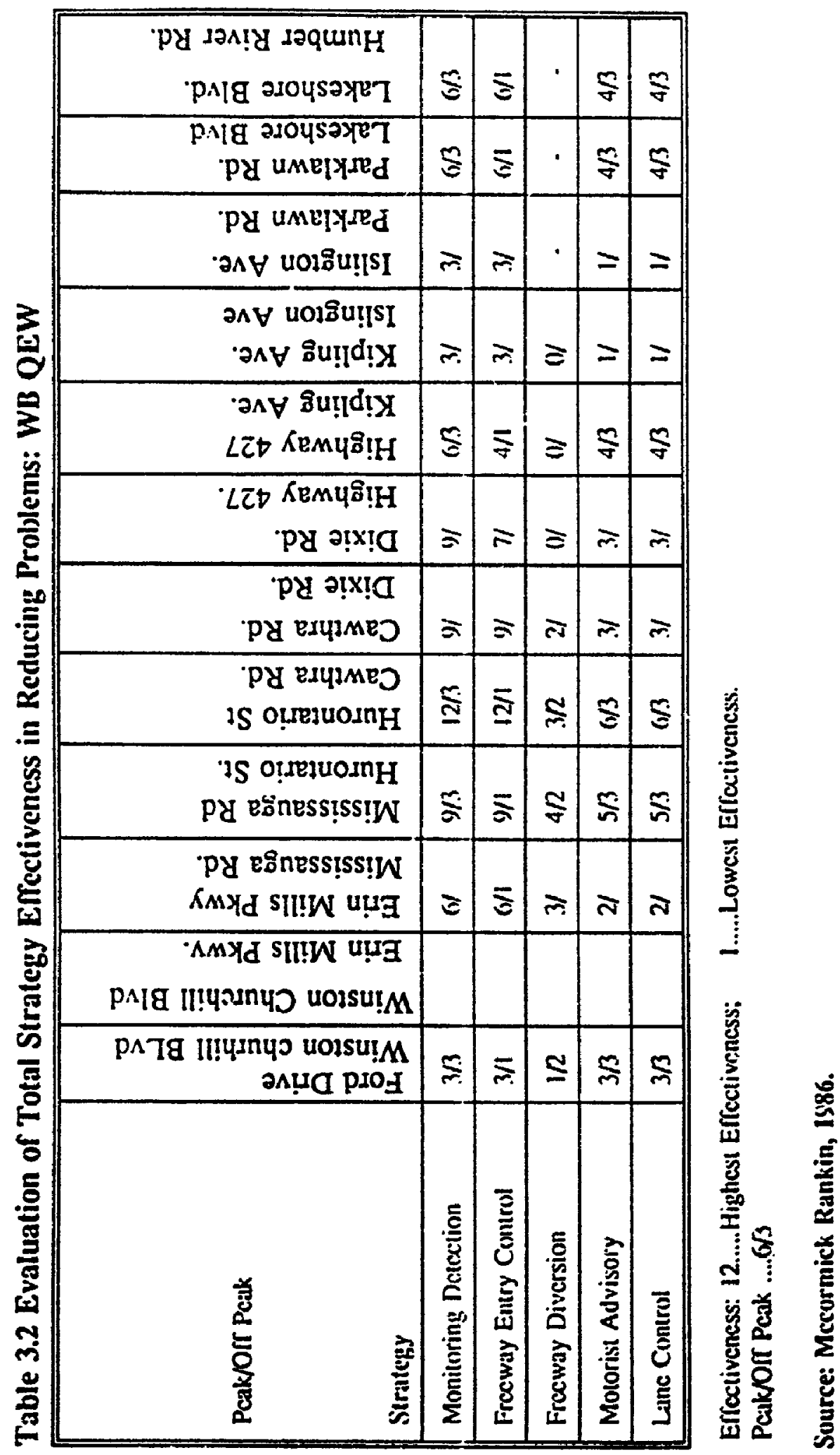


D Traffic Responsive Metering

a Merge Control

a Integrated Ramp Control

\subsubsection{Ramp Closure}

Ramp closure is the simplest, the most effective and restrictive method of ramp control. The control procedure simply restricts all traffic from entering the freeway by manual or remote closing. It is the least popular method but in some cases the best control strategy and yields positive results. It is used when:

a there is totally inadequate storage space for ramp vehicles wanting to enter the freeway and would cause interference to surface streets,

D upstream mainline traffic is operating at capacity whereas alternate routes are well below capacity,

- sub-standard ramp geometrics with inadequate acceleration lanes, and restricted visibility, and

- close ramp spacings, where weaving vehicles are causing a serious congestion and shockwave propagation.

Ramp closure has been used successfully in Houston, Los Angeles, Osaka, Tokyo Ottawa (permanent closure) and Toronto (Gardiner Expressway) [Wainwright, 1972; US DOT, 1976; Robinson \& Doctor, 1989|. For maximum effectiveness, it is important to conduct origin destination studies to determine the traffic pattern, bottleneck sections, and what ramps have to be closed for maximum effectiveness. 


\subsubsection{Pretimed Metering}

The first ramp metering system involved police officers to stop and release vehicles one by one using a stop watch and a ringer to determine the metering rate.

Pretimed metering now operates in a sinilar way as a pretimed intersection signal: traffic discharge is predetermined with the help of historical and projected data. Depending on volume variation, there can be nore than one metering plan. These metering plans are based on historical traffic variations. The major comfonents are noted below and shown in Fig 3-2:

a Traffic Signals.

- Vehicle detectors (optional),

- Advance Warning Flashers,

- Controller Cabinet.

Because metering plans are static, it is insensitive to upstream and or downstream traffic variation. Traffic signals and the controller cabinet are the essential componenis. The traffic signal controls metering rates, advanced warning signs are placed prior to the signals to warn motorists of metering and to give them an option to either use the freeway or the surface route. It is simple, easy to install, relatively inexpensive and very suitable for traffic patterns with predominantly recurring congestion and low frequency of incidents. Because metering plans are "off line", control algorithms could be formulated to any degree of sophistication. Although control strategies are not responsive to real time traffic conditions, metering rates are consistent, making ramp queues and waiting times predictable. Motorists are encouraged to diven as they are aware of the expected ramp 


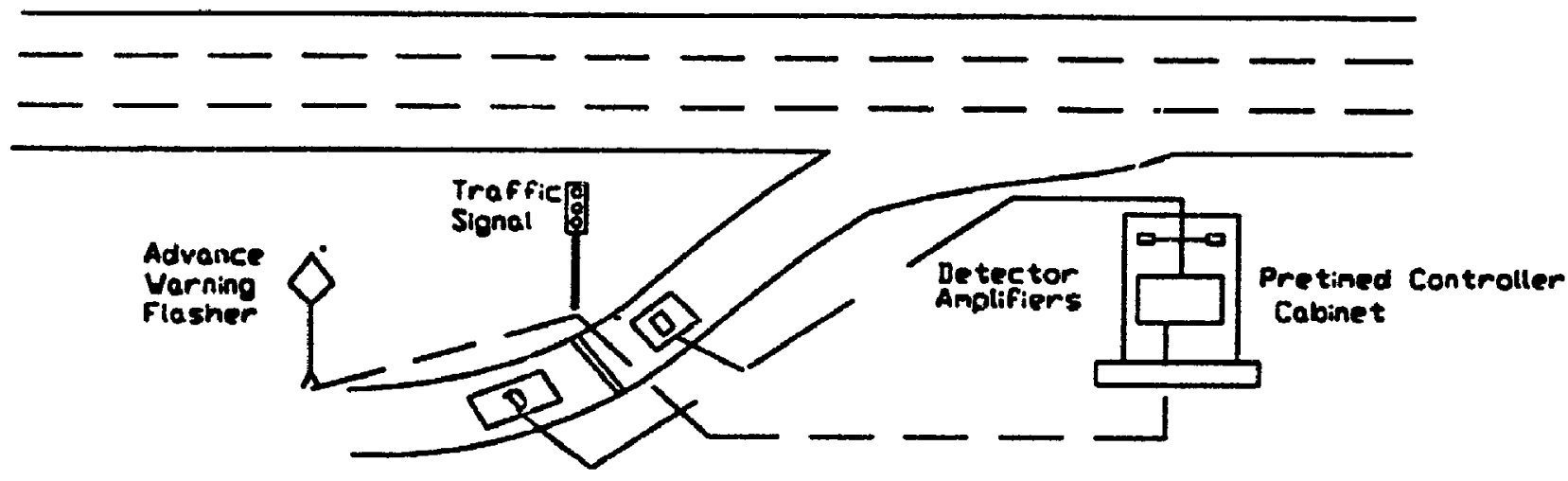

Fig 3.2 Pretimed Metering Source: Bluementritt et al 1981

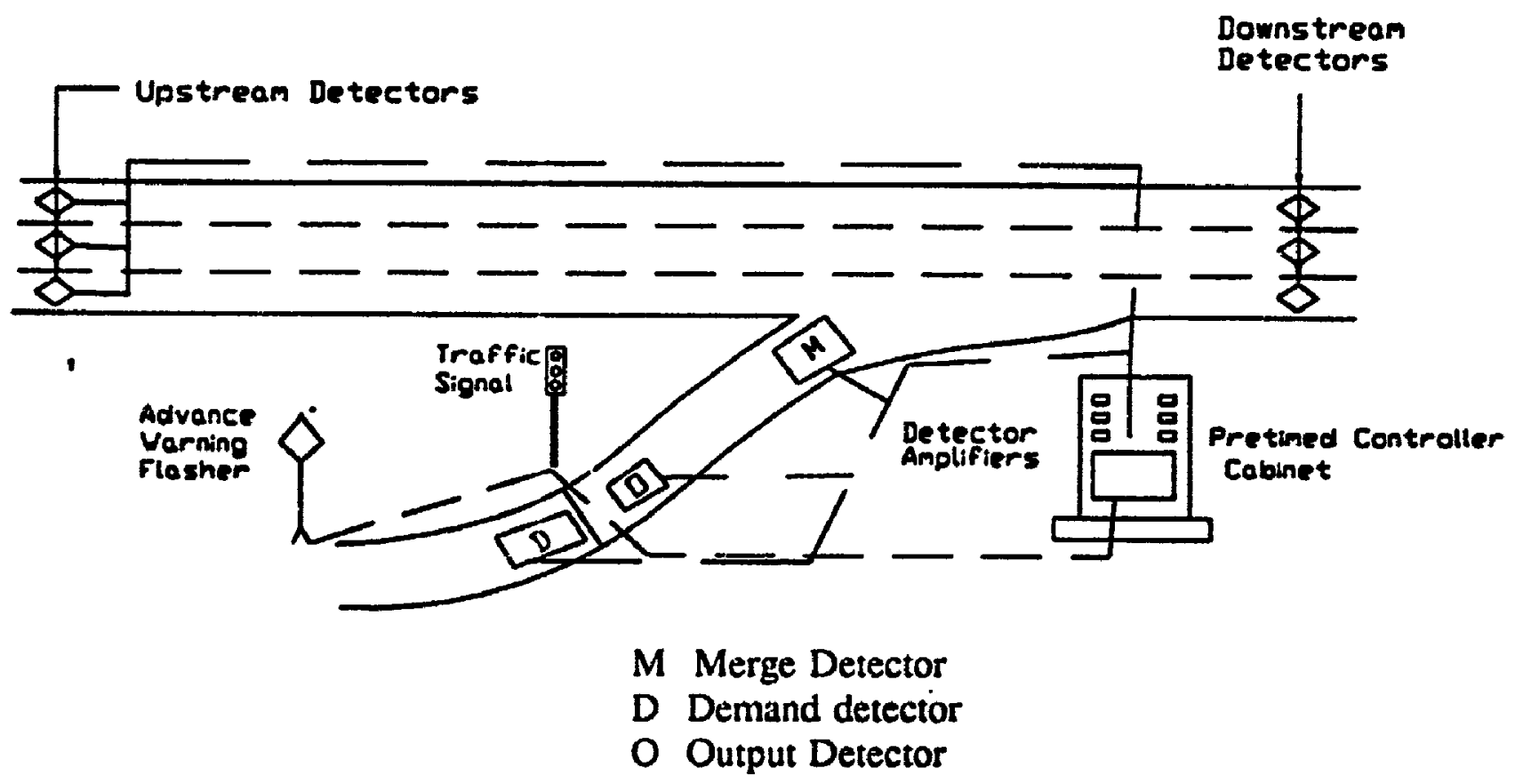

Figure 3.3 Local Responsive Metering Source: Bluementritt et al, 1981. 
conditions. Where the objective of metering is only to break platoons of vehicles discharged from a signalised intersection, substandard geometrics, or to reduce rear end collisions and chaos at ramp bottlenecks, its use is highly recommended [Bluementritt, 1981; Masher et al 1975; ITE handbook. 1992I.

\subsubsection{Traffic Responsive Metering}

Metering rates are based on prevailing upstream and downstream traffic. The major components are

a traffic signals,

- vehicle detectors (upstrean, downstream, check in, merge, and queue detectors),

- Controller Cabinet,

- Advance Warning Flasher.

On line traffic volumes, occupancy and speed parameters from both upstream and downstream detectors, are used to calculate real time metering rates based on local conditions, hence unanticipated traffic conditions are taken care of. Metering rates vary, depending on the prevailing traffic conditions. Passage detectors confirm the entry of a ramp vehicle into the merge section and merge detectors ensure that the lead vehicle has merged into the mainline. The main disadvantage of this method is that metering plans are determined under local traffic conditions. 


\subsubsection{Merge Control}

The concept of merge control is to afford maxinum utilisation of acceptable gaps in mainline lane that ramp vehicles would merge [Wainright, 1972; Pignataro, 1973]. It is intended to maximize the number of ramp vehicles merging safely onto the mainline, hence reduce disruptions to freeway traffic caused by ramp bottlenecks. It doesn't calculate metering rates. Ramp tratfic is guided in a way that it arrives at ramp merge section when there is an acceptable gap. The system operates according to the following guidelines:

- detection of acceptable ramp merge gap,

- projection of the time this gap is made available at the point of entrance ramp, and

- releasing ramp vehicles in time to merge into these gaps.

Two types of merge control strategies exists:

- Gap acceptance merge control,

- Moving Merge.

\subsubsection{Gap Acceptance Merging}

Gap acceptance injection times a ramp vehicle's release such that there is an acceptable gap by the time it reaches the merge section. A number of vehicle detectors are placed in mainline lane 1 to measure vehicle speeds and gaps and compute the times prospective acceptable gaps would be available at merge point. The progressive gap speed is taken into account based on the distance from the ramp to the merge point, the vehicle is 
released in time to merge into these gaps.

Its major elements are:

- traffic signals

- vehicle detectors (gap/speed, queue, check in, check out, merge and slow vehicle detectors).

Its advantages are:

- ideal for entrance ramps with substandard geometrics, and

- $\quad$ safer merging of vehicles, with significant reduction in rear end collisions.

The disadvantages are:

- high construction and maintenance costs,

- metering rates, are not much different from pretimed and local responsive types,

- violation rates are higher: wide variation in metering rates makes drivers either impatient or think signals are mal-functioning,

- it requires several vehicle detectors, and its control algorithms are complicated,

- ramp vehicles released to merge in a progressive acceptable gap are not continuously guided; sometimes mainline lane changes render these gaps occupied.

\subsubsection{Moving Merge (Pacer System)}

It is similar to gap acceptance system, except that ramp vehicles are guided continuously into the merge point. By keeping pace with a positive indication on a string of signals. or in a band of light, the vehicle is placed in a proper merging position for entering a safe available gap in the mainline lane 1 traffic. The speed of moving merge signal is 
determined by the mainline lane 1 acceptable gap speed.

Major components of the system are the same as the gap acceptance type, except that there is a continuous set of signals at about $600 \mathrm{~mm}$ intervals. Furthermore, because the paths of acceptable gaps are monitored continuously, more vehicle detectors are required. The pacer system was developed to alleviate situations where acceptable gaps were not available at merging point to on ramp released vehicles because of vehicles changing from other freeway lanes to occupy identified acceptable gaps.

\subsubsection{Integrated Ramp Control}

All ramp control strategies discussed so far operate independently on local upstream and or downstream traffic conditions. The concept of an integrated ramp control is to link a series of ramps together for proper cu-ordination. The control concept is to maintain mainline volumes at or below a threshold capacity on a system wide basis, rather than on a section by section basis. It could be applied to pretimed, local responsive, or moving merge to achieve maximum utilisation of the entire study area.

In addition to the basic components of pretimed, traffic responsive, and merge control, it requires an element to monitor the whole system. A control centre is required to receive information from vehicle detectors and traffic controllers and send the best control decision logic to each ramp. The main elements include all the hardware and software of the local responsive mode, a central computer and a communications system, to collect data and override local control metering rates with optimal system-wide rates under some predetermined constraints, if necessary. 
As the hardware components increase in number, control and communication equipments play a major role in the system. This is evident as more computer resource allocations are required for sophisticated signal control algorithms as well as increased occupancy, speed. volumes and other constraint computations. A central high speed, high memory computer where all data from each ramp are sent for analysis and decision making, through a two way communication system becomes a necessity (Bluementritt, 1981; Masher et al, 1975; US DOT, 1976; Pignataro, 19731.

\subsection{Components of Freeway Traffic Management System:}

A freeway traffic managenent system includes all or any combination of

- Freeway Ramp Metering

- Closed circuit TV surveillance

- Highway Advisory Radio

D Changeable Message signs (CMS)

- Emergency Vehicle Patrols

a Lane Control System

The selection of freeway traffic management components depends on the predominant type of congestion (recurring or non recurring), mainline and surface street conf, zuration, traffic patterns, and its relative change with time.

On Highway 401 in Toronts for instance, where immediate response to incidents : wery vital due to the heavy traffic in its urban section (over 300,000 everyday users), the system consists of [MTO, 1993]: 
a $\quad 32$ closed circuit tv cameras with pan and zoom capabilities,

- 850 vehicla detectors,

- changeable message signs,

a emergency MTO patrols and standby tow trucks,

- coaxial cable communications,

- traffic operations centre, and

a a craffic and road information system (TRIS) delivering up to minute information to drivers, emergency patrols, Ontario Provincial Police staff, radio and television stations, and fire stations, via telephones, faxes, and video signals.

In the case of Highway 401 , ramp metering strategy was not necessary, because both express and collector lanes are uninterrupted controlled access facilities. Therefore emphasis are placed on detection and advisory to make maximum use of available corridor capacity.

A Proposed Freeway Traffic Management system for the Ottawa-Carleton Region is shown in Figure 3.4.

\subsubsection{Control Hardware:}

Vehicle Detectors

A number of vehicle detectors exist but the main ones are

- Ultrasonic detectors

- Magnetometers

a Inductive Loop Detectors 


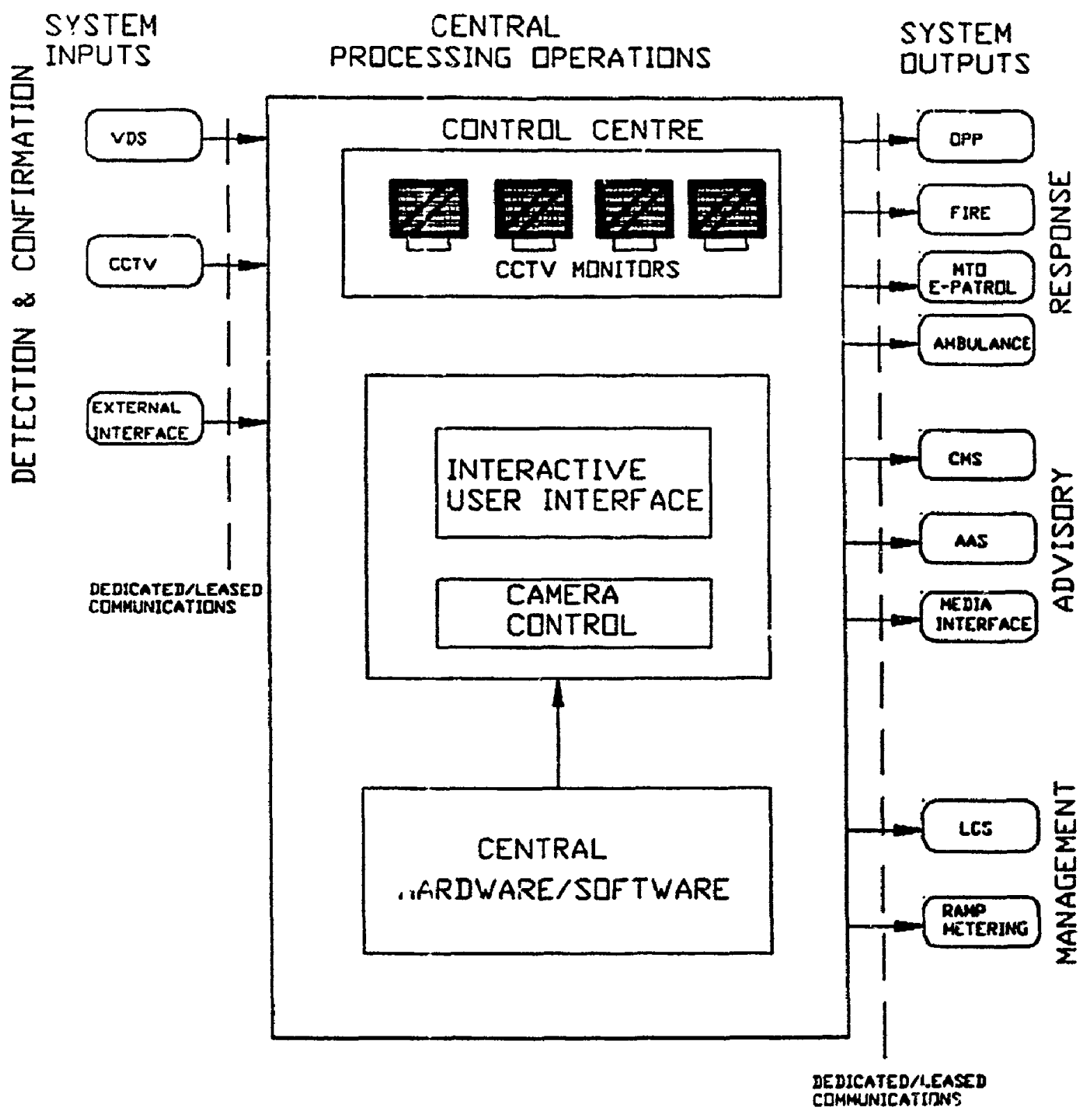

Figure 3-4: Proposed FTMS For The Ottawa-Carleton Region

Source: IBI Group, 199.3 
a Microwive dete';ors

- Video image processing

Most vehicle detectors are activated whenever a vehicle comes within its area of sensitivity through magnetic, sonic microwave or radar technologies. Inductive loop detectors are the most widely used vehicle detection devices. These consist of a flexible cable, turned a number of times and laid in rectangular or diamond shaped saw cut slots made in the wearing course. Magnetic fields are generated when a vehicle traverses its area of influence. These signals are transmitted to the traffic control centre via control cabinet substations. Detectors can be used to measure speed, volume, and occupancy with 5\% error [Masher, DP et al, 1975; Michalopoulos et al 1993]. Speed, occupancy, and volume are measured on line. Loops are usually placed in each lane. Disruption of traffic during maintenance and false congestion detection alarms are their major disadvantages. Because of these set-backs, the Ministry of Transportation is actively testing microwave detectors, which would be mounted on overhead structures above or beside the freeway. Initial reports are very encourawing [MTO, 1993].

Inductance loops, as well as sonic, microwave, and magnetometer detectors are based on the principle of discrete detection. In many locations where there is a higher probability of non-recurring congestion on the freeway, a closed circuit television syste.m is used to confirm congestion detected by loops [MTO, 1991; Ayland et. al., 1991; IBI Group, 1991].

Video im: ge processing techniques, by virtue of continuous detection on an areawide basis, are likely to take over from loops. Initial tests conducted in Mirnesota 
indicate $95 \%$ accuracy to detect volumes, speed, \& occupancy measurements in all weather. About $80 \%$ of incidents could be detected by a single camera within a $3 \mathrm{~km}$ range with only 0.65 false alarms per day! This means a single camera could replace a number of loops [Michalopoulos et al 1993]. The Municipality of stetropolitan Toronto is presently using the Autoscope system on the Gardiner-Lakeshore corridor, to manage traffic at locations where the use of loops is not possible, in its corridor rehabilitation.

\subsubsection{Controllers}

Controllers are devices that send messages to the traffic signals, instructing them when to turn green, amber, or red. The main types are

- Dial-and-cim unit, controlled by a timer

- Digital Controller

- Central Controller

- Microprocessor based controller

Dial-and-cam unit are electromechanical controllers with dials, cams, switches, synchronous motor, and timing gears. The dials are used to set different timing plans. Very limited timing plans can be delivered. This type of controller can be used for pretimed metering where metering rates are static.

Recent controllers include hardware and software systems with microprocessors, detector amplifiers and conflict monitors. The architecture is based on a standard hard'vare system into which a number of software programs with the help of menu driven assistance, can be easily entered to perform a variety of traffic control functions. Signal timing plans 
could also be put into "silicon chips" and assembled in a microprocessor unit. Detector amplifiers found in controllers, pick up loop signal. and transmit them to regional or central controllers. The most widely used controllers in North America are the NEMA type 170 and NEMA II controllers.

\subsubsection{Communications}

Communication is essential when data are to be transferred from mainlines or ramps to a central control point. Conmunication links could be

- !easid telephone lines,

- coaxial cable,

- fibre optic.

These communication links can be rented, leased or owned by the transportation agency. At present, the traftic management department of MTO is engaged in a pilot project, evaluating the ce"t effectiveness of sending compressed video images through telephone lines on Highway 401 and Sheppard Avenue interchange [MTO, 1993].

\subsection{Metering Concepts}

Pretimed, traffic responsive and integrated ramp controls operate on the concept of fluid flow through a tank. That is volume input should $b$ fual to volume output, otherwise there is storage in the tank (see Figure 3-5a \& b). 

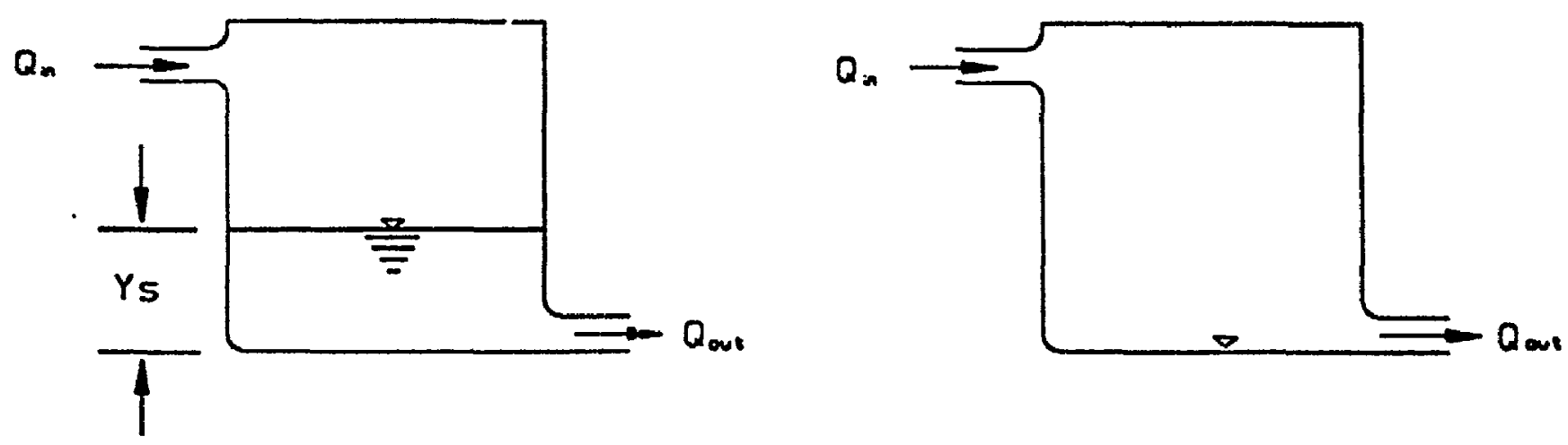

Figure 3-5 a \& b Principles of Fluid Flow.

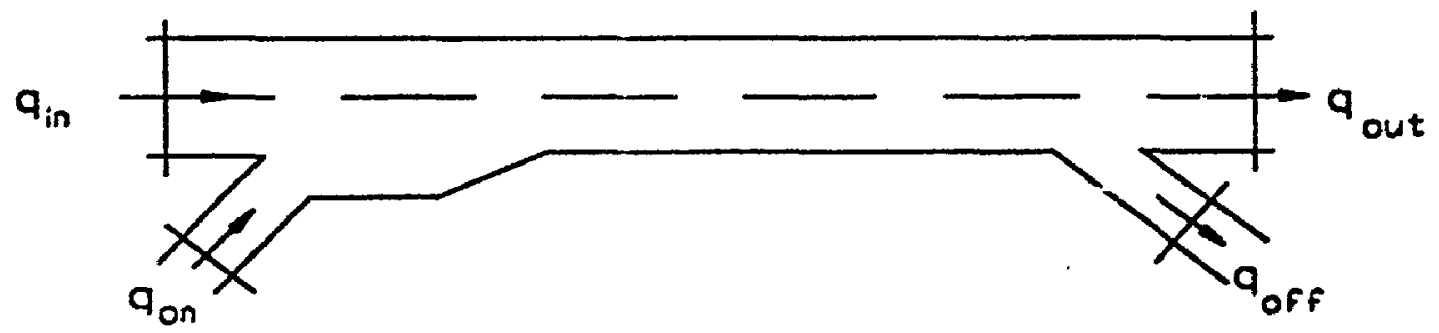

Figure 3-6 Input Output Flow Illustration. 
Case 1: $Q_{\mathrm{in}}>\mathrm{Q}_{\mathrm{out}}$ (Figure 3-5a)

$$
Y_{s}=Q_{\text {input }}-Q_{\text {out }}
$$

Case 2: $Q_{\text {oul }} \Rightarrow Q_{\text {in }}$ (Figure 3-6b)

$$
Y_{s}=Q_{\text {input }}-Q_{\text {out }}=0
$$

To prevent storage, $Q_{\mathrm{in}}$ for case $I$ will have to be decreased by an amount equal to $Y_{s}$, the rate of storage.

Applying the same concept to ramp control, mainline input plus on ramp volume should be equal or less than off ramp volume plus mainline output volume. This is expressed mathematically as:

$$
\begin{gathered}
\left(q_{\text {input }}+q_{o n}\right) \leq\left(q_{\text {out }}+q_{o f f}\right) \ldots \text { No storage } \\
\left(q_{\text {input }}+g_{o n}\right)>\left(g_{\text {out }}+q_{o f f}\right) \ldots \text { storage condition } \\
q_{a}=q_{o n}-\left(q_{o n}+q_{\text {input }}-g_{o u t}-q_{o f f}\right)
\end{gathered}
$$

Where

q. Allowable on ramp vehicles.

$q_{\text {input }}, q_{o n}, q_{o f l}, \& q_{\text {out }}$ are all illustrated in Figure 3-6 
The amount of vehicles allowed at an entrance ramp is found by subtracting the amount of storage on mainline from the entrance ramp volume.

As stated earlier freeway ramp control is the most positive method of freeway traffic management system. This is explained by Newell's theory, as reported by Pretty, who discovered that where mainline traffic was congested, almost half of the downstream mainline lane 1 traffic are ramp traffic [Pretty, 1984]. If the freeway is already at a LOS E or worse, this extra $50 \%$ ramp traffic worsens the state of congestion and increases queue build ups upstream of the bottleneck. Ramp control is introduced to reduce the percentage of downstream mainline lane 1 traffic originating from on ramps. To account for minor fluctuations in traffic, mainline sections must be maintained slightly below its capacity (threshold capacity) for pretimed metering [Payne, 1973; Jacoisen et. al., 1989]. A successful metering philosophy is the one that will introduce metering before the peak period to induce diversion in space, time and modal shifts and also to ensure a smooth transition from maximum metering rates to minimum rates. It should also be incorporated in new urban ireew $y$ construction, as is being planned for the proposed Highway 407 in Toronto [MTO, $1990 \& 1992 ;]$.

\subsection{Control Strategies}

The principal control strategies are [ITE, 1992]

- Demand Capacity Control, and

- Occupancy Control 


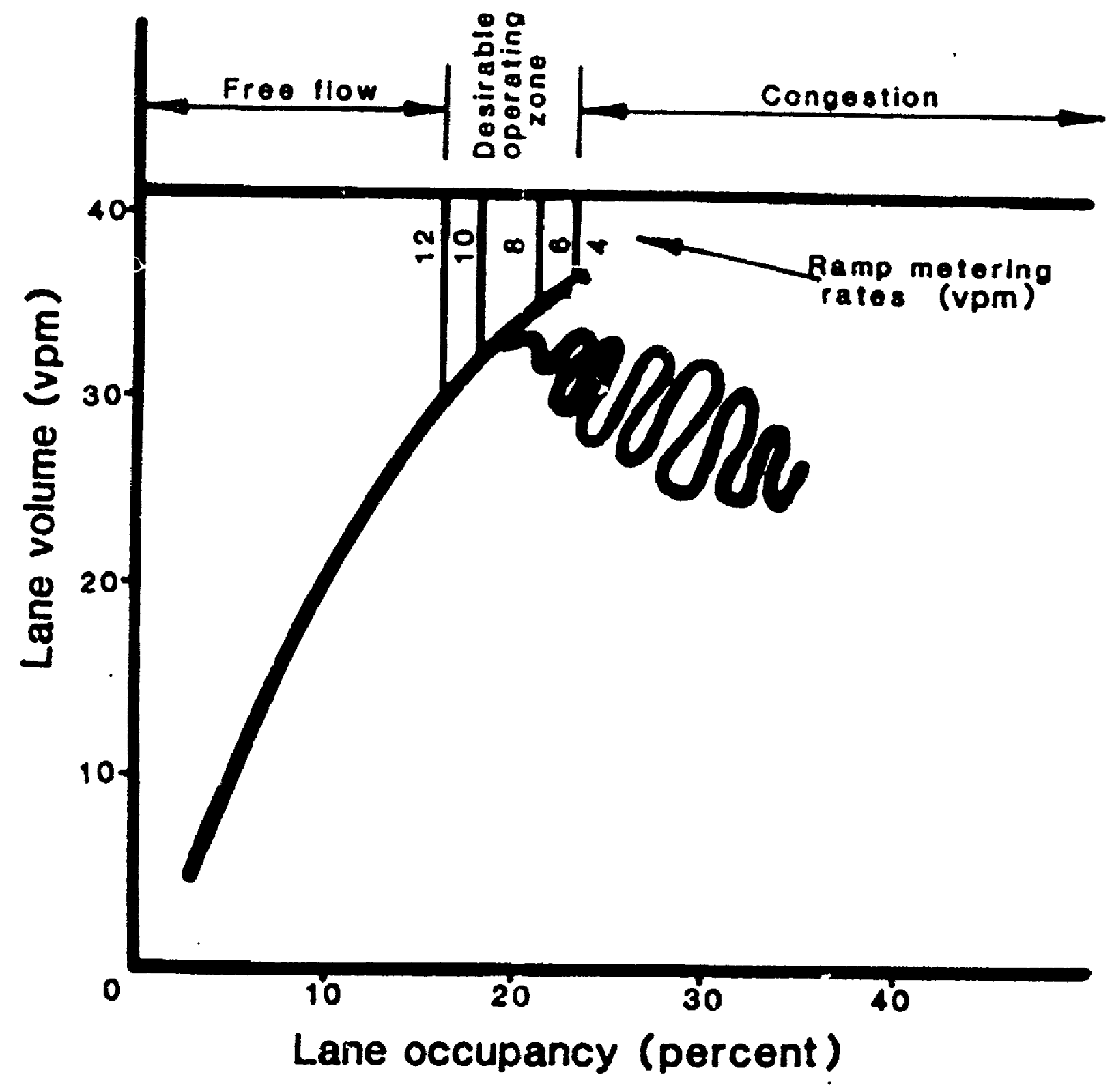

Figure 3.7: Volume Occupancy Plot For Calculation of Entrance Ramp Metering as Reported in ITE 1992 Handbook. 

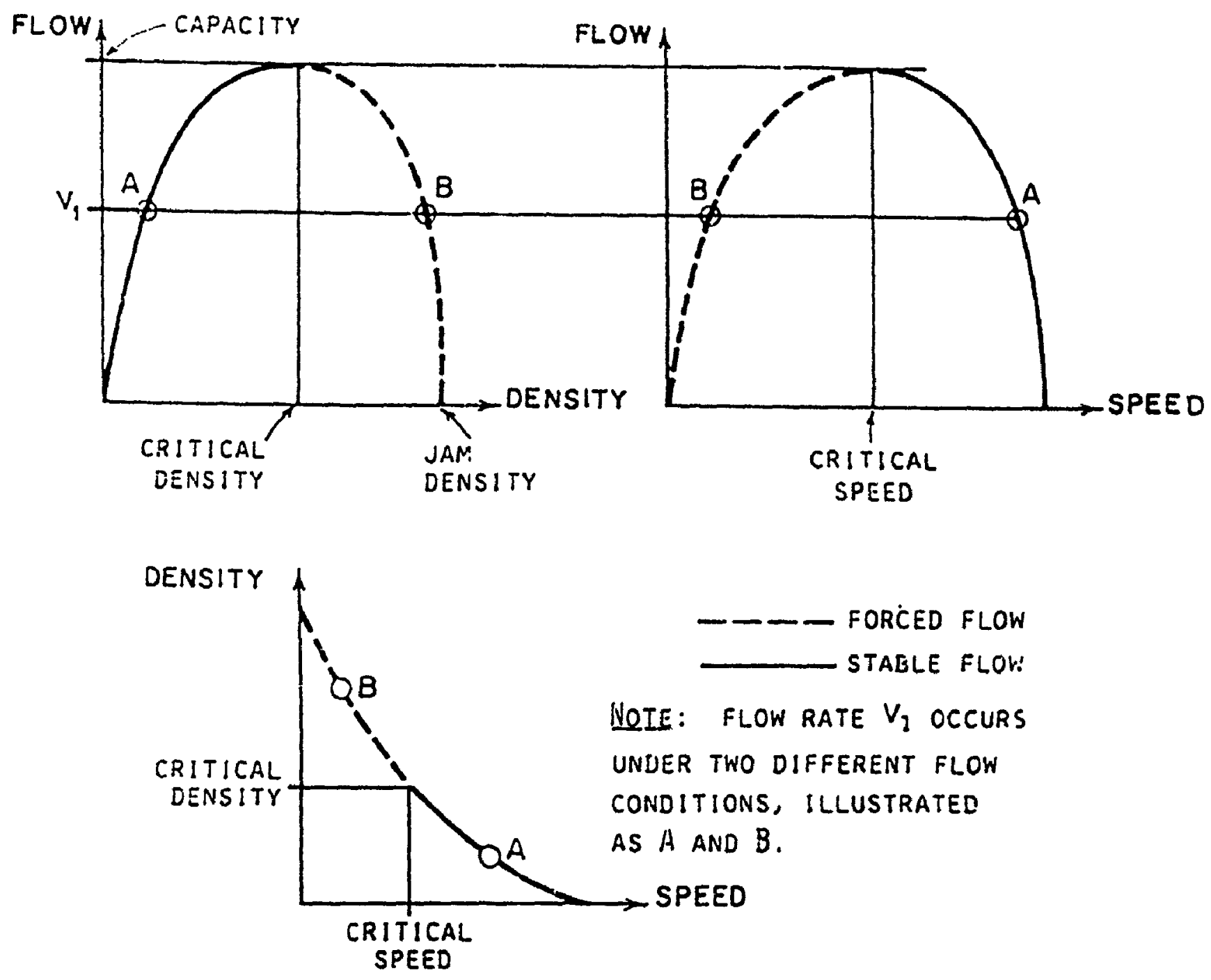

Figure 3.8 Flow, Speed, \& Density Relations For Uninterrupted Flow. Source: Highway Capacity Manual, 1985 
Metering rates for demand capacity control depends on real time or historical upstream mainline traffic and downstre:tm capacity. If the upstream traffic is more than the downstream capacity, then the permissible on ramp traffic is set equal to the difference between these mainline volumes on condition it doesn't violate the minimum and maximum metering rates, as well as maximum queue length for each ramp. Metering rates for occupancy control are based on on-line upstream or downstream detector occupancies. These percentage occupancies are converted into traffic volumes and permissive metering rates determined in a similar way as that for demand capacity. Figure 3-7 is a volume occupancy plot from Chicago Area Expressway. From the figure, as lane volume increases, its corresponding o'cupancy increases as well. This is logical because within facility capacity, vehicie occupancies are directly proportional to traffic volume. Without metering, lane capacity of about 33 vehicles per minute (1980 vph) occurs at an occupancy of about $19 \%$. Any further increase in capacity results in erratic, unstable, stop and go, and forced flow conditions. If metering begins at an occupancy of about $14 \%$, each lane can accommodate up to $36 \mathrm{vpm}(2200 \mathrm{vph})$ at a steady flow rate.

Occupancy is a better indicator of freeway traffic conditions because measured volumes lower than mainline capacity could occur in forced flow as well as free flow conditions [Transportation Research Board, 1985; ITE Handbook, 1992]. Furthermore capacity of a road facility is not fixed but depends on prevailing roadway and traffic conditions. From flow, speed and density relations shown in Figure 3-6 for instance, flow rate $V_{1}$ occurs under two different flow conditions, illustrated by $A$ \& $B$.

This concludes the prologue of this thesis. The previous chapters, including this 
one, have identified the current pitfalls in freeway ramp control as well as the current state of the art of metering. Subsequent chapters propose modifications and additions to existing methodologies to address these problems such as,

- co-ordinating ramp signals with alternate traffic signals,

- conducting detailed analysis of the impacts of metering on alternate routes, and

- introducing a methodology to determine metering rates, considering freeway traffic conditions as well as surface street traffic delays. 


\section{CHAPTER 4}

\section{RAMP CONTROL STRATEGIES AND TACTICS:}

\section{CAPACITY ANALYSIS}

This Chapter, and Chapter 5 pre ient a methodology for evaluating ramp control strategies and tactics. Here, a brief backgrourid of the Queensway is presented, followed by the first step of the methodology: Capacity Analysis Module.

\subsection{The Ottawa Queensway: Introduction and Need}

Highway 417 is an east west uninterrupted controlled access facility. It is the only continuous east west link through the study area. It is a Provincial Freeway which serves both intra city and inter city traffic in the Ottawa-Carleton Region. The section of this freeway of interest to this research, namely the Ottawa Queensway, is defined by the Eagleson Road Interchange \& Highway 417 and 17 Interchange.

Urban land use patterns, increasing growth in satellite cities, especially Orleans and Kanata, and the preservation of the green belt areas, have all precipitated increased 
trips to and from the CBD during morning and afternoon peak periods. In Kanata for instance, its population is expected to increase from the present 42,000 to 100,000 in the early years of the next century [Ray, R 1994].

Highway 417, popularly known as the Queensway, was constructed in 1966, from Richmond to Montreal Rd for uninterrupted traffic flow [IBI Group, 1987]. Various expansion and rehabilitation works have been executed for more than a decade which have insproved its traffic flow. Present and future conditions indicate that it is and will continue to experience both recurrent and non-recurrent congestion, characterised by erratic traffic flow, stop and go traffic, increased travel times, driver frustration and other undesirable attributes at peak periods.

With increasing traffic, decreasing budget allocations to transportation agencies. and increasing environmental awareness, it has become necessary to examine ways to efficiently manage traffic flow at minimum cost.

\subsection{Capacity Analysis Module.}

For this methodology to be useful and successful, the following functional requirements are necessary:

- The freeway traffic is operating at an undesirabie LOS, manifested by low speeds, erratic stop and go operation, high densities, etc.

- There is an alternative route, operating below capacity, where some traffic could be diverted;

- The freeway on ramps have adequate ramp storage capabilities. 
The first step of the methodology is a two stage process to investigate if the first two requirements are satisfied ihrough:

- Freeway Capacity Analysis;

- $\quad$ Arterial Capacity Anal; sis;

Figure 4.1 is a flow chart to illustrate Capacity Analysis Module.

\subsubsection{Capacity Analysis: Highway 417}

The purpose of freeway capacity analysis is to identify problem areas on the Queensway. Analysis was undertaken on the basic freeway sections of the Queensway. Section by section mainline traffic data was not available; therefore traffic volumes on all sections of Highway 417 were estimated based on 1992 ramp counts and data from a mainline permanent count station located about $1.5 \mathrm{~km}$ west of Highway 7 and Highvay 417 interchange in the months of July and August, 1992. The Ministry of Transportation of Ontario (MTO) provided the above noted information. Mainline hourly volumes of each section of the freeway were obtained by addition and subtraction of entrance and exit ramp volumes, for each hour. Tables $4.1 \& 4.2$ provide a summary of 1992 ramp counts from $06: 00$ to $10: 00$ and $14: 00$ to $18: 00$ by either loop detectors or pneumatic tube counters obtained from MTO.

Figure 4.2 indicates estimated mainline and ramp volumes for eastbound (EB) traffic during the a.m. and p.m. peak hours (hourly volumes). The 1992 screenline traffic volumes, obtained from the Regional Municipality of Ottawa-Carleton (RMOC) were compared with calculated volumes and these are also shown. Al:hough all traffic volumes 


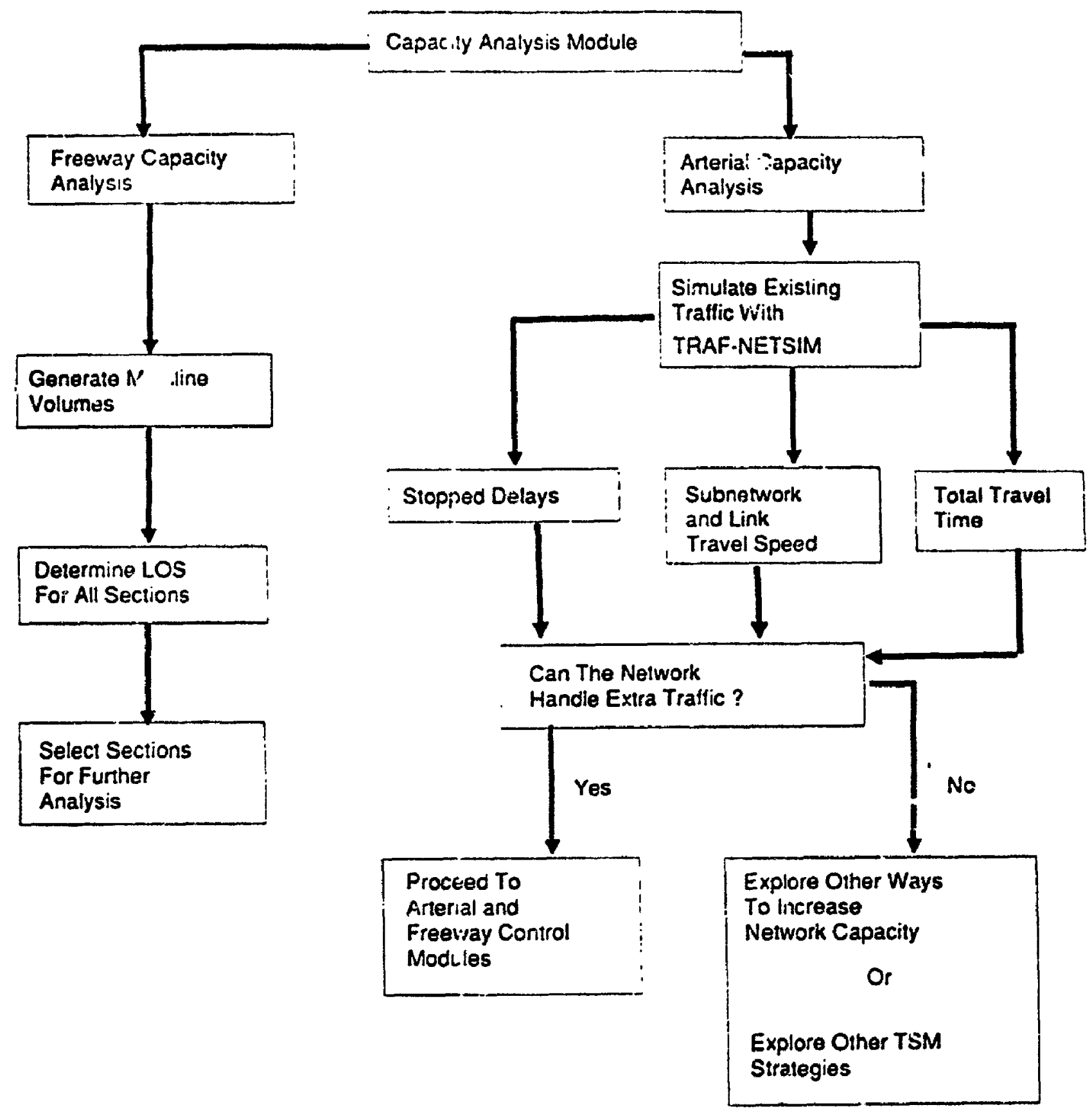

Figure 4.1: Capacity Analysis Module 
Table 4.1: 1992 Highway 417 Westbound Ramp Volumes (vph)

\begin{tabular}{|c|c|c|c|c|c|c|c|c|c|}
\hline Ramp & Date & $6-7 \mathrm{am}$ & 7.8am & 8-9am & 9.10am & $2-3 p m$ & $3-4 \mathrm{pm}$ & $4-5 \mathrm{r}$ & $5-6 \mathrm{pm}$ \\
\hline $\begin{array}{ll}66 & 7 / 17 \\
56\end{array}$ & Jul 24 & $\begin{array}{l}167 \\
7\end{array}$ & $\begin{array}{l}303 \\
4\end{array}$ & $\begin{array}{l}305 \\
9\end{array}$ & $\begin{array}{l}405 \\
7\end{array}$ & $\begin{array}{l}601 \\
13\end{array}$ & $\begin{array}{l}731 \\
12\end{array}$ & $\begin{array}{l}945 \\
14\end{array}$ & $\begin{array}{l}868 \\
13\end{array}$ \\
\hline $\begin{array}{l}\text { Carp } \\
\text { Rd }\end{array}$ & $\begin{array}{l}\text { Aug } 14 \\
.92\end{array}$ & \begin{tabular}{|l|}
148 \\
16
\end{tabular} & $\begin{array}{l}254 \\
49\end{array}$ & $\begin{array}{l}260 \\
36\end{array}$ & $\begin{array}{l}199 \\
44\end{array}$ & $\begin{array}{l}280 \\
58 \\
\end{array}$ & $\begin{array}{l}316 \\
79 \\
\end{array}$ & $\begin{array}{l}403 \\
93 \\
\end{array}$ & $\begin{array}{l}384 \\
94 \\
\end{array}$ \\
\hline $\begin{array}{l}\text { Terry } \\
\text { Fox }\end{array}$ & $\begin{array}{l}\text { Jul } 24 \\
.92\end{array}$ & $\begin{array}{l}7 \\
35 \\
128 \\
\end{array}$ & $\begin{array}{l}11 \\
76 \\
221\end{array}$ & $\begin{array}{l}17 \\
54 \\
219\end{array}$ & $\begin{array}{l}19 \\
62 \\
157\end{array}$ & $\begin{array}{l}26 \\
115 \\
310\end{array}$ & $\begin{array}{l}17 \\
130 \\
363\end{array}$ & $\begin{array}{l}32 \\
198 \\
555\end{array}$ & $\begin{array}{l}19 \\
234 \\
473\end{array}$ \\
\hline $\begin{array}{ll}15 & \\
61 & \text { Eagleson }\end{array}$ & $\begin{array}{c}\text { Jul } 24 \\
\cdot 92\end{array}$ & $\begin{array}{l}20 \\
19 \\
431\end{array}$ & $\begin{array}{l}53 \\
36 \\
802\end{array}$ & $\begin{array}{l}52 \\
45 \\
949\end{array}$ & $\begin{array}{l}64 \\
46 \\
614\end{array}$ & $\begin{array}{l}111 \\
76 \\
912\end{array}$ & $\begin{array}{l}94 \\
141 \\
1193\end{array}$ & $\begin{array}{l}161 \\
203 \\
1447\end{array}$ & $\begin{array}{l}121 \\
105 \\
1351\end{array}$ \\
\hline $\begin{array}{l}36 \\
26 \\
61 \\
61\end{array}$ & $\begin{array}{l}\text { July } 24 \\
\text { '92 }\end{array}$ & $\begin{array}{l}20 \\
23 \\
344 \\
\end{array}$ & $\begin{array}{l}43 \\
47 \\
747 \\
\end{array}$ & $\begin{array}{l}60 \\
74 \\
879 \\
\end{array}$ & $\begin{array}{l}41 \\
56 \\
518 \\
\end{array}$ & $\begin{array}{l}86 \\
124 \\
555 \\
\end{array}$ & $\begin{array}{l}162 \\
101 \\
621 \\
\end{array}$ & $\begin{array}{l}215 \\
140 \\
667\end{array}$ & $\begin{array}{l}152 \\
160 \\
575\end{array}$ \\
\hline $\begin{array}{l}36 \\
26 \\
61\end{array}$ & $\begin{array}{c}\text { July } 24 \\
' 92\end{array}$ & $\begin{array}{l}98 \\
14 \\
204 \\
\end{array}$ & $\begin{array}{l}172 \\
48 \\
330 \\
\end{array}$ & $\begin{array}{l}179 \\
52 \\
339 \\
\end{array}$ & $\begin{array}{l}113 \\
35 \\
393 \\
\end{array}$ & $\begin{array}{l}312 \\
36 \\
668 \\
\end{array}$ & $\begin{array}{l}387 \\
77 \\
827 \\
\end{array}$ & $\begin{array}{l}433 \\
77 \\
1056 \\
\end{array}$ & $\begin{array}{l}458 \\
50 \\
1063 \\
\end{array}$ \\
\hline $\begin{array}{ll}36 & \\
26 & \text { Pinecrest } \\
61 & \end{array}$ & $\begin{array}{l}\text { July } 24 \\
' 92\end{array}$ & $\begin{array}{l}63 \\
88 \\
186 \\
\end{array}$ & $\begin{array}{l}62 \\
244 \\
520\end{array}$ & $\begin{array}{l}78 \\
260 \\
779 \\
\end{array}$ & $\begin{array}{l}79 \\
217 \\
569 \\
\end{array}$ & $\begin{array}{l}113 \\
265 \\
781\end{array}$ & $\begin{array}{l}125 \\
293 \\
1068\end{array}$ & $\begin{array}{l}189 \\
410 \\
1336 \\
\end{array}$ & $\begin{array}{l}181 \\
315 \\
1136 \\
\end{array}$ \\
\hline $\begin{array}{l}16 \\
63 \text { Woodroffe } \\
62 \\
88\end{array}$ & $\begin{array}{l}\text { Jul } 24 \\
\cdot 92\end{array}$ & $\begin{array}{l}278 \\
227 \\
72 \\
13\end{array}$ & $\begin{array}{l}325 \\
388 \\
139 \\
57\end{array}$ & $\begin{array}{l}276 \\
i 16 \\
209 \\
71\end{array}$ & $\begin{array}{l}340 \\
322 \\
198 \\
43\end{array}$ & $\begin{array}{l}502 \\
471 \\
342 \\
5\end{array}$ & $\begin{array}{l}574 \\
659 \\
319 \\
20\end{array}$ & $\begin{array}{l}482 \\
814 \\
342 \\
48\end{array}$ & $\begin{array}{l}403 \\
754 \\
370 \\
51\end{array}$ \\
\hline $\begin{array}{l}16 \text { Maitland } \\
61\end{array}$ & $\underset{992}{\text { Aug } 14}$ & $\begin{array}{l}144 \\
217\end{array}$ & $\begin{array}{l}367 \\
508\end{array}$ & $\begin{array}{l}476 \\
511\end{array}$ & $\begin{array}{l}402 \\
413\end{array}$ & $\begin{array}{l}528 \\
585\end{array}$ & $\begin{array}{l}656 \\
698\end{array}$ & $\begin{array}{l}848 \\
771\end{array}$ & $\begin{array}{l}723 \\
670\end{array}$ \\
\hline $\begin{array}{l}66 \text { Carling } \\
67\end{array}$ & $\underset{\cdot 92}{\text { Aug } 14}$ & $\begin{array}{l}139 \\
375\end{array}$ & $\begin{array}{l}314 \\
930\end{array}$ & $\begin{array}{l}389 \\
1080\end{array}$ & $\begin{array}{l}347 \\
798\end{array}$ & $\begin{array}{l}529 \\
961\end{array}$ & $\begin{array}{l}712 \\
997\end{array}$ & $\begin{array}{l}838 \\
1145\end{array}$ & $\begin{array}{l}652 \\
869\end{array}$ \\
\hline $\begin{array}{l}61 \text { Parkdale } \\
16\end{array}$ & $\begin{array}{l}\text { Aug } 21 \\
\text { Aug } 14\end{array}$ & $\begin{array}{l}360 \\
175\end{array}$ & $\begin{array}{l}716 \\
350\end{array}$ & $\begin{array}{l}627 \\
345\end{array}$ & $\begin{array}{l}523 \\
299\end{array}$ & $\begin{array}{l}513 \\
446\end{array}$ & $\begin{array}{l}661 \\
537\end{array}$ & $\begin{array}{l}466 \\
515\end{array}$ & $\begin{array}{l}697 \\
468\end{array}$ \\
\hline 16 Rochester & Jul 24 & 182 & 240 & 285 & 196 & 310 & $3: 1$ & 552 & 376 \\
\hline $\begin{array}{l}16 \text { Bronson } \\
61 \text { Ave. }\end{array}$ & $7 / 24 / 92$ & $\begin{array}{l}170 \\
5 \pi:\end{array}$ & $\begin{array}{l}355 \\
1056\end{array}$ & $\begin{array}{l}462 \\
1011\end{array}$ & $\begin{array}{l}329 \\
703\end{array}$ & $\begin{array}{l}464 \\
782\end{array}$ & $\begin{array}{l}583 \\
770\end{array}$ & $\begin{array}{l}590 \\
770\end{array}$ & $\begin{array}{l}533 \\
688\end{array}$ \\
\hline 36 Lyon & July 24 & 111 & 322 & 424 & 388 & 667 & 793 & 1009 & 857 \\
\hline
\end{tabular}


Table 4.1: (continued) 1992 Highway 417 Ramp volumes (vph) Westbound

\begin{tabular}{|c|c|c|c|c|c|c|c|c|c|c|}
\hline Ramp & IC & Date & $6-7$ & 7.8 & 8.9 & 9.10 & 2.3 & $3-4$ & $4-5$ & 5.6 \\
\hline $\begin{array}{l}66 \\
62\end{array}$ & Metcalfe & Jul 24 & $\begin{array}{l}338 \\
97\end{array}$ & $\begin{array}{l}809 \\
556\end{array}$ & $\begin{array}{l}844 \\
648\end{array}$ & $\begin{array}{l}53 \times 4 \\
4 ! 17\end{array}$ & $\begin{array}{l}520 \\
337\end{array}$ & $\begin{array}{l}617 \\
405\end{array}$ & $\begin{array}{l}622 \\
387\end{array}$ & $\begin{array}{l}484 \\
300\end{array}$ \\
\hline 76 & Occonor & Jul 24 & 96 & 339 & 481 & 370 & 532 & 712 & 808 & 664 \\
\hline $\begin{array}{l}43 \\
36 \\
62 \\
64\end{array}$ & Nicholas & $\begin{array}{l}\text { Jul } 24 \\
\text { Jul } 24 \\
\text { Jul } 26^{*} \\
\text { Jul } 26^{*}\end{array}$ & $\begin{array}{l}158 \\
153 \\
720 \\
128\end{array}$ & $\begin{array}{l}384 \\
286 \\
1641 \\
343\end{array}$ & $\begin{array}{l}487 \\
360 \\
1377 \\
270\end{array}$ & $\begin{array}{l}316 \\
293 \\
1018 \\
214\end{array}$ & $\begin{array}{l}413 \\
506 \\
972 \\
283 \\
\end{array}$ & $\begin{array}{l}490 \\
552 \\
1092 \\
282\end{array}$ & $\begin{array}{l}585 \\
628 \\
1179 \\
334\end{array}$ & $\begin{array}{l}463 \\
502 \\
253 \\
316\end{array}$ \\
\hline $\begin{array}{l}36 \\
26 \\
61\end{array}$ & Riverside & $\begin{array}{l}\text { Aug } 28 \\
\text { Jul } 24 \\
\text { Jul } 24\end{array}$ & $\begin{array}{l}347 \\
215 \\
581\end{array}$ & $\begin{array}{l}696 \\
531 \\
882\end{array}$ & $\begin{array}{l}761 \\
762 \\
708\end{array}$ & $\begin{array}{l}538 \\
650 \\
508\end{array}$ & $\begin{array}{l}661 \\
620 \\
531\end{array}$ & $\begin{array}{l}851 \\
781 \\
591\end{array}$ & $\begin{array}{l}833 \\
810 \\
658\end{array}$ & $\begin{array}{l}630 \\
613 \\
612\end{array}$ \\
\hline $\begin{array}{l}36 \\
26 \\
31\end{array}$ & $\begin{array}{c}\text { St } \\
\text { Laurent }\end{array}$ & $\begin{array}{l}\text { Jul } 24 \\
\text { Jul } 24 \\
\text { Jul } 24\end{array}$ & $\begin{array}{l}321 \\
118 \\
265\end{array}$ & $\begin{array}{l}636 \\
225 \\
561\end{array}$ & $\begin{array}{l}682 \\
349 \\
452\end{array}$ & $\begin{array}{l}503 \\
375 \\
378\end{array}$ & $\begin{array}{l}722 \\
451 \\
491\end{array}$ & $\begin{array}{l}836 \\
537 \\
429\end{array}$ & $\begin{array}{l}797 \\
549 \\
432\end{array}$ & $\begin{array}{l}755 \\
448 \\
363\end{array}$ \\
\hline
\end{tabular}


Table 4.2: 1992 Highway 417 Eastbound Ramp Volumes (vph)

\begin{tabular}{|c|c|c|c|c|c|c|c|c|c|c|}
\hline Ram & IC & Date & 6.7 & 7.8 & $8-9$ & 9.10 & 2.3 & $3-4$ & $4-5$ & 5.6 \\
\hline & $7 / 417$ & Jul 24 & 490 & 648 & 416 & 311 & 369 & 413 & 470 & 395 \\
\hline $\begin{array}{l}51 \\
35 \\
25\end{array}$ & Carp Rd & $\begin{array}{l}\text { Jul } 24 \\
\text { Jul } 24 \\
\text { Jul } 24\end{array}$ & $\begin{array}{l}53 \\
97 \\
91\end{array}$ & $\begin{array}{l}90 \\
178 \\
176\end{array}$ & $\begin{array}{l}72 \\
152 \\
154\end{array}$ & $\begin{array}{l}46 \\
108 \\
104\end{array}$ & $\begin{array}{l}47 \\
129 \\
111\end{array}$ & $\begin{array}{l}62 \\
156 \\
99\end{array}$ & $\begin{array}{l}57 \\
155 \\
122\end{array}$ & $\begin{array}{l}46 \\
146 \\
119\end{array}$ \\
\hline $\begin{array}{l}51 \\
35 \\
25\end{array}$ & Terry Fox & " & $\begin{array}{l}44 \\
3 \\
267\end{array}$ & $\begin{array}{l}148 \\
15 \\
495\end{array}$ & $\begin{array}{l}111 \\
21 \\
417\end{array}$ & $\begin{array}{l}109 \\
12 \\
251\end{array}$ & $\begin{array}{l}97 \\
18 \\
208\end{array}$ & $\begin{array}{l}113 \\
10 \\
258\end{array}$ & $\begin{array}{l}145 \\
12 \\
256\end{array}$ & $\begin{array}{l}123 \\
14 \\
210\end{array}$ \\
\hline $\begin{array}{l}51 \\
35 \\
25 \\
\end{array}$ & Eagleson & " & $\begin{array}{l}80 \\
382 \\
446 \\
\end{array}$ & $\begin{array}{l}167 \\
647 \\
759 \\
\end{array}$ & $\begin{array}{l}155 \\
664 \\
685 \\
\end{array}$ & $\begin{array}{l}69 \\
415 \\
444 \\
\end{array}$ & $\begin{array}{l}89 \\
359 \\
401 \\
\end{array}$ & $\begin{array}{l}98 \\
492 \\
428 \\
\end{array}$ & $\begin{array}{l}79 \\
580 \\
469 \\
\end{array}$ & $\begin{array}{l}94 \\
480 \\
487 \\
\end{array}$ \\
\hline $\begin{array}{l}51 \\
35 \\
25\end{array}$ & Moodie & ". & $\begin{array}{l}98 \\
34 \\
215\end{array}$ & $\begin{array}{l}257 \\
82 \\
436\end{array}$ & $\begin{array}{l}262 \\
103 \\
330\end{array}$ & $\begin{array}{l}175 \\
133 \\
274\end{array}$ & $\begin{array}{l}192 \\
157 \\
326\end{array}$ & $\begin{array}{l}176 \\
396 \\
398\end{array}$ & $\begin{array}{l}200 \\
492 \\
384\end{array}$ & $\begin{array}{l}179 \\
334 \\
377\end{array}$ \\
\hline $\begin{array}{l}51 \\
35 \\
25\end{array}$ & Richmond & $\begin{array}{l}\text { Aug } 14 \\
" "\end{array}$ & $\begin{array}{l}74 \\
158 \\
267\end{array}$ & $\begin{array}{l}140 \\
271 \\
721\end{array}$ & $\begin{array}{l}152 \\
226 \\
632\end{array}$ & $\begin{array}{l}182 \\
203 \\
343\end{array}$ & $\begin{array}{l}219 \\
372 \\
376\end{array}$ & $\begin{array}{l}262 \\
348 \\
416\end{array}$ & $\begin{array}{l}299 \\
339 \\
403\end{array}$ & $\begin{array}{l}288 \\
365 \\
341\end{array}$ \\
\hline $\begin{array}{l}51 \\
35 \\
25\end{array}$ & Pinecrest & $\begin{array}{l}\text { Aug } 14 \\
\text { Aug } 14 \\
\text { Jul } 24\end{array}$ & $\begin{array}{l}139 \\
190 \\
455 \\
\end{array}$ & $\begin{array}{l}273 \\
310 \\
i n 33 \\
\end{array}$ & $\begin{array}{l}379 \\
317 \\
954 \\
\end{array}$ & $\begin{array}{l}245 \\
278 \\
600 \\
\end{array}$ & $\begin{array}{l}329 \\
267 \\
518 \\
\end{array}$ & $\begin{array}{l}348 \\
334 \\
615 \\
\end{array}$ & $\begin{array}{l}418 \\
275 \\
599 \\
\end{array}$ & $\begin{array}{l}441 \\
283 \\
551 \\
\end{array}$ \\
\hline $\begin{array}{l}77 \\
51 \\
35 \\
25\end{array}$ & Woodroffe & $"$ & $\begin{array}{l}35 \\
205 \\
59 \\
390\end{array}$ & $\begin{array}{l}48 \\
392 \\
198 \\
983\end{array}$ & $\begin{array}{l}38 \\
396 \\
189 \\
965\end{array}$ & $\begin{array}{l}5 \\
344 \\
169 \\
559\end{array}$ & $\begin{array}{l}20 \\
353 \\
248 \\
477\end{array}$ & $\begin{array}{l}77 \\
379 \\
223 \\
515\end{array}$ & $\begin{array}{l}49 \\
467 \\
203 \\
519\end{array}$ & $\begin{array}{l}40 \\
414 \\
234 \\
481\end{array}$ \\
\hline $\begin{array}{l}51 \\
15\end{array}$ & Maitland & $"$ & $\begin{array}{l}225 \\
283\end{array}$ & $\begin{array}{l}537 \\
\$ 23\end{array}$ & $\begin{array}{l}713 \\
799\end{array}$ & $\begin{array}{l}396 \\
584\end{array}$ & $\begin{array}{l}343 \\
547\end{array}$ & $\begin{array}{l}416 \\
632\end{array}$ & $\begin{array}{l}408 \\
678\end{array}$ & $\begin{array}{l}376 \\
559\end{array}$ \\
\hline $\begin{array}{l}57 \\
55 \\
65\end{array}$ & Carling & Aug 14 & $\begin{array}{l}267 \\
316 \\
127\end{array}$ & $\begin{array}{l}562 \\
826 \\
244\end{array}$ & $\begin{array}{l}572 \\
1076 \\
246\end{array}$ & $\begin{array}{l}454 \\
787 \\
219\end{array}$ & $\begin{array}{l}504 \\
876 \\
269\end{array}$ & $\begin{array}{l}525 \\
958 \\
280\end{array}$ & $\begin{array}{l}508 \\
983 \\
307\end{array}$ & $\begin{array}{l}480 \\
810 \\
268\end{array}$ \\
\hline $\begin{array}{l}51 \\
15\end{array}$ & Parkdale & Jul 24 & $\begin{array}{l}354 \\
315\end{array}$ & $\begin{array}{l}718 \\
582\end{array}$ & $\begin{array}{l}592 \\
671 \\
\end{array}$ & $\begin{array}{r}457 \\
514 \\
\end{array}$ & $\begin{array}{l}427 \\
684 \\
\end{array}$ & $\begin{array}{l}451 \\
870 \\
\end{array}$ & $\begin{array}{r}416 \\
868 \\
\end{array}$ & $\begin{array}{l}378 \\
619 \\
\end{array}$ \\
\hline 51 & Rochester & Jul 24 & 219 & 580 & 663 & 353 & 343 & 400 & 462 & 318 \\
\hline 51 & Bronson & $"$ & 360 & 618 & 730 & 497 & 518 & 587 & 573 & 604 \\
\hline 52 & Kent & $"$ & 303 & 882 & 1046 & 607 & 437 & 484 & 516 & 416 \\
\hline 75 & Metcalfe & $"$ & 322 & 785 & 1658 & 903 & 1449 & 1753 & 2170 & 1681 \\
\hline $\begin{array}{l}35 \\
45 \\
54 \\
52\end{array}$ & Nicholas & $"$ & $\begin{array}{l}606 \\
277 \\
80 \\
246\end{array}$ & $\begin{array}{l}846 \\
431 \\
245 \\
640\end{array}$ & $\begin{array}{l}747 \\
483 \\
295 \\
672\end{array}$ & $\begin{array}{l}693 \\
380 \\
178 \\
539\end{array}$ & $\begin{array}{l}1104 \\
536 \\
201 \\
531\end{array}$ & $\begin{array}{l}1399 \\
653 \\
255 \\
566\end{array}$ & $\begin{array}{l}1561 \\
640 \\
245 \\
600\end{array}$ & $\begin{array}{l}1228 \\
574 \\
240 \\
572\end{array}$ \\
\hline
\end{tabular}


Table 4.2: (contd) 1992 Highway 417 Eastbound Ramp Volumes (vph).

\begin{tabular}{|c|c|c|c|c|c|c|c|c|c|c|}
\hline Rannp & IC & Date & $6-7$ & 7.8 & $8-9$ & $9-10$ & $2-3$ & $3-4$ & 4.5 & 5.6 \\
\hline $\begin{array}{l}51 \\
35 \\
25\end{array}$ & Riverside & Jul 24 & $\begin{array}{l}793 \\
90 \\
93\end{array}$ & $\begin{array}{l}1468 \\
162 \\
225\end{array}$ & $\begin{array}{l}1322 \\
192 \\
348\end{array}$ & $\begin{array}{l}1069 \\
172 \\
203\end{array}$ & $\begin{array}{l}1313 \\
278 \\
344\end{array}$ & $\begin{array}{l}1469 \\
472 \\
561\end{array}$ & $\begin{array}{l}1541 \\
404 \\
611\end{array}$ & $\begin{array}{l}1165 \\
306 \\
434\end{array}$ \\
\hline $\begin{array}{l}51 \\
35 \\
25\end{array}$ & St Laurent & $"$ & $\begin{array}{l}524 \\
68 \\
57\end{array}$ & $\begin{array}{l}1222 \\
97 \\
79\end{array}$ & $\begin{array}{l}1254 \\
114 \\
125\end{array}$ & $\begin{array}{l}1604 \\
126 \\
168\end{array}$ & $\begin{array}{l}1291 \\
298 \\
185\end{array}$ & $\begin{array}{l}1332 \\
335 \\
251\end{array}$ & $\begin{array}{l}1346 \\
426 \\
316\end{array}$ & $\begin{array}{l}1002 \\
414 \\
231\end{array}$ \\
\hline
\end{tabular}

were not measured on the same day, due to relatively low variation in traffic during the weekdays, these estimates can be considered to be satisfactory. The next step was to determine the level of service of $a_{\text {. }}$ the sections of the study section using the Highway Capacity Manual (1985) methodology, based on the following data and assumptions'.

- $\quad 3.66 \mathrm{~m}$ lanes

- $\quad 1.83 \mathrm{~m}$ shoulder widths and lateral clearances. (On some scctions of the freeway the clearance to the median barrier was less than $1.83 \mathrm{~m}$ but this doesn't affect the capacity as indicated by $\mathrm{HCM}$

- $7 \%$ trucks and $1 \%$ buses (obtained from 1992 RMOC traffic characteristics).

- A peak hour factor of 0.9 was assur. $d$, based on RMOC fifteen minute counts, which varies from 0.8 to 0.9 .

- Freeway and ramp lanes were obtained from MTO aerial photographs and through visual observations. 


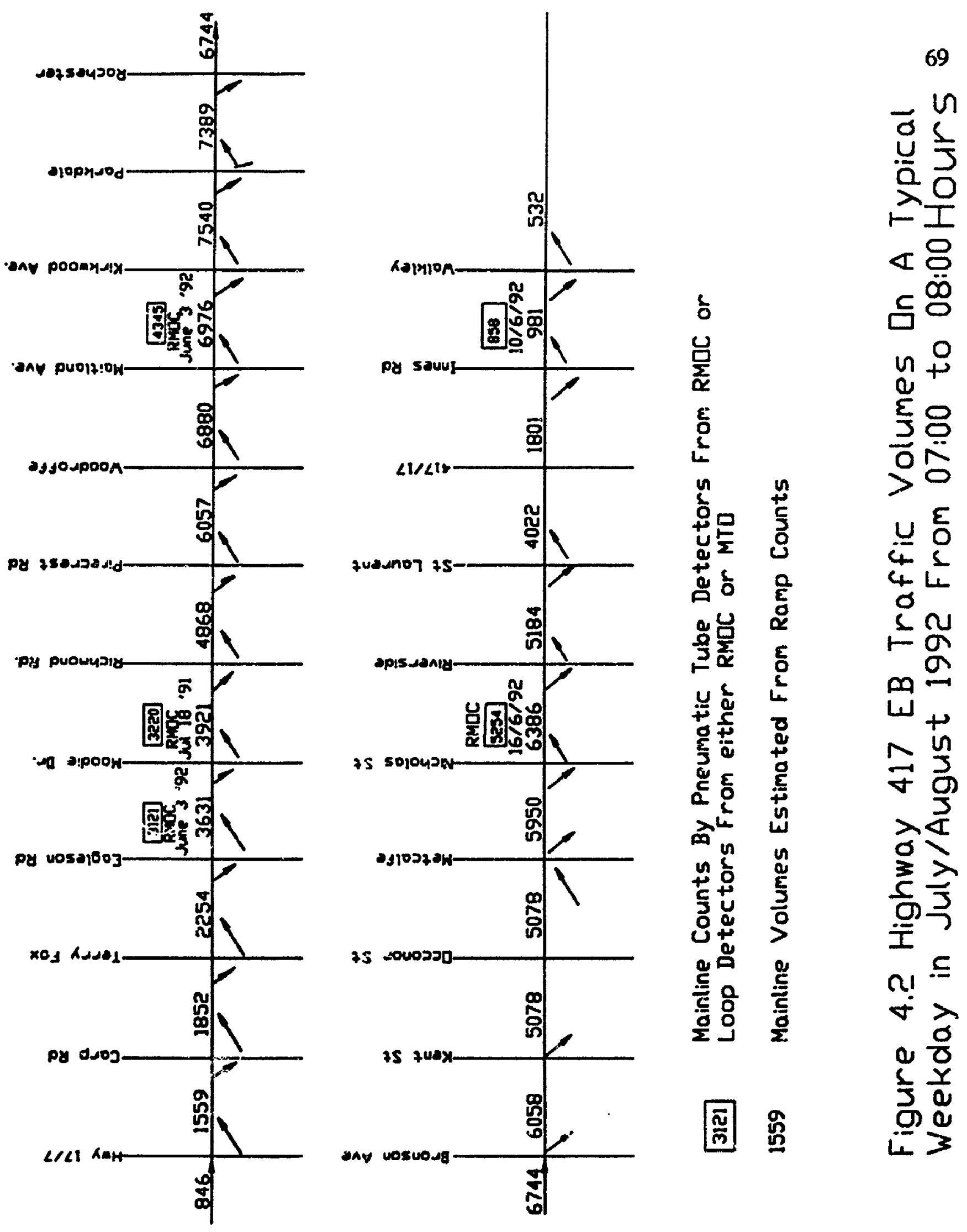



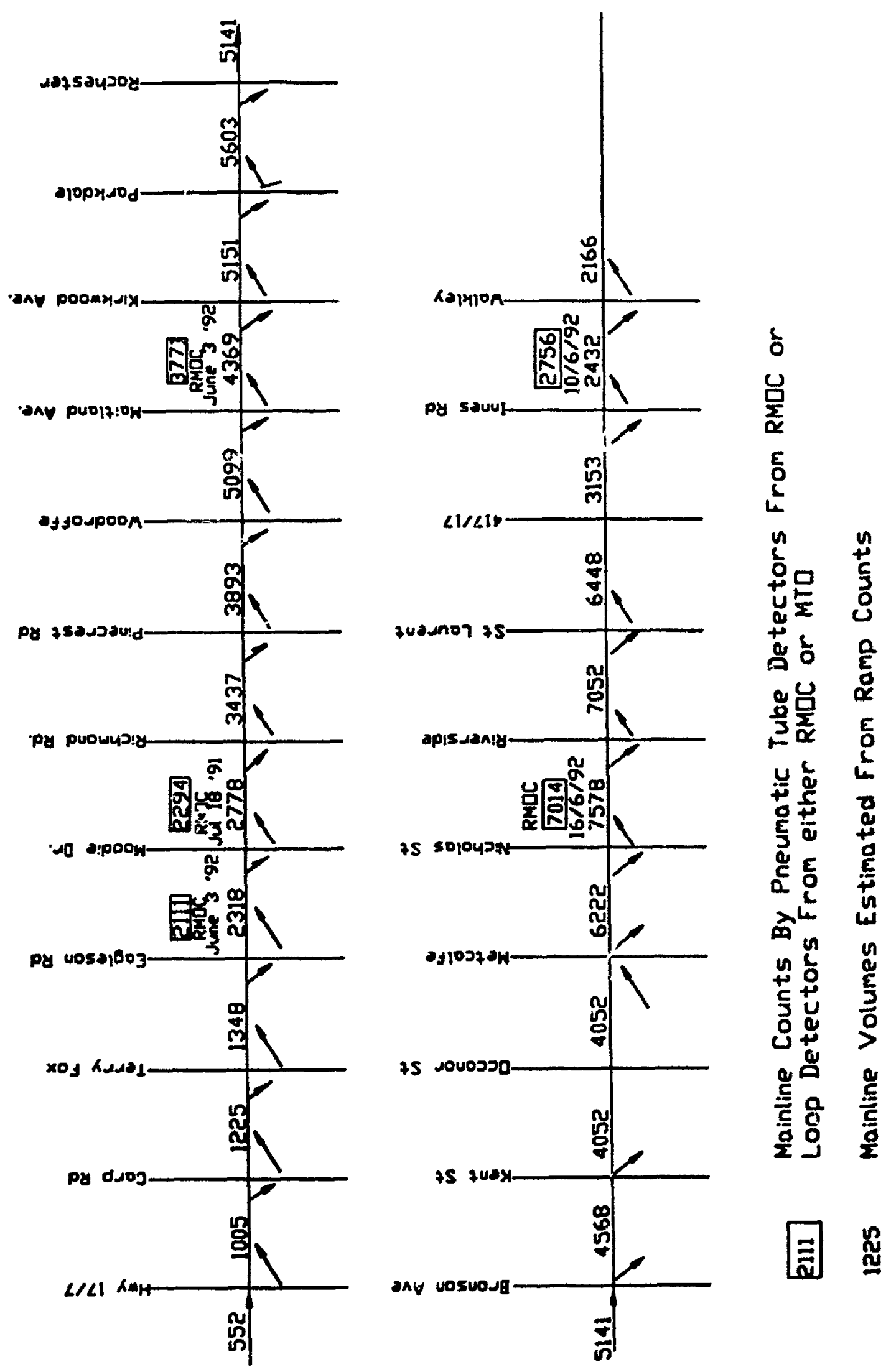

$\overline{0}$

un

ลิ

$\lambda$ D

-I

$\leftarrow 8$

드

u

兵

○

$>=$

$u \varepsilon$

(

41

0

$\& N$

$1 \sigma$

$\infty$ 元

$\omega$

$N$ v

I

$\forall$ O

$\lambda \frac{J}{4}$

0

$\sum \lambda$

익

I

$n$.

ष

a 웅

$\frac{y}{0}$

ग)

43 
- Drivers are regular users of the facility.

Figures $4.2 \& 4.3$ are eastbound am and pm mainline hourly volumes estimated from ramp counts. Hourly traffic volumes were converted into peak flow rates and the level of service (LOS) at all sections of the Queensway was estimated by the following equations: $^{2}$

$$
S F=\frac{\text { Mainline Volume }}{\text { PHF }}
$$

To find the level of service, the effective $\mathrm{v} / \mathrm{c}$ ratio of the section is computed as

$$
\frac{v}{C}=\frac{S F}{C_{j} N f_{w} f_{p} f_{k V}}
$$

where

SF Service flow rate,

$c_{\mathrm{j}}$ Canacity under ideal conditions (2000Pcphpl),

N Number of lanes in one direction,

$f_{w} \quad$ A factor for lane width and lateral clearance, and

$f_{\mathrm{HV}}$ A factor to adjust for the effect of heavy vehicles,

PHF Peak hour factor,

$f_{p} \quad$ A factor to adjust for the effect of driver population.

Figures $4.4 \& 4.5$ are graphical representation of the LOS for both EB \& WB Queensway. Sections with a LOS D or worse are sections of the freeway which would be considered for metering. 


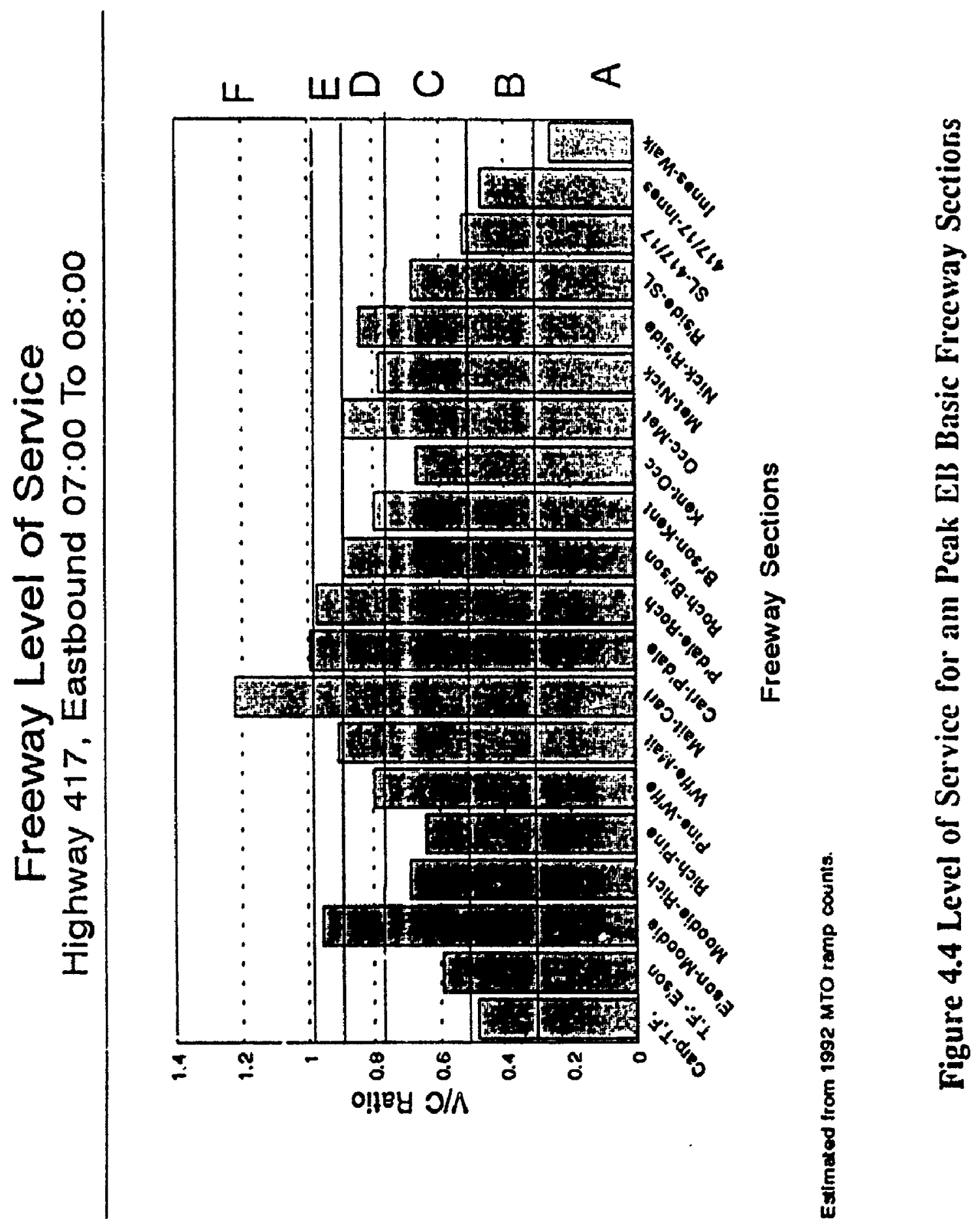




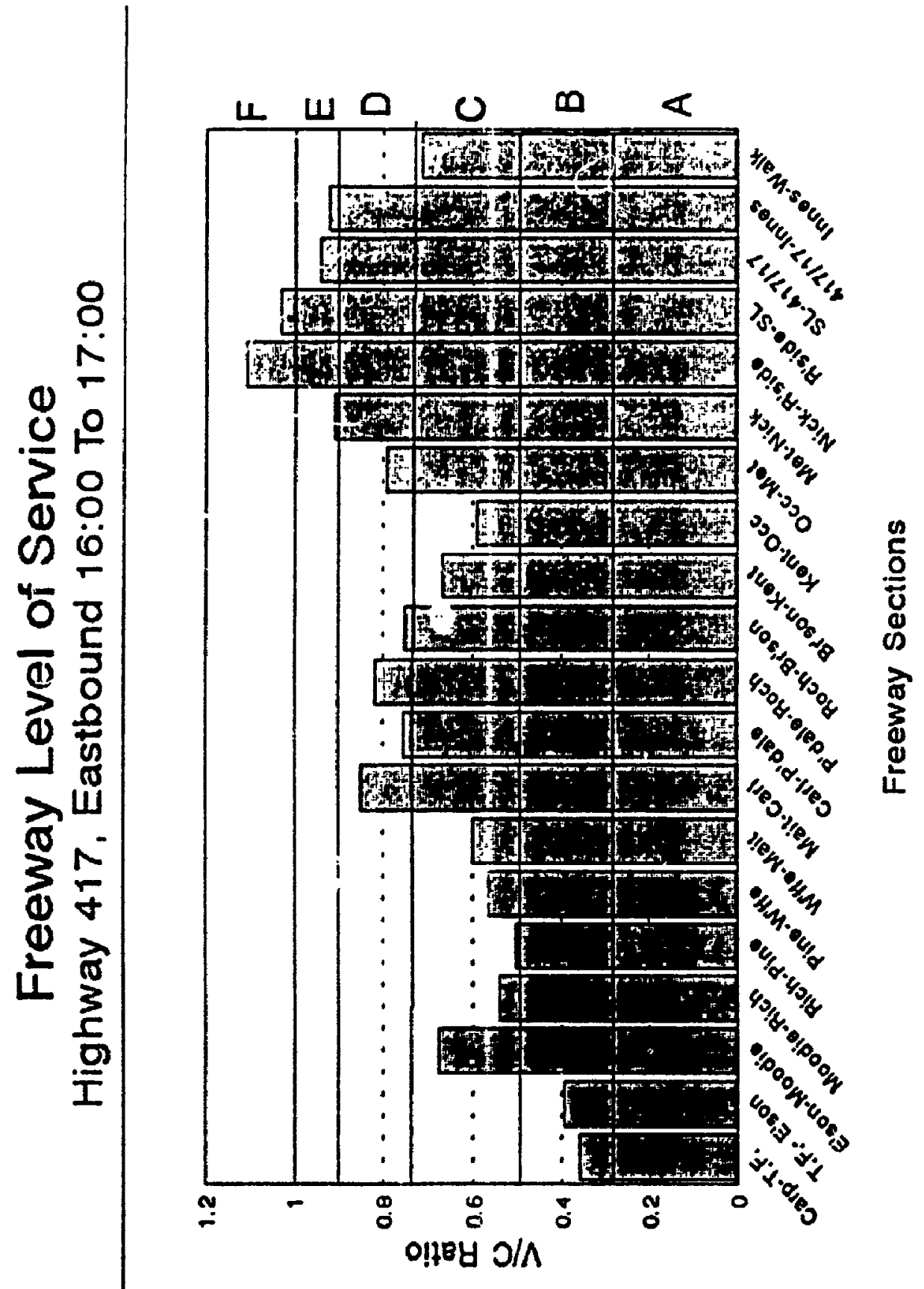

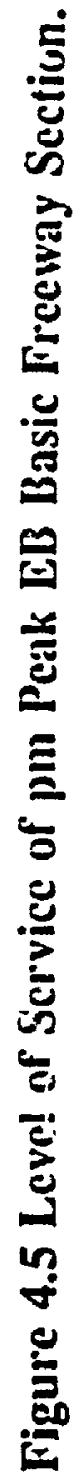




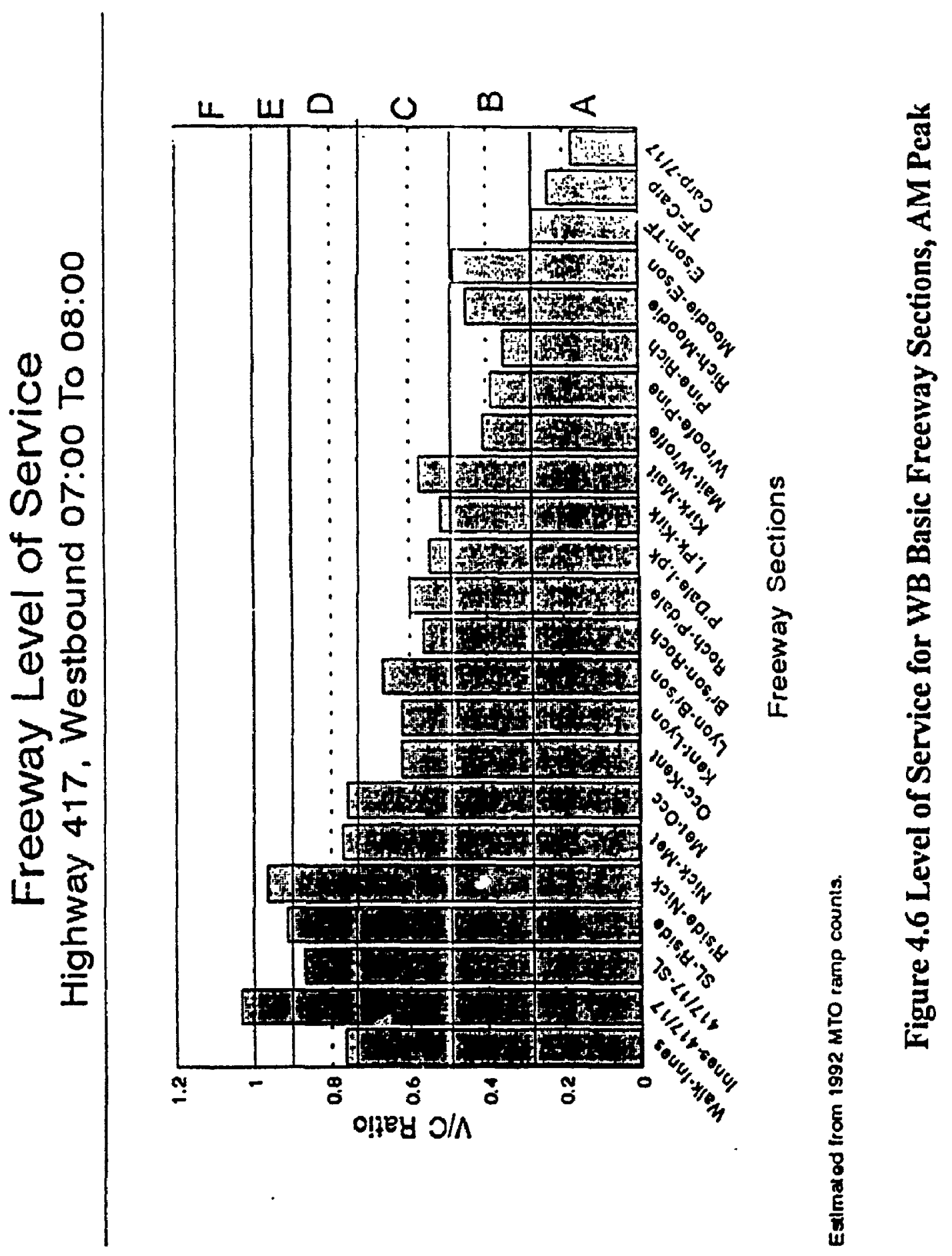



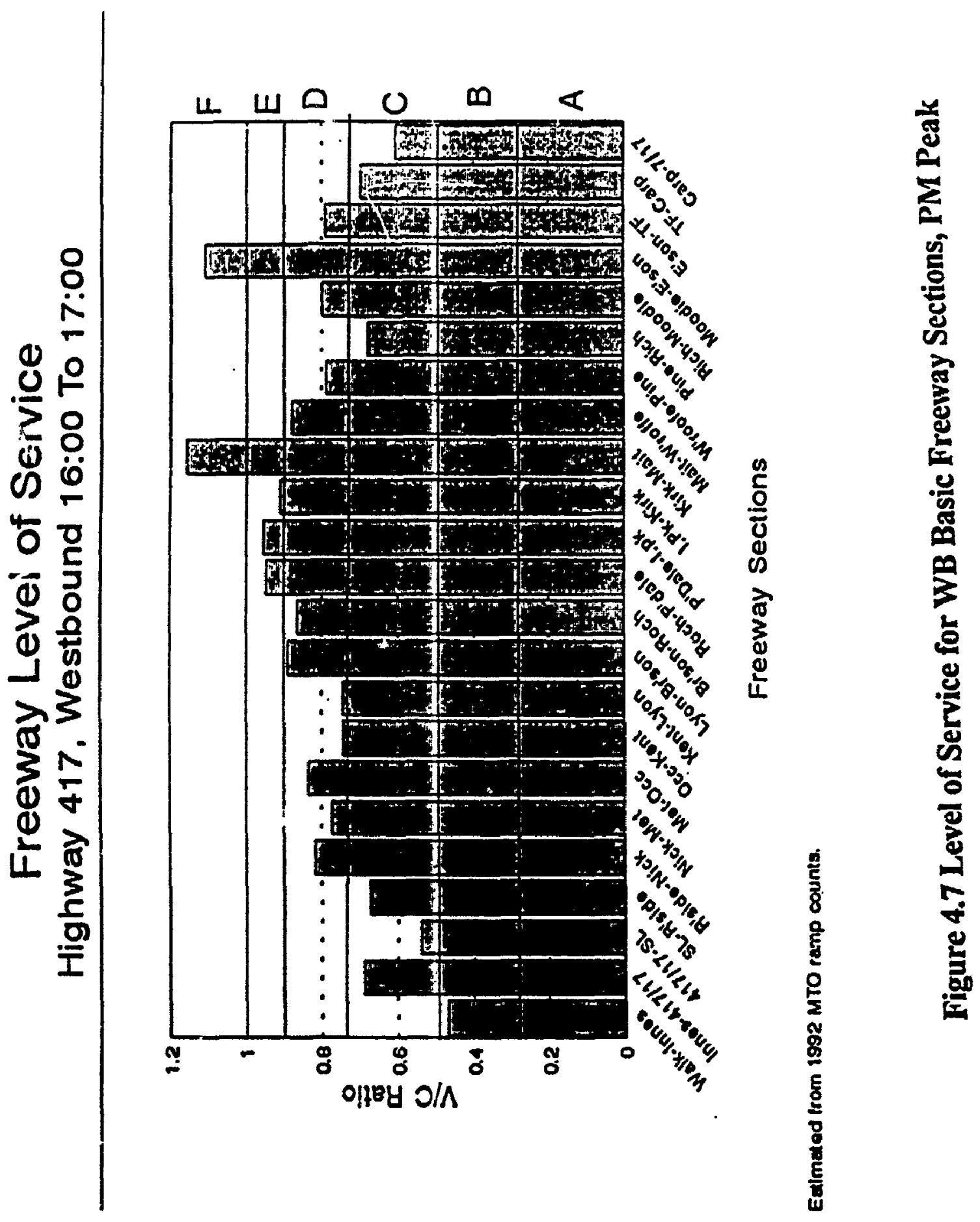
Existing peak period is directional: Eastbound traffic from Pinecrest to Kirkwood interchange, westbound traffic from Orleans to Vanier are very heavy in the morning, whereas opposing traffic is relatively free flowing. For maximum effectiveness of metering, it is essential to trace the path of all vehicles in the study section. Eastbound Highway 417 from Pinecrest to Carling was selected for further analysis because it was the only section for which origin and destination (OD) data were available.

\subsection{Capacity Analysis on Carling Avenue}

The purpose of arterial analysis is to find out:

- if there are candidate routes available for diversion, and

- the present state of peak period traffic on these routes.

It is only when a comparison of both arterial and freeway present traffic conditions are made that meaningful and realistic strategies can be adopted.

$\mathrm{Fi}_{i}$ 4.8 is part of a regional map of the study section. Two streets were identified as alternate routes for vehicle diversion, namely Carling Ave and Baseline Rd Carling Ave was chosen as an alternative route because it provided better entrance and exit links with the Queensway.

Fig 4.9 is a network diagram of the surface street. It is made up of links and nodes. The nodes represent signalized intersections and the links represent the street sections (not to scale). The EW Carling Ave from Pinecrest to Kirkwood, including all signalised crossing streets, are shown. Capacity analysis of the entire network was done with the help of a computer simulation package called TRAF-NETSIM. Before 


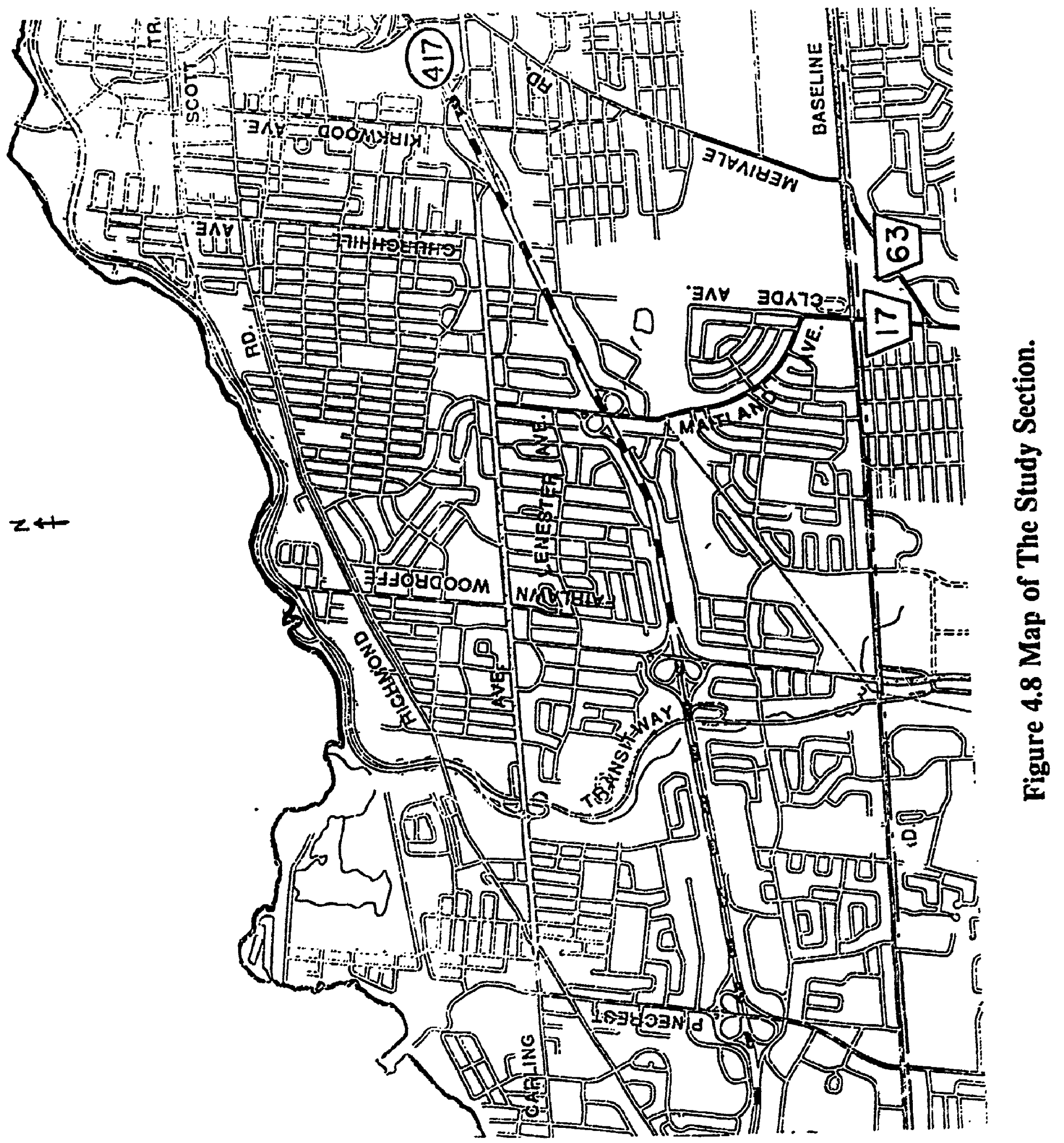


describing network analysis, a brief introduction of this simulation package follows.

\subsubsection{The TR •. - NETSIM Software}

Traf-Netsim, forn.erly known as the Urban Traffic Control System 1 (UTCS-1), is a microscopic simulation model developed in the early seventies and has been used by many traffic and transportation research engineers. Its original purpose at that time was to evaluate the significance of the first and second generation computer-based urban traffic control strategies by careful study. Today, its accuracy has precipitated its use in a number of other purposes [Ferlis, et. al., 1976].

Vehicles are modelled individually, based on car-following, queue disc: arge and lane switching decision rules. Interrupted traffic, unlike freeway trafíic, involves a number of elements which affect traffic flow. These are traffic volume, bus volume and operations, parking manoe. vres, pedestrians, orclerly movement of traffic al-grade intersections, traffic signs and signals and many more. Netsim simulates each vehicle's movement with respect to these elements.

When vehicles enter a network, each is allocated a lane. Thesc lane assignments depend on wether the vehicle would turn right or left at subsequent intersections. Right turners are allocated to the right lane, most left turners are assigned to left lane and through vehicles are assigned to either through lanes or lanes with the least occupancy. The speed of the first vehicle on a link is dependent on vehicle -naracteristics (i.e., wether it is a bus, car, or a truck), the free flow speed of the subject link and the safe stopping distance. Speed and acceleration of second, third, fourth, fifth, and other vehicles depend 


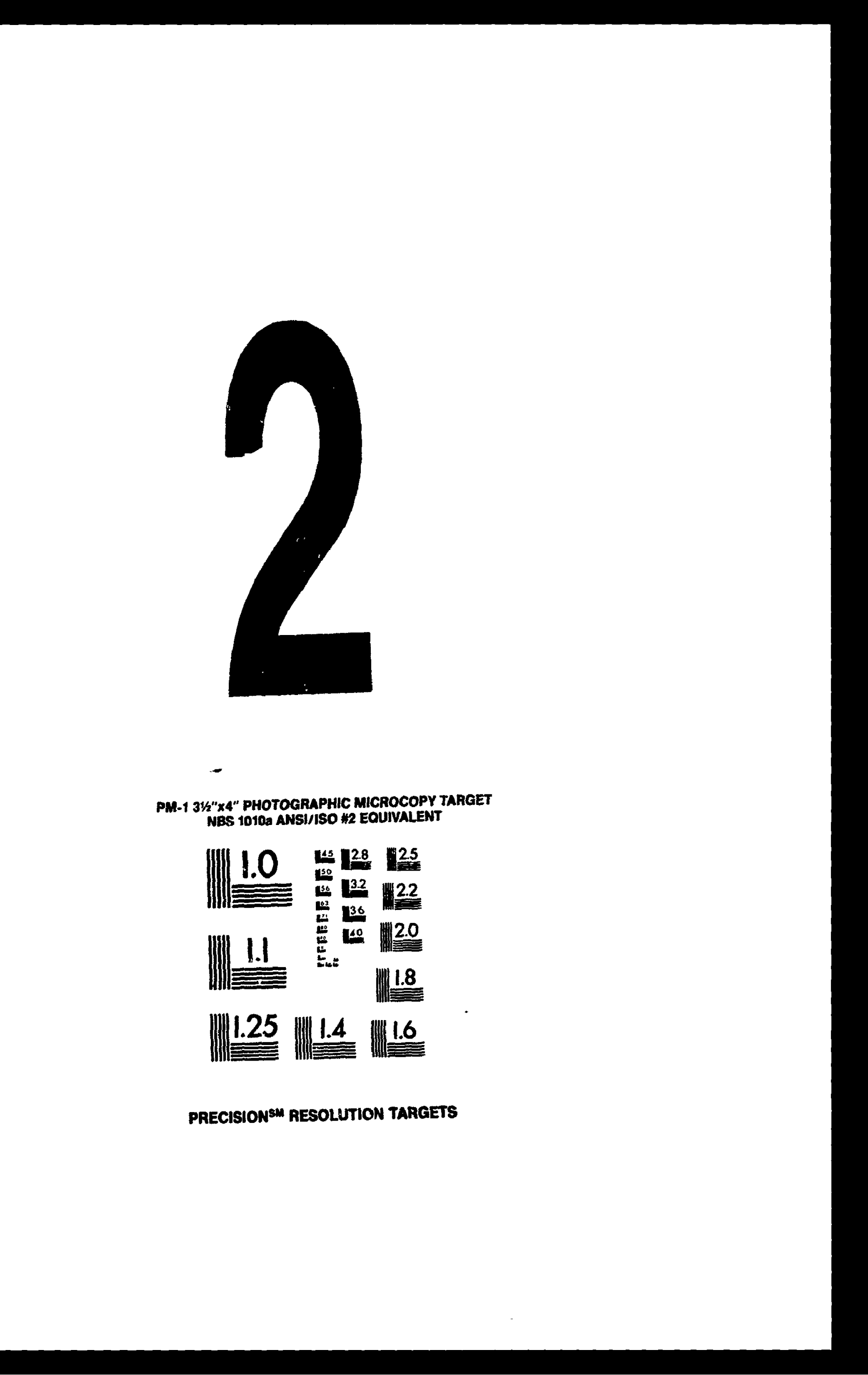


on their cwn characteristics, the behaviour of the precedings vehicle, the slope of the link, driver characteristics and traffic flow on immediate adjacent lanes. There are four classes of vehicles specified in the model, namcly private auto, truck, bus, and car pool. Vehicles in the same class may not behave in the same way due to different driver characteristics. In order to account for this, each vehicle's speed is obtained by multiplying the specified free flow speed by a percentage. There are ten percentage values (known as random numbers 1 to 10 ) generated randomly by the model and each represents a driver characteristic. The default values, ranging from 75 to $125 \%$, - 'ssigned to a vehicle as it enters the network, randomly. This means that two or more vehicles with the same characteristics would be travelling at different free flow speeds. Gap acceptance for left turns, right turn on red (RTOR) queue discharge headways, start up and lost times, are all assigned randomly in a similar way, with transparent default values [Ferlis, 1976; US DOT 1993; Wong, 1990].

When a vehicle approaches an intersection, it either stops, slows down or continues its speed. depending on wether it is controlled by a stop sign, yield sign, or a traffic signal. If it s a stop sign, it comes to a stop, looks for an acceptable gap, and then proceeds. At yield signs, it will not stop if there is an acceptable gap. At traffic signals, it continues at its speed on a green signal. When it turns amber, it stops only if its position is further than the safe stopping distance. Otherwise it proceeds through the intersection. When it changes from red to green, the vehicles move through the intersection under the following decision variables:

- position of the vehicle in the queue, 
- discharge headway of each vehicle,

- vehicle characteristics, and

- driver characteristics.

Vehicles react to lane closures, obstruction or parked vehicles by changing lanes. As the first vehicle moves towards an obstruction, it starts to look for an acceptable gap in the adjacent lane to make a lane change. If there are not any gaps within 1.5 meters from the obstruction, it stcps and looks for one. As long as the first vehicle moves, following vehicles will follow until it stops, then the immediate vehicle after the leader will attempt to make a lane change. Most vehicles will always move back to their preferred lane after avoiding an obstruction. At signalised intersections, turning vehicles are modelled in detailed terms. During a green signal, left turn vehicles will make the turn on protected green or wait for acceptable gaps on permissive green. When the signal turns amber the left turn leader is allowed to make the turn. The model assigns a probability of $0.97,0.77, \& 0.37$ for second, third, and fourth vehicle respectively to make the turn. Left turns are also affected by pedestrian volume. A right turn on red vehicle will wait for an acceptable gap [US DOT, 1993; Wong, 1990].

If downstream lanes are full, upstream vehicles will either wait for a downstream space or block the intersection.

TRAF-NETSIM also models pretimed, semi-actuated and fully-actuated signals, as well as transit buses. 


\subsubsection{Why TRAF-NETSIM ?}

Netsim was chosen for simulation because:

- it has a number of features not available on TRANSYT 7-F, for instance it could model bus flow, and other transit operations accurately,

- it is a network simulation model,

- it has been tested and validated by a number of research organisations for different traffic pattems with encouraging results, which prompted the Federal Highway Administration (FHWA) to integrate it into the TRAF system, an integrated set of simulation models, which represent the traffic environment, and

- it is readily available at Carleton University.

\subsubsection{Case Studies of NETSIM applications:}

Chang, Cohen, et. al. used NETSIM simulation model to compare MAXBAND, MAXBAND 86 and TRANSYT-7F timing plans [Chang et. al., 1988].

Rathi used NETSIM to evaluate and test various levels of traffic metering in a congested Central Business District (CBD) in a typical peak period [Rathi, 1991].

Sadegh et. al. compared SIGOP III, PASSER II-84, and TRANSYT-7F performance measures using NETSIM because it was assessed to be reliable for micro-simulation [Sadjeh et. al., 1987].

Yauch et. al. used NETSIM to evaluate the effects of drawbridge openings on adjacent signalised intersections, using the bus flow cards to model boat demand for bridge openings and concluded that: 
"NETSIM proved to be a powerful tool in the evaluation of the effects of drawbridge openings on adjacent signalised intersections. The program, although data intensive, provided a realistic simulation of varying traffic conditions. Unlike the simulation mode of TRANSYT-7F, NETSiM permits the building of queues over one cycle length, thus clearly indicating when and where congestion is likely to occur" [Yauch et. al., 1988]. From these case studies and many others not reported here it appears that NETSIM is a very reliable network simulation model. Table 4.3 compares NETSIM with TRAISYT-7F, PASSER-II \& SOAP computer programs.

Table 4.3: Comparison of TRAF-NETSIM with Other Traffic Engineering Programs

\begin{tabular}{||lllll||}
\hline Program Features & Traf-Netsim & Transyt-7F & PasserII & Soap \\
\hline Simulates isolated intersections & Yes & Yes & Yes & Yes \\
Simulates fixed time signals & Yes & Yes & Yes & Yes \\
Simulates actuated signals & Yes & No & No & No \\
Simulates stop and yield signs & Yes & Yes & No & No \\
Simulates nerwork & Yes & Yes & No & No \\
Simulates intersection with different & & & & No \\
cycle lengths & Yes & No & No & No \\
Simulates saturated conditions & Yes & No & No & No \\
Simulates pedestrians & Yes & No & No & No \\
Simulate buses & Yes & Yes & No & No \\
Simulates lane closures & Yes & No & No & No \\
Simulates parking & Yes & No & No & No \\
Simulates any combination of & & & & No \\
the above features & Yes & No & Yes & Yes \\
Optimises timing plans & No & Yes & & \\
\hline
\end{tabular}

Siurce: TRAF User Reference Guide, Version 4.01993.

\subsubsection{Data Sources}

The following data were obtained or assumptions were made in order to conduct a detailed network analysis:

Approximation only 
- The 1992 am peak period intersection volume counts for left tums (LT), right turns (RT), and straight through (ST), for all intersections from Richmond to Kirkwood were obtained from RMOC (see appendix for intersection counts),

- Distance between signals were scaled from RMOC 1:506 regional plans,

- Left turn pockets, right turn pockets and number of lanes in each link were all estimated on site.

- The topography of the area is relatively flat; road geometrics are also straight, therefore zero grades were assumed for all links.

- $\quad 60 \mathrm{Km} / \mathrm{hr}$ free flow speed,

- In order to simulate existing traffic behaviour during the peak period, signal timing plans were obtained from RMOC Signals Department,

a $\quad 2.2$ seconds discharge headway,

- Light pedestrian traffic was assumed for all intersections,

- Bus volumes, bus routes, and bus paths were obtained from OC Transpo Planning Dept; bus stop locations were estimated on site. Bus paths were divided into five routes for simplicity.

Vehicle specifications used for the model are indicated in Table 4.4.

\begin{tabular}{|l|c|c|c|}
\hline $\begin{array}{l}\text { Fleet } \\
\text { Component }\end{array}$ & $\begin{array}{l}\text { Maximum } \\
\text { Acceleration } \\
\text { (km/h/sec) }\end{array}$ & $\begin{array}{l}\text { Maximum } \\
\text { Velocity } \\
\text { (km/h) }\end{array}$ & $\begin{array}{l}\text { Length } \\
\text { (meters) }\end{array}$ \\
\hline Private Auto & 8.85 & 120 & 5.18 \\
Truck & 4.82 & 97 & 10.36 \\
Bus & 3.23 & 80 & 14.33 \\
\hline
\end{tabular}

Source: TRAF User and Relcrence Guide Version 4.0 


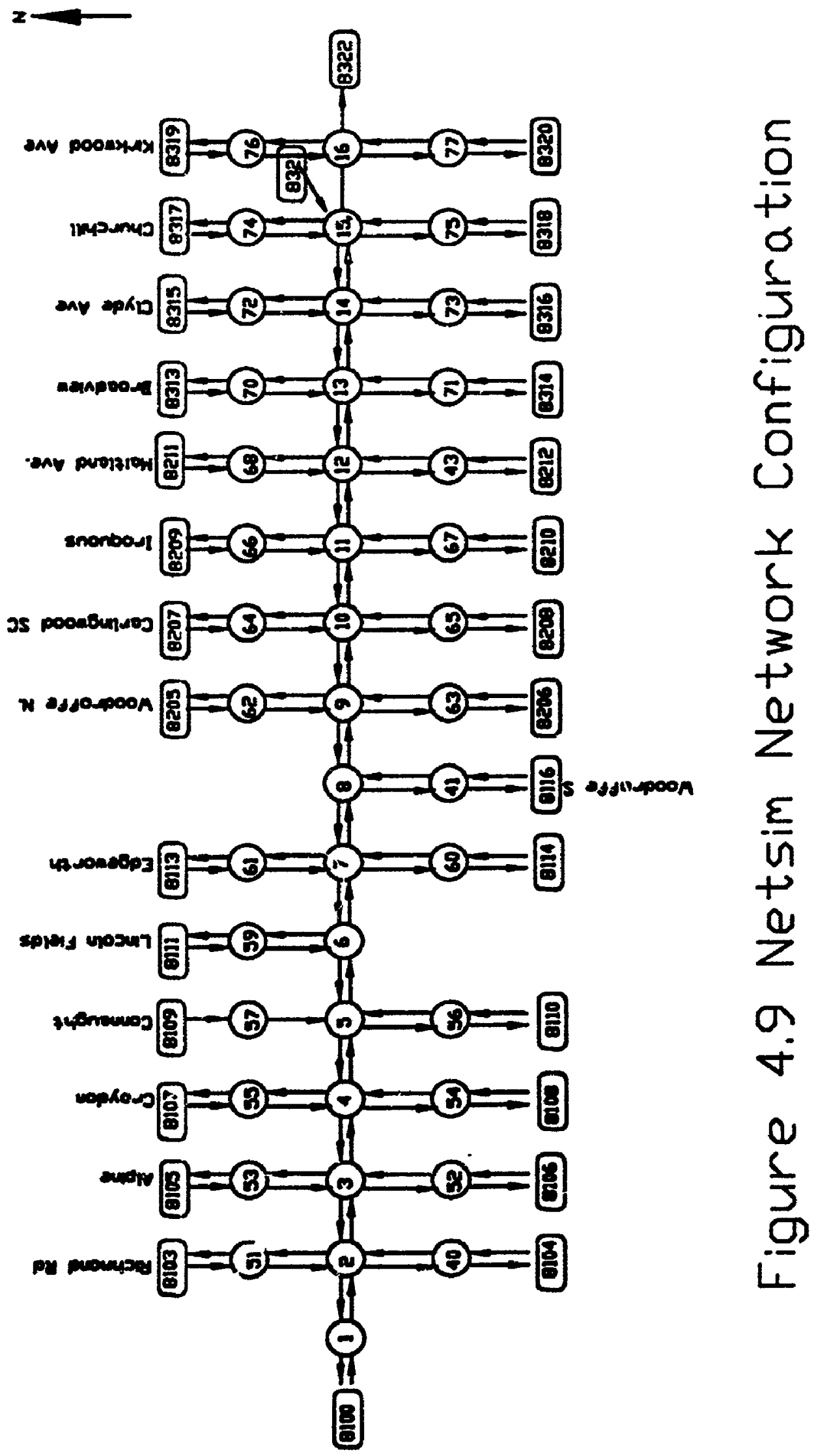




\subsubsection{Data Preparation for first NETSIM Run:}

TRAF-NETSIM, is data hungry and requires experience and engineering judgement for some data input. There are a lot of options and default values which provide varying levels of accuracy. Netsim networks consist of links and nodes which represent one directional segments of streets and intersections respectively. Entry node numbers range from 8000 to 8999 whilst internal nodes range from 1 to 750 . Figure 4.9 is a network diagram used to enter all NETSIM data.

Intersection count data from Pinecrest to Kirkwood avenue were converted into percentages and entered into each link. Left turn pocket, right turn pocket, upstream node number, downstream node number, number of lanes in all pockets \& links were all specified on a link by link basis. Traffic volumes were specified for entry links 8100 to

\begin{tabular}{|l|l|l|}
\hline \multicolumn{1}{|c|}{ Record Number ? 1 } & NETSIM Card Options Menu & \\
\hline Title (00) & Phase Operations (47) & Amber Phase (144) \\
Identification (01) & Pedestrian Oper. (48) & Accept. Gaps (145) \\
Run Control (02) & Entry Link Volume (50) & Pedestrian Delay (146) \\
Time Spec. (03,04) & Source/Sink Volume (51) & Free-Flow Spced (147) \\
Output Options (05) & Load Factor (52) & Short Term Dur. (148) \\
Link Names (10) & Short Term Events (54) & Link Distributions (149) \\
Link Chars. (11) & Long Term Events (55) & Bus Dwell Times (150) \\
Tum Movements (21) & Parking Activity (56) & Delimiter (170) \\
Cond. Tum Move. (22) & Vehicle Type (58) & Bus Station (185) \\
Signal Control (35,36) & Environment. Table (60) & Dwell Time (186) \\
Approach Config. (43) & Link Aggreg. (90) & Bus Path (187) \\
Act. Signal Coord. (44) & Tum Calibration (140) & Bus Route (188) \\
Traffic Movements (45) & Spill back \& Misc. (141) & Bus Flow (189) \\
Act. Cont. Det. (46) & Side Gaps (142,143) & Final (210) \\
& & \\
\hline
\end{tabular}

F6-Explain, F7-Print, F8-Help, F9-Defauh, F10-Accept, ESC, CK, BS, HOME, END Enter (A)dd, (M)odify, (D)elete, or ESC.

\section{Figure 4.10 Netsim Input Main Screen ${ }^{4}$}


8321. Simulation runs were conducted for the peak fifteen minutes. NETSIM data input structure consists of cards and record numbers. Fig 4.10 is the main NETSIM input screen. Run control parameters were first entered in card 02. An initialization time of 30 mins, a simulation period of 840 seconds, an English data input and a metric data output were specified as illustrated by Figure 4.11. Bold Characters in Figures 4.11 through 4.16 indicate entered data.

\begin{tabular}{|l|}
\hline \multicolumn{1}{|c|}{ Run Control Card (R) Card 02 } \\
\hline Additional Case Study ? (Y)es or (N)o: N \\
Type Of Simulation (N)ETSIM analysis. (D)ata check only: $\mathbf{N}^{3}$ \\
Initialization Time (min):30 \\
Environmental Data Code:0 \\
Input Units (E)nglish, (M)etric:E \\
Output Units (S)ame as input, (E)nglish, (M)etric, (B)oth:M \\
Simulation Start Time (hrs \& min): 07:45 \\
Signal Transition Code: \\
Random Number Seed For Traffic Stream: \\
General Random Number Seed:
\end{tabular}

F6-Explain, F7-Print, F8-Help, F9-Default, Fl0-Accept, ESC, CR, BS, HOME, END Enter data or ESC.

Figure 4.11 Input Data For Run Control Card ${ }^{6}$

- All characters shown in bold letters are input data into NETSIM

- Source: TRAF User Reference Guide, Version 4 
Because only the peak 15 mins of simulation was undertaken, only one time period was selected for card numbers $03, \& 04$. Duration of simulation of 840 seconds instead of 900 seconds was used because a simulation period should be a multiple of cycle lengths. Existing timing plans of RMOC are based on 120 secs for the study section; hence $840 \mathrm{sec}$ was used.

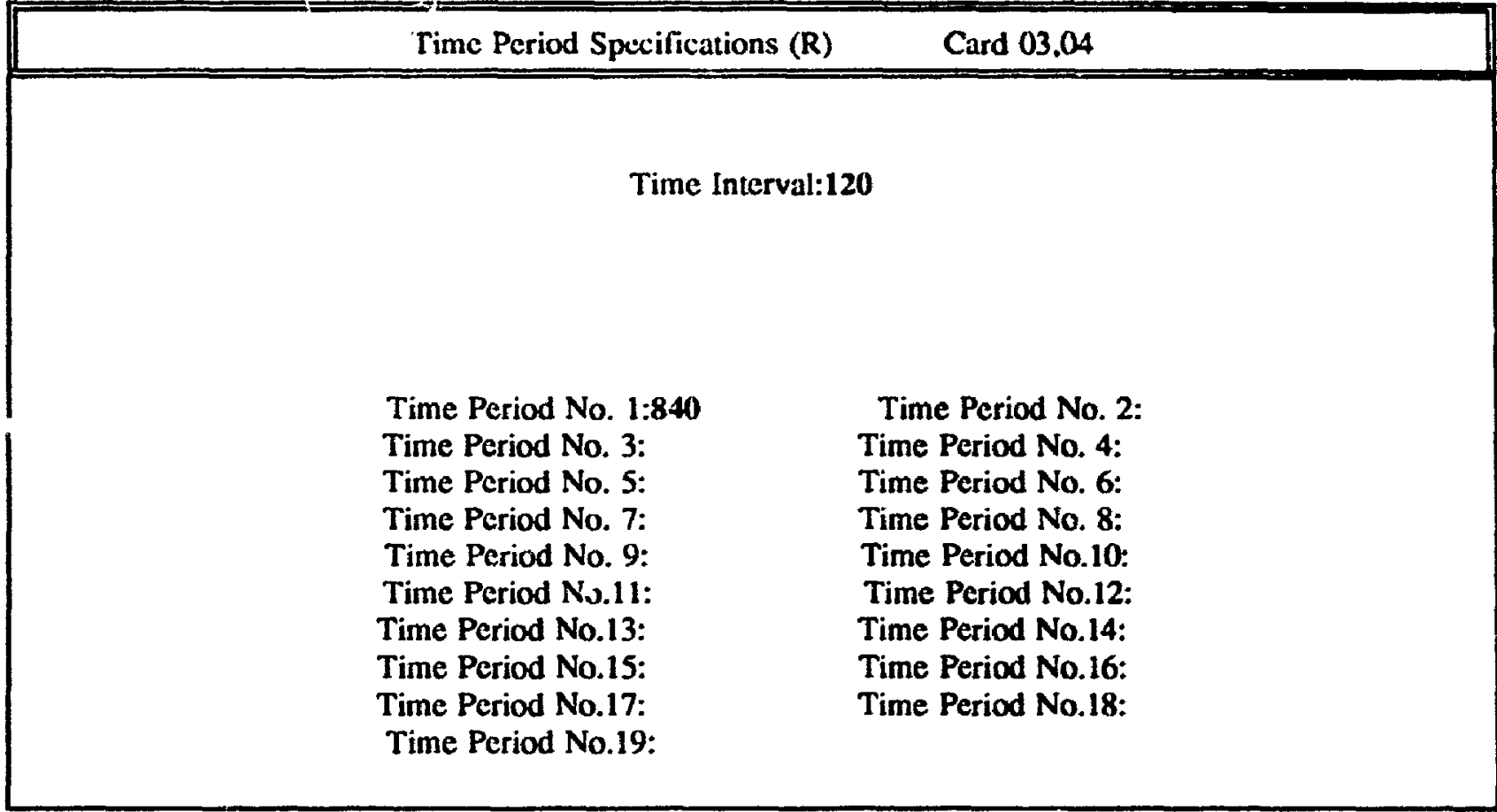

F6-Explain, F7-Print, F8-Help, F9-Default, F10-Accepl, ESC, CR, BS, HOME, END Enter data or ESC.

\section{Figure 4.12 Time Period Input Specifications For Netsim Run?}


Upstream node, downstream node, link length, left and right turn pockets, pedestrian traffic, link grade and discharge headways were all entered for each link direction in separate record numbers, on card number 11.

Intersection iurn movements for each node were converted into percentages and entered in card number 21, as shown in Figure 4.14

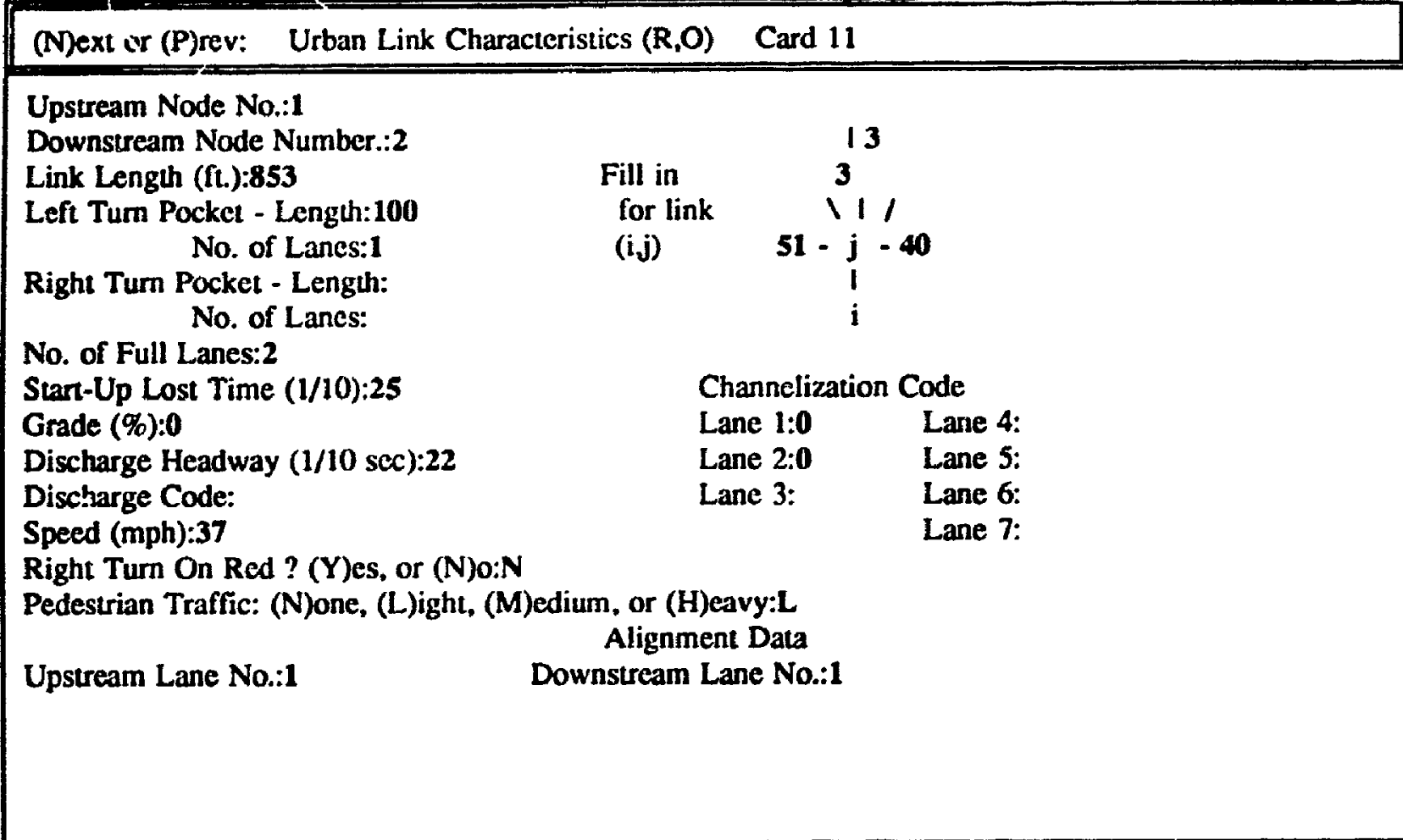

F6-Explain, F7-Print, F8-Help, F9-Default, F10-Accepl, ESC, CR, BS, HOME, END Enter data or ESC.

\section{Figure 4.13 Netsim Input Data For Link 1-2}

- Source: TRAF User Reference Guide Version 4 


\begin{tabular}{|c|c|c|c|c|c|}
\hline \multicolumn{2}{|c|}{ (N)ext or (P)rev: } & \multicolumn{3}{|c|}{ Turning Movement $(R, O)$} & \multirow[b]{2}{*}{ Diagonal } \\
\hline $\begin{array}{l}\text { Upstream } \\
\text { Node }\end{array}$ & $\begin{array}{l}\text { Downsuream } \\
\text { Node }\end{array}$ & $\begin{array}{l}\text { Left Turn } \\
\text { \% or Vol. }\end{array}$ & $\begin{array}{l}\text { Through } \\
\% \text { or Vol. }\end{array}$ & $\begin{array}{l}\text { Right Turn } \\
\% \text { or Vol. }\end{array}$ & \\
\hline 2 & 3 & 1 & 98 & 1 & \\
\hline 3 & 4 & 3 & 97 & & \\
\hline
\end{tabular}

F6-Explain, F7-Prim, F8-Help, F9-Default, F10-Accepı, ESC, CR, BS, HOME, END Enter data or ESC.

\section{Figure 4.14 Typical Input Data For Turning Movement Traffic'}

Existing intersection timing plans for the network were entered on a node by node basis. Figure 4.15 is a pretimed signal plan for Carling/Alpine intersection, which indicates a two phase signal with 10 secs eastbound leading green followed by 95 secs of eastbound and westbound permitted green. The second phase is 15 secs of permitted north and southbound green. Approaches $2 \& 4$ are eastbound and westbound Carling Ave and approaches $53 \& 52$ are south and northbound Alpine street. Protected, permitted, and combined phasing were all input in sequence for all signalised intersections. Signal transition green was left blank because it is not required for one timing plan.

- Source: TRAF User and Reference Guide Version 4.0 


\begin{tabular}{|c|c|c|c|c|c|c|}
\hline \multicolumn{2}{|c|}{ (N)ext Gr (P)rev: } & \multicolumn{4}{|c|}{ Sign or Pre-limed Signal Timing (R) } & Card 35,36 \\
\hline \multicolumn{2}{|c|}{ Node Number:3 } & $\mathrm{X}$-coor & \multicolumn{3}{|c|}{$\begin{array}{l}\text { Y-coord: Transitio } \\
\text { Upstream Node of }\end{array}$} & Green: \\
\hline Orfset:3 & & 2 & 53 & 52 & 4 & \\
\hline $\begin{array}{c}\text { Interval } \\
\text { No. } \\
1 \\
2 \\
3 \\
4 \\
5 \\
6 \\
7 \\
8 \\
9 \\
10 \\
11 \\
12\end{array}$ & $\begin{array}{c}\text { Duration } \\
\begin{array}{c}10 \\
95 \\
15\end{array}\end{array}$ & $\begin{array}{c}\text { Approach } 1 \\
1 \\
1 \\
2\end{array}$ & $\begin{array}{c}\text { Approach } 2 \\
2 \\
2 \\
1\end{array}$ & $\begin{array}{c}\text { Approach } 3 \\
\begin{array}{c}2 \\
2 \\
1\end{array}\end{array}$ & $\begin{array}{l}\text { Approach } 4 \\
\qquad \\
2 \\
1 \\
2\end{array}$ & Approach 5 \\
\hline
\end{tabular}

F6-Explain, F7-Print, F8-Help, F9-Default, F10-Accept, ESC, CR, BS, HOME, END

Enter data or ESC.

Figure 4.15 Signal Timing Plan For Carling/Alpine Intersection. ${ }^{10}$ 
Entry link volumes were entered for all entry links. A sample entry link input screen is shown in Figure 4.16 for entry links 8106,8107 and 8108 .

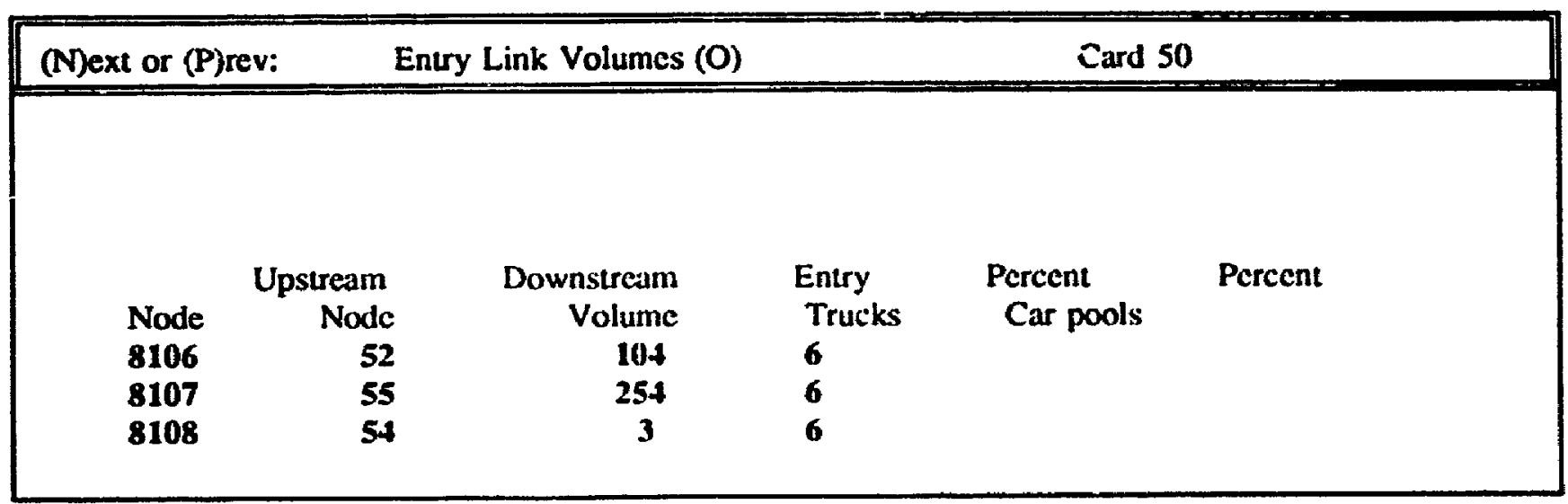

F6-Explain, F7-Print, F8-Help, F9-Default, F10-Accept, ESC, CR, BS, HOME, END

Enter data or ESC.

\section{Figure 4.16 Sample Entry Link Volume Entered Into NETSIM ${ }^{11}$}

Bus paths were broken down into 5 routes:

- Route 1 was allocated for eastbound buses entering Pinecrest intersection (entry link 8100) and leaving to the Carlingwood mall (link) 
- Route 2 was allocated to eastbound buses entering at Carlingwood intersection and going through Kirkwood Ave.

- Route 3 was allocated to westbound buses entering at Churshill intersection and exiting at Maitland Ave.

- Route 4 buses entered westbound Carling at Maitland and made an exit at Carlingwood mall.

- Route 5 was designated for buses using westbound Carling at the Carlingwood intersection and went through Pinecrest.

Before RETSIM proceeds with simulation, it first checks all input data for completeness \& consistency with the help of the pre-processor component of the model. When errors are detected it exits from the program indicating the errors which halted its execution.

Secondly it fills the network with vehicles until equilibrium is reached. This is known as "initialisation time". It is important for network to reach equilibrium before simulation begins. As a rule of thumb, in tialisation time should be the time taken for a vehicle to traverse the study section [US DOT, 1993].

\subsubsection{Output From NETSIM}

The following measures of effectiveness are generated by NETSIM:

$$
\begin{aligned}
& \text { - throughput in vehicle kilometres, } \\
& \text { - vehicle trips, }
\end{aligned}
$$


a travel time: move time, delay time and total time in vehicle-minutes and seconds per vehicle,

- stopped delay in seconds per vehicle,

- average link volumes in vehicles per hour,

- average speed in $\mathrm{km} / \mathrm{h}$ or $\mathrm{mph}$,

a signal phase failures, and

- queue lengti

For interrupted traffic flow, travel time is the most important performance measure. Network analysis was therefore based on:

- travel time (measured by the to cil time taken to traverse a given segment),

- intersection stopped delay, and

- arterial travel speed (measured by the total distance between the street segment divided by the total time taken to travel).

Figures 4.15 is a printout of some of the MOEs generated by NETSIM. Intersection levels of service and arterial levels of service were all determined using tables 4.5 and 4.6 from the Highway Capacity Manual ${ }^{12}$.

12 Source: Highway Capacity Manual 1985, Table 9-1 \& 11.1 


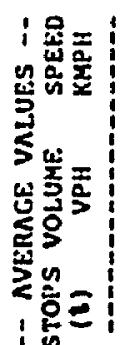

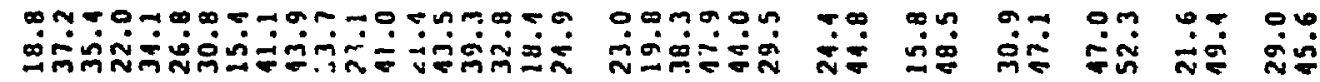

ocmorom

$+\infty \infty$

9m om $0=0$

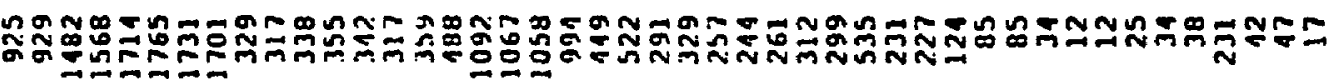

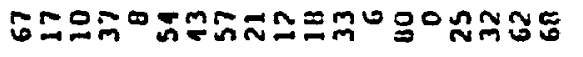

Sลก⿻ำ

$\mathbb{\infty}^{\circ}$

50

$\Omega^{\circ} \stackrel{\circ}{0}^{\circ}:^{\circ}$

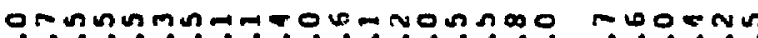

$\because 0$

$\div 0$

Do mo no no

岁穿类

率部

$\checkmark$

象类

巡峞的

|

onmmnronnopm-rorr:-

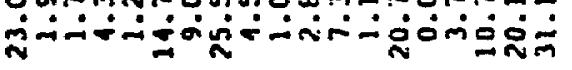

Smonno

$\approx 0$ i

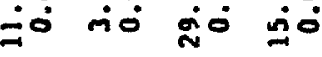

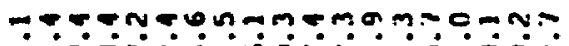

$0:-0=0 n$

$0-100$

:0 mo mo no

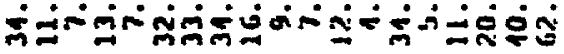

iginging

ถั่

mommanmañon

$\infty 000=5$

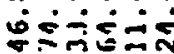

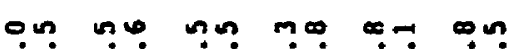

-m

करत्य

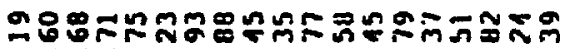

Nö́ló

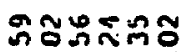

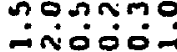

$\sim m$

min

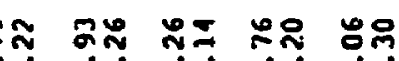

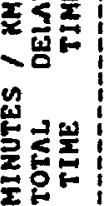

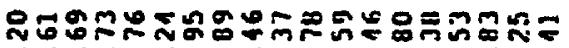

ำตำำำ

$0=$

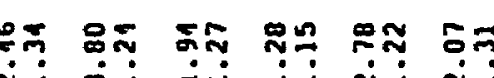

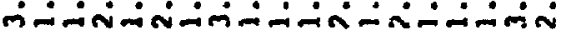

ن் $\dot{0} \dot{A}$

울훙ㅎㅇ

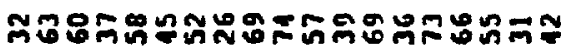

ำกำ

F⿻

กั

กี⿱口

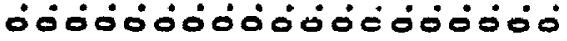

ธं0ं0ं0

is

O० Do io io io

|

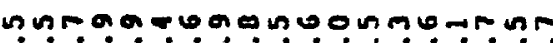

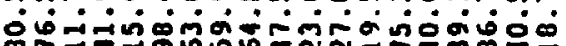

$\because \ln 00 \infty$

ติ

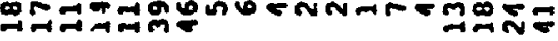

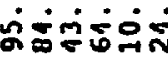

ที่

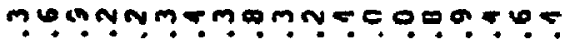

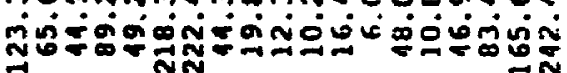

$\rightarrow m+50$

ininging

ont 00

iू

$\therefore$

ถ⿻ำ

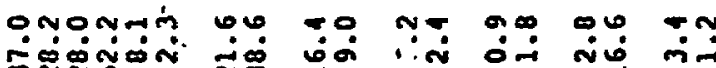

ติกงก

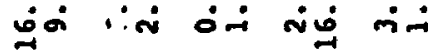

空

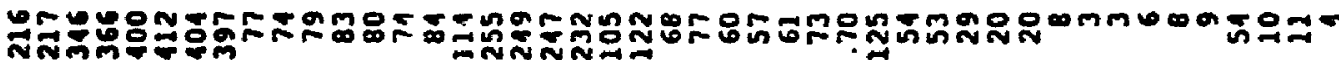

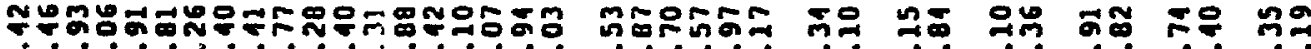
คดำ

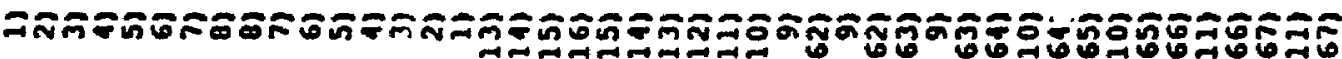


Table 4.5 Level of Service Criteria For Signalised Intersections

\begin{tabular}{|c|c|}
\hline Level of Service & Stopped Delay per Vehicle (sec) \\
\hline A & $<5.0$ \\
B & 5.1 to 15.0 \\
C & 15.1 to 25.0 \\
D & 25.1 to 40.0 \\
E & 40.1 to 60.0 \\
F & $>60.0$ \\
\hline
\end{tabular}

Source: Highway Capacity Manual 1985

Table 4.6 Level of Service for Arterial Class II

\begin{tabular}{|c|c|}
\hline Level of Service & Average Travel Speed $(\mathrm{Km} / \mathrm{h})$ \\
\hline A & $>48$ \\
B & $>39$ \\
C & $>29$ \\
D & $>23$ \\
E & $>16$ \\
F & $<16$ \\
\hline
\end{tabular}

Source: Highway Capacity Manual 1985

Except Richmond which operates at a LOS D, all eastbound intersection approaches are operating at a LOS C or better; Alpine, Croydon, Connaught, Lincoln Fields, Woodroffe South, Carlingwood, Iroquous and Broadview eastbound approach have an average stopped delay of $10 \mathrm{sec} / \mathrm{veh}$ or less (LOS B). This means traffic moves with little or no stops which is mainly due to very good progression (see Figure 4.18).

Despite efficient traffic progression, Pinecrest-Richmond, Woodroffe SouthFairlawn, \& Clyde-Churchill links are travelling at lower speeds $(18 \mathrm{~km} / \mathrm{hr}$ or less see Figure 4.19). This is due to high left turns, ranging from 142 to 250 vehicles per hour (see appendix A) which interferes with through traffic. Apart from these links, all other eastbound approach traffic travel at a speed of $28 \mathrm{~km} / \mathrm{hr}$ or higher (LOS D or better). 


\section{Intersection Stopped Delay Eastbound Carling Ave}

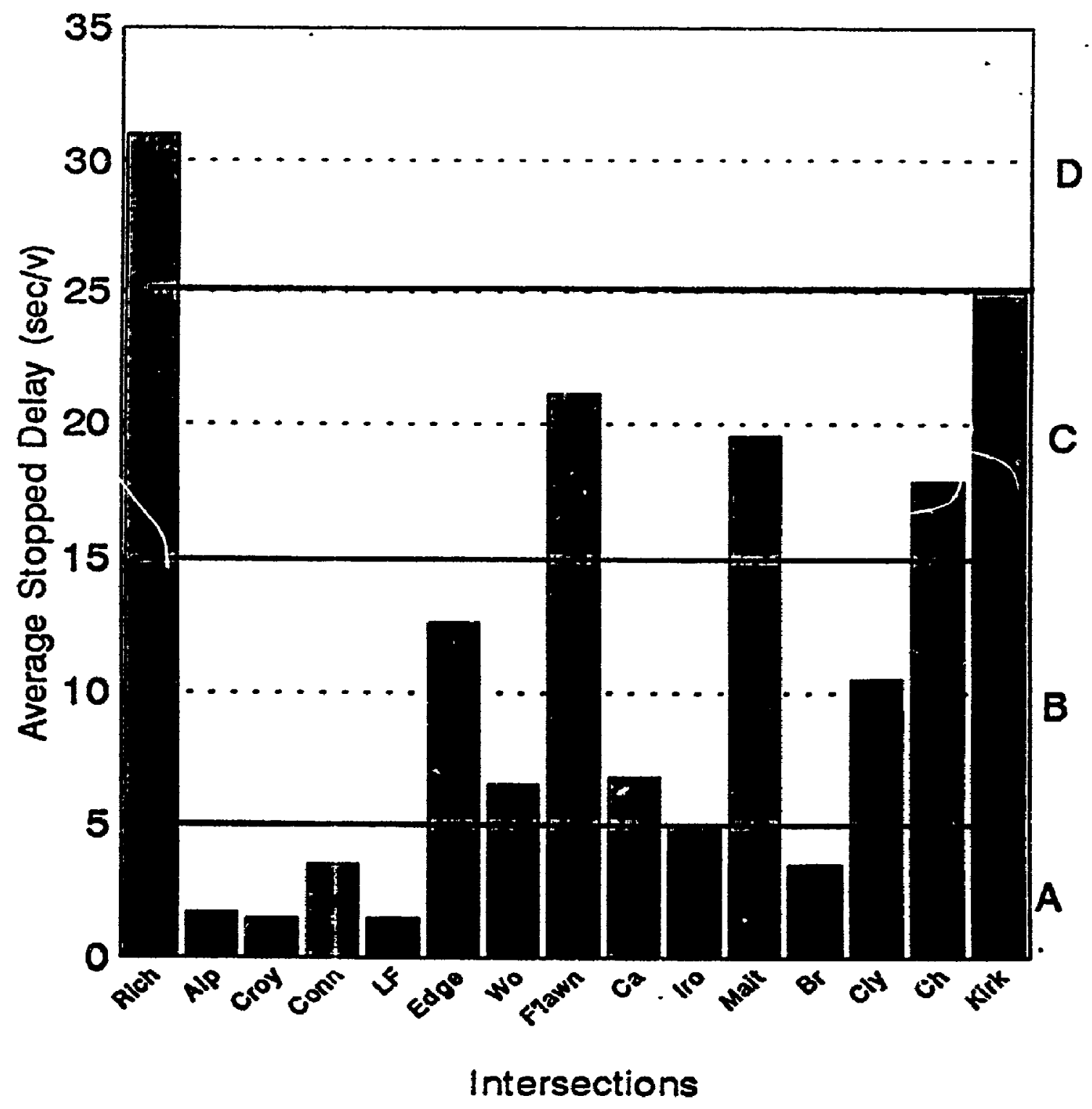

Based on 1992 RMOC intersection counts and existing timina plan

Figure 4.18 Level of Service for Eastbound Carling 
Link Travel Speed

Eastbound Carling

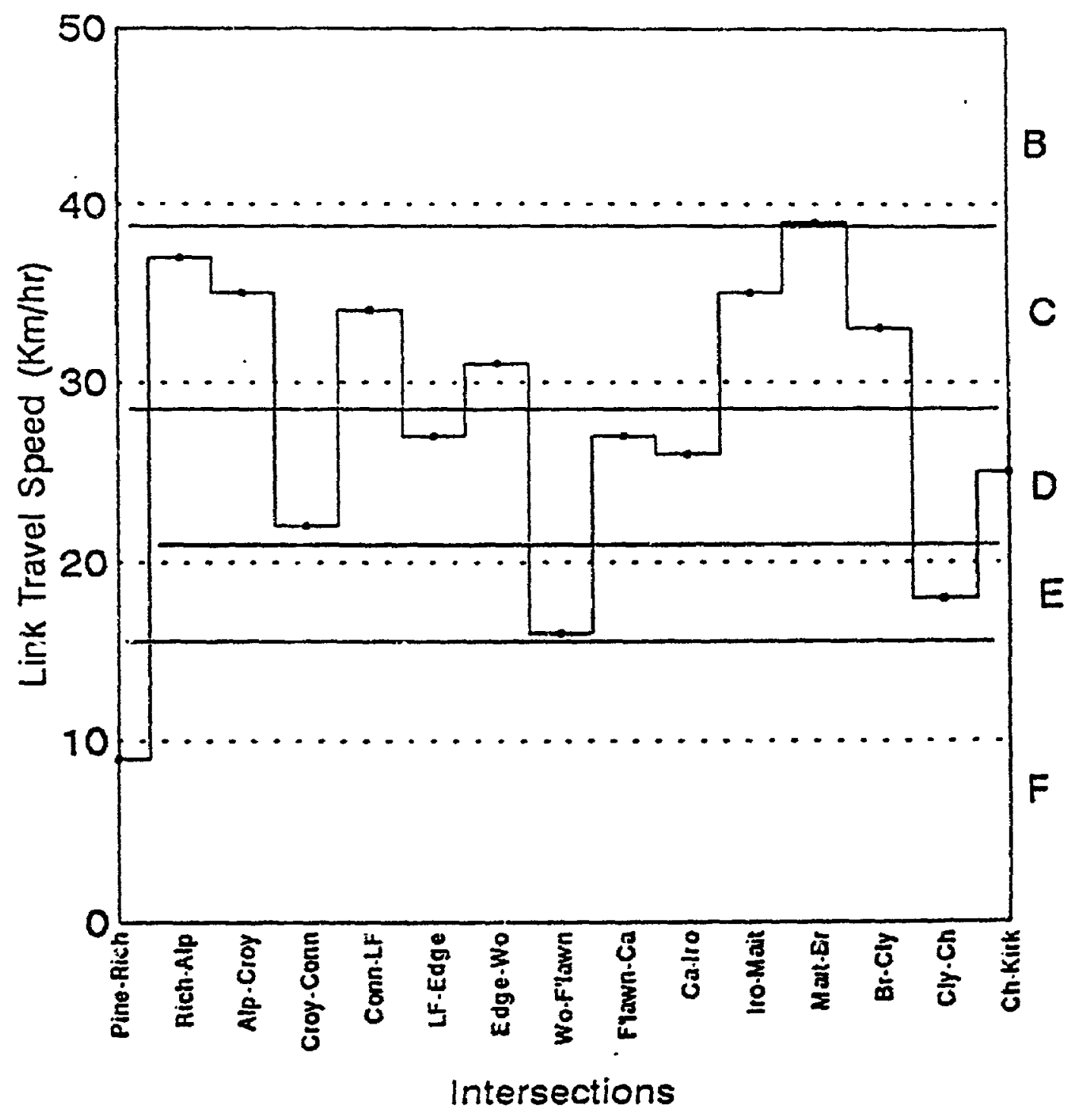

Based on 1992 RMOC interstction counts and existing timing plan

Figure 4.19 Link Travel Speed for Eastbound Carling. 


\section{Cumulative travel Time} Existing Eastbound Carling

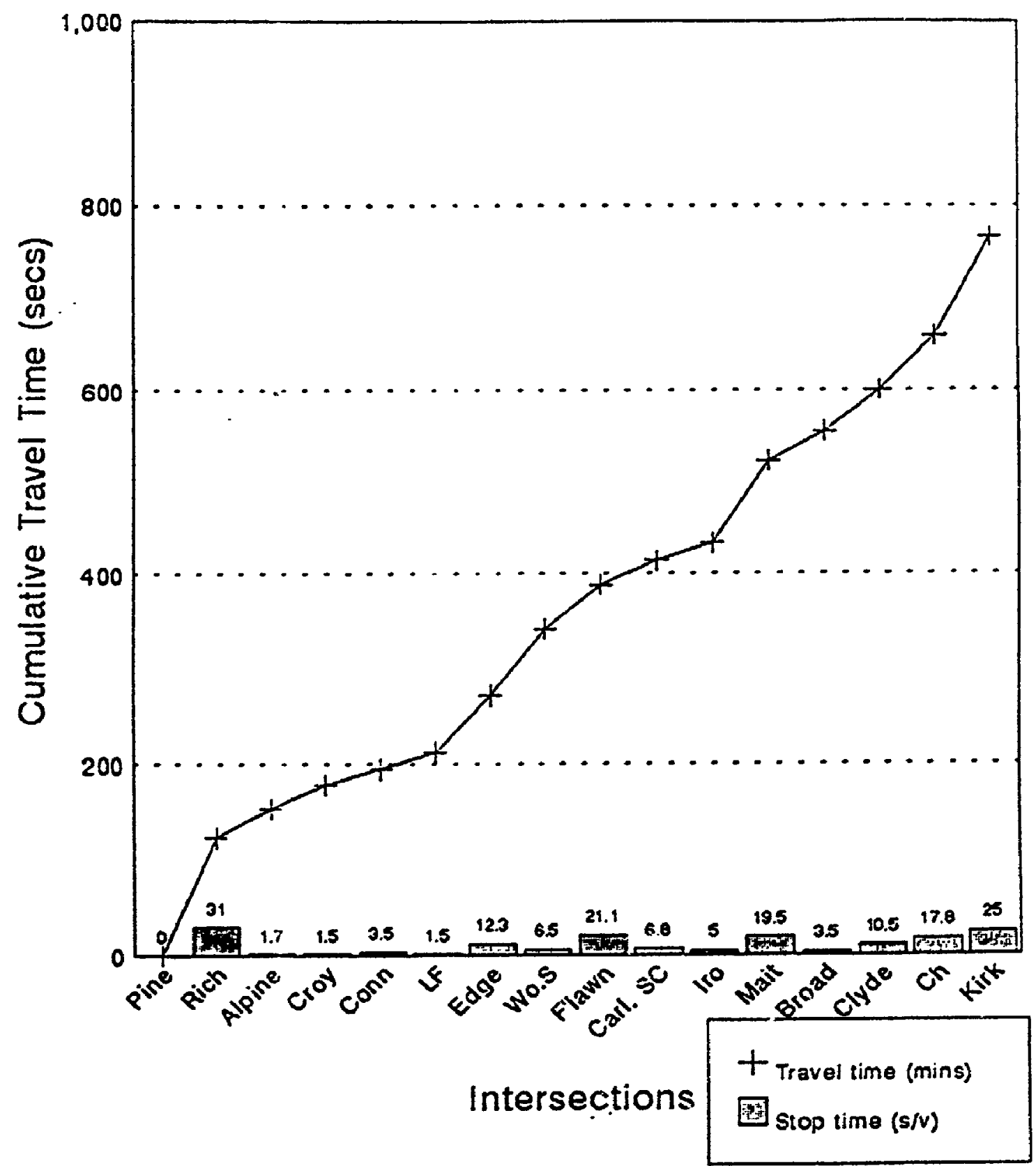

Based on 1992 RMOC intersection counts and existing timing plan

Figure 4.20 Cumulative Eastiound Travel Time. 


\section{Intersection Stopped Delay Westbound Carling Ave}

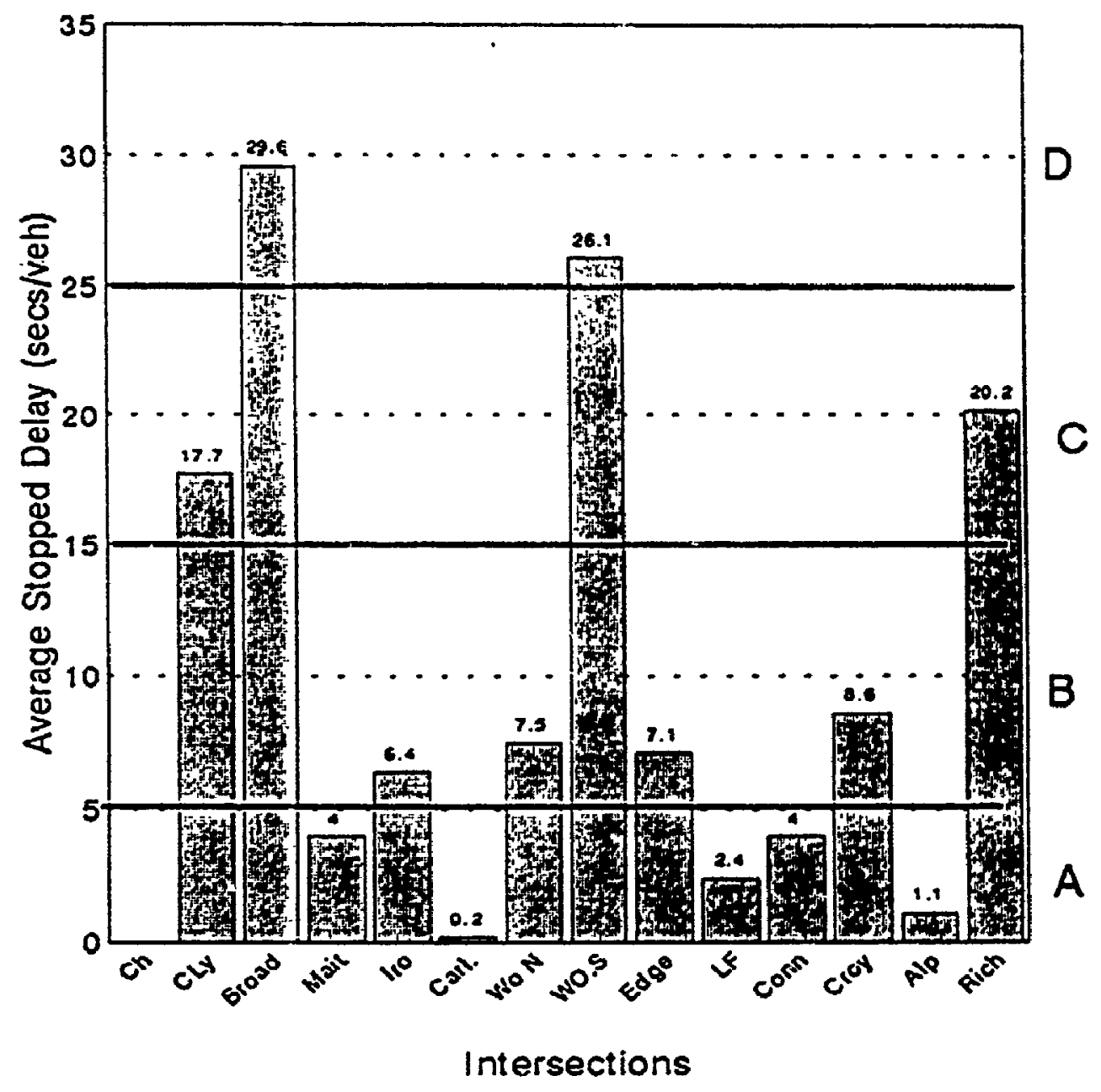

Based on 1992 RMOC intersec:ion counts and existing timing plan

Figure 4.21 Āverage stopped Delays for Westbound Carling. 
Cumulative eastbound travel time frum Finecrest to Kirkwood is 12.8 minutes (766.9 secs) (see Figure 4.20). For the westbound traffic, Woodroffe South \& Broadview intersections experience an average stopped delay of 26.1 and 29.6 secs/veh respectively (LOS D), but all other intersections exhibit a stopped delay of $20.2 \mathrm{sec} / \mathrm{veh}$ or better (LOS C or better, see Figure 4.21). Cumulative travel time on westbound Carling from Churchill to Richmond is 8.3 minutes. The entire eastbound traffic is travelling at an average speed of $25 \mathrm{~km} / \mathrm{h}$, which corresponds to a LUS D whereas the entire westbound traffic is travelling at an average speed of $32 \mathrm{~km} / \mathrm{h}$, a LOS C.

From both arterial and freeway capacity analyses it could be concluded that: whereas the eastbound Queensway between Pinecrest and Maitland is experiencing a combination of near capacity to forced flow conditions, Carling Avenue traffic in the same direction enjoys a LOS D or better,

- during the peak 15 mins, despite its 16 signalized intersections, cumulative travel time on Carling Avenue is less than its freeway counterpart, and therefore, this section of Carling Avenue can accommodate additional traffic from the freeway. 


\section{Cumulative Travel Time Wesibound Carling Ave}

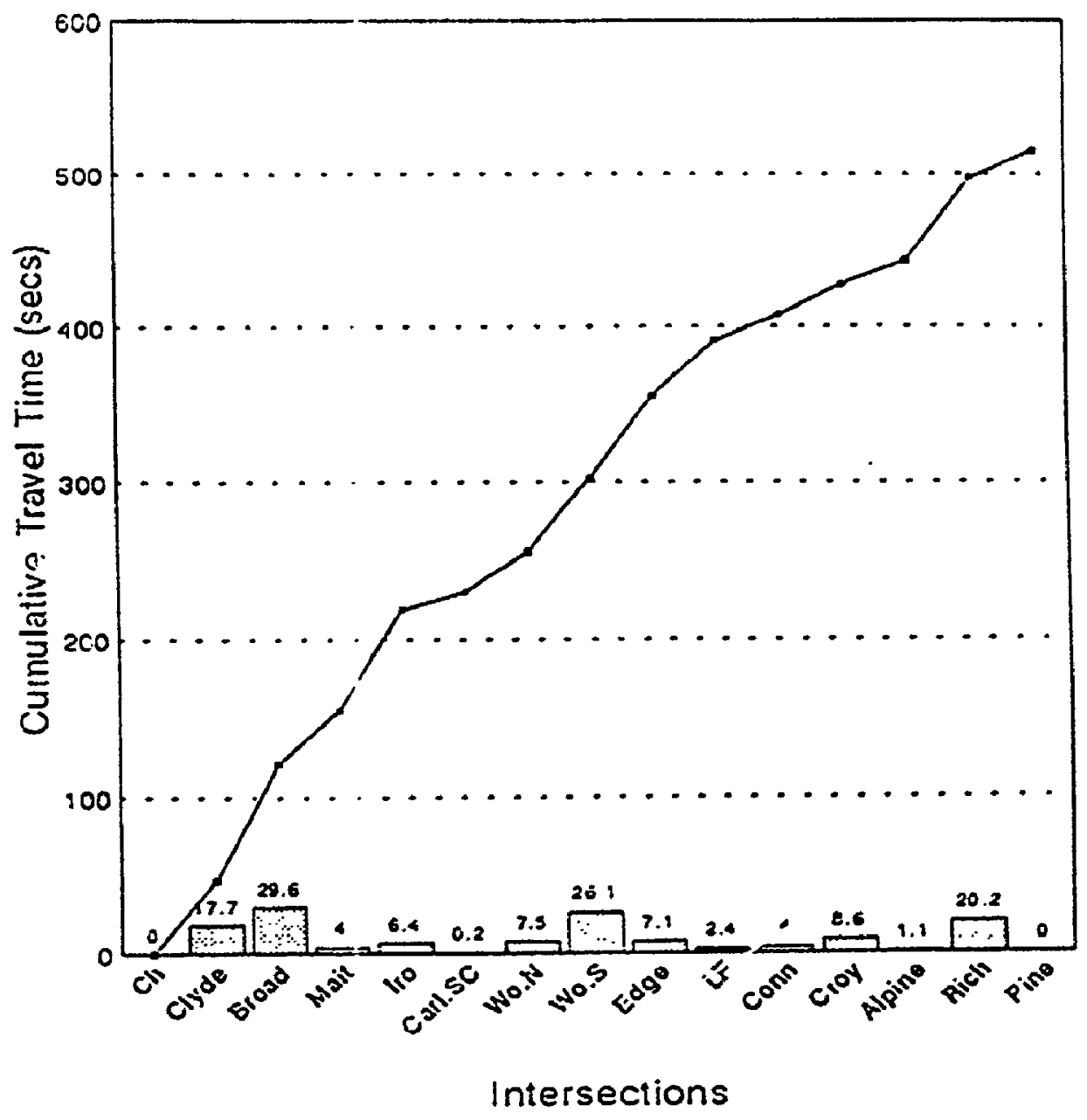

Easid on 1992 AMOC intersection counts and existing timing plan 


\section{CHAPTER 5}

\section{RAMP CONTROL STRATEGIES AND TACTICS: CORRIDOR ANALYSIS}

In Chapter 3 the main types of ramp metering and other freeway traffic management strategies were discussed. From Chapter 4 it was revealed that the mainline section just upstream of the bottleneck section was experiencing queue build ups and congestion whilst the section of Carling Avenue east of Pinecrest \& west of Kirkwood Ave was operating at a level of service $C$, which makes it a suitable route for diversion. This Chapter deals with freeway and arterial control modules.

A successful metering strategy is one that ensures a balanced level of service for both the freeway and the alternative route. In other words, the total travel time in the corridor should be at least equal to or lower than the pre-metering conditions.

\subsection{Entrance Ramp Control Feasibility}

Although most of the case studies proved that ramp control is successful, it does not in any way suggest that ramp control is feasible on all freeways. Unlike traffic signals, freeway ramp control signals have no specific warrants for their installation. The Canadian Manual on traffic control devices (1976) makes no mention of guidelines or 
warrants for their installation. The Manual on Uniform Traffic Control Devices [US DOT 1988] contains some guidelines, not warrants, for ramp control signals. Implementation of ramp control strategies should therefore be based on a detailed engineering analysis on the major factors affecting the feasibility of metering such as:

- bottleneck analysis,

- trame diversion analysis (amount of diversion, candidate routes for diversion, and impacts of diversion),

- geometriv design factors,

- enforcement analysis,

- public acceptance analysis,

- accident analysis,

- benefit-cost and cost-effectiveness analysis.

This part of the study covers bottleneck analysis, geometric design and traffic analysis of both the freeway and arterial. Bottleneck analysis involves identifying sections of the freeway where demand is higher than capacity and deciding what control measures would best improve flow. In Chapter 4, freeway bottlenecks were identified, based on demand/capacity criterion. Bottlenecks could also be due to other exogenous and endogenous factors such as horizontal and vertical alignment, the condition of the pavement, and effect of weather conditions such as rain, snow, etc 


\subsection{Metering Alternatives:}

For on ramp metering, three options ought to be considered. These are

- Single entry metering,

- Platoon metering, and

- Two lane metering.

For single entry metering, only one vehicle is allowed per green. Vehicles merge smoothly with the mainline and violation rates are the lowest when this alternative is used.

In platoon metering, two or three vehicles are allowed to enter the freeway per cycle length. The main reason for platoon metering is to achieve higher ramp throughput, especially for a single lane metering.

Two lane metering requires at least two ramp lanes. Two vehicles, side by side, are allowed entry per cycle length.

Single entry metering was chosen for the Ottawa Queensway for the following reasons:

- ramp volumes of the section were not high enough to justify platonn or two lane metering, and

- it is better to use one alternative than to switch from one alternative to the other to avoid higher violation rates and driver confusion.

\subsection{Metering rates}

Minimum and maximum metering rates were determined, based on the minimum cycle length of a ramp signal to allow only a vehicle to be discharged per green (4 secs) and 
the maximum tolerable waiting time for a motorist (20 secs). Experience from a number of locations indicate that when ramp signals remain on red for more than 20 secs, violation rates are higher because motorists are either impatient or they think of the signals as malfunctioning [Bluementritt et. al., 1981; US DOT 1976; ITE Handbook 1992].

$$
\begin{aligned}
& \text { Min. Metering Rate }=\frac{3600 \text { secs }}{20 \text { secs }}=180 \mathrm{vph} \\
& \text { Max. Metering Rate }=\frac{3600 \text { secs }}{4 \text { secs }}=900 \mathrm{vph}
\end{aligned}
$$

Metering rates were based on demand/capacity criterion for two reasons :

- $\quad$ Pretimed strategies were used.

- Occupancy metering requires a historical relationship to be established between occupancy and mainline volume; there are no such data available in the OttawaCarleton region at present as there are no vehicle detectors installed in the Queensway to conduct such studies.

\subsection{Control Strategies}

In Chapter 4, the four major metering methods were discussed. Pretimed metering was chosen for Highway 417 using the following elimination procedure:

- Moving merge and gap acceptance control strategies are not cost-effective due to numerous vehicle detectors, and other taardware components required. Moreover, Pinecrest, Maitland, Woodroffe and Carling ramps 
offer adequate ramp geometrics.

- Experience in many locations has revealed that there is a diminishing rate of return, with respect to cost, when control hardware and software for locally actuated and integrated centrally computer controlled metering are used iWainright 1972; Jacobson et al 1989 Bluementritt et al 1981; Cocoran \& Hickman, 19911. It is better to install pretimed because it could easily be upgraded to either local responsive or integrated systems if or when necessary.

\subsection{Experiment Set Up}

The following procedure were adopted for corridor analysis. Existing freeway traffic (1992 condition) was simulated with the FREFLO simulation model, using the data as discussed in the previous chapter (see section 5.5.1 lor a description of the FREFLO model). Ramp metering rates were optimised using linear programming. Out of the traffic diverted from the mainline, 20 queued on the ramps and the rest were diverted to Carling A.ve. The diverted volumes were all assumed to use EB Carling Avenue to Kirkwood. Signal timing plans for the network were optimized to suit the increased volumes by using PASSER II-87 computer software. The new timing plans were entered into TRAFNETSIM to simulate these new volumes. Optimized metering rates were increased by very small amounts, repeatedly, until the threshold level of service for all intersection approaches were sarisfied. For every metering increase, corresponding traffic on the alternate route, in this case Carling Ave, was adjusted accordingly. Performance measures 

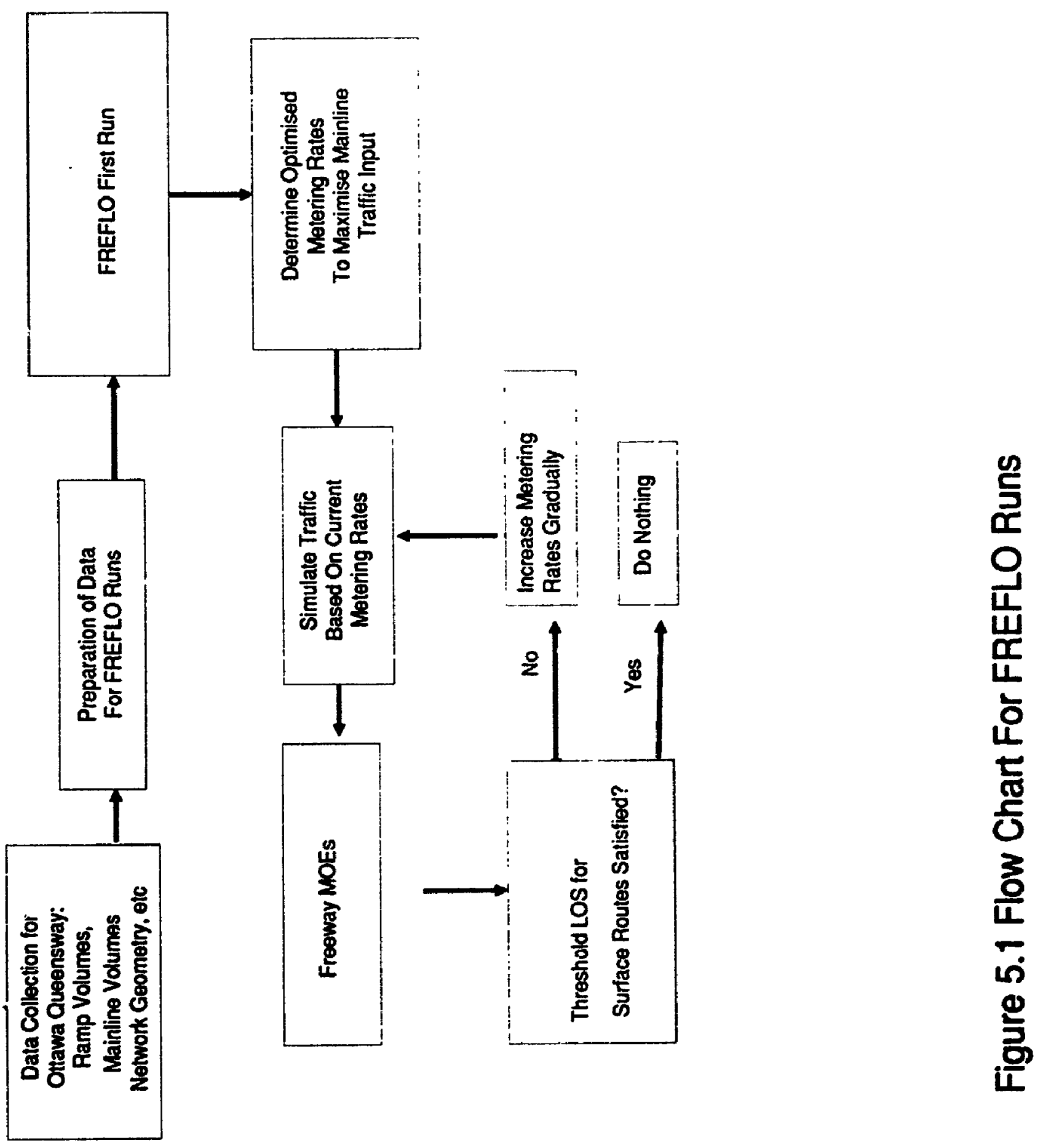
for both directions of the corridor were recorded. Each time traffic was increased on alternate routes, traffic signals were fine-tuned to optimize traffic flow. Figure 5.1 is a flow chart of the experiment set up and analysis. A brief introduction to FREFLO and PASSER II-87 is provided in the following sections.

\subsubsection{FREFLO Model}

FREFLO is the successor to the MACK simulation model, developed by HJ Payne. It is a macro simulation model, which models flow on freeway networks on an aggregate basis. It is also a subset of TRAF, a family of simulation programs integrated by the FHWA.

The model is based on the principle of fluid flow conservation: the volume of a section of the freeway is the sum of input volume, the entrance ramp volume and the exit ramp volumes. During free flow conditions, the linear flow speed and density relations apply. As the freeway sections approach capacity, drivers tend to adjust their speed to the equilibrium speed density relationship and finally tend to slow down. The conservation equation is expressed as [Payne \& Isaken 1973; Rathi et al 1987; Payne, 1979]

$$
\rho_{j}^{n+1}=\rho_{j}^{n}+\frac{\Delta t}{1_{j} \Delta x_{j}}\left[q_{j-1}^{n}+f_{j}^{o n, n}-q_{j}-f_{j}^{o f f_{0}, n_{j}}\right.
$$

The normal speed-density relation:

$$
q_{j+1}^{n+1}=\rho_{j}^{n} u_{j}^{n}
$$

The dynamic speed-density relation: 


$$
u_{j}^{n+1}=u_{j}^{n}-\Delta t\left(u_{j}^{n}\left[\frac{u_{j}^{n}-u_{j-1}^{n}}{\Delta x_{j}}\right]+\frac{1}{T}\left[u_{j}^{n}-u_{e}\left(\rho_{j}^{n}\right)+v \frac{\rho_{j+1}^{n}-\rho_{j}^{n}}{\Delta x_{j}}\right]\right)
$$

Where
n
$l_{j}$
Current point in time;
Current section;
Number of lanes along section $j$
$\Delta \mathbf{x}_{\mathbf{j}}$
Length of section $j$;
$\rho_{j}{ }^{n}$
Density of section $\mathrm{j}$ for the current point in time;
$u_{j}^{n}$
Space mean speed of section $j ;$
$\mathbf{q}_{j}^{\mathrm{n}}$
The rate at which vehicles pass section $x_{j}$ for the current point in time, in vehicles per hour per lane per hour per lane
$f_{j}^{\text {on, n }}$
On ramp volume
$f_{j}^{\text {off,n }}$
Off ramp volume
$\mathrm{T}$
The relaxation time coefficient
$\mathbf{v}$
Anticipation coefficient
$\left(u_{j}^{n}-u_{j-1}{ }^{n}\right) / \Delta x$
Represents convection that is upstream vehicles at section $j-1$ will travel at that speed as they enter section $j$
$u_{j}^{n}-u_{e}\left(p_{j}^{n}\right)$
Represent the tendency of drivers to adjust their speeds to the equilibrium speed density relationship
$\left(\rho_{j+1}{ }^{n}-\rho_{j}^{n}\right) / \Delta x_{j}$
The effect of drivers changing their speed in anticipation of changing density.
$\Delta \mathrm{t}$ Incremental time, $t$. 
Freeway sections are divided into links and nodes where nodes are ramp junctions, or and links are distance between nodes. Before simulation begins, the preprocessor checks the input data for completeness and logic. If there are any errors, it terminates and exits the program indicating the errors that halted execution. Its initialisation period is done the same way as NETSIM [US DOT 1993].

FREFLO have been used by a number of agencies and transportation professionals including Demenstry, Bluementritt, et. al. A survey of freeway simulation models conducted by May, et. al. also revealed FREFLO \& FREQ as the two main candidate models which could adequately simulate freeway traffic [May, Adolf et. al., 1982]. Furthermore, it has been recognised by the FHWA and incorporated into the TRAF family of simulation programs

\subsubsection{Model Calibration:}

Calibration of the model involves collecting field data on speed flow and density to select the type of speed-density relationships and determine its coefficients. For accurate results, data needs to be collected on a link-by-link basis.

Speed density calibration requires data collection on the study section continuously from free flow condition to forced flow condition. A sample size of at least 50 to 100 is required [McShane \& Roess, 1990]. Depending on the quality of data, it could be more. The next step is to conduct a multiple regression analysis using the dependent variable 
(speed) and the independent variable (density) in a polynomial form, similar to the expression established by the alternative forms of the model:

$$
\begin{gathered}
\text { Speed }=K_{1}+K_{2} p 10^{2}+K_{3}\left(p 10^{-2}\right)^{2}+K_{6}\left(p 10^{-2}\right)^{3} \\
\text { Speed }=\frac{10^{4}}{K_{1}+K_{2}\left(\rho 10^{2}\right)+K_{3}\left(p 10^{-2}\right)^{2}+K_{4}\left(\rho 10^{-2}\right)^{3}}
\end{gathered}
$$

Where

$$
\begin{aligned}
& K_{1}, K_{2}, K_{3}, K_{4}, \quad \text { are constants to be established by multiple regression, } \\
& p \\
& p \quad \text { density in } \mathrm{km} / \mathrm{hr} \text { or } \mathrm{mph}
\end{aligned}
$$

Such calibration could be best undertaken in a freeway environment where continuous speed, volume and occupancy data are collected automatically. In the case of the Ottawa Queensway where there is only one permanent mainline volume counting station, $1.5 \mathrm{~km}$ west of highway $417 / 7$ interchange, it is obvious that automatic freeway data generation is not possible. Given the enormous time, resources and effort for other methods, the video camera technique posed the next alternative, but camera positions to capture all the basic freeway sections of the study section were not attainable.

For the purposes of this study, speed-density equation (5-6) was assumed and the following default values, calibrated for a typical freeway, were used:'

$$
\begin{array}{ll}
\mathrm{K}_{1} & \mathbf{1 7 2} ; \\
\mathrm{K}_{2} & -\mathbf{5 9 7} ; \\
\mathrm{K}_{3} & \mathbf{8 9 6} \\
\mathrm{K}_{4} & -495 ;
\end{array}
$$



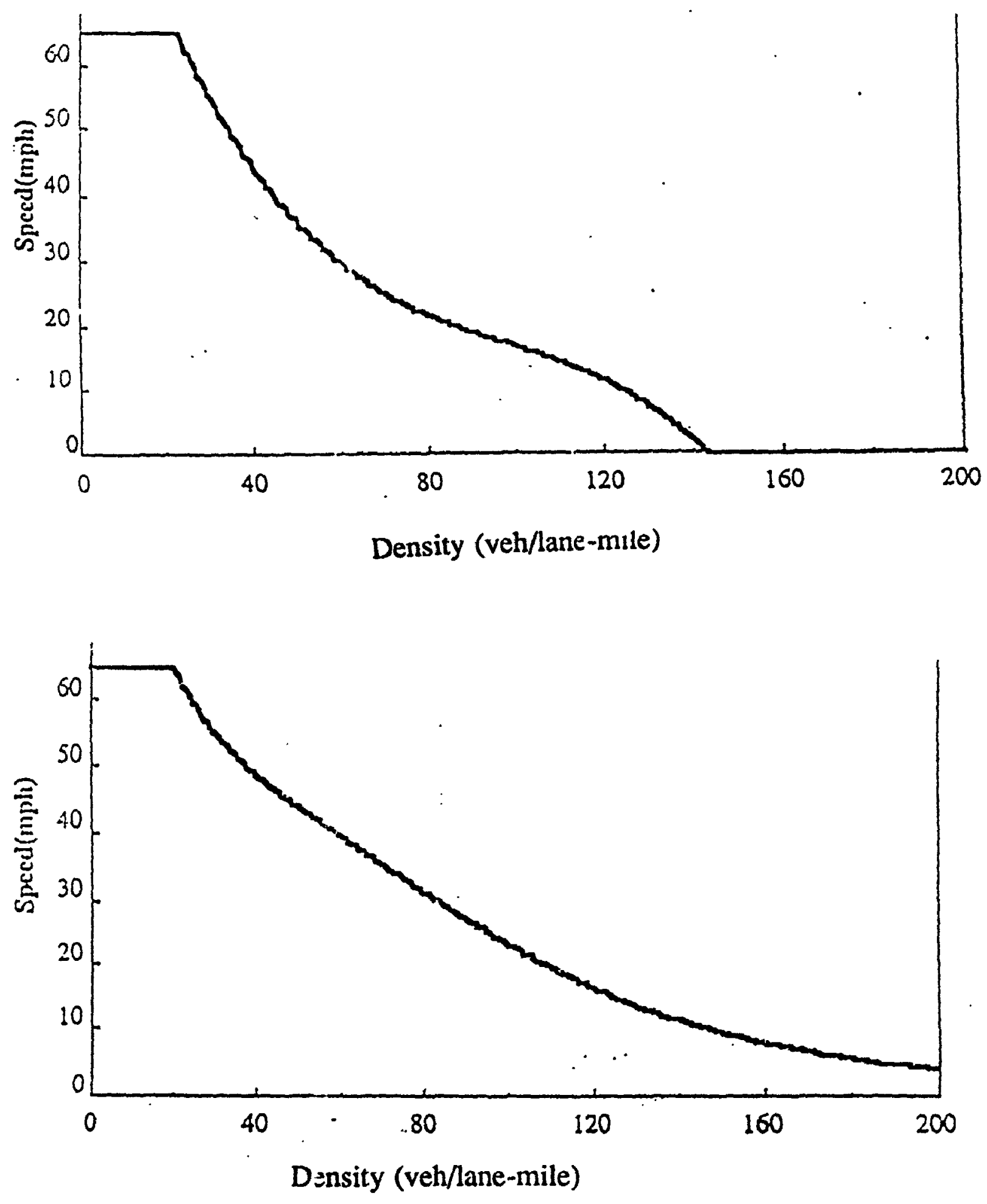

Fig 5.2 Typical Speed Density Relations Used By FREFLO. 
Making these assumptions means that traffic in the study section will behave in the same way as other freeways used to calibrate the model. The accuracy of the model relative to the conditions of the Queensway was tested by conducting travel tine studies, reported in Chapter 7.

\subsection{PASSER II-87}

PASSER II-87 stands for Progression Analysis \& Signal System Evaluation Routine 1987 version. It is a computer model that maximizes arterial progression and at the same time, minimizes intersection delay. It calculates signal times, phase sequence, cycle lengths (within $10 \%$ of the maximum input cycle length) $\vdots$ nd signal offsets through a number of iterations and selects a timing plan which maximizes bandwidth progression and minimizes arterial travel delays on a two way or one way street [Texas Transportation Institute, 1988; Messer et. a!., 1973].

The main input data required are traffic volumes (LT, ST, RT), cycle length, number of lanes, distance between signals, minimum phase time, phase sequence and progression speed. Based upon these intersection movements, possible signal phasing options are recommended by the model, for each intersection, for selection by the analyst. Ideal saturation flow of $1800 \mathrm{vphgpl}$ is assumed as the default value, which could be increased or decreased to $2400 \& 1500 \mathrm{vphgpl}$, respectively. Saturation flow rate is estimated by assuming an ideal saturation flow rate and multiplying by a number of factors to adjust for specific roadway and traffic conditions, as recommended by the HCM [Transportation Research Board, 1985]. 
Saturated flow rate is given by

$$
S=s_{0} N f_{W} f_{H V} f_{g} f_{p} f_{b b} f_{a} f_{R T} f_{L T}
$$

Signal phases are based on demand/capacity concept as analyzed by Webster and reported in Messer et. al., (1973):

$$
g_{i m}=\frac{D_{i m}}{S_{i m}} C+L_{i m}
$$

The average stopped delay for random arrival is

$$
d=0.38 C \frac{[1-g / C]^{2}}{[1-g / C(X)]}+173 x^{2}\left[(x-1)+\sqrt{(x-1)^{2}+(16 x / C)}\right]
$$

where

S Saturated flow rate

$\mathrm{S}_{0} \quad$ Ideal saturation flow rate

N Number of lanes

$f_{w} \quad$ Adjustment factor for lane width

$f_{\mathrm{HV}} \quad$ Adjustment factor for heavy vehicles

$f_{8} \quad$ Adjustment factor for grade

$f_{p} \quad$ Adjustment factor for the presence of a parking lane

$f_{b b} \quad$ Adjustment factor for the blocking effect of buses

f. Adjustment factor for area type

$\mathrm{f}_{\mathrm{RT}} \quad$ Adjustment factor for right turns in the lane group

$f_{L T} \quad$ Left turn adjustment factor

d Average stopped delay in secs/veh

C Cycle length in secs

g/C the ratio of the green time over cycle length

$X \quad v / c$ ratio for the lane group

c Capacity of lane group 
$\mathrm{g}_{\text {im }} \quad$ Green time for movement $\mathrm{m}$ at intersection $\mathrm{i}$

$D_{i m} \quad$ Traffic demand for movement $m$ at intersection $i$

$S_{\text {im }}$ Degree of saturation (the ratio of volume to capacity)

$\mathrm{L}_{\mathrm{am}} \quad$ Lost time

It uses the National Electrical Manufacturers Association (NEMA) phase numbering system, illustrated in Figure 5.3. The NEMA convention assigns numbers to different traffic movement. Figure 5.4 shows the PASSER II volume input screen.

Existing arterial offsets could also be simulated to evaluate existing performance measures

Its analysis is based on HCM's methodology for signalised intersections.

Figure 5.5 preserts a sample of PASSER II-87 optimised timing plans.

\subsubsection{Ruasons for choosing PASSER II-87}

This software is popular and user friendly. The following factors led to its choice:

- It is used by RMOC for signal optimisation

- It is used by The Metropolitan Toronto for signal optimization

- PASSER II maximum bandwidth solution has been widely accepted and applied throughout many cities in USA and Canada.

\subsection{Freeway Traffic Optimisation}

\subsubsection{Traffic Optimisation Using Linear Programming.}

Integrated pretimed control strategy was used to establish initial metering rates using a linear programming technique. Linear programming is a method to optimize a system 


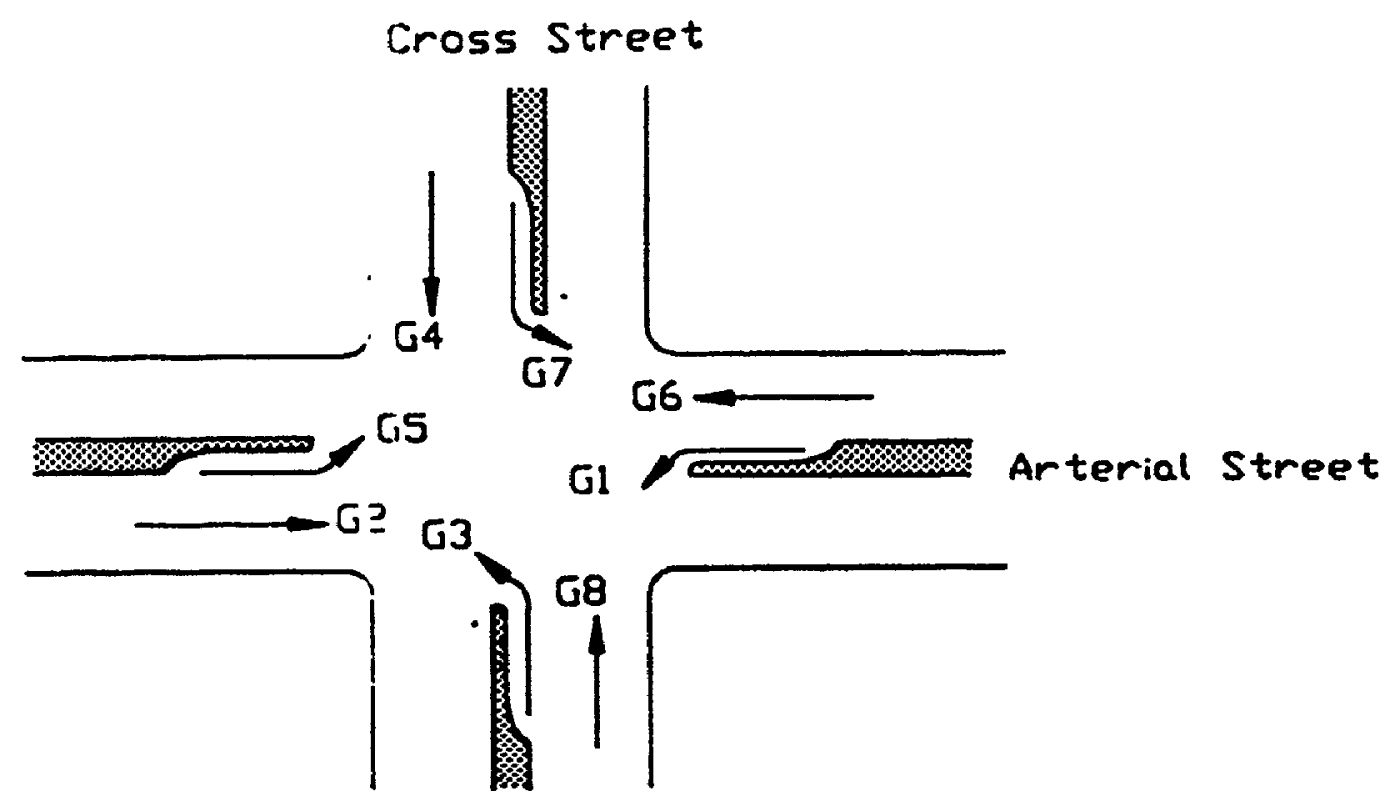

Figure 5-3: NEMA Movement Designation ${ }^{2}$

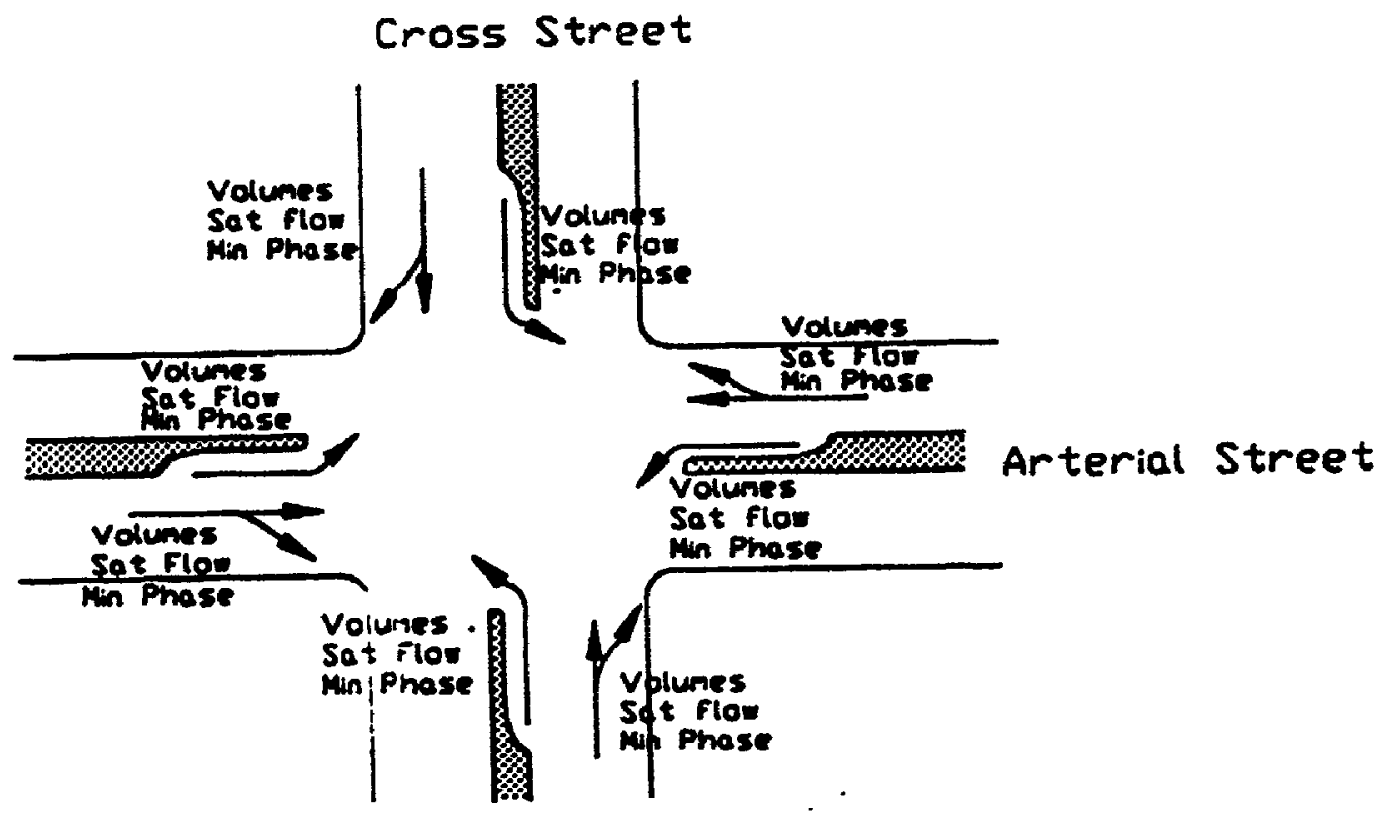

Figure 5.4: Passer II-87 Volume Input Screen 
(BEST.SOLN)

PASSER II-8

TEXAS DERARTMENT OE HIGHWAYS AND PUBLIC TRANSPORTATION

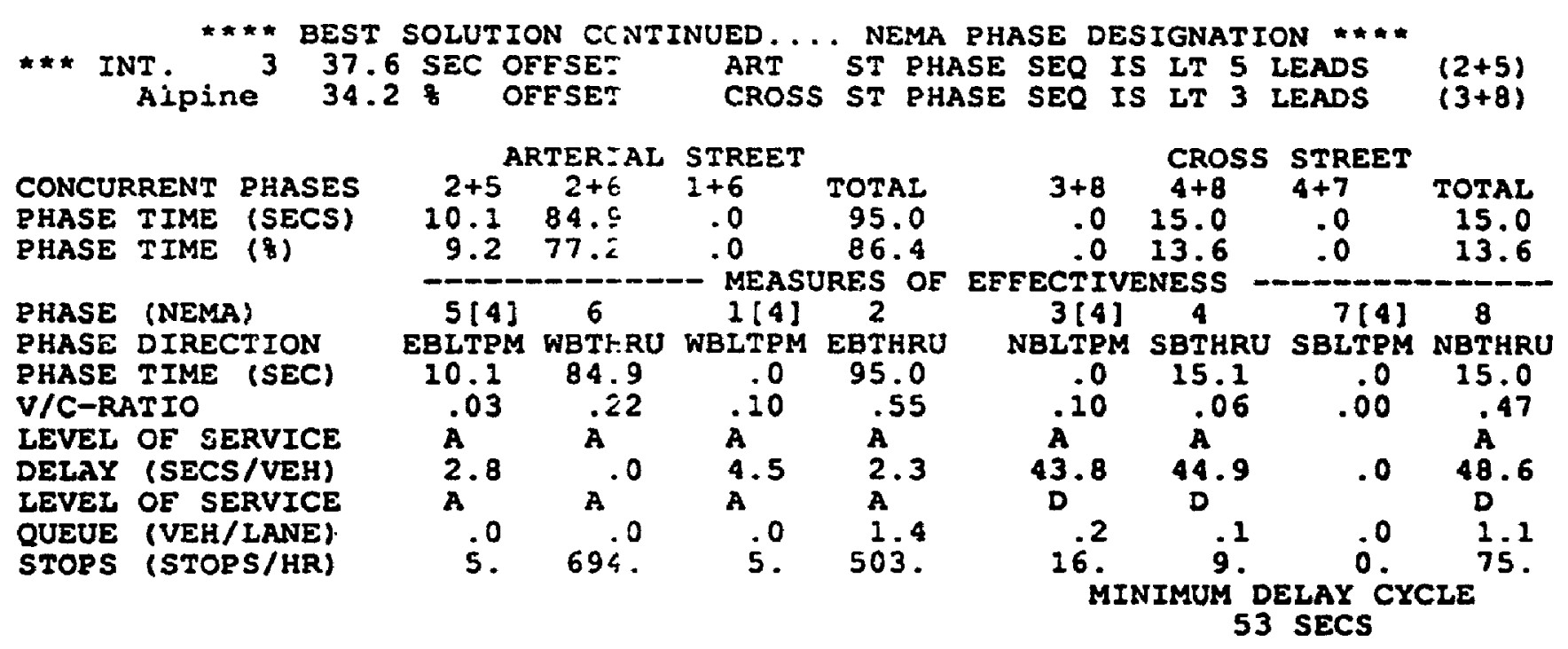

(BEST.SOLN)

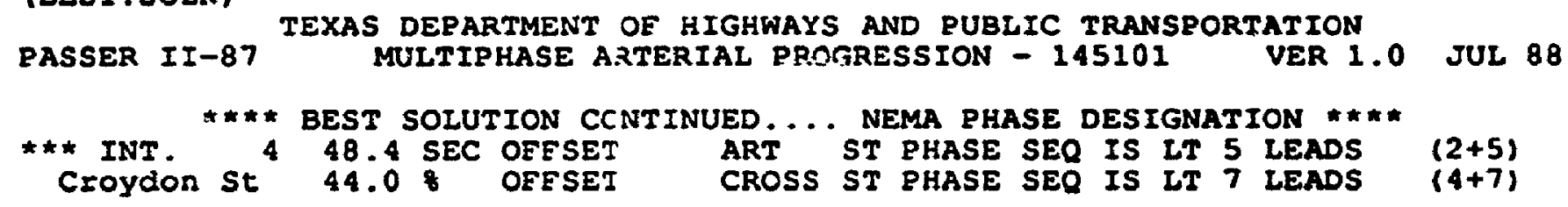

\section{CONCURRENT PHASES \\ PHASE TIME (SECS) \\ PHASE TIME ( $z$ )}

PHASE (NEMA)

PHASE DIRECTION

PHASE TIME (SEC)

V/C-RATIO

TEVEL OF SERVICE

DELAY (SECS/VEH)

LEVEL OF SERVICE

QUEUE (VEH/LANE)

STOPS (STOPS/HR)

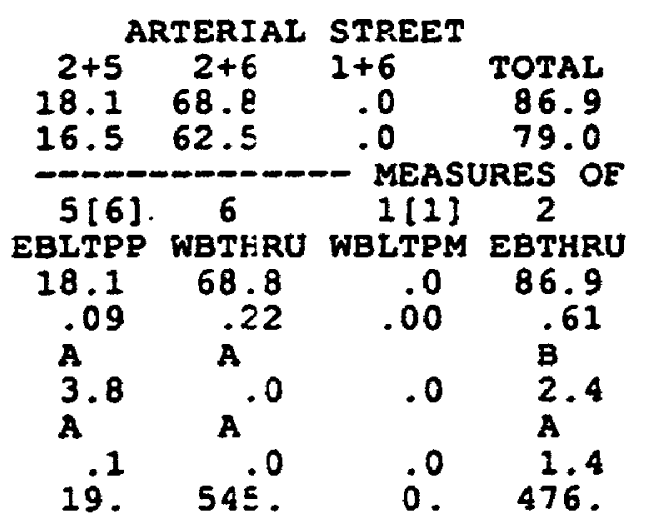

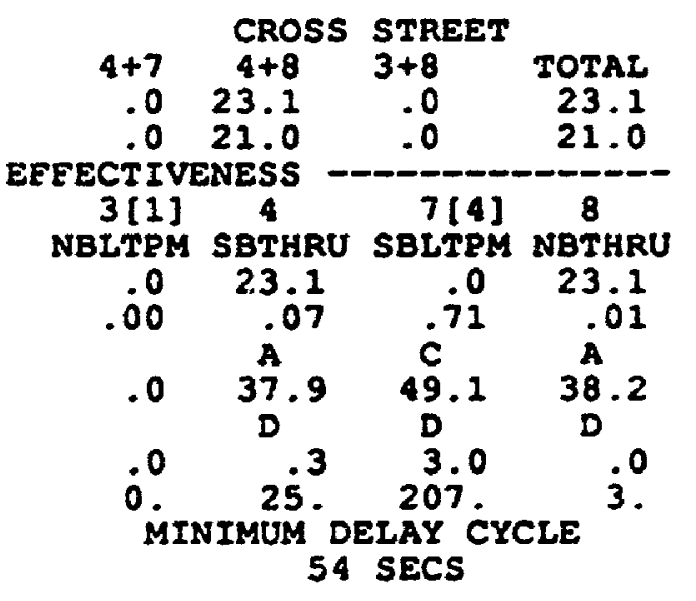


under a number of constraints. The basic components of a linear programming problem are the objective function (what we want to optimize), and the constraints. It has been observed that most drivers regard travel time as the most important factor and perceive cost as secondary, because out of pocket differences between alternative routes is apparently not realised [Pretty, 1984]. Therefore travel time is the single most important measure of effectiveness. But the total travel time in a system, in vehicle-hours or minutes, could be minimised either by decreasing the number of vehicles on the facility or decreasing individual travel time. Traffic volume in a system therefore directly affects freeway travel time. For a fixes input facility, maximising the total traffic input, is equivalent to minimising the travel time. This is proved mathematically as follows:

Figure 5.6a illustrates traffic volume in a system plotted against time period $t_{1}$ to $t_{2}$, whilst Figure 5.6b illustrates traffic on a freeway section. From Figures $5 a \& b$, the following expressions are derived:

$$
\begin{gathered}
T=V t \\
T=\int_{t 1}^{t 2} V t d t \\
\text { But } V_{t}=V_{0}+I t-O t \\
T=\int_{t 1}^{t 2}\left[V_{0}+I t-O t\right] d t
\end{gathered}
$$




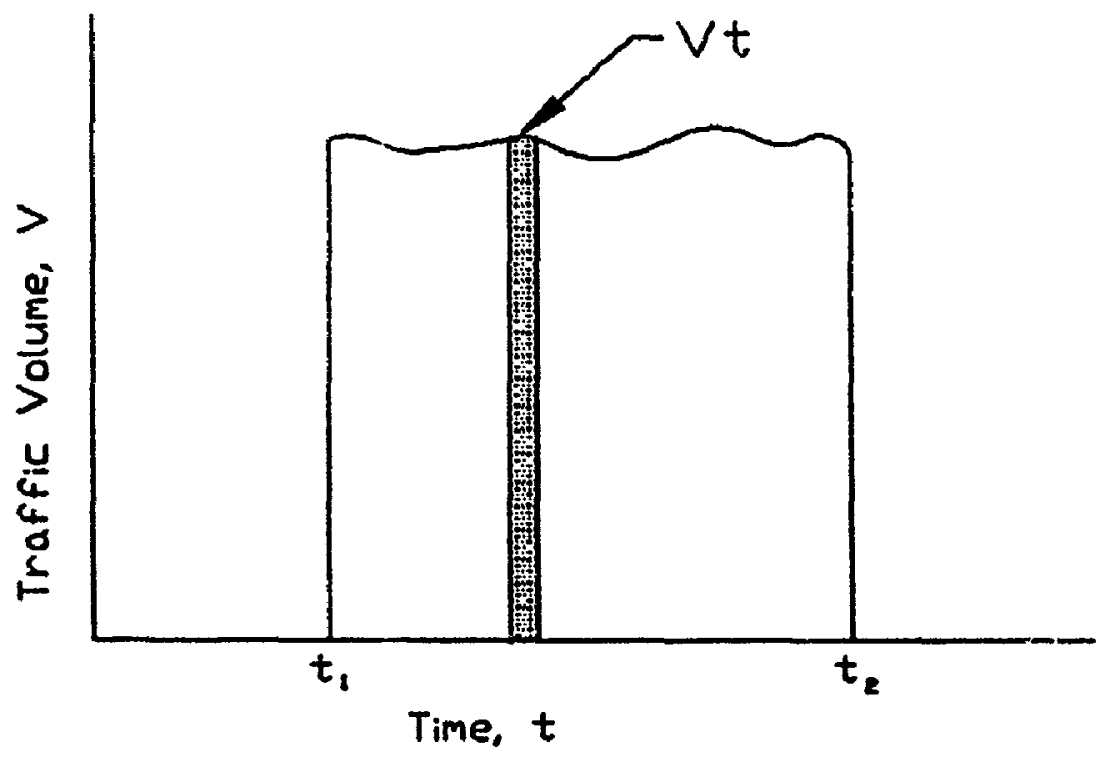

Figure 5.6a Traffic Volume versus Travel Time

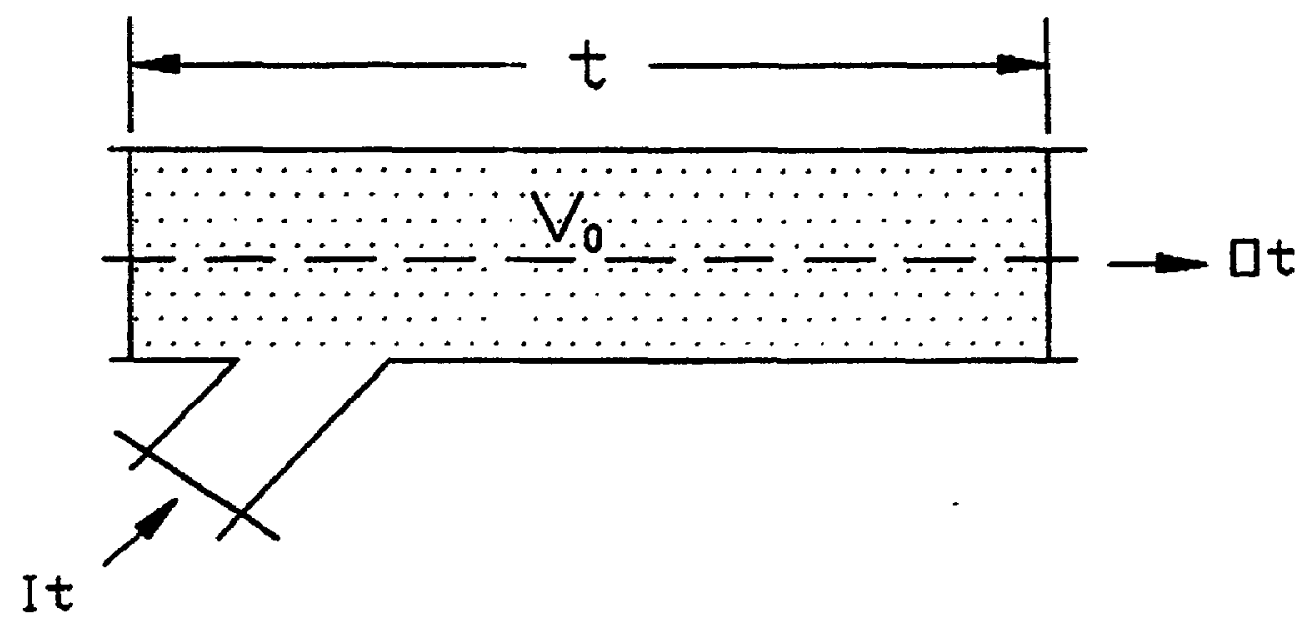

Figure 5.6b Input \& Output Traffic. 


$$
\begin{gathered}
T=V_{0}\left(t_{2}-t_{2}\right)+\int_{t_{1}}^{t_{2}} I t d t-\int_{t_{1}}^{t_{2}} O t d t \\
\text { Putting } k_{1} \text { for } V_{0}\left(t_{2}-t_{1}\right) ; k_{2} \text { for } \int_{t_{1}}^{t_{2}} I t d t ; \\
\text { Total Travel Time }=k_{1}+k_{2}-\int_{t_{1}}^{t_{2}} O t d t
\end{gathered}
$$

Where

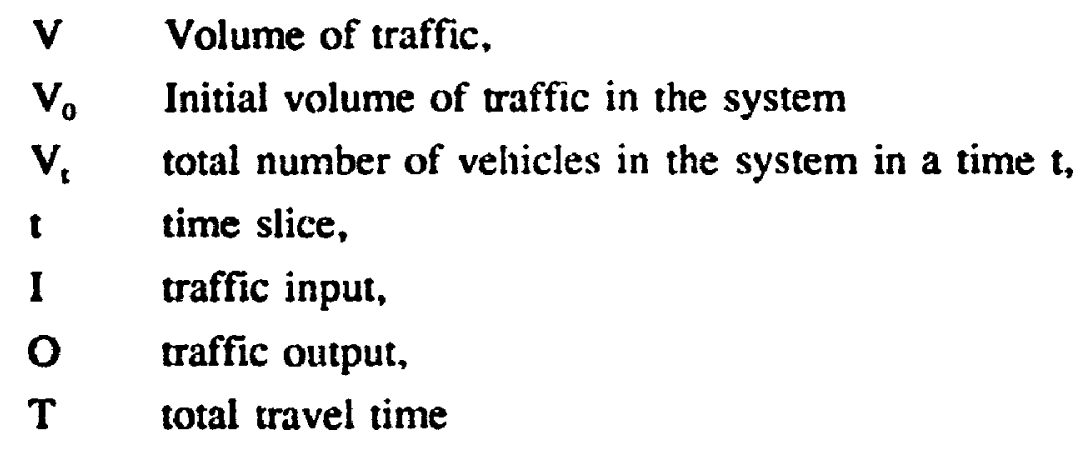

Therefore at peak periods. given that only recurring congestion is present and traffic input is fixed, minimising the total travel time is equivalent to maximising traffic in the system. For this study, the objective function will be taken to maximize the total traffic input into the system. The main constraint is to maintain the traffic flow on all sections of the freewa; below its capacity.

The concept of freeway ramp metering using mathematical programming is not new. It 'vas first used by Wattleworth on the Congress Street Expressway in Chicago [Wattleworth, 1967]. Subsequent studies were done by Brewer et al, Ovaici et al, May etc [Brewer et. al., 1969; Ovaici et. al., 1975; May, 1974] utilising various objective $\cdots$ functions such as "maximize traffic" on the freeway, "minimise total travel time", 
"maximize the number of persons sened", "minimise person-hrs", etc. Linear programming methodology as used in this research is similar to the one used by Wattleworth but the difference is that ramp queue lengths are replaced by the condition that all surface streets in the corridor should not operate beyond an established threshold average stopped delays. Two initial metering strategies have been developed for this research study; "Priority" and "Non Priority" strategies. Non priority for mulation is similar to the methodology developed by Wattleworth. For the priority strategy, it is based on providing exclusive lanes for Higher Occupancy Vehicles (HOV).

\subsubsection{Origin Destination Information}

The pattern of network and freeway traffic is highly dependent on O.D. information and influences:

- the propensity of a motorist to choose a particular route in response to his/her perceived value of travel time, cost, inconvenience, comfort, and safety, when there are competing routes, and

- the effects of an on ramp control.

True corridor control strategies may be unsuccessful unless there is a complete understanding of underlying O.D. patterns.

\subsubsection{Ramp Metering Optimisation (See Figure 5.7a).}

$$
\text { Maximise } x_{j}
$$




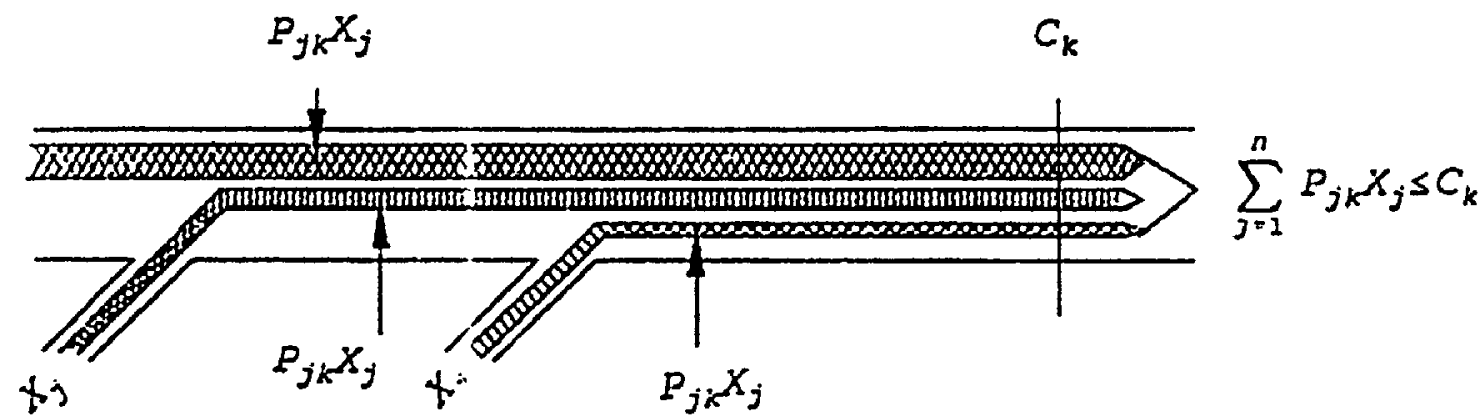

Figure 5.7a Non Priority Metering

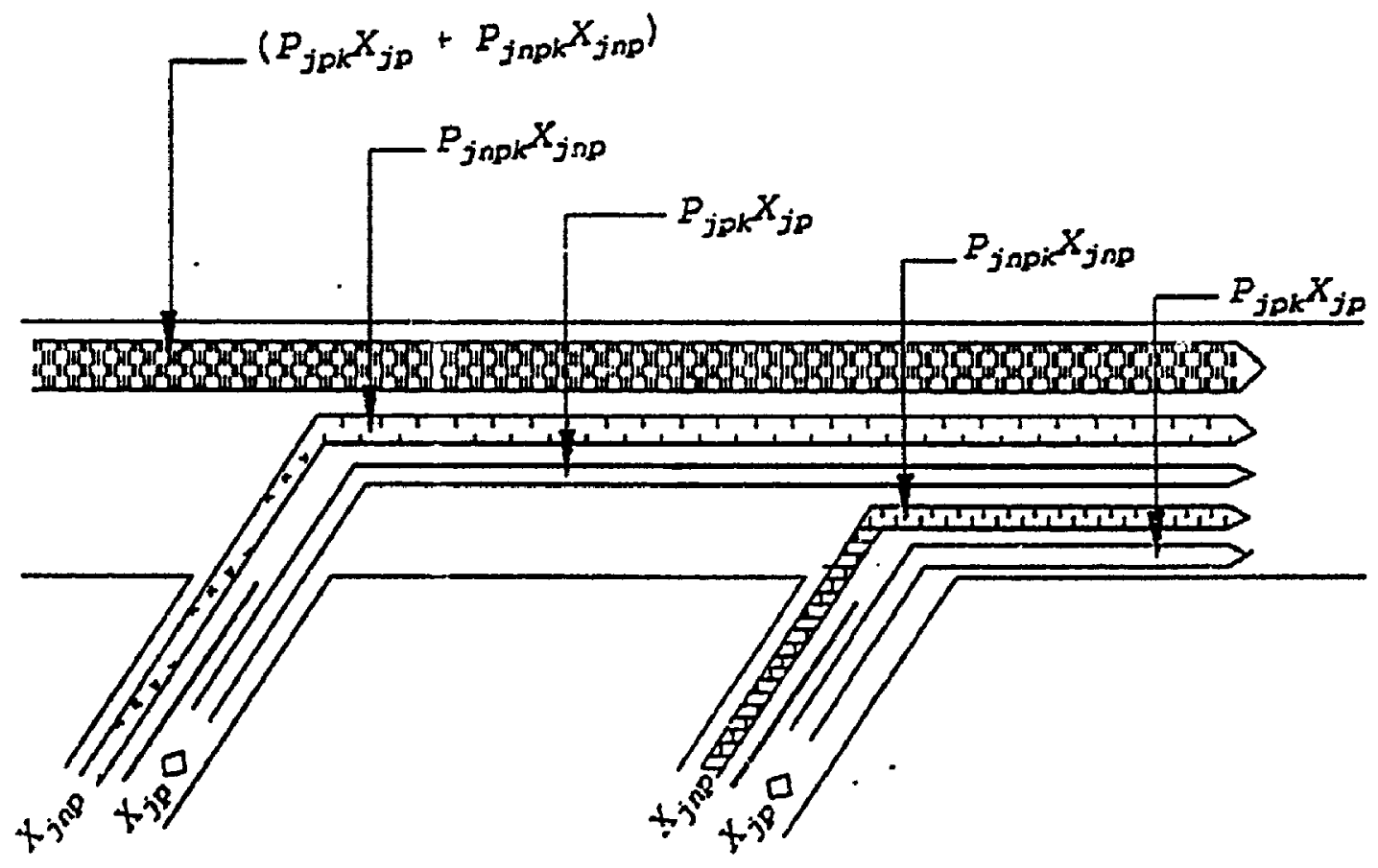

Figure 5.7b Priority Metering. 
Subject to

$$
\begin{gathered}
\sum_{j=1}^{n} P_{j k} X_{j} \leq C_{k} \quad k=1 \ldots m \\
X_{j} \leq D_{j} \quad j=1 \ldots n \\
X_{j} \geq 0 \\
M_{j \max } \geq X_{j} \geq M_{j \min } \\
X_{j} \leq R_{j}
\end{gathered}
$$

Where

$$
\begin{array}{lll}
P_{j k} & = & \text { Fraction of vehicles entering input } j \text { and going } \\
& & \text { through } k \\
X_{j} & = & \text { Traftic volume at Input } j \\
C_{k} & = & \text { Capacity at section } k \\
D_{j} & =\text { Traffic demand at } j \\
R_{j} & \text { Ramp capacity at } j \\
M_{j \min } \& M_{j \max } & =\text { Minimum and maximum metering rates at } \mathbf{j}
\end{array}
$$

Equation 5-17 states the objective function, in this case, to maximize traffic input on all ramps. Equation 5-18 is a capacity constraint, which ensures that the total freeway traffic at critical sections does not exceed its threshold capacity. Equation 5-19 ensures that entrance ramp volumes are not greater than its ramp demand. Equation 5-20 ensures that 
ramp and mainline traffic input cannot be negative. Equation 5-21 are constraints for maximum and minimum metering rates, and the purpose of equation $5-22$ is to maintain input volumes below ramp capacity.

\subsubsection{Priority Ramp Optimization.}

In priority ${ }^{3}$ ramp optimization, some form of priority is given to classes of vehicles such as ca: pools, van pools, and buses. Priority optimization cc $\mathrm{d}$ be done by maximizing person throughput or person kilometres. The methodology developed here is to give priority to HOV through providing exclusive lanes on entrance ramps, to guarantee that priority vehicles experience no delays on ramps. The next section develops an optimized metering methodology, by taking priority vehicles into consideration.

\subsubsection{Priority Metering With Exclusive Lanes (See Figure 5.7b)}

$$
\text { Maximise } \sum_{j=1}^{n}\left(x_{j p}+x_{y n p}\right)
$$

Subject to

3riority optimization, as used here, relers to providing ramp by-pass lanes for transit and other Higher Occupancy Vchicle lanes 


$$
\begin{gathered}
\sum_{j=2}^{n}\left(P_{j p k} X_{j p}+P_{j n p k} X_{j n p}\right) \leq C_{k} \\
\text { FOr } k=1 \ldots m \\
x_{j p}=D_{j p} \\
M_{j \max } \geq x_{j n p} \geq M_{j m i n} \\
x_{j} \leq R_{j} \\
x_{j n p} \leq D_{j n p}
\end{gathered}
$$

Where

$X_{\text {jnp }} \quad$ Total number of non priority vehicles entering ramp $j$

$X_{j p} \quad$ Total number of priority vehicles entering ramp $j$

$P_{\text {jnpk }}$ Fraction of non priority vehicles entering input $j$ and going past section $k$

$P_{\mathrm{jpk}} \quad$ Fraction of priority vehicles entering input $\mathrm{j}$ and going past section $\mathrm{k}$

$D_{j p} \quad$ Demand of priority vehicles at input $j$

$\mathbf{M}_{\mathrm{jmin}} \mathbf{M}_{\mathrm{jmin}}$ and $\mathbf{R}_{\mathrm{j}}$ are all defined earlier

By equating priority vehicle input to its demand, all priority vehicles are allowed to enter the freeway without ramp control. To ensure that no multi occupant vehicle which qualifies as a priority vehicle is delayed, ramp bypass lanes are entered into the linear programming model as pseudo ramps.

Equation 5-23 is the objective function: to maximize both priority and non priority vehicles on all ramps. A capacity constraint, to prevent the sum of the total freeway 
vehicles from exceeding a specified capacity is enforced by Equation 5-24. Equation 5-25 ensures that all priority vehicles are allowed to enter the mainline (through ramp bypass lanes). Equation 5-26 has been explained earlier.

\subsection{Application of Ramp Optimization to the Queensway.}

In the preceding chapters the methodology was covered for estimating ramp and mainline volumes on both EB \& WB sections of the freeway. At this stage, we will apply the concept of ramp optimisation to the Queensway. A non priority type of strategy is intended here.

The O.D. ${ }^{4}$ information was taken from a forecast based on MTO license plate surveys [IBI Group, 1987] and were converted into percentages as shown in table 5.1. Table 5.2 indicates volumes crossing various sections, (i.e. \% volumes going through a particular section).

Where two or more entry ramps were present at an interchange, it was necessary to determine the O.D. paths of each ramp. For this work, it was assumed that the number of vehicles from ramp $i$ to $j$ was directly proportional to the aggregate traffic from interchange I to destination $\mathrm{J}$.

- In this thesis, Origin-Destination (O.D.) implies the on-ramp location (origin) and off ramp location (destination) 
Table 5-1a O.D. Surveys for am Peak, Converted into Percentages

\begin{tabular}{||l|c|c|c|c|c||}
\hline \multicolumn{1}{|c|}{ Origin } & Pinecrest & Woodrofle & Maitland & Carling & $\begin{array}{l}\text { Beyond } \\
\text { Carling }\end{array}$ \\
\hline Mainline & 6.22 & 7.41 & 8.4 & 6.87 & 71.1 \\
\hline Pinecrest & & 8.6 & 6.4 & 7.7 & 77.3 \\
\hline Woodroffe & & & 7.1 & 8.4 & 84.5 \\
\hline Maitland & & & & 9.3 & 90.7 \\
\hline
\end{tabular}

Source: 181 Group, 1987

Table 5-1b Percentage vehicles going past various ramps (am peak period).

\begin{tabular}{|l|c|c|c|c||}
\hline & \multicolumn{4}{|c|}{ \% Vehicles going past } \\
\hline \multicolumn{1}{|c|}{ Origin } & Pinecrest & Woodroffe & Maitland & Carling \\
\hline Mainline & 93.8 & 86.37 & 77.97 & 71.1 \\
\hline Pinecrest & & 91.4 & 85.0 & 77.3 \\
\hline Woodroffe & & & 92.9 & 84.5 \\
\hline Maitland & & & & 90.7 \\
\hline
\end{tabular}

The next stage of the process was to identify sections with potential bottlenecks. The critical sections of the bottlenecks are $\mathrm{C}_{1} \& \mathrm{C}_{2}$. Our main constraints were to restrict traffic flow rate at the potential bottenecks from exceeding a level of service $D$. The problern was formulated in the following manner:

$$
\text { Maximise } x_{1}, x_{2}, x_{3}, x_{6}, x_{5}, x_{6}, x_{7}, x_{8} \quad(5-29)
$$

Subject to 


$$
\begin{aligned}
& 0.711 x_{1}+0.773 x_{2}+0.773 x_{3}+0.845 x_{4}+0.845 x_{5}+0.907 x_{6} \\
& +x_{7}+x_{8} \leq 6524 \\
& 0.863 X_{1}+0.914 X_{2}-0.914 X_{3}+X_{4}+X_{5} \leq 6524 \\
& 0.780 x_{1}+0.85 x_{2}+0.85 x_{3}+0.929 x_{4}+0.929 x_{5}+x_{6} \leq 5262 \\
& X_{1}=4868 \\
& 345>=X_{2}>=190 \\
& 800>=X_{3}>=190 \\
& 220>=X_{4}>=190 \\
& 800>=X_{5}>=190 \\
& 692>=X_{6}>=190 \\
& 800>=X,>=190 \\
& 244>=X_{8}>=190
\end{aligned}
$$

$X_{1}, X_{2} \ldots X_{8}$ are traffic inputs into the mainline as illustrated in Figure 5.8. The coefficients of $X_{1}, X_{2}, \ldots X_{8}$ in equation 5-30 are percentage traffic entering these inputs which proceed past $c_{1}, c_{2}$ or $c_{3}$. The minimum and maximum metering rates were taken as 190 vph \& $800^{5}$ vph (see Chapter 2). 345, 220, 692 and 244 are existing on ramp volumes (Figure 5.9a). The assumption here is that diverted vehicles will use Carling Ave

3 In this study $800 \mathrm{vph}$ is used instead of $9(0) \mathrm{vph}$ because experience indicates that it is not possible to achieve the latter 


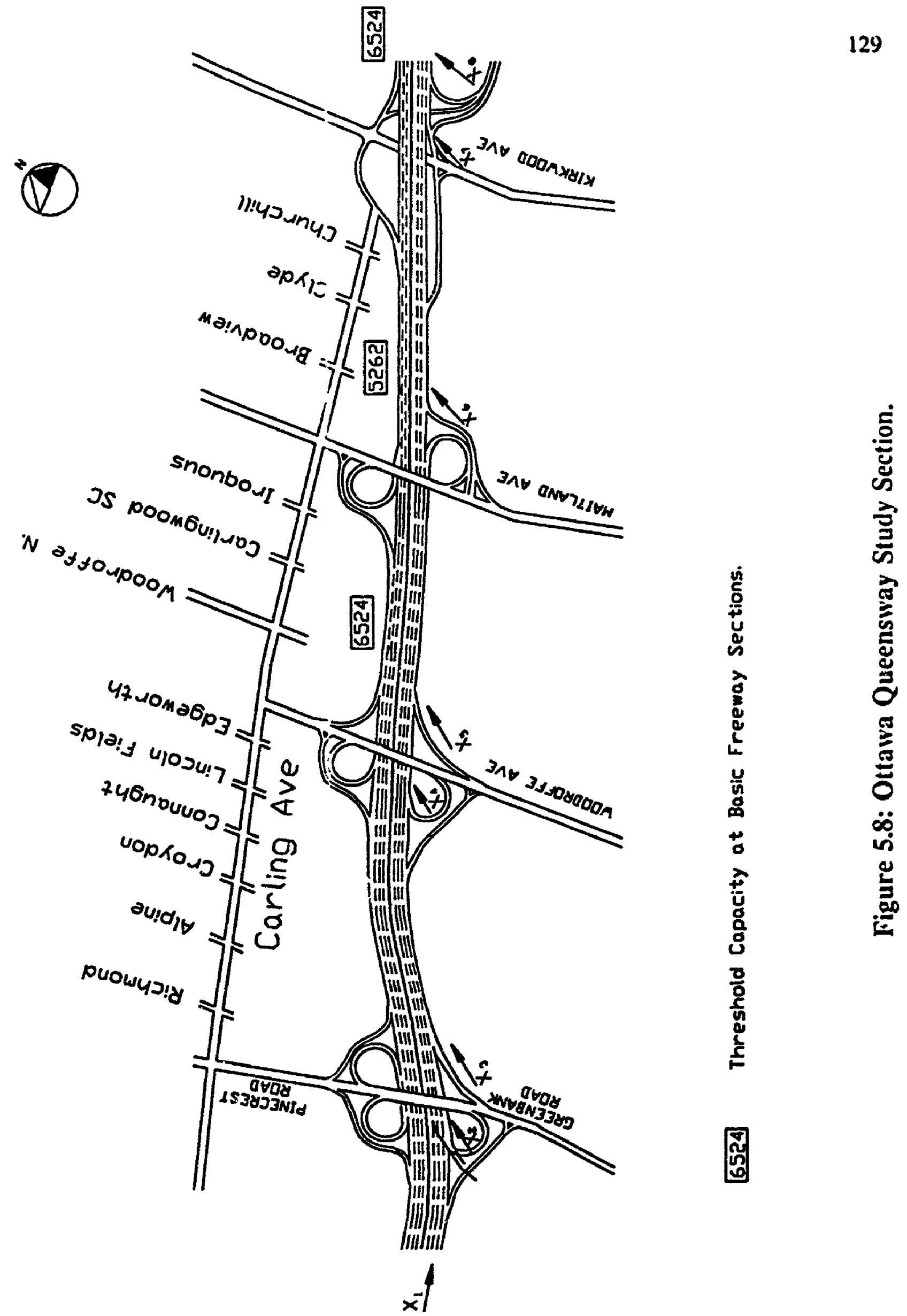


and will not enter any downstream ramps, hence existing ramp traffic is taken as maximum metering rates. The next step is to convert all the inequalities into equations by adding a slack variable. These equations were solved using a simplex method. The initial simplex tableau is shown in Table 5-2. The simplex method uses the Gauss Jordan Complete elimination procedure to solve a group of linear equations where the number of variables in a group of equations are more than the number of equations in the same group. It (simplex) is a systematic method for obtaining an optimal solution for a linear program. The last row represents the objective function, whereas the fifth row, through to the last but one row are the constraints. The solution is found by performing a number of iterations, such that none of the figures in the last row is negative [Gliksman, 1963]. The optimal solution was obtained by a computer program known as Linear Programming LP88 available at Carleton University.

Fig 5.9a shows existing ramp volumes and Figure $5.9 \mathrm{~b}$ are the optimised metering rates obtained from linear programming.

The metering plan was entered into FREFLO simulation model to evaluate the effect of ramp metering on the freeway. Corresponding traffic due to metering, on Carling Avenue was also simulated on Carling Avenue using Traf Netsim micro simulation model.

\subsubsection{FREFLO First Run:}

Figure 5.10 shows freeway network configuration for FREFLO input data. Data entry involved:

- Setting up run control parameters such as initialisation time, duration of 


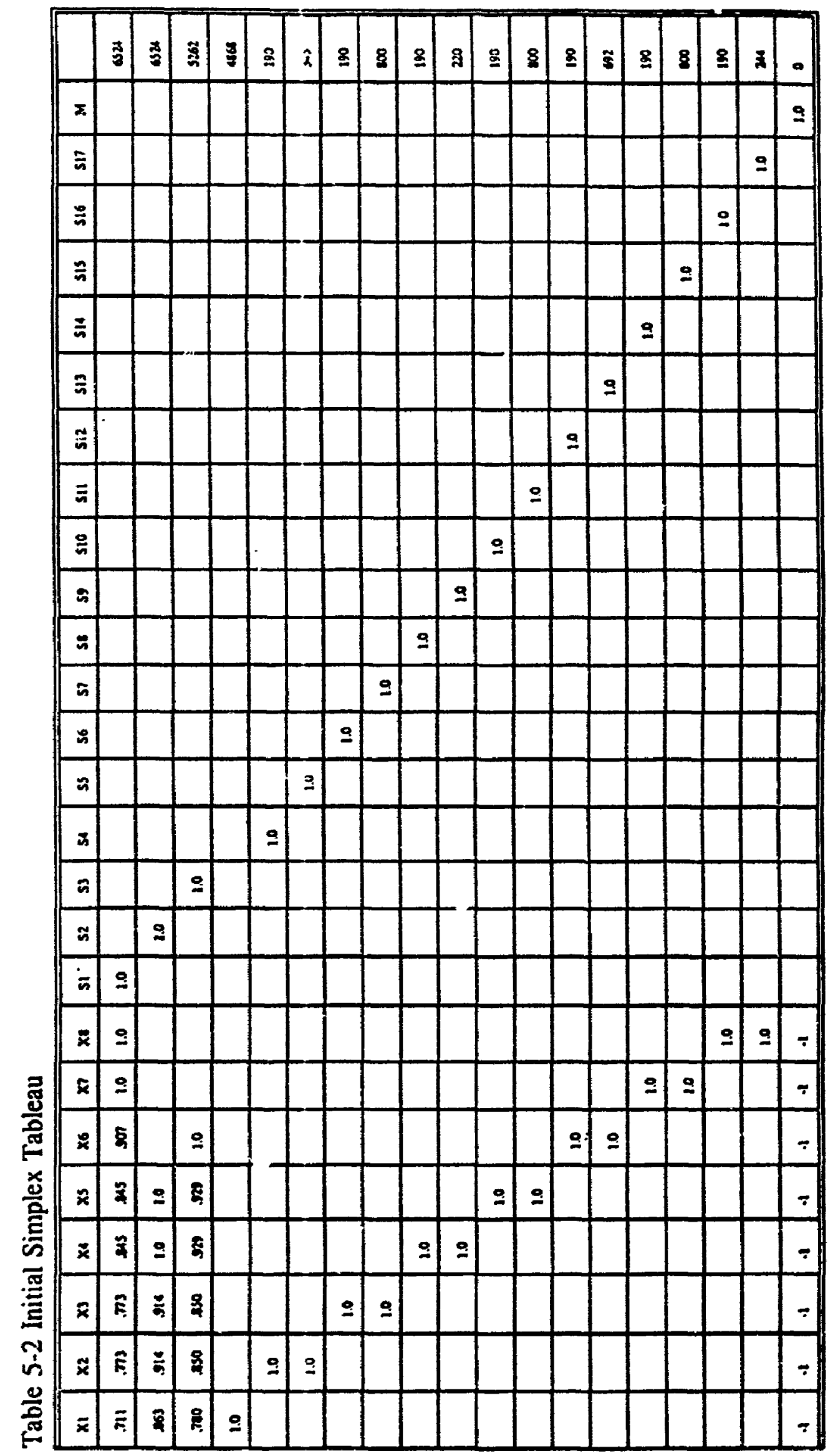




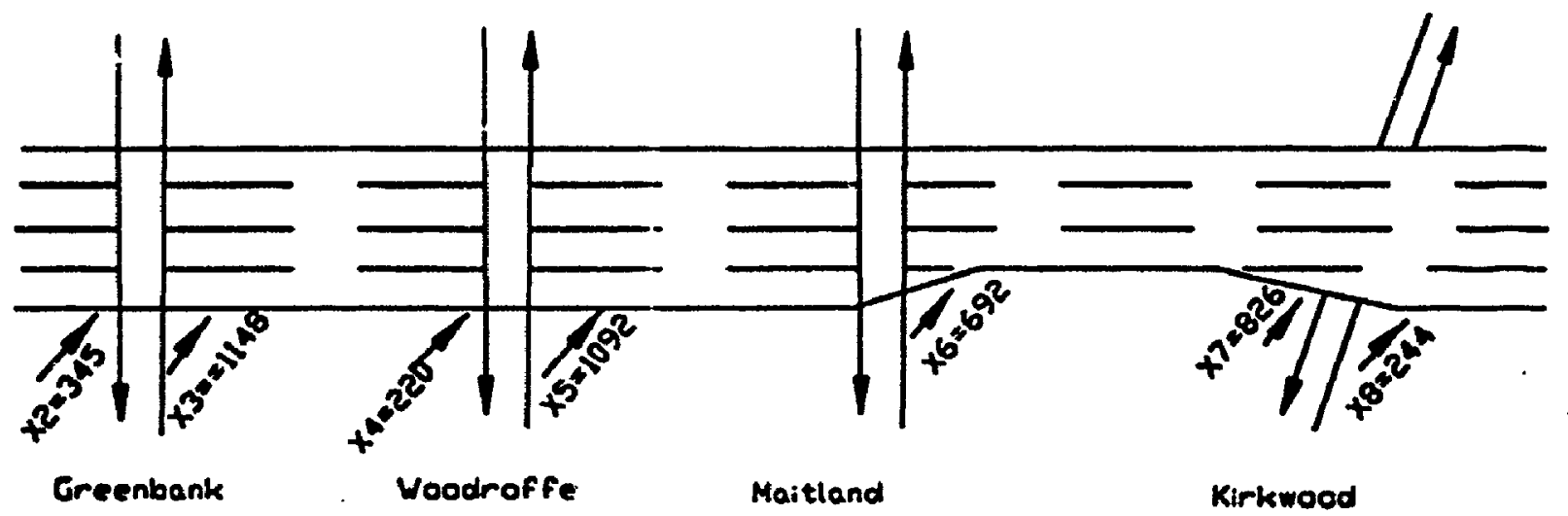

Figure 5.9a Existing Traffic

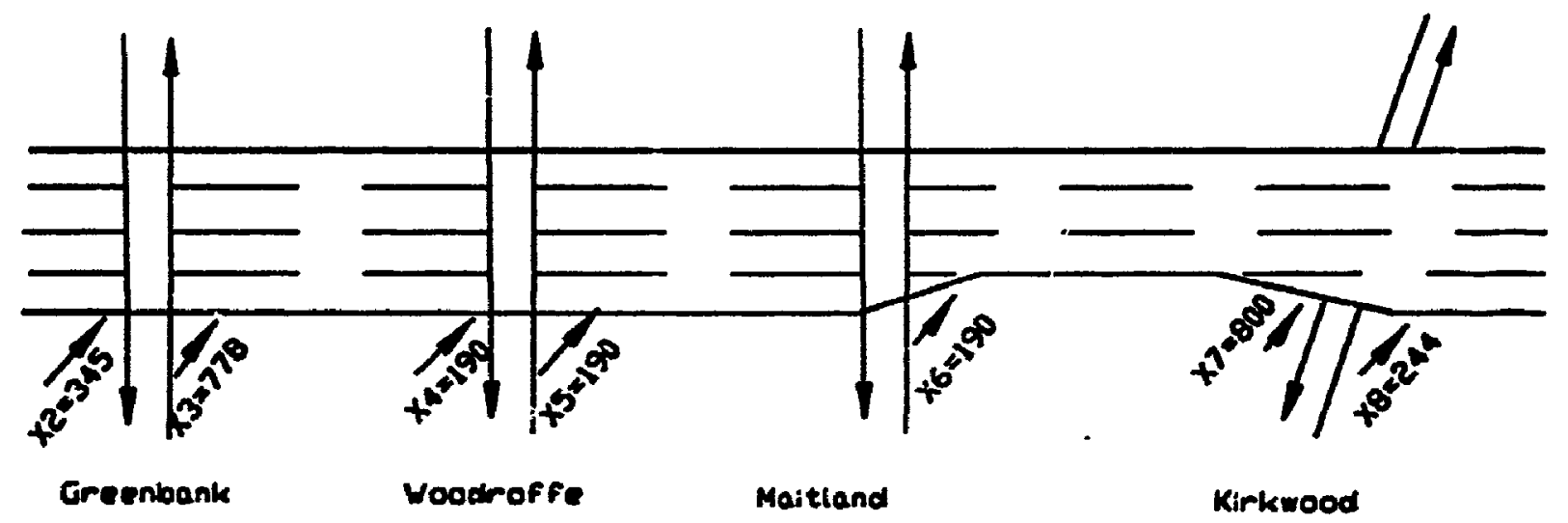

Figure 5.9b Optimised Metering Rates 
simulation, time period, specifying input data in metric etc.

- Defining link distances, number of lanes, entrance and exit ramps, percentage exits, lane capacities, etc

- Entry link volume input for nodes $8400,8402,8403,8405,8406,8408$, 8410 and 8411 were all entered.

- A capacity of 1890 vphpl was used, based on capacity analysis performed in Chapter 4

- At exit ramps movement percentages were estimated as the ratio of exit volumes to the mainline volume just upstream of its node multiplied by 100;

- Traffic was simulated for the morning peak $15 \mathrm{~min}$ flow rate at time intervals of 60 seconds.

- Initialization time of 10 minutes was used.

Subsequent simulation runs were executed for Highway 417 and Carling Ave in the following manner:

a Metering rates for each interchange began with the "optimised rates"s determined from linear programming,

- Corresponding ramp diversion was estimated by deducting metering rates from the total ramp demand,

5 "Cprimised Metering Rates" in this thesis refers to metering rates determined by the Linear Programming Technique. 


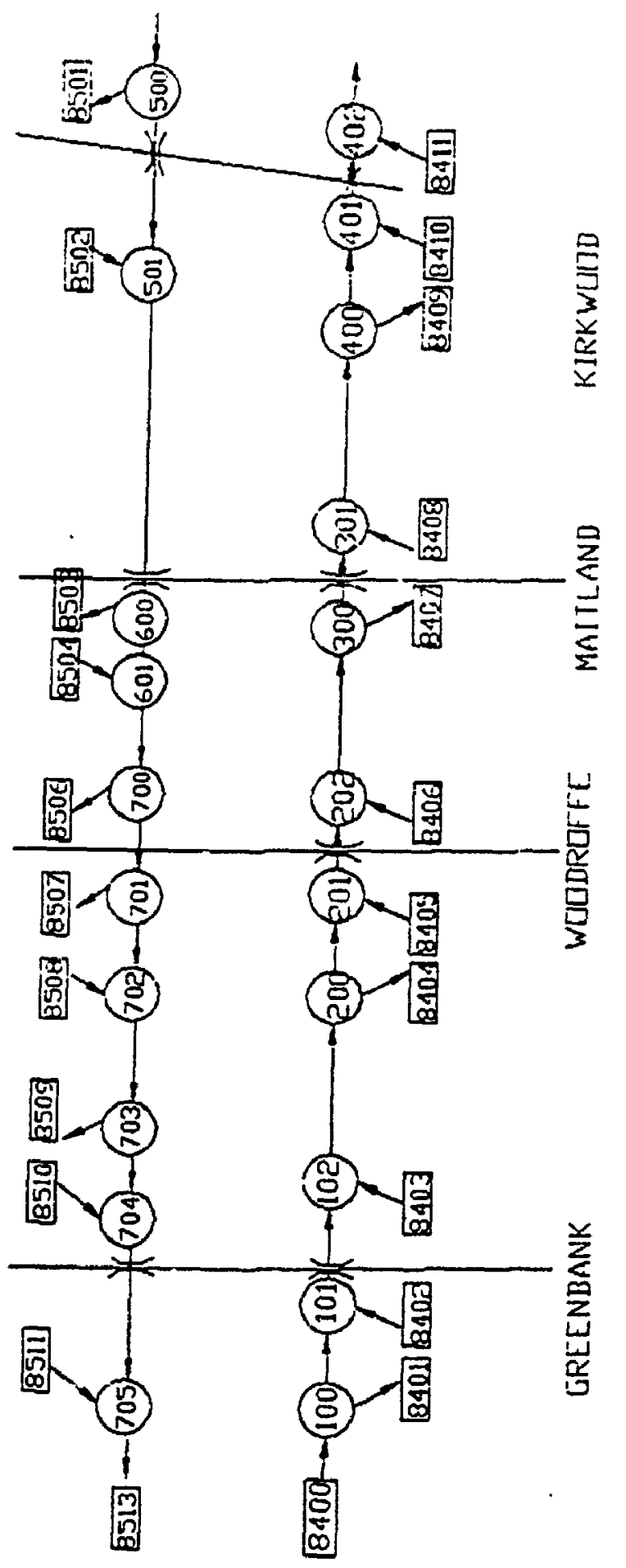

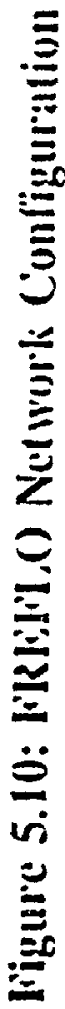


- If the optimised metering rates did not satisfy threshold level of service for each intersection approach, ramp metering rates were increased by $30 \mathrm{vph}$ for each interchange and alternate route network traffic adjusted accordingly. The procedure was repeated a number of times until all intersection approach threshold LOS were satisfied,

- For each volume change on Carling Avenue, traffic signals were optimised with PASSER II-87 as discussed before. Figure 5.8 is a flow chart illustrating revised signal plan methodology,

- For the purposes of this experiment, metering rates were increased until maximum allowable metering rates were achieved,

- Movement percentages for each node and for each NETSIM run were adjusted to maintain constant left and right turns, using a computer spreadsheet package known as QUATTRO PRO (except for nodes 40-2, 41-8 \& 43-12 where right turn traific was adjusted to reflect traffic on NB Richmond, NB Woodroffe, \& NB Maitland). 

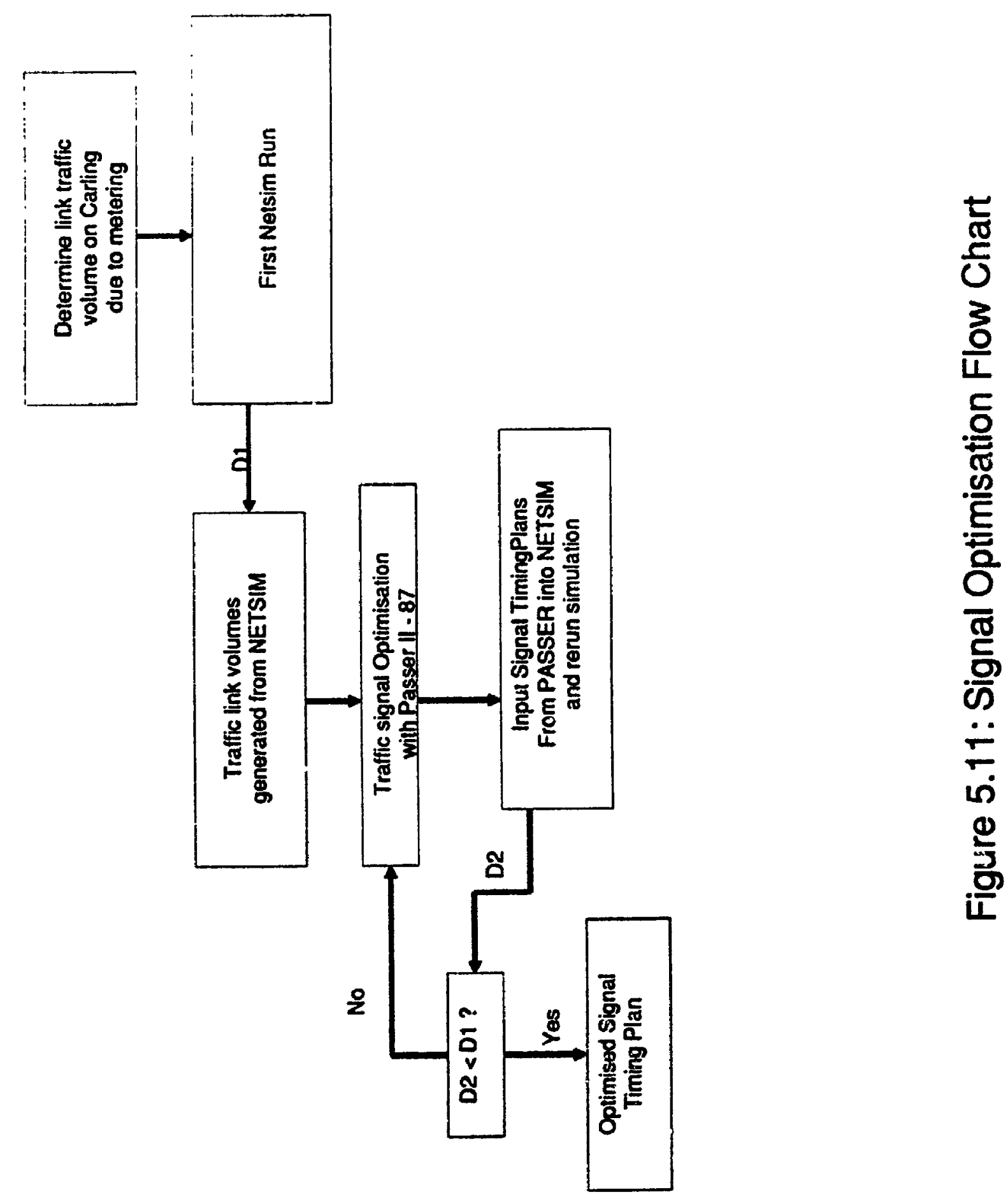
Table 5-3 shows metering strategies for each simulation run.

In the next chapter, simulation results and the experiment will be discussed.

Table 5-3: Freeway Simulation Runs

\begin{tabular}{|c|c|c|c|c|c|c|c|}
\hline \multirow{2}{*}{$\begin{array}{l}\text { Simulation } \\
\text { Run }\end{array}$} & \multicolumn{7}{|c|}{ Ramp Metering Rates } \\
\hline & $\begin{array}{l}8402- \\
101^{6}\end{array}$ & $8403-102$ & $8405-201$ & $8406-202$ & $8408-301$ & $8410-401$ & $\begin{array}{l}8411- \\
402\end{array}$ \\
\hline FwyOa? & 345 & 1148 & 220 & 1092 & 692 & 826 & 244 \\
\hline Fwyla & 345 & 778 & 190 & 190 & 190 & 800 & 244 \\
\hline Fwyza & 345 & 808 & 195 & 215 & 220 & 800 & 244 \\
\hline Fwy3a & 345 & 838 & 200 & 240 & 250 & 800 & 244 \\
\hline Fwy $4 a$ & 345 & 868 & 205 & 265 & 280 & 800 & 244 \\
\hline Fwy5a & 345 & 898 & 210 & 290 & 310 & 800 & 244 \\
\hline Fwy6a & 345 & 900 & 215 & 315 & 340 & 800 & 244 \\
\hline Fwy7a & 345 & 900 & 220 & 340 & 370 & 800 & 244 \\
\hline Fwy8a & 345 & 900 & 220 & 370 & 400 & 800 & 244 \\
\hline Fwy9a & 345 & 900 & 220 & 400 & 430 & 800 & 244 \\
\hline Fwyloa & 345 & 900 & 220 & 430 & 460 & 800 & 244 \\
\hline Fwylla & 345 & 900 & 220 & 460 & 490 & 800 & 244 \\
\hline Fwy12a & 345 & 900 & 220 & 490 & 520 & 800 & 244 \\
\hline Fwy13a & 345 & 900 & 220 & 520 & 550 & 800 & 244 \\
\hline Fwy $14 a$ & 345 & 900 & 220 & 550 & 580 & 800 & 244 \\
\hline Fwy15a & 345 & 900 & 220 & 580 & 610 & 800 & 244 \\
\hline Fwy16a & 345 & 900 & 220 & 610 & 640 & 800 & 244 \\
\hline fwy $17 a$ & 345 & 900 & 220 & 640 & 670 & 800 & 244 \\
\hline fwy $18 a$ & 345 & 900 & 220 & 670 & 692 & 800 & 244 \\
\hline fwy $19 a$ & 345 & 900 & 220 & 700 & 692 & 800 & 244 \\
\hline fwy $20 a$ & 345 & 900 & 220 & 730 & 692 & 800 & 244 \\
\hline fwy $21 a^{9}$ & 345 & 900 & 220 & 760 & 692 & 800 & 244 \\
\hline fwy $22 a$ & 345 & 900 & 220 & 790 & 692 & 800 & 244 \\
\hline fwy $23 a$ & 345 & 900 & 220 & 810 & 692 & 800 & 244 \\
\hline Fwy24a & 345 & 900 & 220 & 840 & 692 & 800 & 244 \\
\hline Fwy25a & 345 & 900 & 220 & 870 & 692 & 800 & 244 \\
\hline Fwy26a & 345 & 900 & 220 & 900 & 692 & 800 & 244 \\
\hline
\end{tabular}

- On Ramp Entry Links. See FREFLO link Configuration

7 Existing Traffic on Entrance Ramps

- Optimised Metering Rates Based On Linear Programming.

- "Best metering rates" 


\section{CHAPTER 6}

\section{SIMULATION RESULTS}

\subsection{Arterial Measures Of Effectiveness}

Selected MOEs used for analysis can be found in appendix B. Link travel time, average stopped Lelays, and total travel on all links were some of the outputs generated directly from NETSIM. Cumulative travel time of the sub-network, for each direction was obtained by link aggregation.

$C_{\mathrm{wu}}=\mathrm{Fwy}_{\mathrm{tu}}+\mathrm{Art}_{\mathrm{tu}}+\mathrm{R}_{\mathrm{w}}$

Where

$$
\begin{array}{lll}
\mathbf{C}_{\mathrm{tu}} & = & \text { Corridor total travel time (veh-mins) } \\
\text { Fwy }_{\mathrm{tu}} & = & \text { Total freeway travel time (veh-mins) } \\
\text { Art }_{\mathrm{tu}} & = & \text { Total arterial travel time (veh-mins) } \\
\mathbf{R}_{w} & = & \text { Ramp waiting time (veh-mins) }
\end{array}
$$

The term $R_{w}$ is added to adjust for vehicles queued on an entrance ramp as a result of 
metering. From a scaled 1:5000 drawing from IBI Group (1987) drawings, Pinecrest. Woodroffe, Maitland and Kirkwood Ramps were taken to be $225 \mathrm{~m}$ or more in length. Using an acceleration lane length of $100 \mathrm{~m}$, and an averay $=$ vehicle spacing of $6.10 \mathrm{~m}$. a maximum ramp queue of 20 vehicles per ramp was obtained. The total ramp waiting time was obtained by the following expression:

$$
R_{w}=V_{\boldsymbol{q}} \times D_{s}
$$

Where

$$
\begin{array}{ll}
V_{q} & \text { Number of queued vehicles } \\
D_{\mathbf{s}} & \text { Duration of simulation. }
\end{array}
$$

For convenience, graphs for Figures 6.1 through 6.9 included average metering rates of $430 \mathrm{vph}$ ("optimised metering rates"), $550 \mathrm{vph}, 646 \mathrm{vph}, 702 \mathrm{vph}$, and the existing traffic.

\subsubsection{Eastbound Carling Avenue}

Travel time on Carling Avenue increased from pre-metering condition of 12.8 minutes to 15.7 mins for "optimised metering rates", a 23\% increase (Figure 6.1).

At "optimised metering" rates, Richmond, Clyde, \& Kirkwood eastbound intersection approach delays, increased significantly, when compared to existing conditions. Eastbound Richmond, for instance increased from $31 \mathrm{sec} / \mathrm{veh}$ to $56.9 \mathrm{sec} / \mathrm{veh}$, whilst Clyde and Kirkwood increased from $10 \mathrm{sec} / \mathrm{veh}$ to $57.8 \mathrm{sec} / \mathrm{veh}$; and 25 to $42.6 \mathrm{sec} / \mathrm{veh}$ respectively (Figure 6.2). Apart from Clyde and Fairlawn intersections, where there was a pronounced change in link travel speed, all others did not show much change in speeds between existing and optimised metering rates $(9 \mathrm{~km} / \mathrm{h}$ to $7 \mathrm{~km} / \mathrm{h}$ for Richmond, 31 to $26 \mathrm{~km} / \mathrm{h}$ 


\section{Ramp Metering \& Cumulative Travel Time Eastbound Carling Ave}

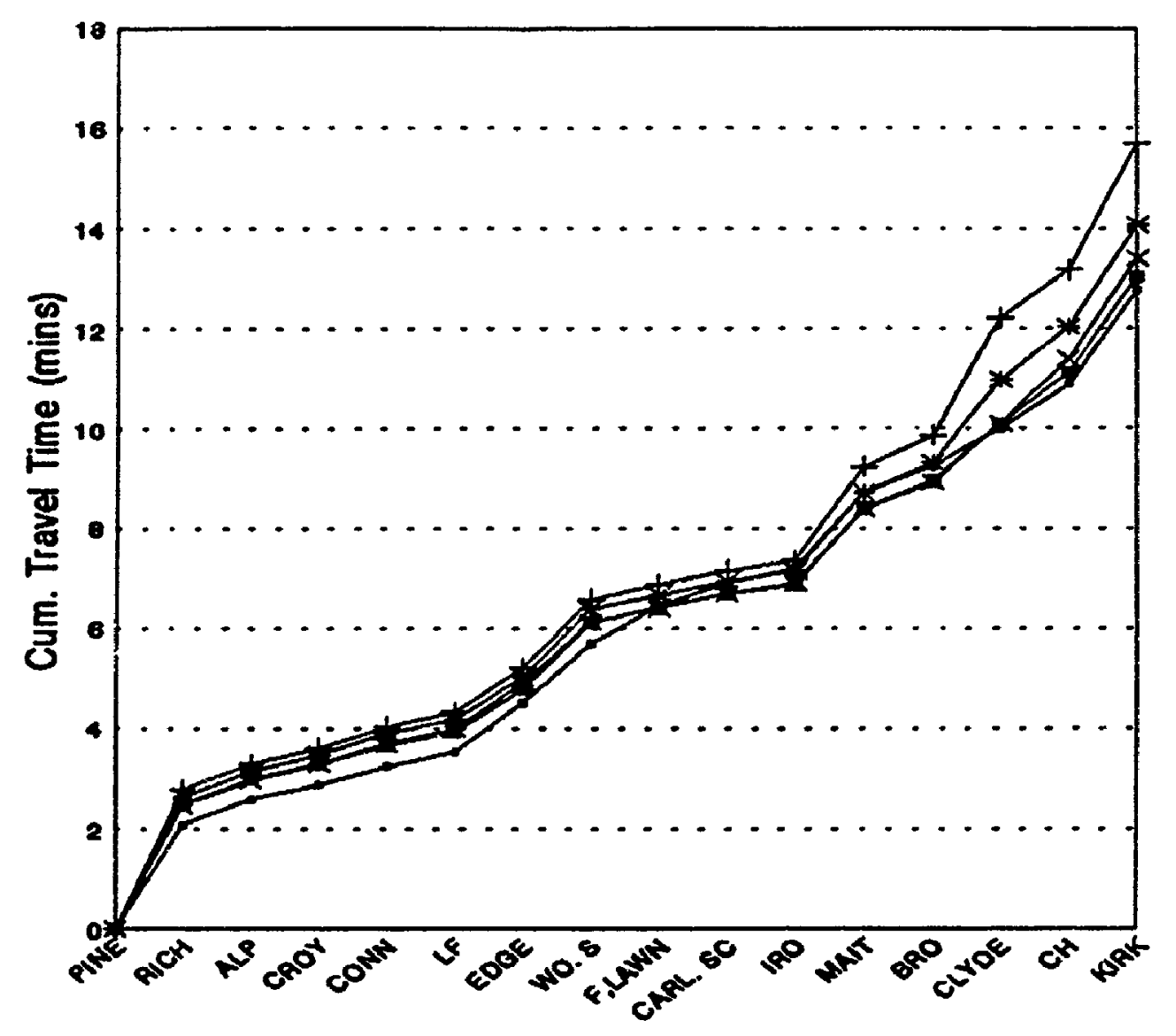

Intersections

$$
\begin{aligned}
& \text { Metering Rates } \\
& \text {-Existing }+_{430 \mathrm{vph}} *_{550 \mathrm{vph}}{ }_{646 \mathrm{vph}} *_{702 \mathrm{vph}}
\end{aligned}
$$

Figure 6.1 Cumulative Travel Time Eastbound Carling 
Ramp Metering \& Intersection stopped Dє'ay Eastbound Carling Ave

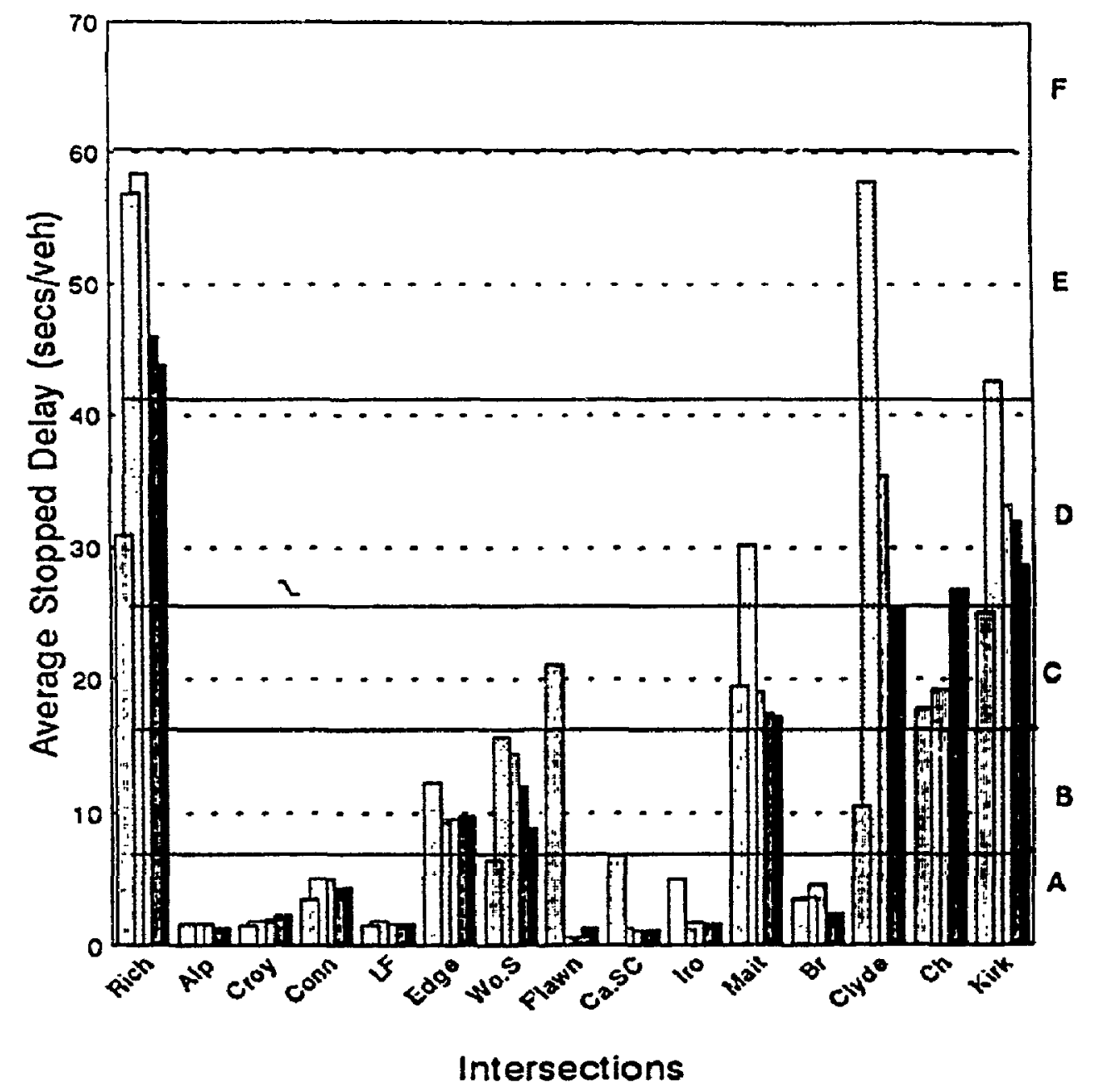

Based on 1992 RMOC intersectlon counts and existing timing plan

$$
\square_{\text {Existing }} \square_{430 v p h} \square_{550 \text { vph }} \square_{646 v p h} \square_{702 \text { vph }}
$$

Figure 6.2 Eastbound Intersection Approach Stopped Delays 


\section{Ramp Metering \& Link Travel Speed Eastbound Carling Ave}

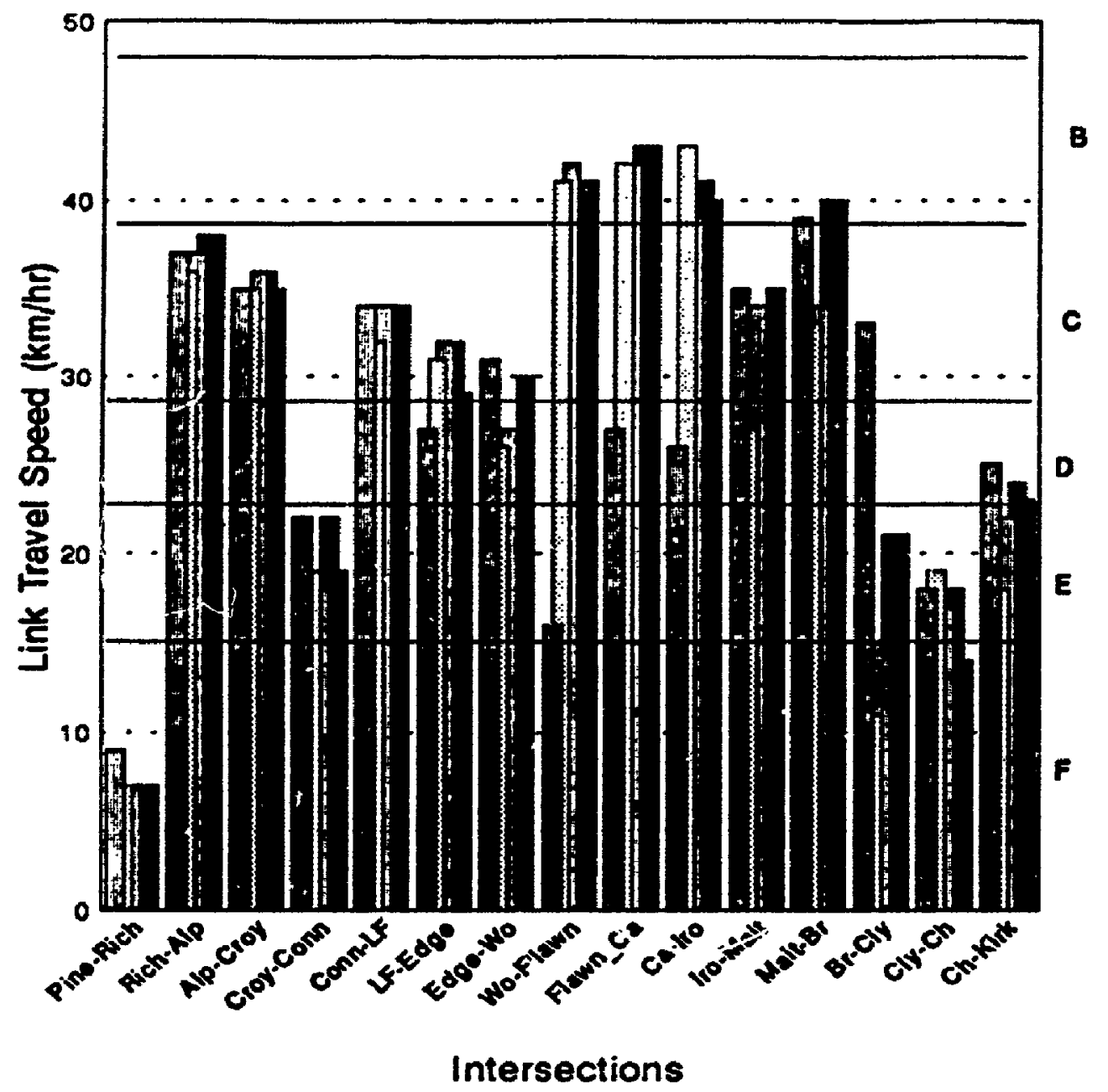

Based on 1992 RMOC Intersection counts and existing timing plan

$$
\begin{gathered}
\text { Average Metering Rates } \\
\square_{\text {Exiating }} \square_{\text {430uph }} \square_{500 \text { vph }} \square_{\text {G4 Guph }} \square_{702 \text { vph }}
\end{gathered}
$$

Figure 6.3 Eastbound Link Travel Speeds 
for Woodroffe South intersection, and $35 \mathrm{~km} / \mathrm{h}$ to $27 \mathrm{~km} / \mathrm{h}$ for Maitland Ave; (see Figure 6.3). This means that at "optimised metering rates", eastbound arterial progression was still efficient. The significant increase in eastbound stopped delays is mainly due to long delays of left turn traffic, at Richmond, Clyde and Kirkwood, caused by high left tum volumes, which interfere with their respective through traffic. As "optimised metering rates" were increased, these approach delays reduced substantially especially for Kirkwood, Clyde, Woodroffe and Richnond (Figure 6.2). Increased metering rates means lesser traffic diversion to Carling Ave and therefore reduced delays.

For the entire eastbound sub-network, the following observations were made when the existing conditions were compared to the "optimised metering rates" (Table 6.1):

- reduction in arterial speed from $25 \mathrm{~km} / \mathrm{h}$ to $20 \mathrm{~km} / \mathrm{h}$,

- increased total travel time from 61 to 94 veh-hrs, a 54\% increase,

- increased traffic throughput from 1556 vehicle-km to 2035 vehicle-km, a $31 \%$ increase,

- increased cumulative travel time from $12.8 \mathrm{mins}$ to 15.7 mins, a $22 \%$ increase.

Table 6.1: Effect of "Optimised Metering Rates" on Eastbound Carling

\begin{tabular}{|l|c|c|c|c|}
\hline & $\begin{array}{l}\text { Travel Speed } \\
(\mathbf{k m} / \mathbf{h})\end{array}$ & $\begin{array}{l}\text { Total Travel } \\
\text { Time (veh-hrs) }\end{array}$ & $\begin{array}{l}\text { Total Travel } \\
(\text { veh-km) }\end{array}$ & $\begin{array}{l}\text { Cum. Travel } \\
\text { Time (mins) }\end{array}$ \\
\hline $\begin{array}{l}\text { Existing Condition } \\
\text { OOptimised Rates }\end{array}$ & 25 & 61 & 1556 & 12.8 \\
15.7
\end{tabular}




\subsubsection{Westbound Carling Ave.}

Clyde, Woodroffe South, and Richmond are the only intersections with a significant increase in average stopped delays when optimised metering rates were used (17.7 to 33.2 sec/veh for Clyde, 26.1 to $44.9 \mathrm{sec} / \mathrm{veh}$ for Woodroffe South, and 20,2 to $38.1 \mathrm{sec} / \mathrm{veh}$ for Richmond; see Figure 6.4). All other intersections experienced $24 \mathrm{sec} / \mathrm{veh}$ or less in vehicle stopped delays.

The highest range in link travel speeds from $30 \mathrm{~km} / \mathrm{h}$ to $21 \mathrm{~km} / \mathrm{h}$, occurred at Fairlawn intersection, otherwise all other travel speeds changed slightly (see Figure 6.5). Traffic throughput, measured in veh-km, for each link, also changed slightly, in the range of $\mathbf{5}$ veh $\mathrm{km}$ or less except for Maitland-Iroquous section, which changed from 48 to 39 $\mathrm{km} / \mathrm{h}$ (see Figure 6.6).

For the entire westbound sub-network, the following was observed when existing traffic conditions were compared with optimised metering rates (Table 6.2):

- Vehicle throughput reduced from existing 322.3 veh-km to 314.3 veh-km, a $2 \%$ reduction.

- Travel time increased from 640.9 veh mins to 723.5 veh mins, a $13 \%$ change, and cumulative travel time increased from 8.3 mins to 9.4 mins.

- Arterial travel speed reduced from $32 \mathrm{~km} / \mathrm{h}$ to $28 \mathrm{~km} / \mathrm{h}$ (a reduction of less than $2 \%$ ), corresponding to a LOS C.

Although ramp control strategies were only applied to the eastbound direction, westbound traffic was affected slightly because of green time reallocation to reflect all 


\section{Ramp Metering \& Intersection Stopped Delay Westbound Carling Ave}

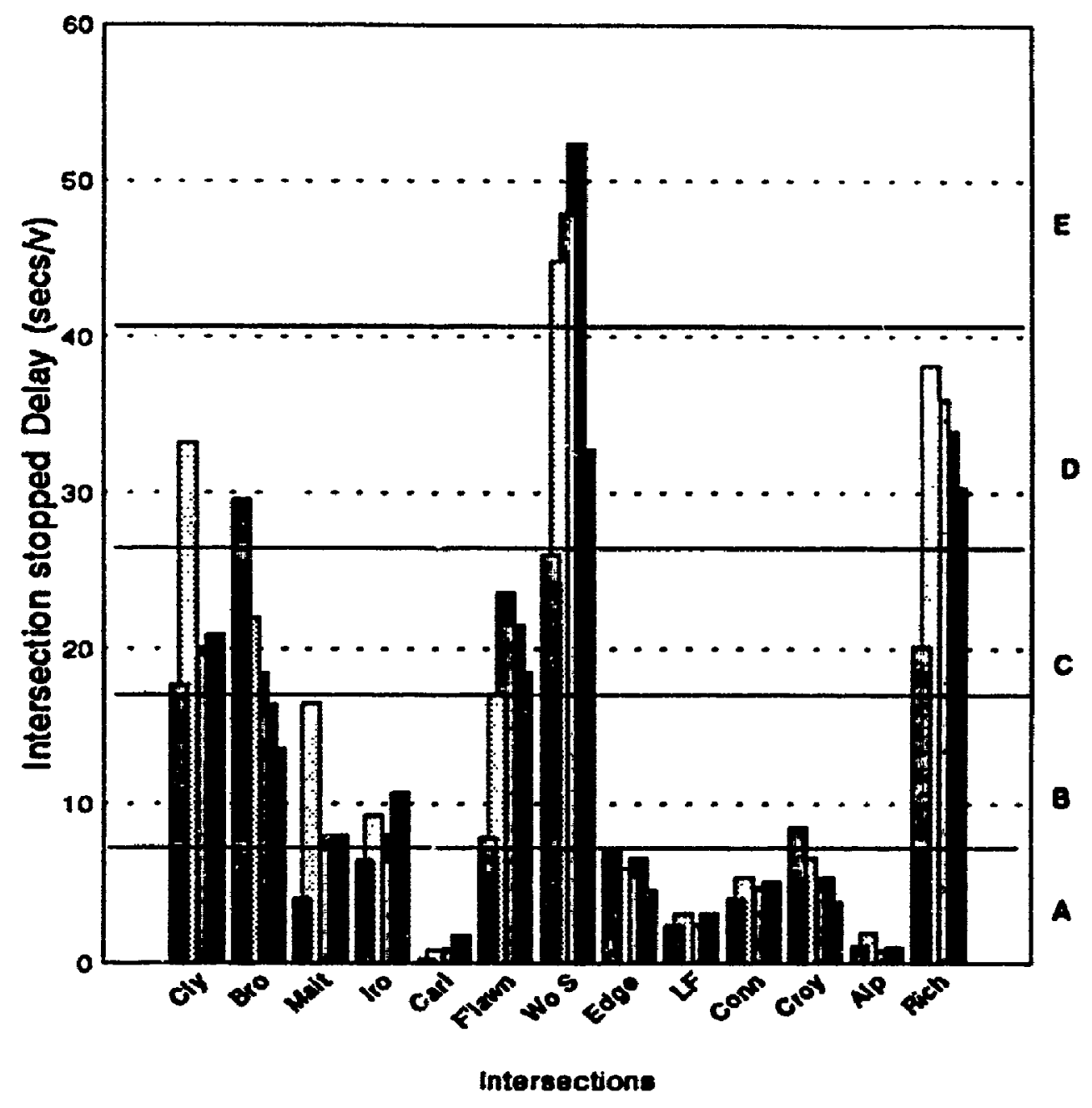

Based on 1992 Amoc intersedion Counts

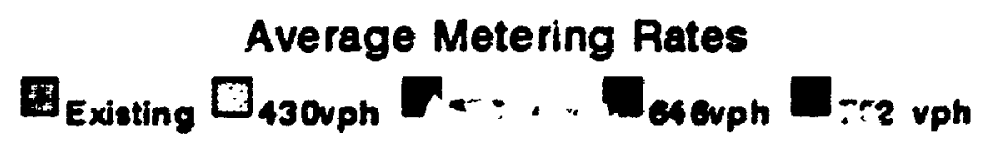

Figure 6.4 Westbound Intersection Stopped Delay 


\section{Ramp Metering \& Link Travel Speed Westbound Carling Ave}

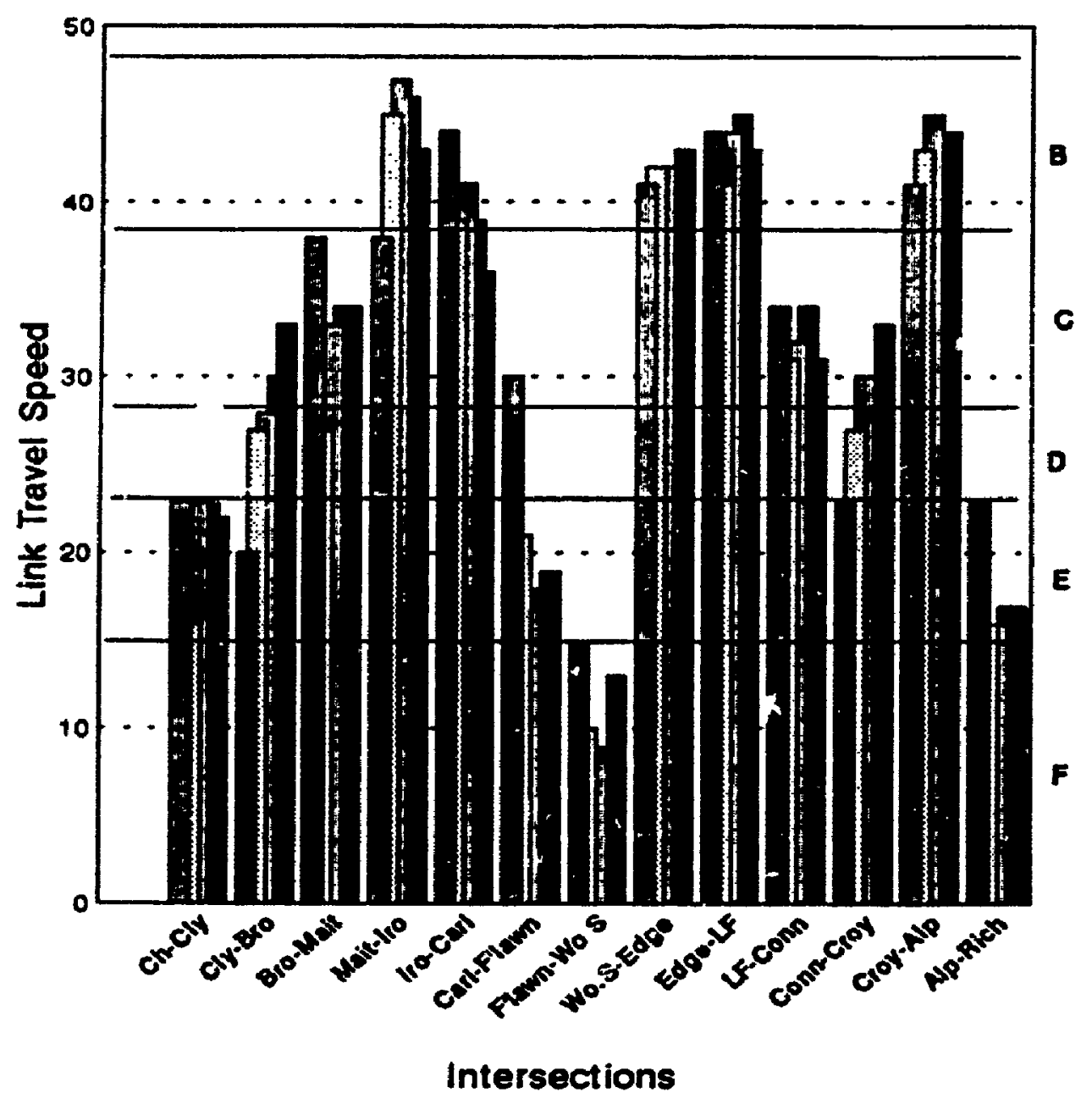

Based on 1992 PMOC Intersection counts and exteting timing plen

$$
\begin{gathered}
\text { Metering Rates } \\
\square_{\text {Exiating }} \square_{\text {430uph }} \square_{550 \text { vph }} \square_{\text {G4 Guph }} \square_{702 \text { vph }}
\end{gathered}
$$

Figure 6.5: Westbound Link Travel Speed 


\title{
Ramp Metering \& Vehicle Throughput Westbound Carling Ave
}

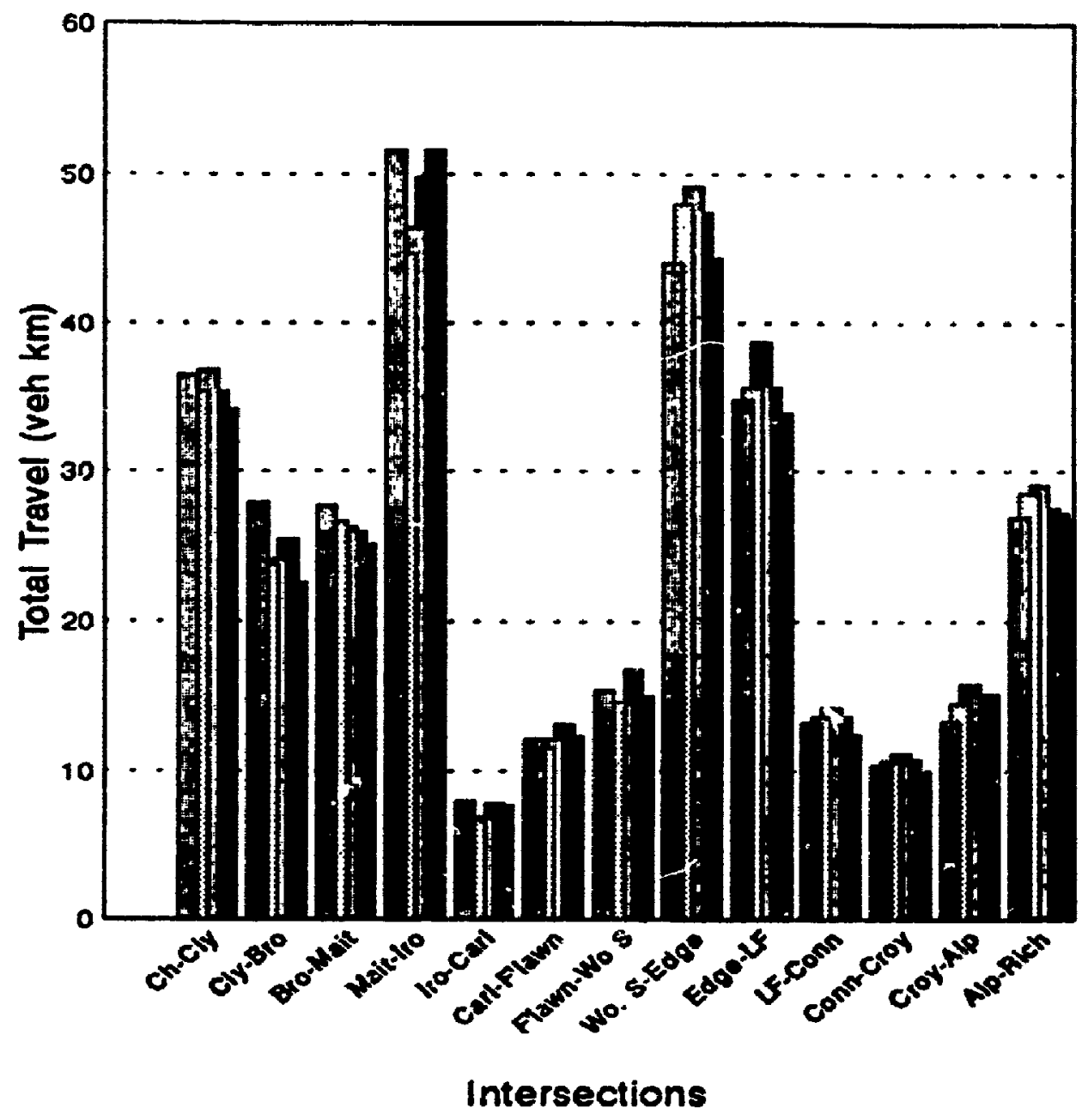

Based on 1992 RMOC Intereoction counts and exlating timing plen

\author{
Metering Rates \\ $D_{\text {Existing }} \square_{\text {430uph }} \square_{550 \mathrm{vph}} \square_{\text {Barph }} \square_{702 \text { uph }}$
}

Figure 6.5 We.thound Link Total Travel 
approach deriands (sce Equation 5-9).

Table 6.2: Effect of "Optimised" Metering Rates on Westbound Carling

\begin{tabular}{|l|c|c|c|c||}
\hline & $\begin{array}{l}\text { Travel Speed } \\
(\mathbf{k m} / \mathbf{h})\end{array}$ & $\begin{array}{l}\text { Total Travel } \\
\text { Time (veh-hrs) }\end{array}$ & $\begin{array}{l}\text { Total Travel } \\
\text { (veh-km) }\end{array}$ & $\begin{array}{l}\text { Cum. Travel } \\
\text { Time (mins) }\end{array}$ \\
\hline Existing Condition & 32 & 10.7 & 322 & 8.3 \\
"Optimised Rates & 28 & 12.1 & 314 & 9.4 \\
\hline
\end{tabular}

\subsubsection{Southbound \& Northbound Approaches:}

Except for Churchill Ave which operated at a LOS E, all other SB approach stopped delays were at a LOS D or better, when the "optimised metering rates" were used (Figure 6.7). Southbound link travel speeds at Croydon, Clyde \& Churchill, operated within a LOS E, but all other Link travel speeds were at a LOS B or better (Figure 6.8). For the Northbound approaches, all other intersections except Richmond and Maitland Avenue operated at a. LOS D or better. Northbound Richmond experienced the worst intersection stopped delay (LOS F) under "optimised metering plans (Fig 6.9). On the average, North \& Sonth bound approaches are not significantly affected even at the lowest metering rates, except NB Richmond and SB Clyde.

\subsection{Freeway Measures of Effectiveness}

The benefits of ramp control had a very positive impact on the eastbound Queensway. At

"ontimised metering rates" the following was observed (Table 6.3):

- reduced cumulative travel time from 13.4 mins to $6.1 \mathrm{mins}$, a $54 \%$ reduction,

- reduced total travel time from 308 veh-hrs to 141 veh-hrs, a 54\% reduction,

- reduced throughput on the freeway from 8680 to 8634 veh-km, (less than $1 \%$ ). 
Ramp Metering \& Intersection Stopped Delays. Southbound Approaches

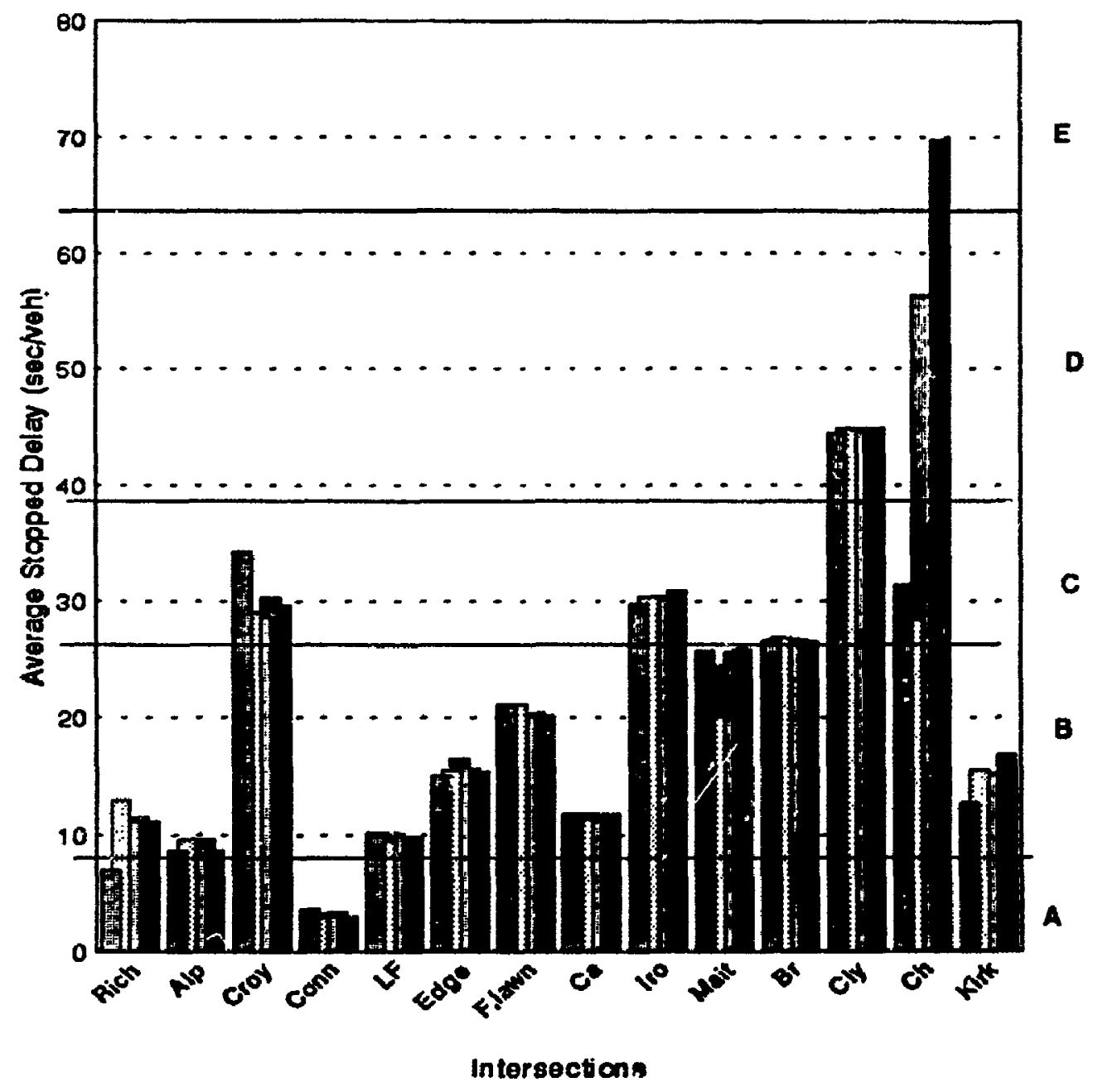

Based on 1992 AMOC Intersection Counts

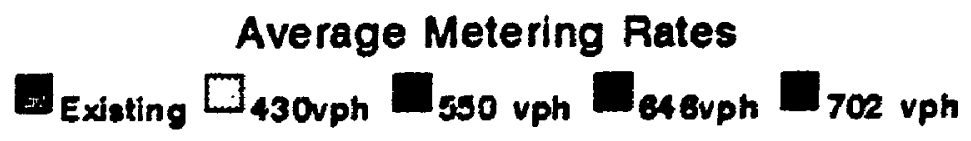

Figure 6.7: Southbound Intersection Approach Delay. 


\title{
Ramp Metering \& Link Travel Speed. Southbound Approaches
}

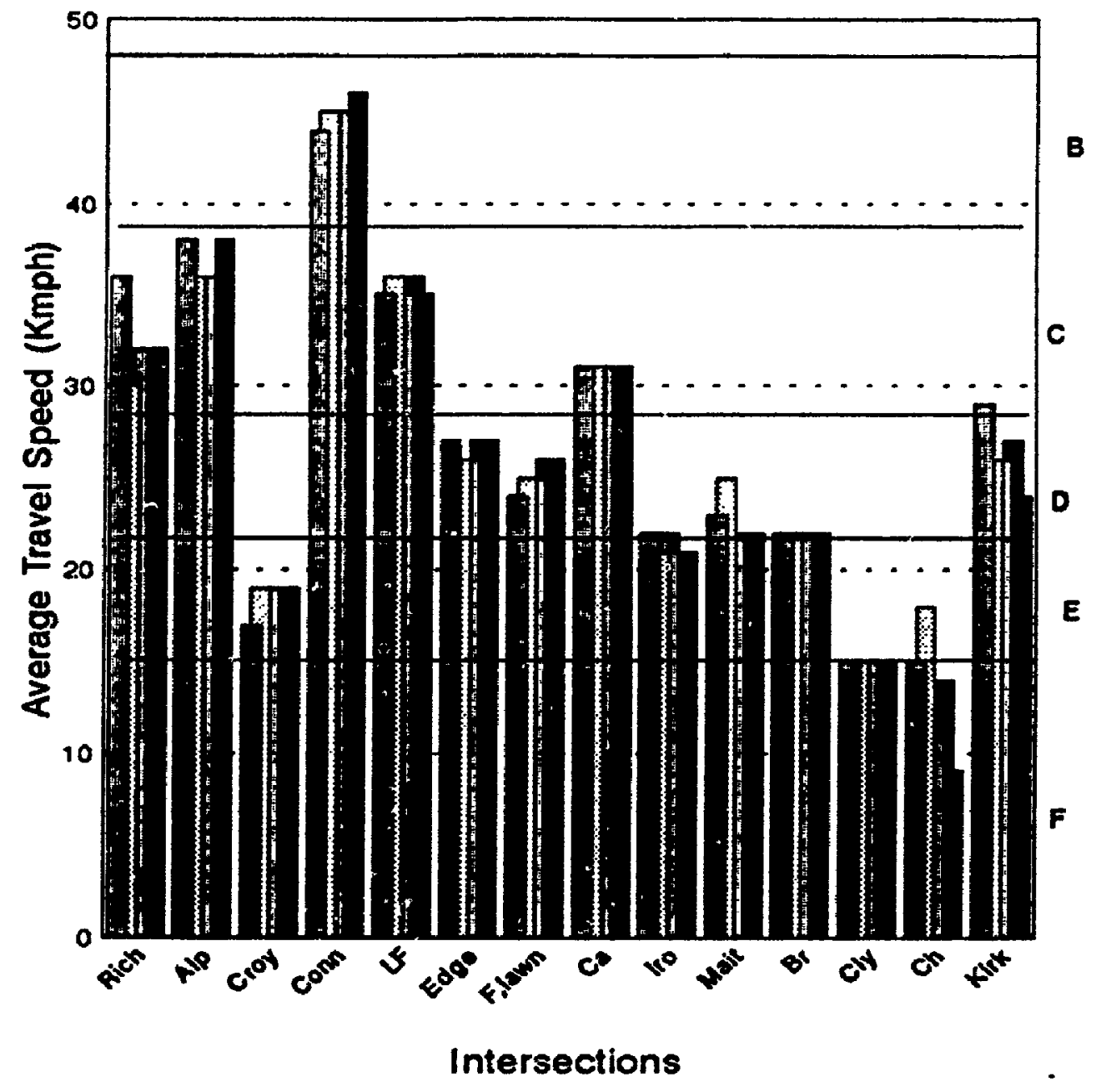

Based on 1992 RMOC Intersection Counts

\author{
Average Metering Rates \\ [r.xisting ${ }_{430 v p h} D_{550 \mathrm{vph}} \square_{\text {S46vph }} \square_{702 \mathrm{vph}}$
}

Figure 6.8 Southbound Link Travel Speed. 
Ramp Metering \& Intersection Stopped Delay. Northbound Approaches

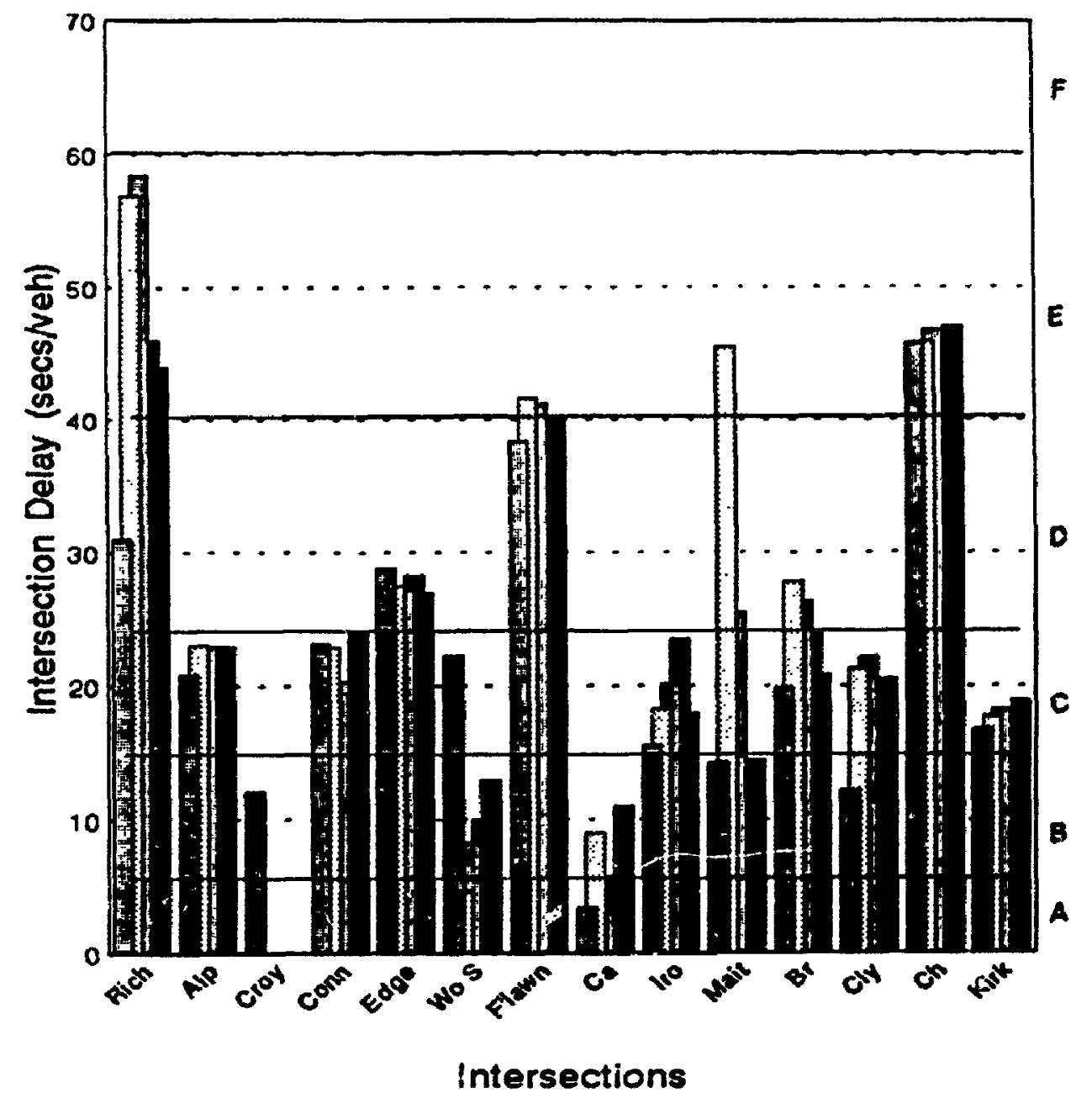

Based on 1992 RMOC Intersection Counts

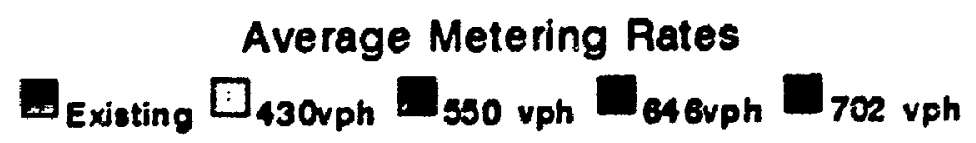

Figure 6.9 Northbound Intersection Stopped Delay. 
Table 6.3: Effect of "Optimised Metering Rates" on Eastbound Queensway

\begin{tabular}{|l|c|c|c|c|}
\hline & $\begin{array}{l}\text { Travel Speed } \\
(\mathbf{k m} / \mathbf{h})\end{array}$ & $\begin{array}{l}\text { Total Travel } \\
\text { Time (veh-hrs) }\end{array}$ & $\begin{array}{l}\text { Total Travel } \\
(\text { veh-km) }\end{array}$ & $\begin{array}{l}\text { Cum. Travel } \\
\text { Time (mins) }\end{array}$ \\
\hline Existing Condition & 29 & 308 & 8680 & 13.4 \\
"Optimised Rates" & 63 & 141 & 8634 & 6.1 \\
\hline
\end{tabular}

\subsection{Corridor Analysis:}

Impacts of metering would be incomplete, unless its effects on the corridor are considered. Corridor MOEs were broken into three sub components:

- WB Corridor, comprising of WB Queensway from Kirkwood interchange to Pinecrest interchange and WB Carling Avenue from Churchill to Pinecrest street.

- EB corridor, consisting of EB Queensway From Pinecrest Intercisange to Kirkwood interchange plus EB Carling Avenue from Pinecrest Street to Kirkwood Avenue.

- Combined corridor MOEs consisting of the sum of EB and WB corridors.

\subsubsection{Eastbound Corridor:}

Existing conditions offered the lowest traffic throughput in the eastbound corridor of 10236 veh-km. At "optimised metering rates", throughput increased to 10669 veh-km, an increase of $4 \%$ (Figure 6.10).

Corridor travel times are highest at pre metering conditions of 369.5 veh-hrs; optinised metering rites (430vph) reduced the total travel time to 235.5 veh-hrs, a 


\section{Ramp Metering \& Corridor Total Travel}

\section{Eastbound Corridor}

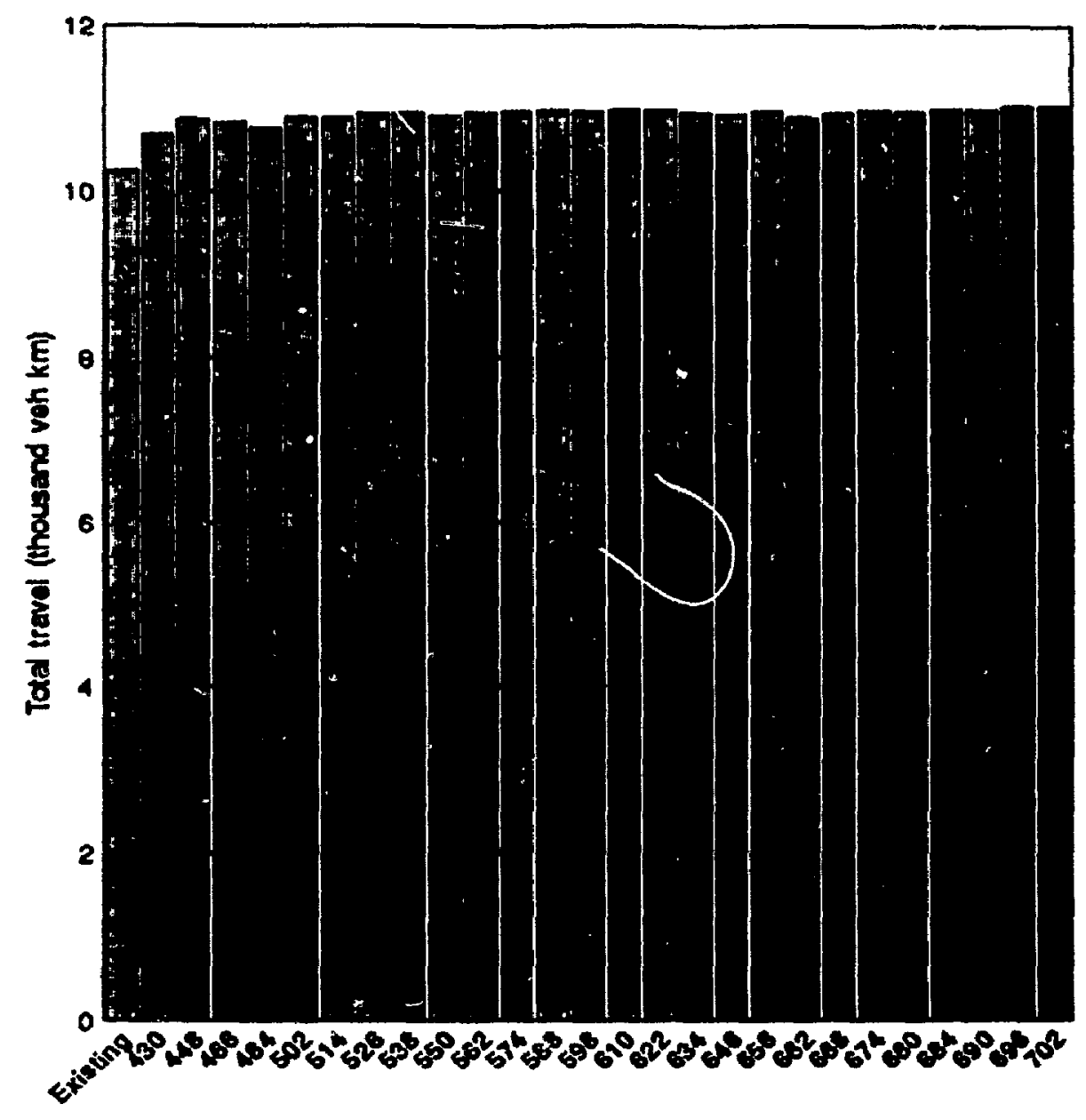

Metaring Rates in vph

Figure 6.10: Eastbound Corridor Total Travel 


\section{Ramp Metering \& Corridor Total Travel Time} Eastbound Corridor

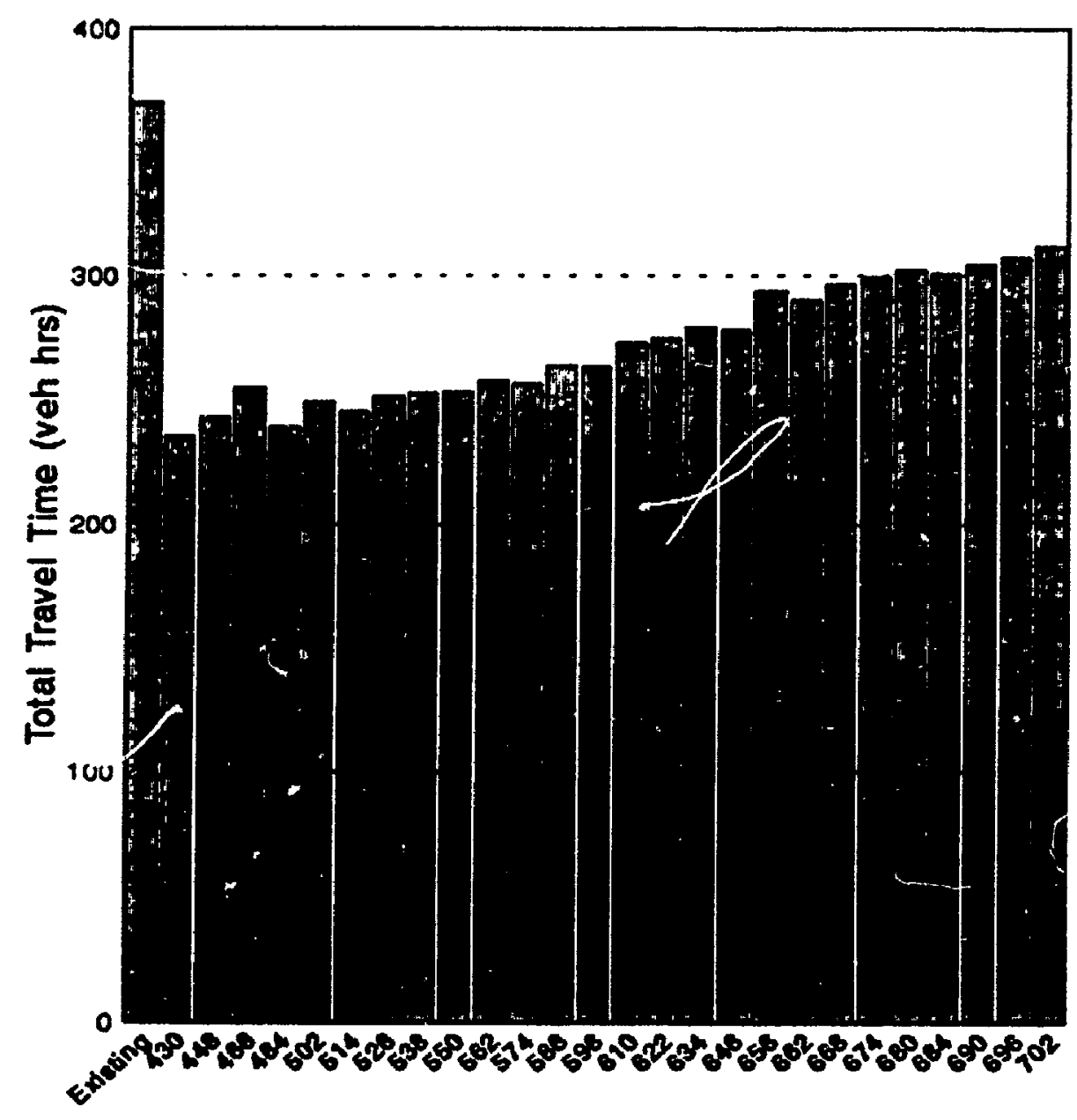

Metering Rates in vph

Figure 6.11: Eastbound Corridor Total Travel Time 
savings of 129 veh-hrs (35\% reduction). See Figure 6.11. The reason for this significant reduction is that, even though arterial total travel time increased, the freeway carries $82 \%$ of the total traffic. Therefore, the net effect was reduced corridor travel time. As metering rates increased from the optimised metering plans, its corresponding corridor total travel time increased.

\subsubsection{WB Corridor:}

Westbound corridor traffic change was neglible. The following observations were revealed when "optimised metering rates" were compared with pre metering conditions:

- reduction of traffic throughput of only 8 veh-km (less than $1 \%$ change). See Figure 6.12,

- A change of 1.4 veh-hr (less than $3 \%$ change see Figure 6.13).

These findings indicate that the effect of eastbound mainline on the westbound traffic is very minimal. Furthermore the change in performance measures were very s.mall. Therefore, its impacts on the westbound corridor is negligible.

\subsubsection{Combined Corridor}

Comparison between pre-metering and metering conditions also revealed that corridor traffic behaved in a manner similar to the eastbound corridor. That is,

D vehicle throughput increased from 14685 veh-km to 15110 veh- $\mathrm{km}$, when optimised metering plans were introduced (see Figure 6.14), and 


\section{Ramp Metering \& Corridor Total Travel Westbound Corridor}

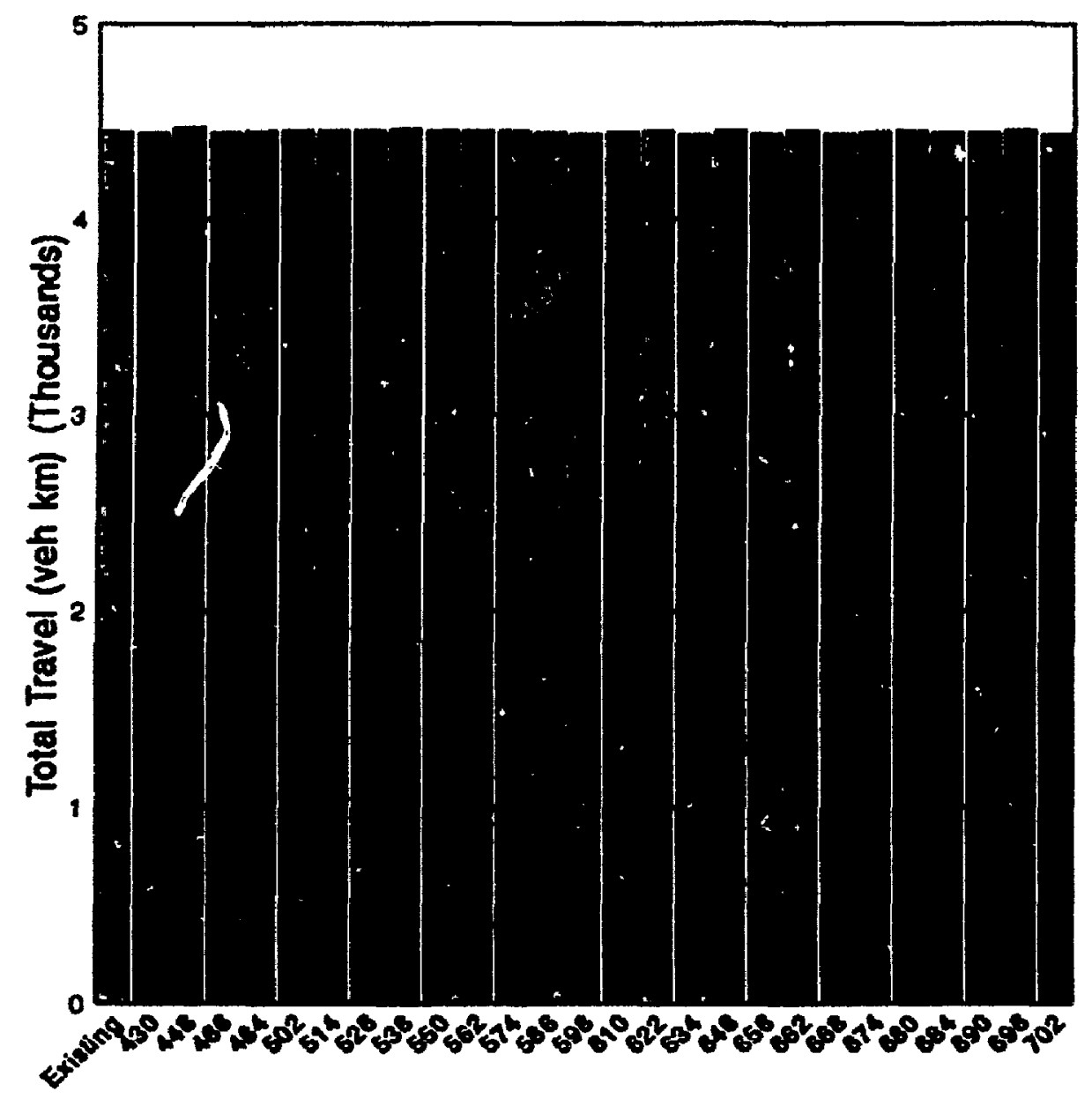

Metering Rates in vph

Figure 6.12 Total Travel For Westbound Corridor 


\section{Ramp Metering \& Corridor Total Travel Time} Westbound Corridor

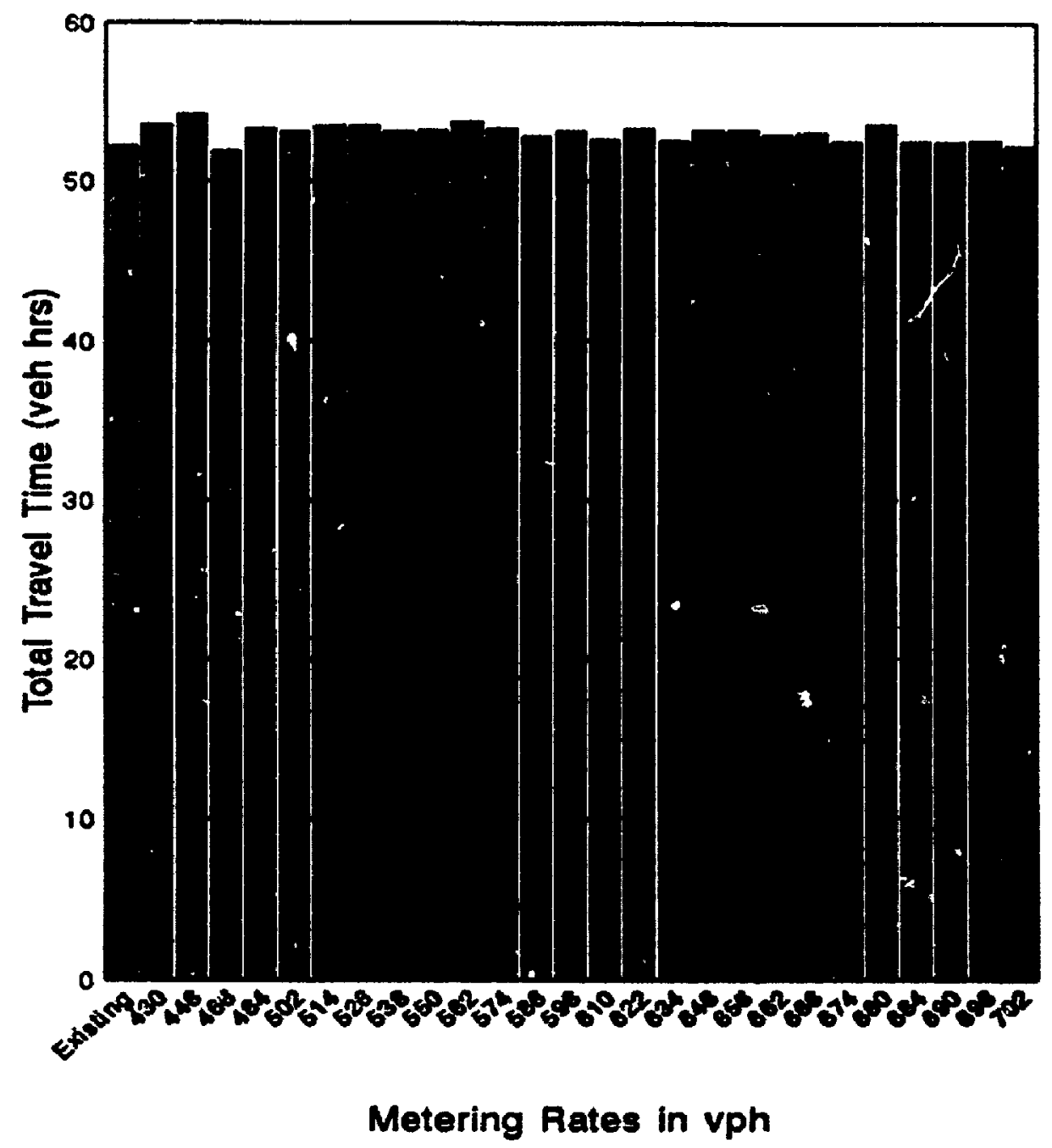

Figure 6.13 Total Travel Time For Westbound Corridor 


\section{Ramp Metering \& Combined Corridor Total Travel}

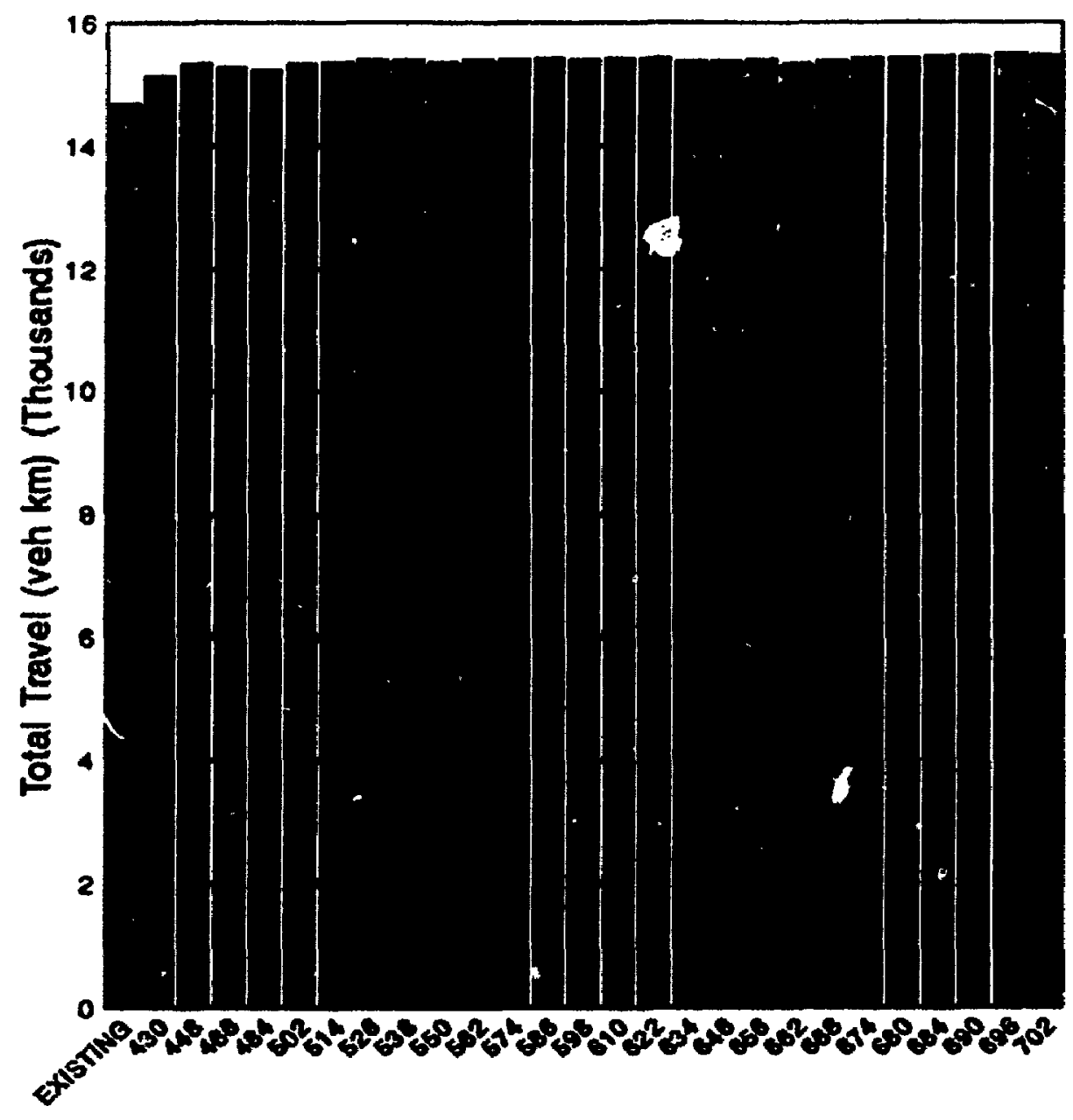

Average Metering Rates

Based on 1992 FuOC intersection counts

Figure 6.14 Corridor Total Travel. 


\section{Ramp Metering \& Combined Corridor Total Travel Time}

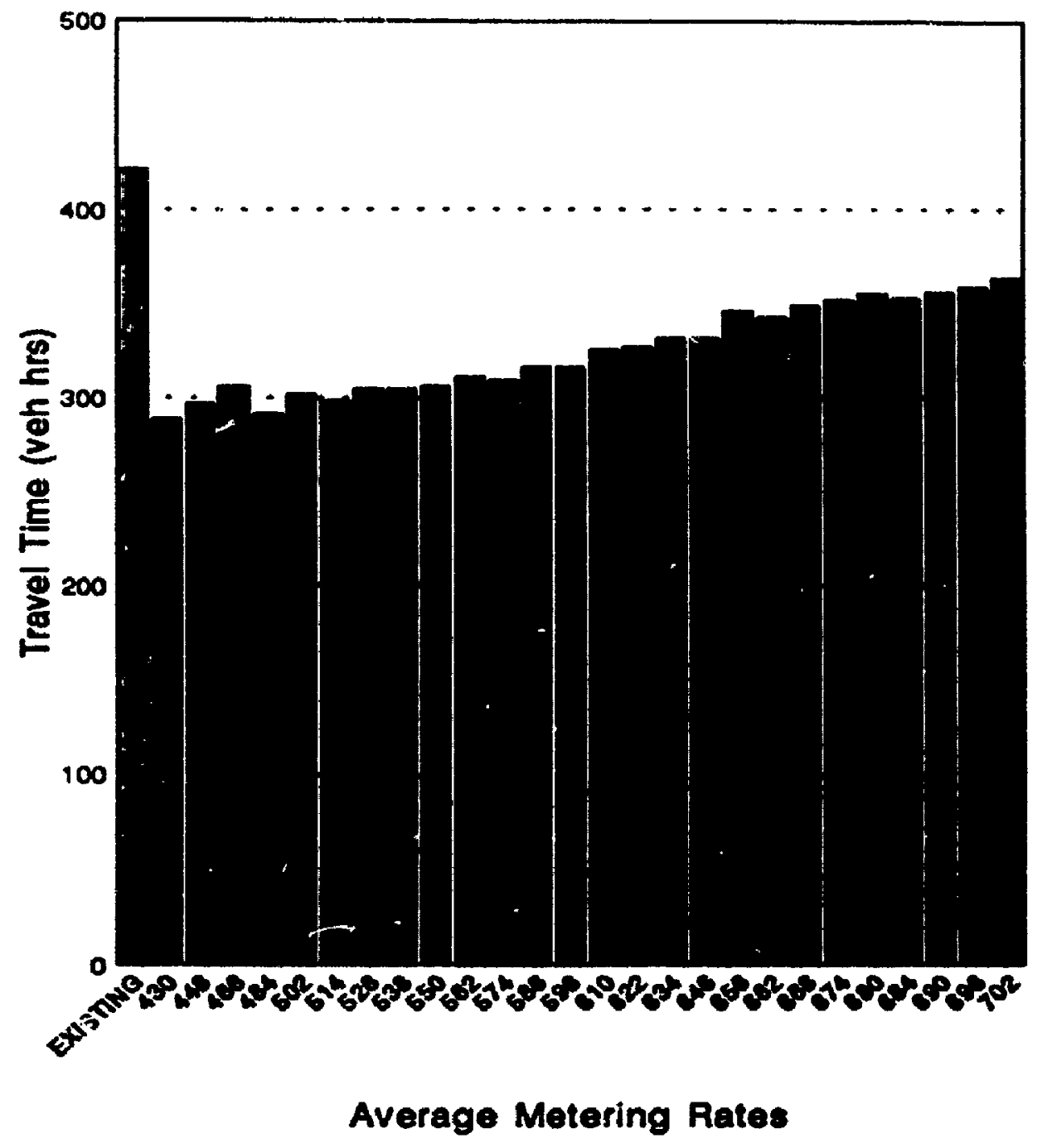

Based on 1992 Fuoc intorsection counts

Figure 6.15 Corridor Total Travel Time 
- total travel times, reduced from existing 421.7 veh-hrs to 289 veh-hrs, when optimised metering rates were introduced (Figure 6.15).

\subsection{Disadivantages of "Optimised Metering Rates"}

"Optimised metering rates" reduced corridor travel time, and increased totai traffic throughput in the corridor, but eastbound Richmond. and Clyde approaches operated in the upper range of LOS E, manifested by longer stopped delays. Intersections such as Clyde, Churchill, Richmond and Maitland experienced very high stopped delays. Although "Optimized metering" plans produced minimum corridor total travel time, it was achieved at the expense of severe delays at a limited number of locations, especially at eastbound and southbound Clyde, northbound Maitland and eastbound Richmond approaches.

\subsection{Suggested Alternative Method}

To avoid severe delays on all surface street approaches, threshold delays are introduced at all intersection approaches. The establishment of these threshold values should complement other activities like ride share, HOV lanes, etc in the corridor. The best metering rates from this methodology were formulated to respond to the disadvantages mentioned in section 6.4 by using the following criteria:

- minimize corridor total travel time, and

- all intersection approach delays should not be greater than its threshold value. 
Establishing threshold delays depends on a number of factors including:

- the objectives and policy of the transportation agency under its jurisdiction.

- the acceptable level of congestion in the region, and

- the severity of congestion on both freeway and the adjacent surface street network.

For this study, the threshold average stopped delays for each approach is taken as $45 \mathrm{sec} / \mathrm{veh}$ which corresponds to an upper range of LOS E. The best average metering rate which satisfies these two conditions occurred at a metering rate of $674 \mathrm{vph}$.

\subsubsection{Comparison of the "Best" with "Optimised" Rates.}

The following observations were made when the best metering rates were compared with the optimised rates (Table $6.4 \& 6.5$ );

- Reduced cumulative travel time from $15.7 \mathrm{mins}$ (optimised) to $13.2 \mathrm{mins}$ for eastbound Carling but increased eastbound freeway travel time from $6.1 \mathrm{mins}$ (optimised) to 9.3 mins (Figure 6.16)

- Increased traffic throughput in the corridor from 15110 veh-km to 15408 veh-km (Figure 6.17),

- Increased total travel time in the corridor from 289 to 352 veh-hrs (Figure 6.18),

- The average stopped delays in all links were less than $26 \mathrm{secs} / \mathrm{veh}$ (LOS C), except eastbound Richmond, which experienced 44.8 secs/veh.

Even though the best metering rates increased corridor total travel time, as well as 
Table 6.4 Comparison of Optimized \& Best Metering Rates

\begin{tabular}{|c|c|c|c|}
\hline & Existing & Or:imized & Best \\
\hline $\begin{array}{l}\text { Cum. travel time, EB Carling (mins) } \\
\text { Cum travel time, WB Carling (mins) } \\
\text { Cum. travel time, EB Qucensway (mins) }\end{array}$ & $\begin{array}{l}12.8 \\
8.3 \\
13.4\end{array}$ & $\begin{array}{l}15.7 \\
9.4 \\
6.1\end{array}$ & $\begin{array}{l}13.2 \\
8.7 \\
9.3\end{array}$ \\
\hline $\begin{array}{l}\text { Traffic throughput, EB Carling (vch-km) } \\
\text { Traffic throughput, WB Carling (veh-km) } \\
\text { Traffic throughput. EB Queensway (veh-km) } \\
\text { Traffic throughput, EB Corridor (veh-km) } \\
\text { Traffic throughput, WB Corridor (vch-km) } \\
\text { Traffic throughput, Combined Corridor veh-km) }\end{array}$ & $\begin{array}{l}1556 \\
322 \\
8680 \\
10236 \\
4449 \\
14685\end{array}$ & $\begin{array}{l}2036 \\
314 \\
8634 \\
10650 \\
4441 \\
15110\end{array}$ & $\begin{array}{l}1927 \\
312.9 \\
9042 \\
10969 \\
4439 \\
15409\end{array}$ \\
\hline $\begin{array}{l}\text { Total Travel Time, EB Cariing (veh-hrs) } \\
\text { Total Travel Time. WB Carling (veh-hrs) } \\
\text { Total Travel Time, EB Qucensway (veh-hrs) } \\
\text { Total Travel Time, EU Corridor (veh-hrs) } \\
\text { Total Travel Time, WB Corridor (veh-hrs) } \\
\text { Total Travel Time, Combined Corridor (veh-hrs) }\end{array}$ & $\begin{array}{l}61.1 \\
10.7 \\
308.4 \\
370 \\
52.1 \\
422\end{array}$ & $\begin{array}{l}94.4 \\
12.1 \\
141.1 \\
236 \\
53.5 \\
289\end{array}$ & $\begin{array}{l}74.6 \\
10.9 \\
225 \\
300 \\
52.4 \\
352\end{array}$ \\
\hline
\end{tabular}

Table 6.5 EB MOE For The Best (NV21A) \& Optimized (NV1A) Metering Rates

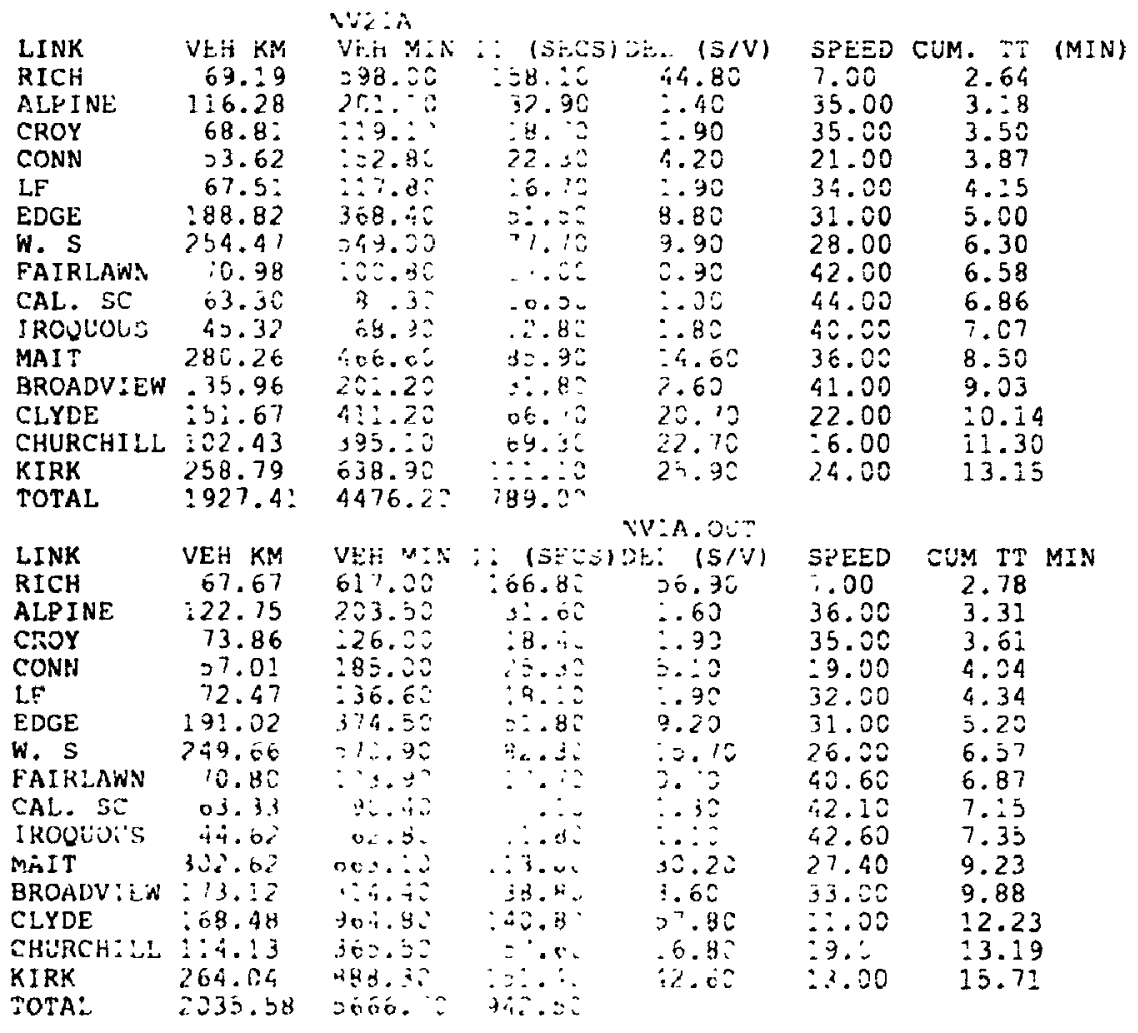




\section{Comparison of Metering Rates Eastioound Corridor}

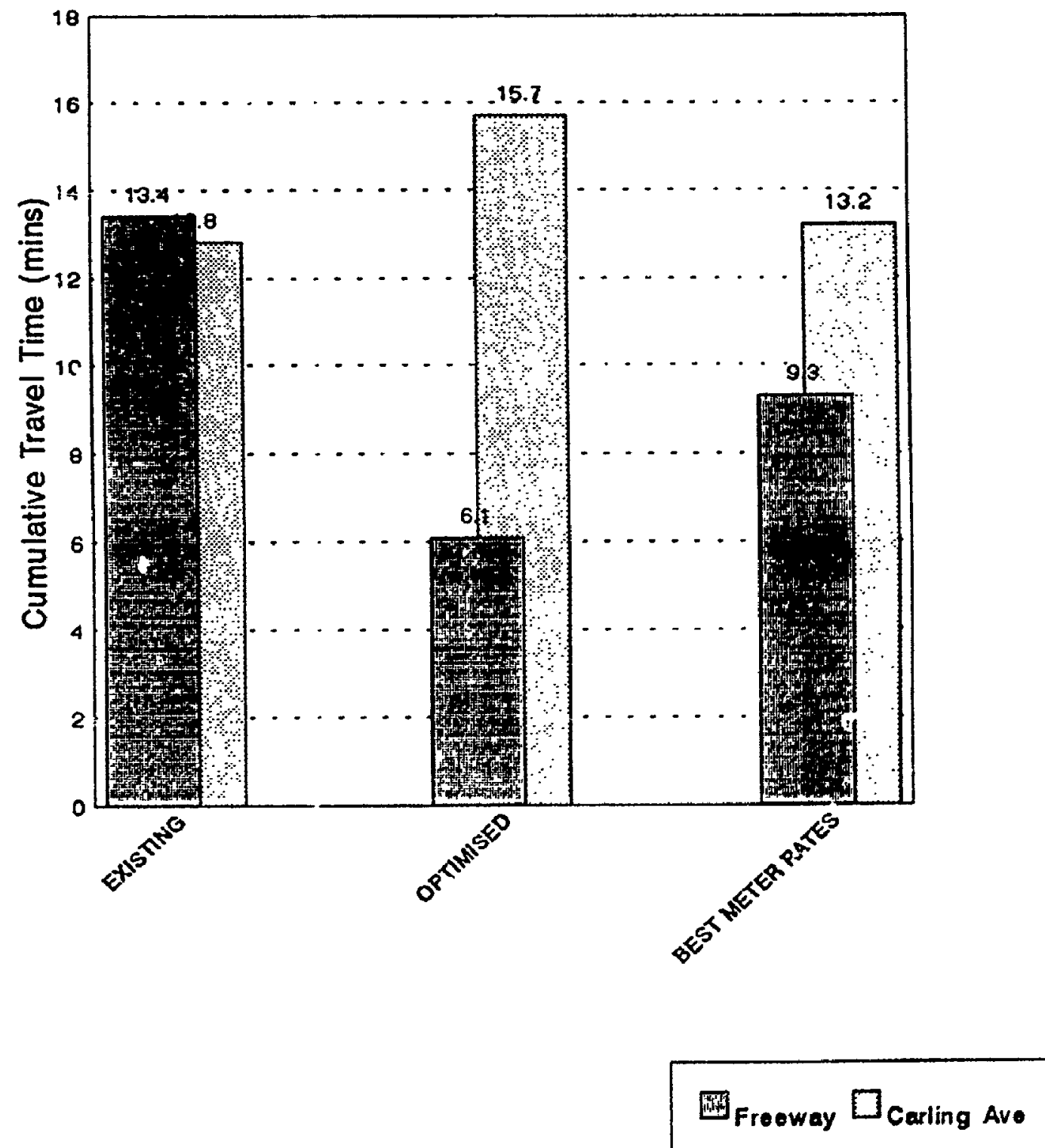

Figure 6.16 Cumulative Travel Time Comparison 


\section{Comparison of Metering Rates Combined Corridor Total Travel}

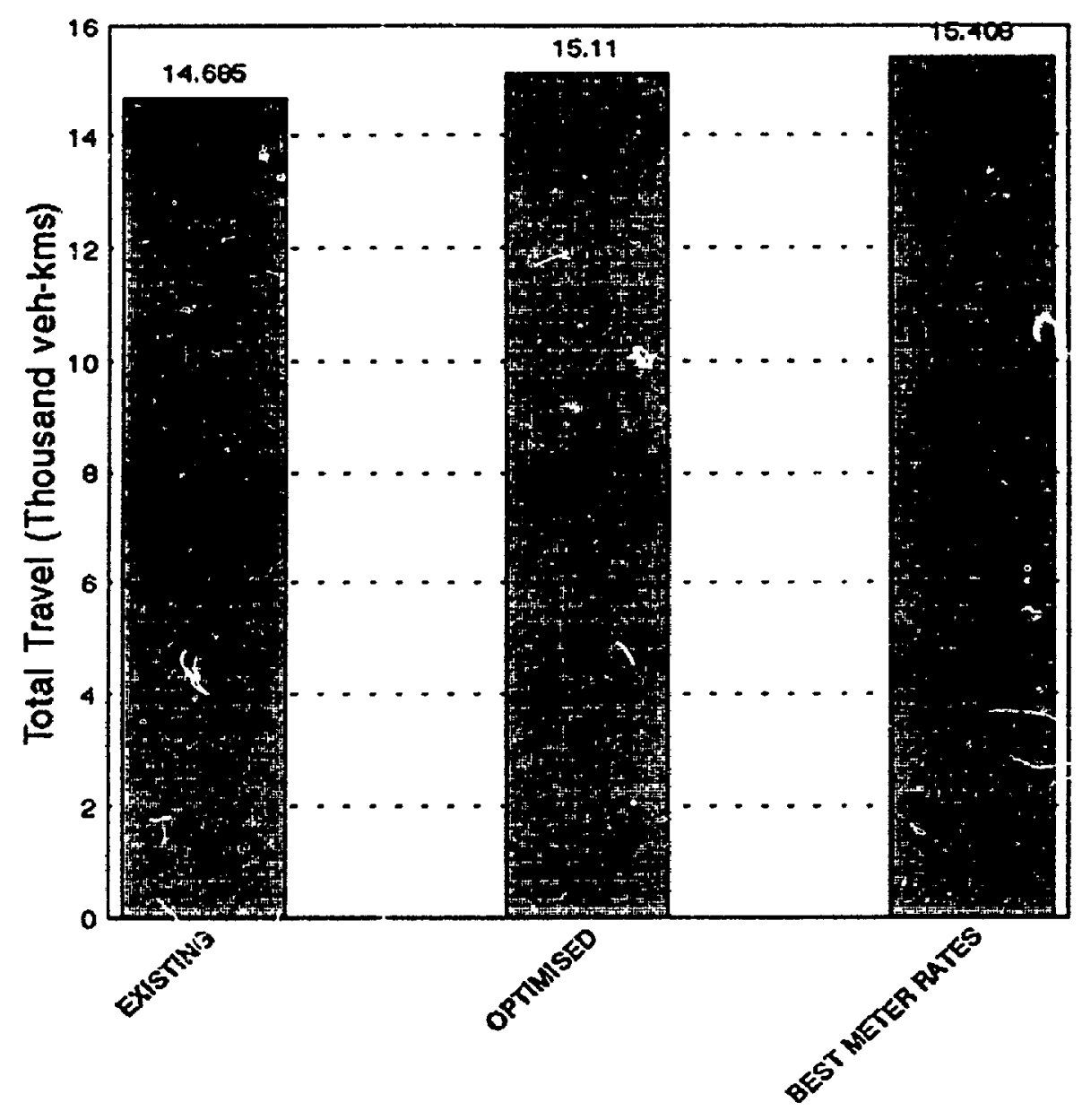

Metering Rates

Figure 6.17 Comparison of Total Travel. 


\section{Comparison of Metering Rates} Combined Corridor Total Travel Time

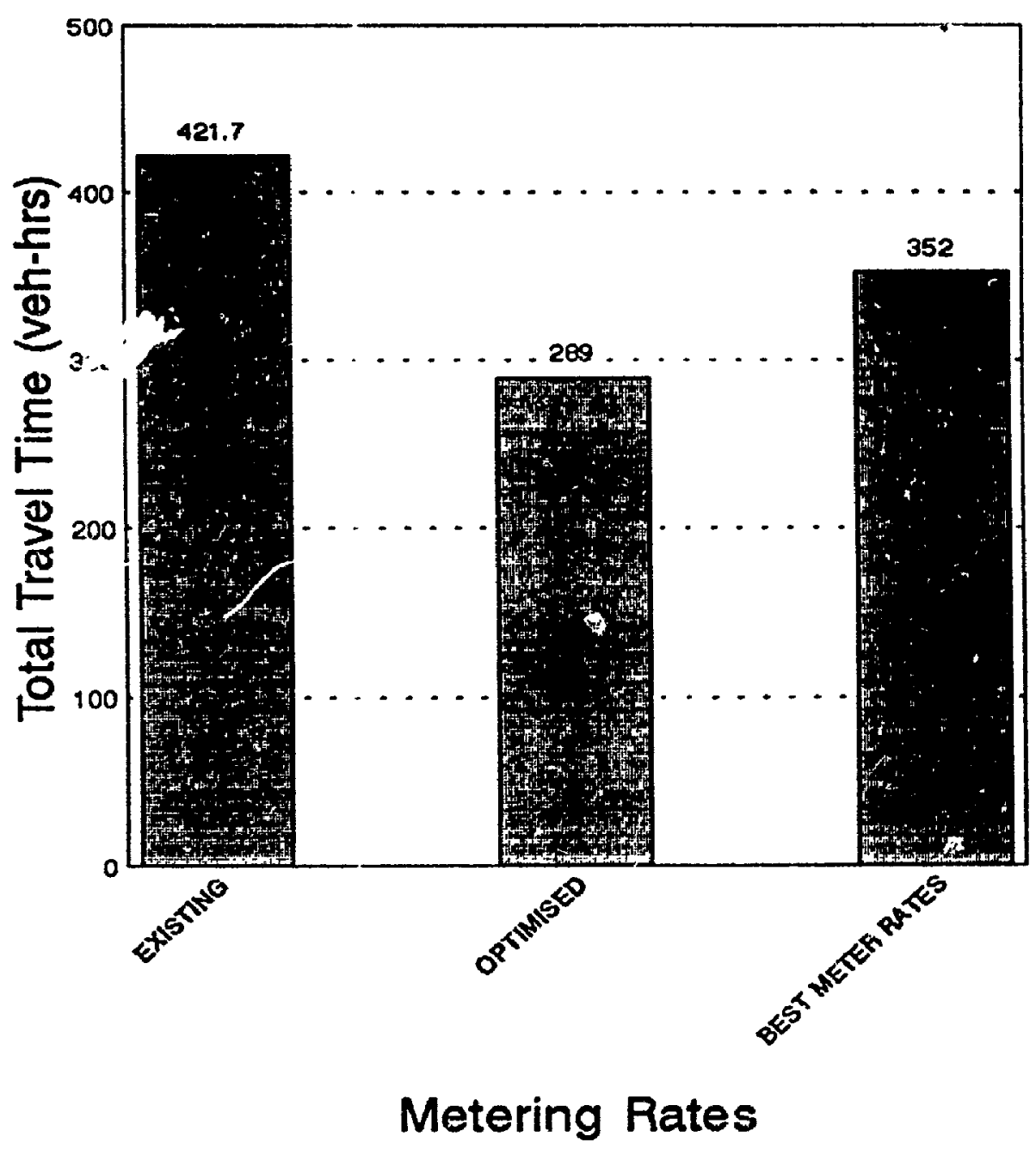

Figure 6.18 Total Travel Time Comparison. 
increased cumulative travel time on the freeways, (when compared to the "optimised rates,) traffic throughput increased, the average stopped delays at all intersection approach are monitored continuously and therefore maintained at or below threshold levels. Furthermore, cumulative travel time for the eastbound Carling reduced.

\subsubsection{Limitations.}

This methodology will likely overestimate all the MO. on the alternate route, hence overestimate the metering rates because traffic assignment was based on the assumption that all traffic would use Carling Ave. This traffic assignment technique is known as "all or nothing" assignment. In real life, northbound Richmond may not experience delays and travel times to this degree and other link volumes on eastbound Carling may not carry these traffic volumes for the following reasons:

- A realistic random variation of a motorist's route choice was ignored, and the effect of capacity restraint was not considered. Some trip makers, for instance would use Baseline Rd instead of Carling Avenue. Random variation of a motorist's route selection is explained by the fact that given two or more competitive routes, the user may not select the best route because the driver may either not be aware of the attractiveness of the non-chosen route or have other reasons for such a selection.

- When a motorist recognises this everyday ramp control, a different time may be chosen or even a change in mode may occur.

- Evun if all diverted vehicles used Carli.g Avenue, they would not all enter 
through Pinecrest, Maitland and Carling Avenue because not all these vehicles would proceed to these ramps before diverting.

- The other assumption that all diverted vehicles would use Carling at least beyond Kirkwood may not be valid. Metering would induce more short trips than long ones to divert, therefore not all diverted trips would travel to Kirkwood.

- The methodology is not responsive to the changing freeway O.D. patterns. At premetering conditions, the O.D. data is based on manifest demand. When metering strategies are introduced, reduction in freeway travel times may cause some latent demand, not accounted for, to use the freeway. As the AVI \& AVC technologies advance and the traffic population of equipped vehicle probes increase, the static $P_{j k} s$ (equation 5-12) could be updated to reflect the changing O.D patterns. Before an O.D update, the reiiability of these $P_{\mathrm{jk}} s$ (which depends on the number of equipped vehicle probes using the freeway), could be determined by conditional probabilities, using Bayes Rule.

Whether vehicles would divert or not also depends on where these vehicles originated from and where they are going. If most vehicles are travelling to longer destinations, they may decide to use the freeway despite the increased amp delays. The need to conduct an origin and destination survey is therefore very essential.

These limitations do not in anyway undermine the usefulness of the results. It simply indicates that given O.D. data in the area, the benefits of the metering rates would be further refined to maximize its benefiis. The intent of this research was to present a 
limited and realistic evaluation of benefits that such strategies could produce. Due to these limitations, the results indicate a conservative estimate of average metering rates, which means that the benefits due to metering would probably be higher. 


\section{Chapter 7}

\section{VERIFICATION OF SIMULATION MODELS}

Travel time runs were carried out on the Ottawa Queensway and Carling Avenue. This chapter presents the procedure used for these studies and compares the field observations with simulated results.

\subsection{Field Studies}

The purpose of the field studies was to assess the accuracy of some of the MOEs generated by NETSIM and FREFLO. Although these simulation models have been well validated, it is important to conduct field tests to ascertain their validity on site-specific conditions.

Travel time studies wure conducted on both the Ottawa Queensway and Carling Avenue during peak period on the dates shown in Tables 7-1 \& 7-2. 
Table 7-1 Travel Time Runs For Highway 417.

\begin{tabular}{|c|c|c|c|}
\hline Date & Duration & $\begin{array}{r}\text { Road } \\
\text { Condition }\end{array}$ & Comments \\
\hline $\begin{array}{l}\text { Feb } 7^{\text {th }} 1994 \\
\text { Feb } 8^{\text {th }} 1994 \\
\text { Feb } 9^{\text {th }} 1994 \\
\text { Feb } 10^{\text {th }} 1994 \\
\text { Feb } 11^{\text {th }} 1994 \\
\text { May } 30^{\text {th }} 1994 \\
\text { June } 2^{\text {nd }} 1994\end{array}$ & $\begin{array}{l}7:(0)-8: 30 \\
7: 00-8: 30 \\
7:(00-8: 30 \\
7: 00-8: 30 \\
7: 00-8: 30 \\
7: 00-8: 30 \\
7: 00-8: 30\end{array}$ & $\begin{array}{c}\text { Bare } \\
\text { Bare } \\
\text { Snow Covered } \\
\text { Bare } \\
\text { Bare } \\
\text { Bare } \\
\text { Bare }\end{array}$ & $\begin{array}{l}\text { Four runs each, EB \& WB } \\
\text { Four runs each, EB \& WB } \\
\text { One rL. each, EB and WB } \\
\text { Four runs each, EB \& WB } \\
\text { Four runs each, EB \& WB } \\
\text { Four runs each, EB \& WB } \\
\text { Four runs each, EB \& WB }\end{array}$ \\
\hline
\end{tabular}

Table 7-2 Travel Time Runs For Cariing Avenue.

\begin{tabular}{|c|c|c|c|}
\hline Date & Duration & $\begin{array}{l}\text { Road } \\
\text { Condition }\end{array}$ & Comments \\
\hline 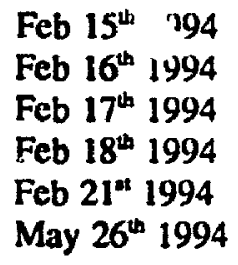 & $\begin{array}{l}7: 00-8: 30 \\
7: 00-8: 30 \\
7: 00-8: 30 \\
7: 00-8: 30 \\
7: 00-8: 30 \\
7: 00-8: 30\end{array}$ & $\begin{array}{l}\text { Bare } \\
\text { Bare } \\
\text { Bare } \\
\text { Bare } \\
\text { Bare } \\
\text { Bare }\end{array}$ & $\begin{array}{l}\text { Four runs each EB \& WB } \\
\text { Four runs each EB \& WB } \\
\text { Four runs each EB \& WB } \\
\text { Four runs each EB \& WB } \\
\text { Four runs each EB \& WB } \\
\text { Four runs each, EB \& WB }\end{array}$ \\
\hline
\end{tabular}

A total of four runs per day, were performed for each di ection of the Queensway, from Pinecrest interchange to Kirkwood interchange. On Carling Avenue, field studies were undertaken from Pinecrest/Carling intersection to Kirkwood/Carling intersection. Road surfaces were bare except on February $9^{\text {th }}$, when it was covered with snow and ice.

\subsection{Procedure}

The study required the use of: 
- a test car,

a stop watch, and

a an observer.

A 1988 VW fox, which was used as the test car, was driven on both eastbound and west bound Highway 417 and Carling Avenue at the speed of the traffic stream. Lane change or passing manoeuvres were made only for passing vehicles travelling far below the average traffic speed. In the case of the eastbound Queensway, there was very limited opportunity to pass other vehicles. Therefore following the car ahead was equivalent to average traffic stream speed. This procedure, known as the "average car method" was used because it was unsafe to use the "floating car method" on the freeway [ITE Handbook, 1992; Transportation Research Board, 1985; McShane \& Roess, 1992]. Furthermore, the average car method has proved to be more reliable and accurate than the floating car method [TTE, 1992]. Cumulative travel times were recorded at the gore of both entrance and exit ramps with a battery powered digital stop watch, whilst distances were recorded from the odometer.

On Carling Arenue, cumulative travel times were recorded at intersections and other locations where the vehicle came to a complete stop. Arterial free flow speed was recorded at mid-blocks of signalised intersections, where it was not hindered by other vehicles. During data collection, the test car was a platoon leader and a platoon follower. Tables 7-3, 7-4, \& 7-5 are sample data sheets of travel time runs for both the Ottawa Queensway and Carling Avenue. 
Table 7-3: A Sample of Travel Time Run For Eastbound Carling Ave

\begin{tabular}{|c|c|c|c|c|c|c|c|c|}
\hline \multicolumn{9}{|c|}{ Street Name:EB Carling Ave } \\
\hline $\begin{array}{l}\text { Cross } \\
\text { Streels }\end{array}$ & $\begin{array}{c}\text { Curn. Dist } \\
\mathrm{Km}_{\mathfrak{m}}\end{array}$ & $\underset{\substack{\text { Cum } \\
\text { muns }}}{\cos }$ & $\begin{array}{l}\text { Segunemt } \\
\text { Trav Time }\end{array}$ & $\begin{array}{l}\text { Stop Time } \\
\text { secs }\end{array}$ & Scb Speed & $\begin{array}{l}\text { Speed } \\
\text { Limit }\end{array}$ & $\begin{array}{l}\text { Ideal } \\
\text { Travel }\end{array}$ & $\begin{array}{l}\text { Segment } \\
\text { Deley }\end{array}$ \\
\hline Pinecrest & 0.45 & 0 & 123 & & 15 & 60 & & \\
\hline Richmon & 0.75 & 1.23 & 0.45 & $0: 48$ & 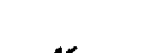 & & & \\
\hline Alpine & 1.1 & 1.68 & & & 60 & ow & & \\
\hline Croydon & 1.25 & 1.95 & 027 & & 34 & 60 & & \\
\hline Connau & 1.4 & 2.27 & 0.32 & & 28 & 60 & & \\
\hline LF & 1.85 & 3.30 & 1.03 & 002 & 26 & 60 & & \\
\hline Edgewor & 2.0 & 3.61) & 0.30 & & 30 & 60 & & \\
\hline & & & $1.6 \$$ & & 21 & 60 & & \\
\hline Wotre 3. & 2.6 & 5.28 & 0.32 & $33:(0)$ & 80 & 60 & & \\
\hline Fairlawn & 2.8 & $5.60)$ & & & & & & \\
\hline Carl. SC & 3.0 & 5.75 & 0.15 & & 28 & 60 & & \\
\hline Iroquous: & 3.15 & 5.95 & 020 & & 45 & 60 & & \\
\hline & & & 1.90 & & 28 & 60 & & \\
\hline Mnitand & 4.05 & 7.85 & 0.40 & $41: 00$ & & 60 & & \\
\hline Broed. & 4.35 & 8.25 & & & & & & \\
\hline Clyde & 4.75 & 9.75 & 1.50 & $48: 00$ & 16 & 60 & & \\
\hline & & & 0.42 & & 43 & 60 & & \\
\hline Churchill & 5.05 & 10.17 & & & & & & \\
\hline Kirkwood & 5.8 & 11.82 & 1.65 & $27: 00$ & 27 & 60 & & \\
\hline
\end{tabular}


Table 7-4: A Sample of Travel Time Run For Westbound Carling Ave

\begin{tabular}{|c|c|c|c|c|c|c|c|c|}
\hline \multicolumn{3}{|c|}{ Strest Name: WB Carling Ace } & \multicolumn{2}{|c|}{ Datelicb $15^{\text {th }}$ 1944 Time:7:51 } & \multicolumn{3}{|c|}{ Weather } & \multirow[b]{2}{*}{$\begin{array}{l}\text { Sezment } \\
\text { Delayy }\end{array}$} \\
\hline $\begin{array}{l}\text { Cruss } \\
\text { Streets }\end{array}$ & $\begin{array}{c}\text { Cum. Dist } \\
\text { Km }\end{array}$ & $\underset{\text { Imuss }}{\text { Cum } \mathrm{TP}}$ & $\begin{array}{l}\text { Segment } \\
\text { Trav Tune } \\
\text { mins }\end{array}$ & $\begin{array}{c}\text { Stop Time } \\
\text { secs }\end{array}$ & Sicg Speed & $\begin{array}{l}\text { Spred } \\
\text { l.init }\end{array}$ & $\begin{array}{l}\text { Idral } \\
\text { Travel } \\
\text { Time }\end{array}$ & \\
\hline Churchilh & 0.3 & & 0.984 & & 27 & 60 & & \\
\hline Cyde & 0.75 & 1.417 & 1.250 & & 12 & 60 & & \\
\hline Broadvie & 1.00 & 2.667 & 0.960 & & 60 & 60 & & \\
\hline Maivand & 1.90 & 3.567 & 0.183 & & 66 & 61) & & \\
\hline Iroquous & 2.10 & 3.750 & 0.167 & & 54 & 60 & & \\
\hline Carl. SC & 2.25 & 3.917 & 0.753 & & 56 & 60 & & \\
\hline Fairlawn & 2.95 & 4.670 & 0.163 & & 74 & 60 & & \\
\hline Wo'ffe & 3.15 & 4.833 & & & 15 & 60 & & \\
\hline Edgewon & 3.20 & 5.033 & & & 35 & 60 & & \\
\hline Lincoln & 3.65 & 5.800 & & & 38 & 60 & & \\
\hline & 3.80 & 6.033 & 0.217 & & 55 & 60 & & \\
\hline Croydon & 4.00 & & 1.567 & & 11 & 60 & & \\
\hline Alpine & 4.30 & & 0.416 & & 43 & 60 & & \\
\hline Rich & 4.60 & 8.233 & & & & 60 & & \\
\hline Pine & 5.10 & 8.750 & & & & & & \\
\hline
\end{tabular}


Table 7-5: Sample Travel Time Runs for EB Queensway.

\begin{tabular}{|c|c|c|c|}
\hline Study Section:Eastbour & Highway 417 & eb $8_{t h} 1994$ & Road Condition:Bare \\
\hline Ramp & $\begin{array}{c}\text { Cumulative 'Distance } \\
\text { (km) }\end{array}$ & $\begin{array}{l}\text { Cumulative Travel } \\
\text { Time (mins) }\end{array}$ & $\begin{array}{l}\text { Av. Link Travel } \\
\text { Speed }(\mathbf{k m} / \mathbf{h}) \text {. }\end{array}$ \\
\hline $\begin{array}{l}\text { Greenbank ramp * } 51 \\
\text { Greenbank ramp \# } 35 \\
\text { Greenhank ramp \# } 25 \\
\text { Woodroffe ramp \# } 51 \\
\text { Woodroffe ramp \# } 35 \\
\text { Woodroffe Ramp \# } 25 \\
\text { Mailland Ramp \# } 51 \\
\text { Mailland Ramp \# } 15 \\
\text { Kirkwood Ramp \# } 57 \\
\text { Kirkwood Ramp \# } 55 \\
\text { Kirkwood Ramp \# } 65\end{array}$ & $\begin{array}{l}0.2 \\
0.7 \\
2.3 \\
2.4 \\
2.7 \\
4.2 \\
4.3 \\
5.5 \\
6.2 \\
6.7\end{array}$ & $\begin{array}{l}0.000 \\
0.450 \\
1.283 \\
5.750 \\
6.100 \\
6.817 \\
10.167 \\
10.400 \\
11.750 \\
12.350 \\
12.567\end{array}$ & $\begin{array}{l}21 \\
\\
27 \\
53\end{array}$ \\
\hline
\end{tabular}




\subsection{Results From Field Studies}

From travel time studies, it was observed that the peak 15 mins in the corridor was 'Jetween 7:50 and 8:05 a.m. in the eastbound direction. Corresponding westbound field and simulated results were also used to compare off peak conditions. Out of a total of 49 runs, only travel time runs in the peak 15 inins of the hour were used for comparison. Table 7-6 shows selected travel time runs, used for comparison. The westbound Queensway travel times were consistent, ranging from 3.5 to 3.8 minutes, a $9 \%$ difference. For the eastbound direction, travel times ranged from 12.6 mins to 21.9 mins (a 74\% change from the minimum to the maximum), suggesting that peak period freeway travel times are unpredictable, inconsistent and erratic. Such traffic patterns are due to high traffic volumes and densities, resulting in shockwaves upstream of mainline and ramp bottlenecks, causing a ripple effect in trifitic flow. The end result is forced flow, increased stopi, and longer travei times on the mainline.

C. the Westbound Carling Avenue, travel times were between 8.5 and 9.5 mins (12\% change between the lowest and the highest rates) whilst the eastbound direction recorded 10.4 to 12.5 mins (20\% change between the highest and the lowest rates). These results indicate that travel time on eastbound Carling Avenue during the peak period is lower than its corresponding section on the Queensway. Furthermore travel time variation on Carling Ave is very low, when compared to the eastbound Queensway. Therefore one can predict the arterial travel time with a reasonable level of accuracy.

Eastbound and westbound travel times for ' oth the Queensway and Carling Avenue were averaged and compared with NETSIM and FREFLO simulation models. 


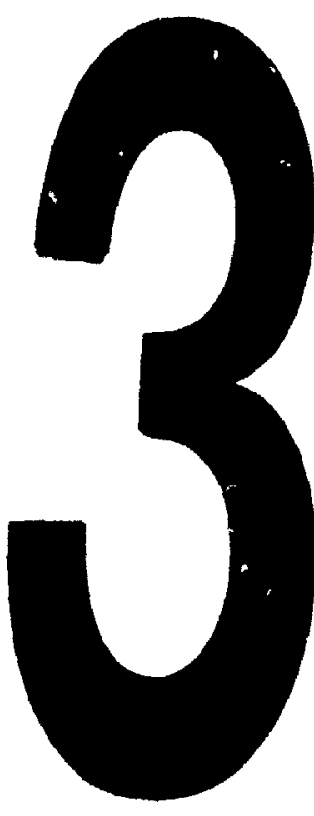

8
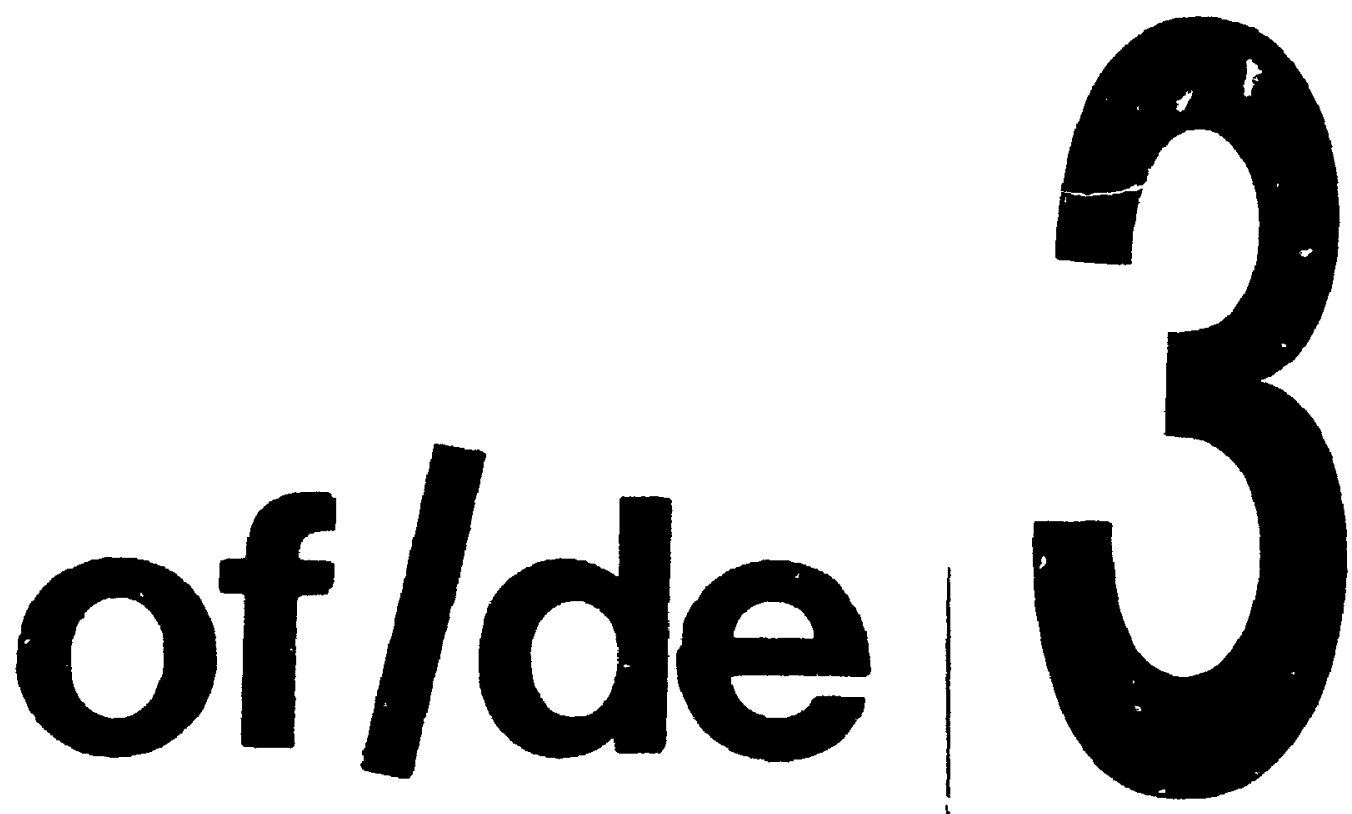

PM-1 31/2"X4" PHOTOGRAPHIC MICROCOPY YARGET NBS 1010A ANSI/ISO *2 EQUIUALENT

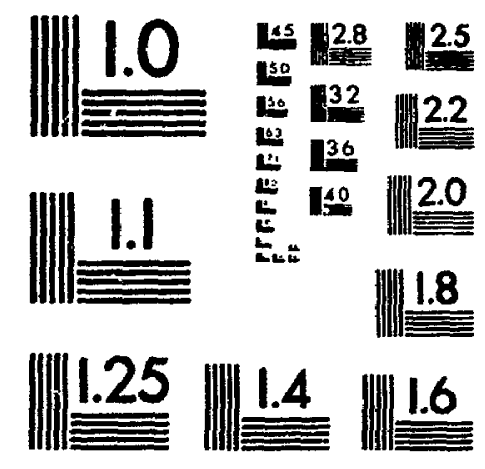

PRECISIONSM RESOLUTION TARGETS 
Table 7-6: Selected Travel Times.

\begin{tabular}{|c|c|c|c|}
\hline Date & Designation & Start Time & Clim Travel Time \\
\hline Feb $7^{\text {th }} 1994$ & WB Quecnsway & $7: 57$ & 3.767 \\
\hline Feb $8^{\text {th }} 1994$ & WB Qucensway & $7: 50$ & 3.533 \\
\hline Feb $10^{\text {th }} 1994$ & WB Qucensway & $8: 00$ & 3.783 \\
\hline May $30^{\text {th }} 1994$ & WB Quecnsway & $8: 01$ & $3: 750$ \\
\hline June $2^{\text {nd }} 1994$ & WB Queensway & $7: 23$ & 3.650 \\
\hline Feb $7^{\text {th }} 1994$ & EB Qucensway & $7: 52$ & 14.583 \\
\hline Feb $8^{\text {th }} 1994$ & EB Queensway & $8: 00$ & 12.567 \\
\hline Feb $10^{\text {ch }} 1994$ & EB Qucensway & $7: 57$ & 21.850 \\
\hline May $30^{\text {th }} 1994$ & EB Qilcensway & $7: 43$ & 13.250 \\
\hline June $2^{\text {nd }} 1994$ & EB Qucensway & $7: 53$ & 12.917 \\
\hline Feb $14^{\text {th }} 1994$ & WB Carling & $8:(1) 4$ & 9.500 \\
\hline Feb $15^{\text {th }} 1994$ & WB Carling & $7: 55$ & 8.50 \\
\hline Feb $16^{\text {th }} 1994$ & WB Carling & $7: 40$ & 8.33 \\
\hline Feb $18^{\text {th }} 1994$ & WB Carling & $8: 02$ & 8.75 \\
\hline May $24^{\text {th }} 1994$ & WB Carling & & 7.63 \\
\hline Feb $14^{\text {th }} 1994$ & EB Carling & $7: 54$ & 10.67 \\
\hline Feb $15^{\text {th }} 1994$ & EB Carling & $7: 51$ & 11.82 \\
\hline Feb $16^{\text {th }} 1994$ & EB Carling & $7: 50$ & 12.52 \\
\hline Feb $18^{\text {th }} 1994$ & EB Carling & $7: 48$ & 11.20 \\
\hline May $24^{\text {th }} 1994$ & EB Carling & $7: 50$ & 10.43 \\
\hline
\end{tabular}

\subsection{Comparison of Simulation and Field Results:}

\subsubsection{FREFLO Model}

Comparison of observed and simulated results for FREFLO are shown in Figures 7-1 \&

7-2. An average westbound travel time run of 3.7 mins was obtained as compared to a 


\section{Travel Time Comparison Westbound Highway 417}

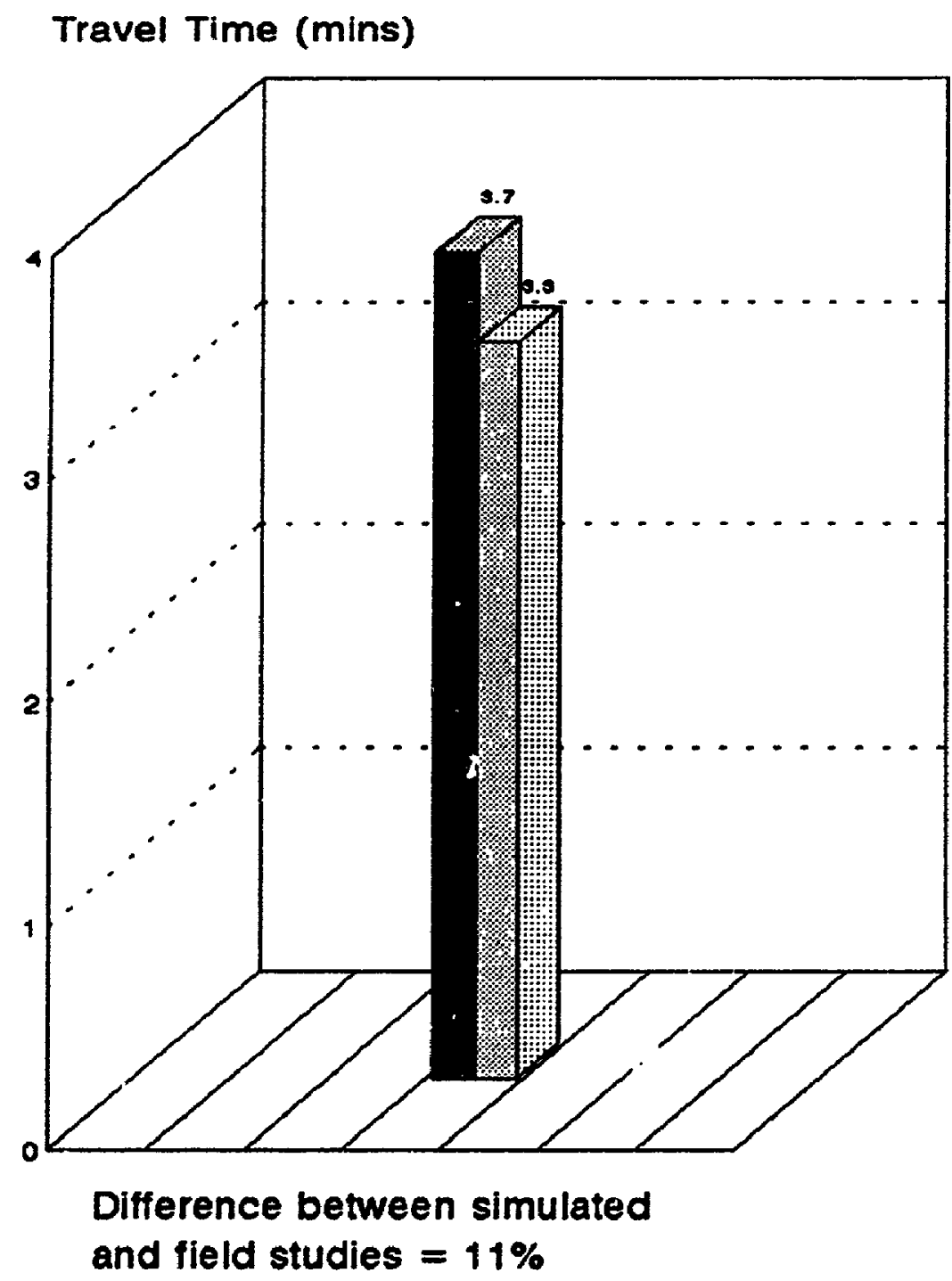

\section{Fiold \\ 图 Simulation}

Figure 7-1 Travel Time Comparison: WB Highway 417 


\section{Travel Time Comparison} Eastbound Highway 417

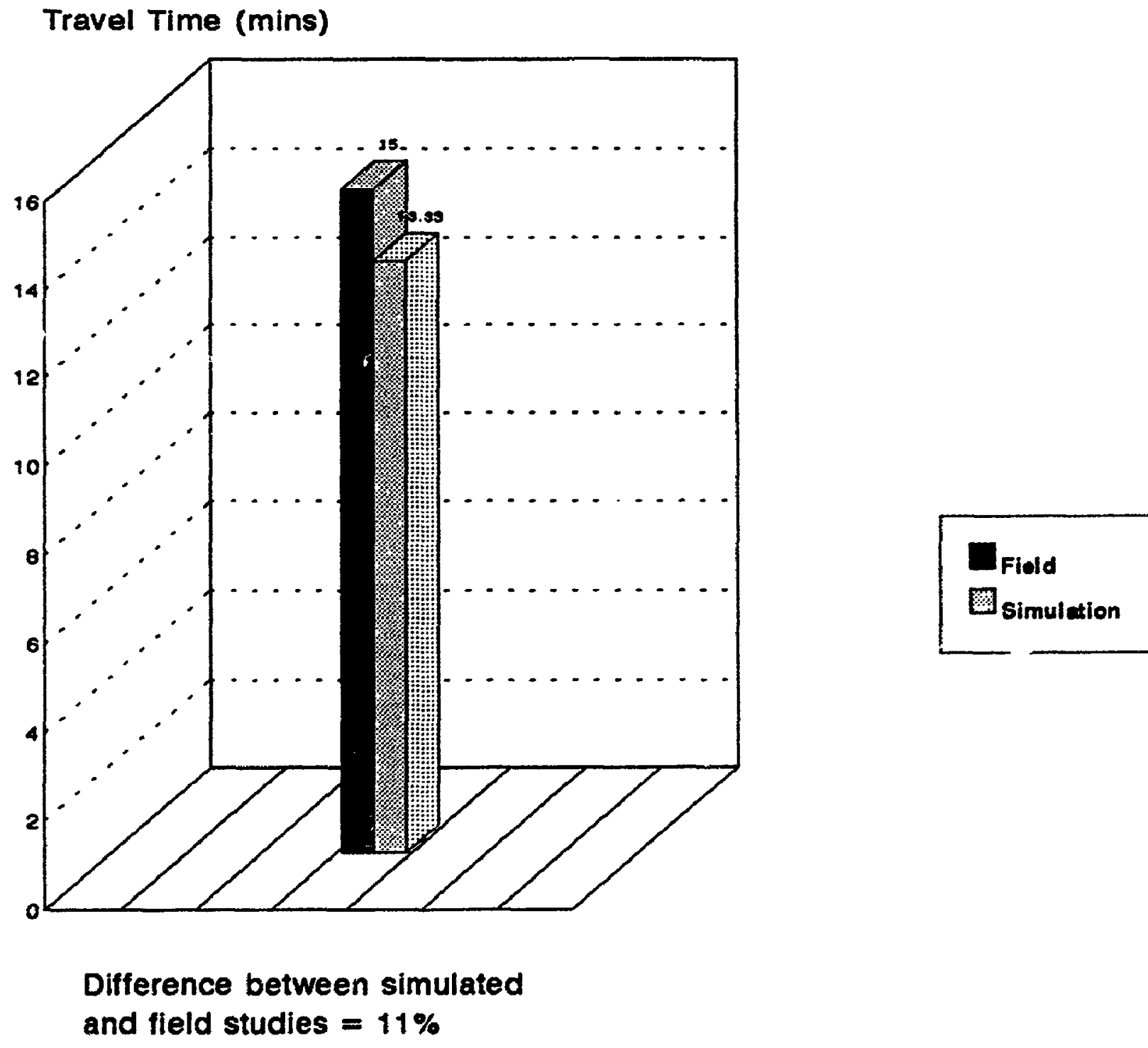

Figure 7-2 Travel Time Comparison EB Highway 417 
simulated 3.3 mins. This gives an error of $11 \%$. An average eastbound travel tims of 15 mins was obtained as compared to a simulated time of 13.4 mins indicating a $11 \%$ error. The model tends to underestimate cumulative travel iimes for both directions.

\subsubsection{NETSIM Model.}

An average eastbound travel time of 11.3 mins, compared with simulated time of 12.8 min yields an error of $12 \%$ for eastbound Carling Ave. For the westbound direction, an average travel time of 8.5 mins, compared with a simulated time of 8.3 mins gives a $3 \%$ difference (Figures $7-3 \& 7-4$ ). Therefore the model overestimated travel times at peak periods whilst it slightly underestimated cumulative travel time at off peak periods.

Based on these results it could be inferred that all performance measures generated by both NETSIM \& FREFLO are within $12 \%$ error.

In general, both FREFLO \& NETSIM models compared reasonably well with field results, given the fact that,

- the FREFLO model was not calibrated with site specific data,

- all intersections on Carling Avenue were modelled as "pretimed." 


\section{Travel Time Comparison Eastbound Carling Avenue}

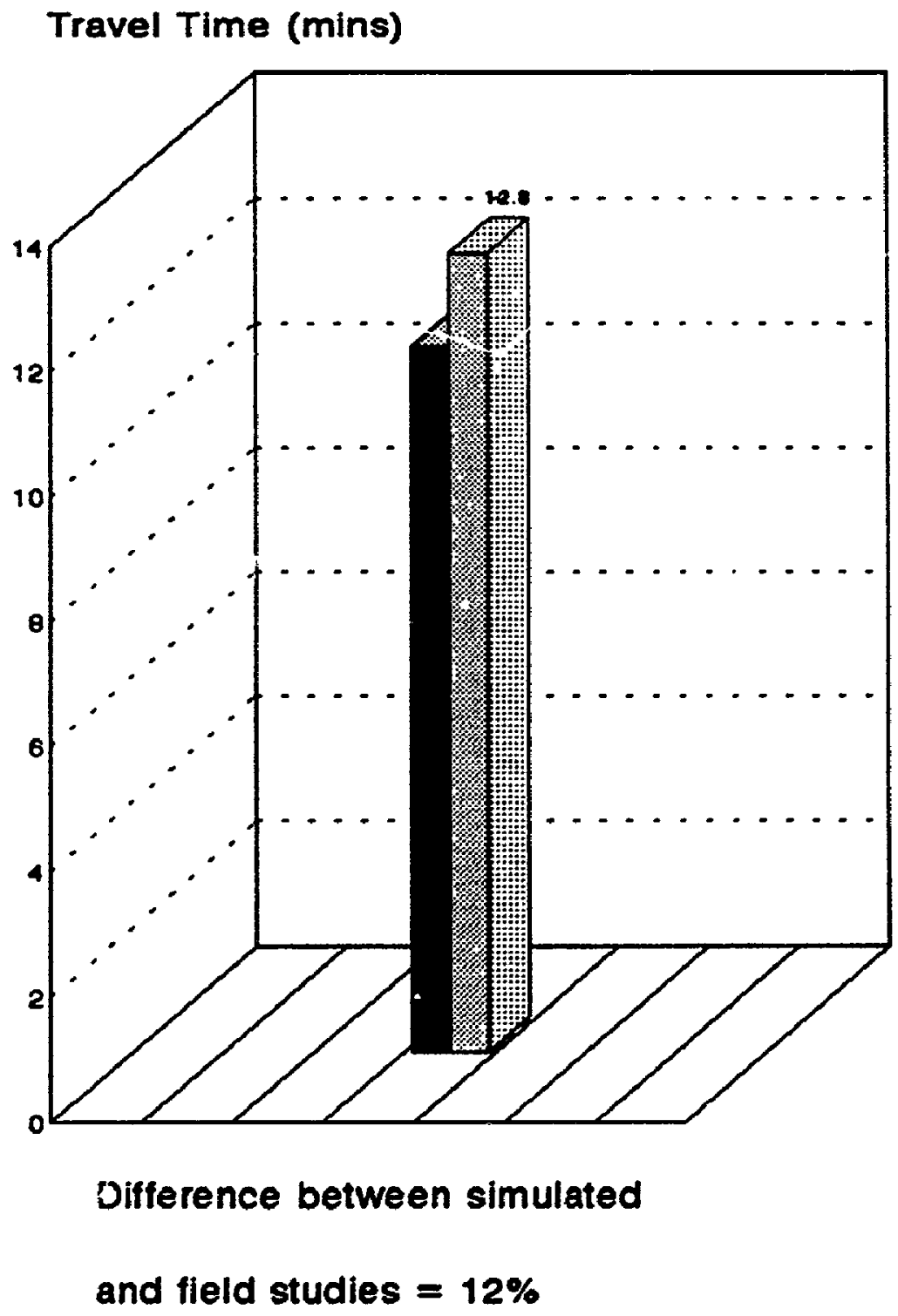

Figure 7-3 Travel Time Comparison EB Carling Ave. 


\section{Travel Time Comparison Westbound Carling Avenue}

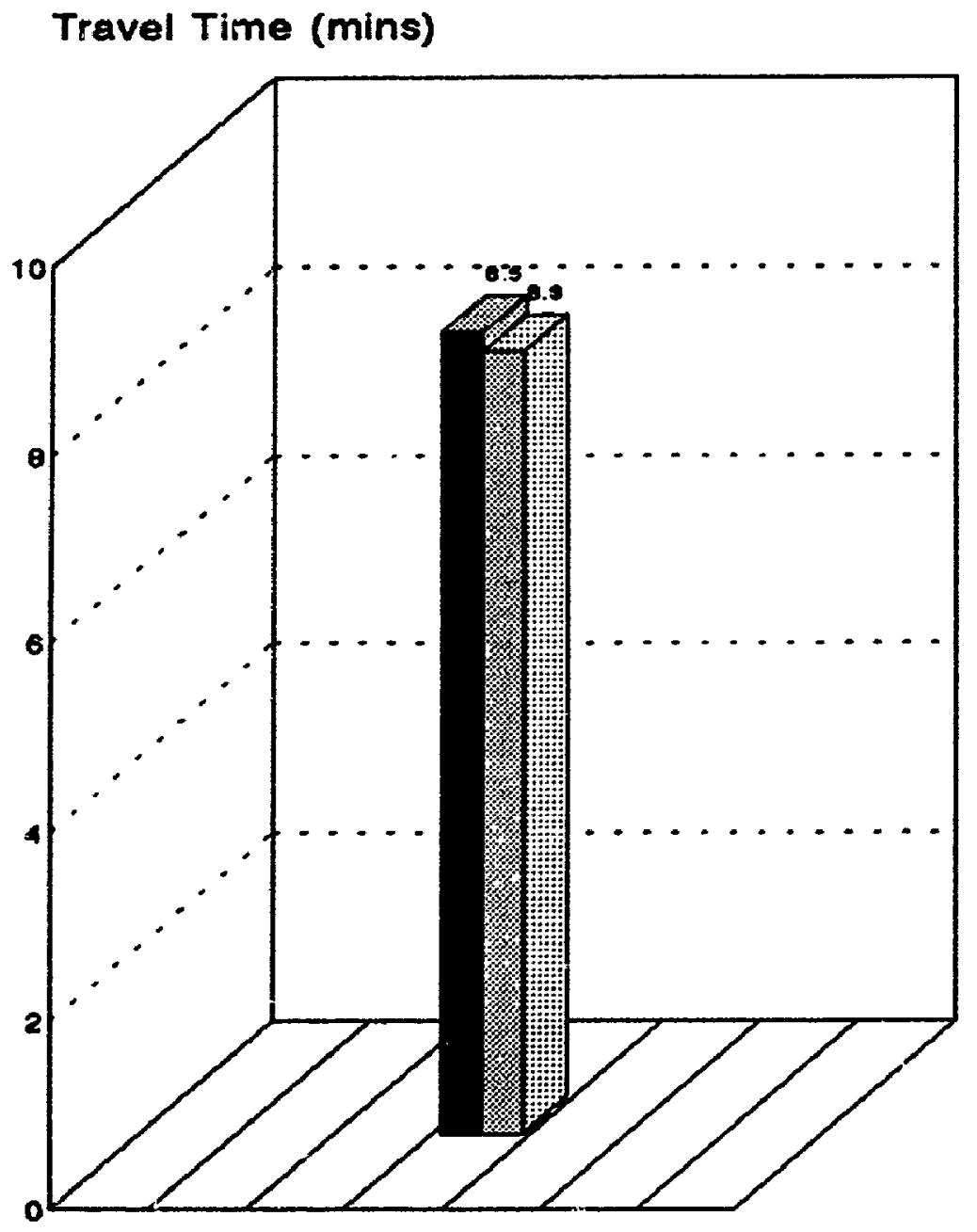

Difference between simulated and fleid studies $=3 \%$

Figure 7-4 Travel Time Comparison WB Carling Ave. 


\section{CHAPTER 8}

\section{IMPLEMENTATION}

\subsection{Introduction}

The purpose of this chapter is to give a brief description of how the methodology developed in this study could be implemented in the field. Because freeway network and surface street network are under different jurisdictions in most urban areas, implementation of freeway and arterial traffic management methods require a system integration. In such a case, strategies will be executed in the corridor with one accord in order to minimise corridor travel time, and make efficient and optimal use of resources.

\subsection{System Integration}

The concept of system integration implies :

- a complete elimination of provincial, municipal and federal boundaries in traffic management and control,

- to coordinate policies and programs in the corridor, and

- to cooperate and communicate in traffic control matters.

These attributes of integration would maximize the efficiency and effectiveness of traffic in the corridor. Integration attempts to converge all transportation systems in the corridor 
and makes them work as a single system in order to maintain a balanced movement of traffic in the corridor. Localised traffic management systems cannot monitor traffic in the entire corridor, and therefore its benefits are localised. Sometimes policies of neighbouring agencies work against each other. Any system integration requires free flow of information between all the agencies. There are three Cs in system integration, namely:

- Co-ordination,

- Co-operation, and

- Communication.

For cost effectiveness, the existing urban and proposed freeway traffic control systems need not be discarded or changed, neither should the responsibilities of these agencies differ. The most economical method is to link both arterial and freeway control systems together, such that both control centres could monitor the entire corridor. This could be made possible through a centralised computer data base, linked to both systems to collect and disseminate corridor information, similar to the one used by the smart corridor in California, and as being planned in the Gardiner-Lakeshore Corridor Traffic Management System in Toronto [Kay, 1992; Kelman, 1992]

When corridor-wic : policies, goals and objectives are developed and a complete knowledge of real time traffic in the corridor are made available, to all agencies, control strategies will be more acceptable, and mobility enhanced.

\subsection{Methodology Application}

The methodology, as discussed in Chapters $4 \& 5$ are best suited for "on line" metering. 
As such, the mainline and alternate surface routes require vehicle detectors, traffic signal controllers, a central traffic control systen, and communications systems.

\subsubsection{Freeway Links}

Field equipment for the freeway is not much different from the planned systems. Induction loop detectors, located upstream and downstream of ramp junctions as well as in between basir, freevay sections collect traffic volume and occupancy data. The ramp controllers, located at interchanges,

- control adjacent ramp signals when the central control system is "off line", collect volume and occupancy data, perform some checks on the accuracy of loop information, and gather and transmit alarm and failure information.

A central control centre, equipped with central computers receives data from vehicle detectors and ramp controllers via communication lines, and sends metering plans to all ramps concerned.

\subsubsection{Surface Streets:}

Real time traffic adjacent to the mainline could be monitored. detected, and controlled by a traffic adaptive control system, similar to the SCOOT or SCATS system.

SCOOT, which stands for Split Cycle \& Offset Optimisation Technique, was developed in Glasgow, United Kingdom, by a team from the Transport Road Research Laboratory (TRRL), the Ferranti, GEC, \& Plessey traffic companies. It is a significant improvement 
over the "First Generation" traffic control systems. First generation traffic control systems use "off line" signal timing plans from computer programs such as TRANSYT, PASSER etc, based on historical traffic data.

The SCOOT system develops timing plans based on real time traffic collected from loop detectors. Cycle splits, and offsets are adjusted automatically in small incremencs to respond to prevailing traffic [Hunt et. al., 1982; Clowes, 1982; Walmsley, 1982].

The SCOOT system is presently used by 25 cities in the UK, and other cities which include Hong Kong, Beijing, Sao Paolo, Red Deer (Alberta), Halifax, and Oxnard (California). Presently, the Municipality of Metropolitan Toronto is conducting a demonstration project on three distinctly different signal network areas, with different operational characteristics and complicated traffic operations using the SCOOT system [Quan, Greenough et. al., 1993]. The Regional Municipality of Ottawa-Carleton have also identified traffic adaptive control as its future traffic control system. The main field equipment for a traffic adaptive control could include:

- vehicle detectors,

- communication unit,

- central controller.

Following is a brief description of the SCOOT system.

Loop detectors, used in the vehicle detection system, are located about 10 to 15 metres downstream of all signalised approaches on all surface street approaches in the corridor, as shown in Figure 3.1. This location enables the collection of traffic volumes 


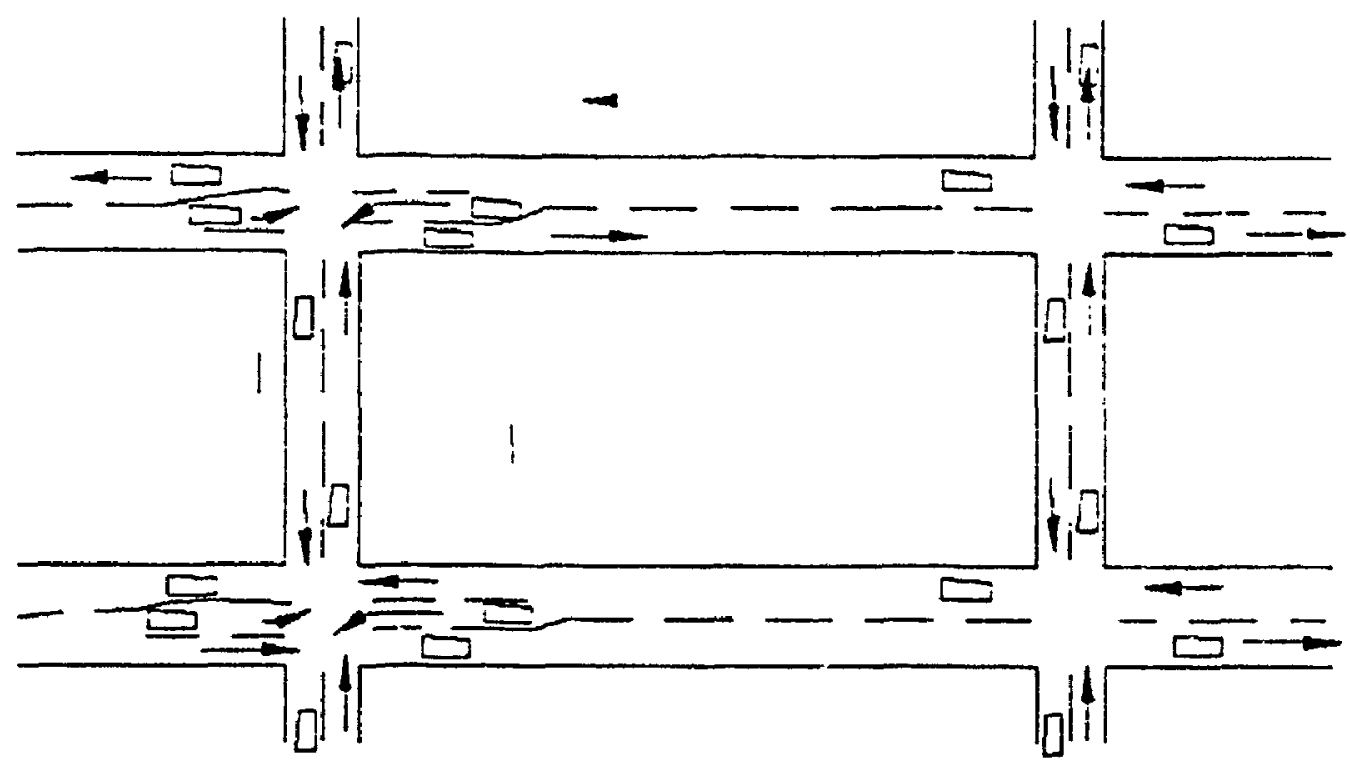

Figure 8.1 Layout of Vehicle Detectors

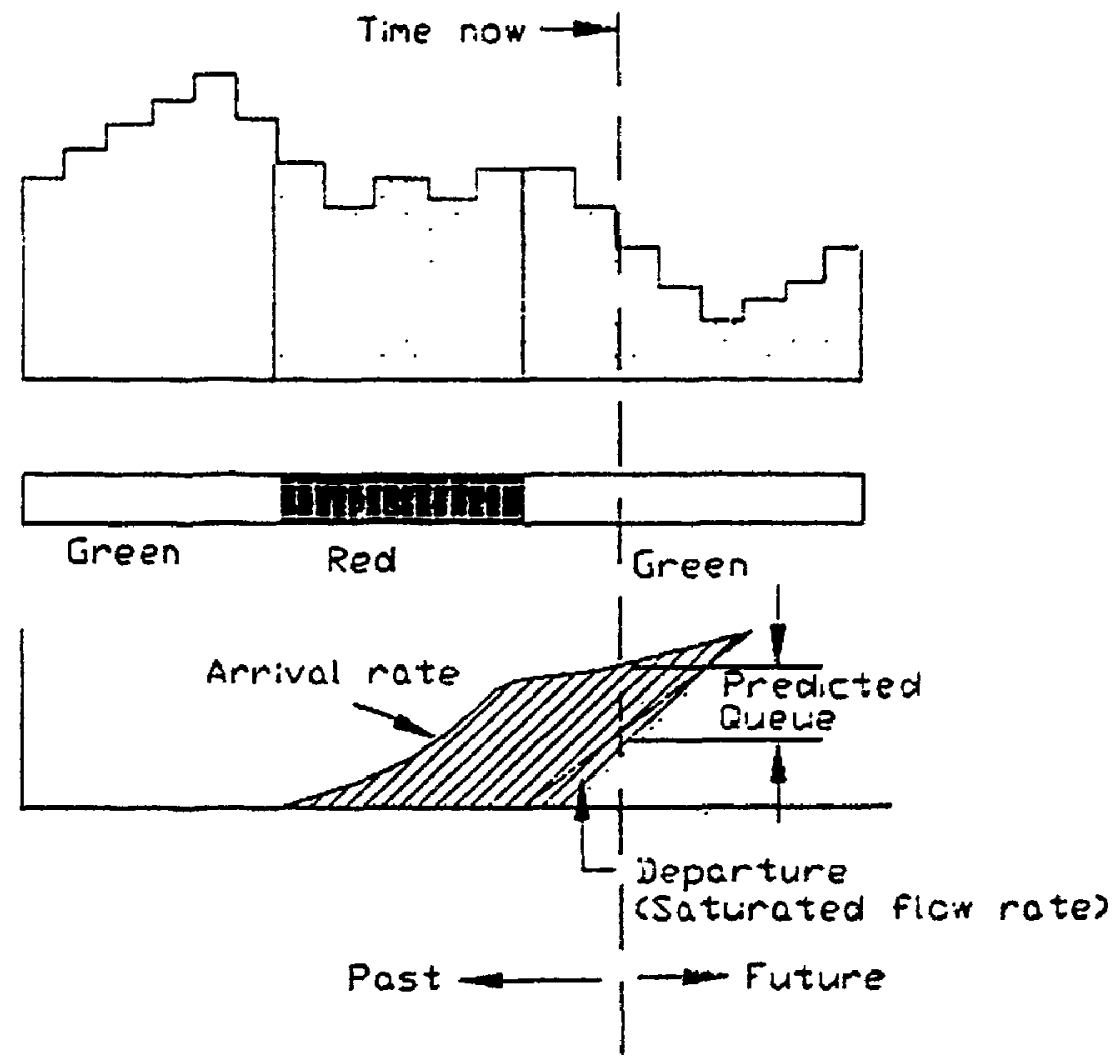

Figure 8.2: Principles of The SCOOT Traffic Model. Source: Hunt et al 1982. 
at free flow conditions. Based on traffic cruise speed, the status of the traffic signal, and saturation flow rate, vehicle occupancies, tratfic volumes and queue lengths are estimated and predicted seconds ahead of time (see Figure 8.2). Traffic queues and occupancy provide an indication of delays at the intersection.

A few seconds before the end of each phase, the split optimizer either decides to decrease or increase the green time based on volume and queue predictions. Cycle lengths are updated any time there is a change in green times, by small increments, for at least 2.5 minutes. Signal of fsets are also adjusted incrementally to minimize stops, delays and maintain a smooth signal transition [Hunt et al, 1982; Clowes, 1982; Walmsley, 1982].

\subsubsection{The Algorithm}

The innovative aspect of this ramp control system lies in its system integration, where ramp controls are coordinated with other corridor traffic control systems. Control algorithms for system integration are outlined in the flow chart shown in Figure 8.3. A description $c$ s the algorithm is provided next.

Mainline detectors are scanned by the microprocessors 60 times a second, to measure volume and occubancy data, which are then sent to the central control computer once every second. The condition of various sections of the mainline are assessed, to determine if these volumes and occupancies are greater or less than the established threshold capacity. Where mainline traffic is less than the threshold value, entrance ramps are not controlled. If on the other hand these values are greater than the established threshold values, metering rates are calculated and introduced using the linear 


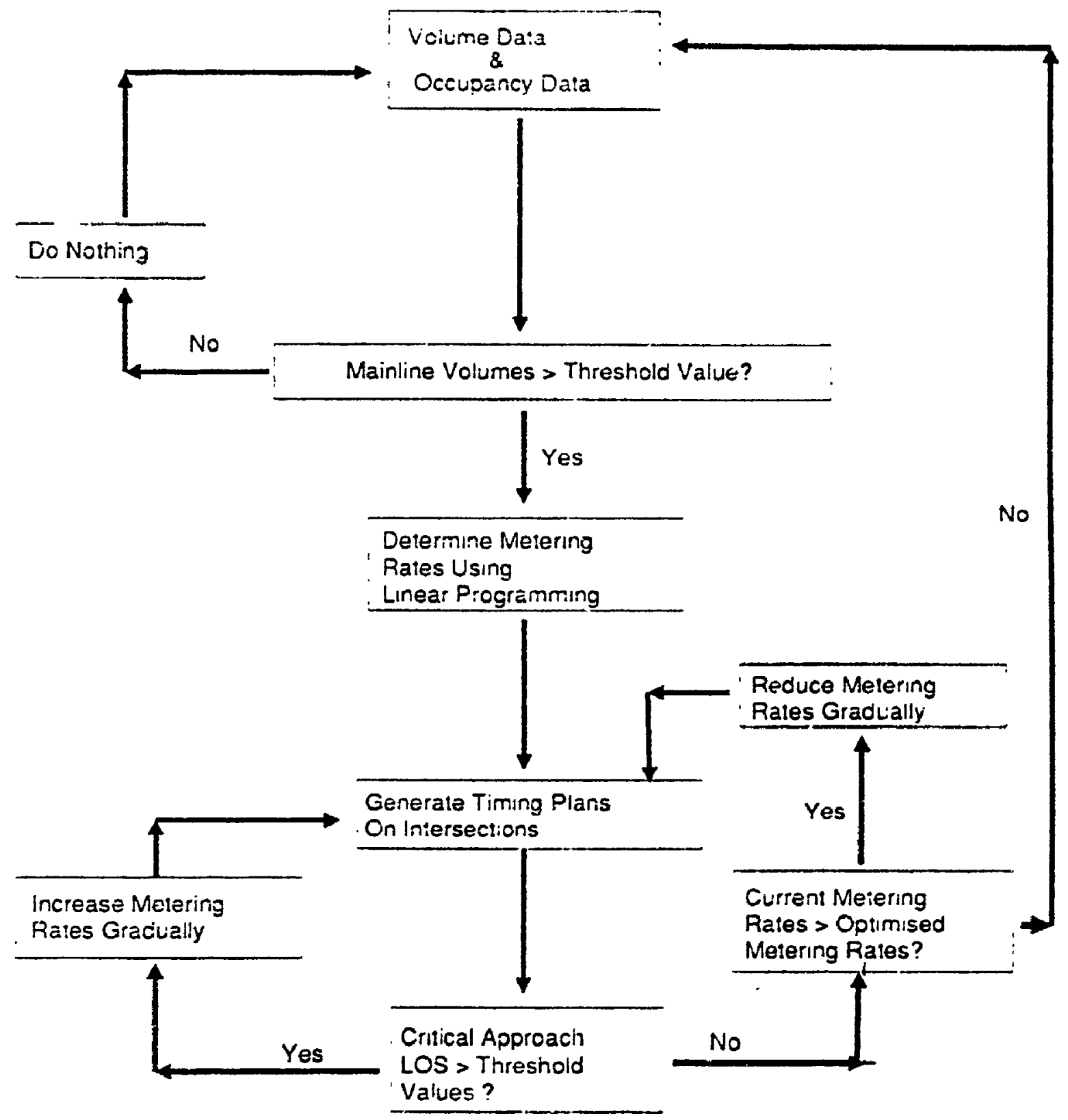

Figure 8.3: Algorithms For Corridor Traffic Control 
programming technique as described earlier.

"On line signal timing plans using the SCOOT system are generated and introduced on all signalized intersections in the corridor. Each signalized intersection approach, by virtus of its geometry, number of lanes, traffic volumes, pedestrian vulumes, etc would need threshold levels of delay established, based on current and predicted traffic conditions on the basic freeway sections. As the mainline LOS deteriorates, the threshold value for intersection stopped delays are increased up to a certain limit, where it is maintained even if mainline conditions continue to deteriorate. The critical approach level of delay influences metering rates. Where the latter is greater than the threshold values, metering rates are increased gradually. Signal timing are fine tuned to respond to reduced traffic on the surface streets, due to increased metering and critical approach delays compared with the threshold values. When critical approach delay is less than its threshold value, existing metering rates are checked if they are greater than the optimized rates. If yes, metering rates are reduced incrementally, and if nc: metering rates are calculated using the linear programming technique.

\subsubsection{Limitations}

- The success of this methodology depends on establishing the changing threshold delay levels for each approach with respect to mainline traffic predictions. The purpose of the changing threshold values is to smoothen the time taken for diverted traffic to have an impact on signalised intersections.

- The algorithm depends solely on the accuracy of the vehicle detection system. The 
accuracy of loop detectors as mentioned earlier is within $6 \%$ which is acceptable for the system. However, image processing techniques, such as the Autoscope techrology, when fully developed will enhance the accuracy of the system.

- The threshold delay values do not take into consideration any origin destination data, therefore these values may be under or over estimated. However historical origin destination data may be used to estimate threshold values within a reasonable range.

\subsubsection{Advantages}

- The algorithm works with real time traffic conditions. The prevailing traffic signal timing plans respond to real time metering rates. The control of traffic in the entire corridor is coordinated to minimise corridor travel time as well as maintain a certain level of acceptable delay on the surface streets. Corridor travel time is therefore predictable, and mobility is improved in the corridor.

- The system does not rely on a traffic assignment procedure. The SCOOT system measures real traffic moving on links, making any traffic assignment unnecessary.

- Improved data for traffic and transportation planners become readily availabie. Real time traffic conditions could be made available to the motorist through a number of systems as in the form of changeable message signs on the freeways, arterial control signs, highway advisory radio and other media dissemination procedures. Such information could also be available at major transit transfer points to avoid routes with longer delays. 
- All agencies comraunicate, coordinate, and cooperate effectively; hence all programs in the corridor are interrelated with common goals.

\section{A Application To The Ottawa-Carleton Region}

The O:tawa-Carleton Region uses a decentralised urban traffic control system, with three levels of control as shown in Figure 8.4:

- Local Control,

- Regional Control, and

- Central Control System.

The local controllers, located close to each signalised intersection,

D monitor traffic at intersections with loop detectors within its jurisdiction,

ㅁ check system components for failure at the local level,

D send traffic data and all other relevant information to the regional conitrollers and

口 send signal timing plans to traffic signals.

The regional controllers, located at Orleans, Kanata, Walkley, Brittannia and Montreal Rd, D provide traffic and equipment information status to the central control system, (via regional controllers) as well as carry instructions from the centralised control system to the local controllers, 


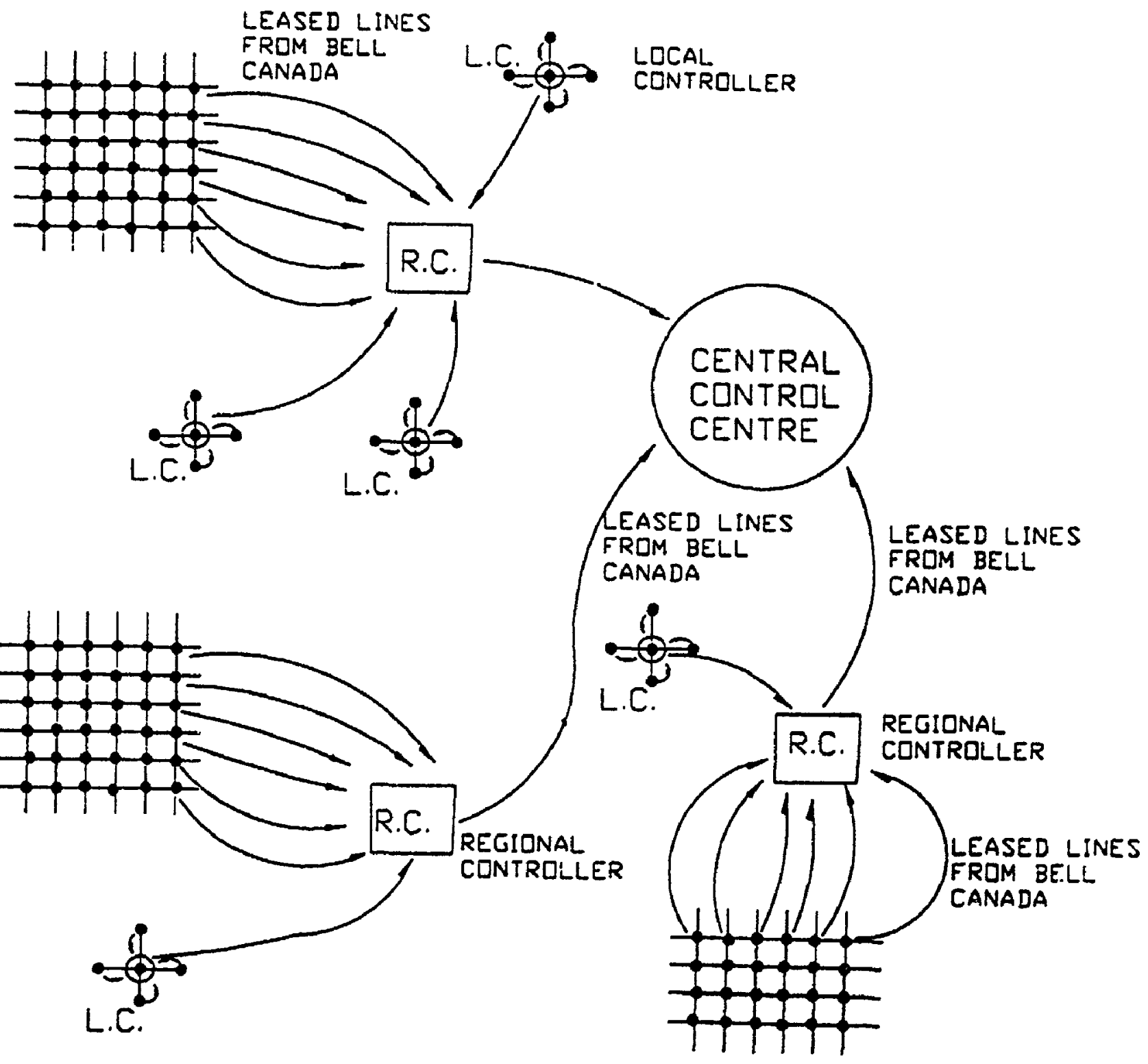

Figure 8.4 The UTCS System In The Ottawa Carleton Region. 
口 communicate with all local controllers in their jurisdiction; these determine timing plans based on time of the day.

The central control system, located at Loretta Ave, (Ottawa):

D is capable of monitoring traffic at any intersection; therefore equipment failures are detected on time, and the proper response executed,

D is capable of controlling and overriding timing plans for any signalised intersection, via the regional controllers.

A set of eight local controllers communicate with their respective regional controller through a leased Bell Canada telephone line with the help of a high speed modem. Regional controllers are also linked to the central traffic control system in a similar manner.

The advantages of the system are:

- reduced cost of communication: the number of telephone lines leased from Bell Can ada is reduced,

- although the local, regional, and central control systems are linked to each other, they can operate independently if any of them is out of order.

Its disadvantage is that field equipment is bigger, more expensive, more complex and require a higher level of protection.

To apply ramp netering as described in the methodology for the Ottawa-Carleton Region, the present loop detectors on Carling Ave and all its crossing streets will have to be re- 


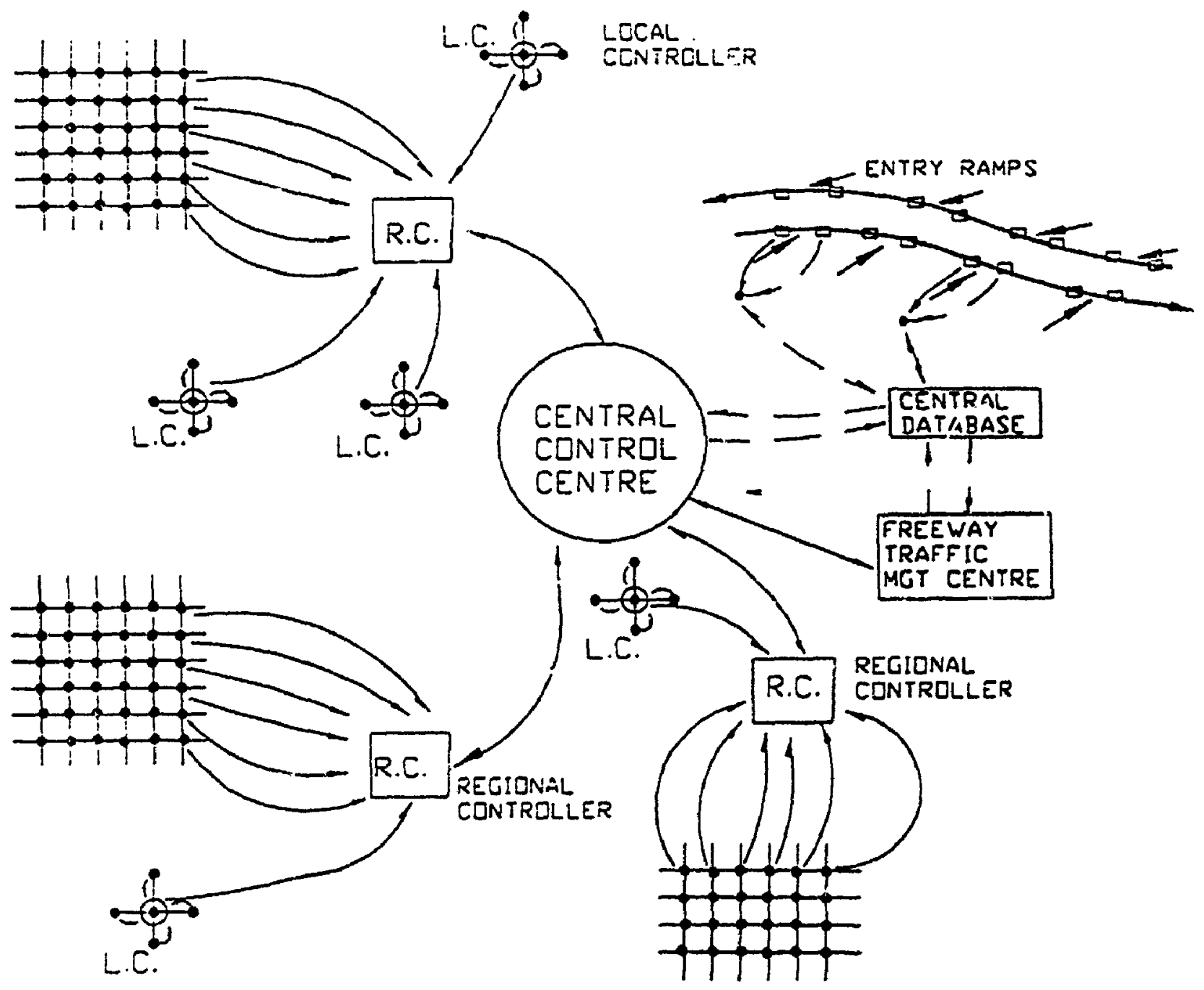

- local controller

- LUDP DETECTORS

Figure 8.5 Proposed System Integration For The Ottawa Queensway Corridor. 
sited within $15 \mathrm{~m}$ downstream of signalized approaches as discussed earlier and shown in Figure 8.1. Local, regional and central control centres need not be modified. An additional system component required is a centralised computer data base, which could be lacated at the freeway traffic management centre to communicate with the latter, as well as the centralised urban traffic control centre (Figure 8.5). Existing control and responsibilities of both RMOC and MTO need not change. The only special feature is to develop algorithms, as described earlier, to override ramp metering rates based on threshold stopped delays.

Advanced sensors, computers and communication technologies are rapidly advancing, which makes it very uncertain what type of hardware and software that any advanced control system should use to be cost-effective and not be obsolete within a few years. Furthermore different agencies may be operating different types of systems which may not be compatible with each other.

The concept of system integration is not only to integrate the overall traffic control system but also to integrate its system components as well. The control system should be developed with an ultimate objective to make its system architecture flexible. The uncertainties in the type of hardware and software to use, could be reduced by a method where integrated transportation agencies could work together to select identical hardware in future as well as to develop a common or compatible software in order to have a complete control of their control systems and reasonably respond to changing technology. As the number of agencies are integrated, there will be more technical experts who can participate in such regional programs. 


\section{CHAPTER 9}

\section{CONCLUSIONS \& RECOMMENDATIONS}

\subsection{Conclusions}

Although the use of current ramp metering methodologies has improved the freeway traffic flow in most application areas, serious inefficiencies have resulted because their impacts have been addressed, in only a few locations, from a corridor perspective. Hence corridor travel time is not optimised. The objective of this research was to develop a methodology for ramp metering as well as to conduct a detailed investigation of its impacts in the corridor. As reported in the previous chapters, these have been accomplished. The impacts of metering were analyzed by using the Ottawa Queensway as a case study. Unlike other ramp metering feasibility studies which have been conducted [McCormick Rankin, 1986; Cocoran et. al., 1991; IBI Group 1987, 1991 \& 1993; Ayland et. al., 1982; etcl, this study carried out the impacts of metering on adjacent parallel routes and all streets crossing this route. Corridor analysis was also undertaken to determine whether metering improved the overall traffic conditions in the corridor.

From the research results, the following conclusions can be drawn:

Unlike traffic signals, there are no warrants for ramp signals in order to determine their installation. Hence a methodology is needed to determine their feasibility, 
such that there is an efficient movement of traffic, with no adverse effects especially on the alternate routes. Existing methodologies only looked at metering feasibility in terms of benefit cost analysis without conducting a full scale analysis on alternate routes. These are therefore opposed by the public, and some Municipal, City and County Transportation Agencies. This methodology provides a comprehensive analysis of alternate routes within a corridor, using operational analysis.

Given residual capacity on alternate routes, freeway ramp control, when integrated and coordinated with arterial traffic control, yields the following results:

- Reduced total corridor travei time is possible.

- Increased traffic throughput in the corridor as well as traffic throughput in the direction of the peak traffic with metering is another useful outcome, even though the objective of metering was not to increase capacity of the freeway, but to maintain a stable flow. Improved traffic conditions meant that there was a stable and orderly movement of traffic on the mainline and the number of vehicles competing for space at on ramp merge and other bottlenecks has been reduced tremendously.

- Efficient progression is capable of causing only a very small change in performance measures of traffic travelling against the peak direction even when "optimised metering rates" are used.

Although travel time on alternate routes were increased owing to traffic diversion, 
the eastbound and total corridor travel times reduced remarkably.

Metering rates under the sole objective of maximising freeway traffic input would yield undesirable impacts on alternate routes, whilst maximum metering rates would slightly improve freeway traffic flow. Therefore the best metering plan is the one that minimizes total corridor travel time and at the same time satisfies the threshold intersection approach stopped delays for all intersections in the corridor. A comparison between field studies and the FREFLO model indicated that during congestion, the model slightly underestimated travel time. The reason cannot be fully attributed to the model since certain speed density relation parameters were assumed due to lack of data. Field studies from link travel analysis confirmed the accuracy of TRAF-NETSIM simulation model.

\subsection{Recommendations}

From the research, the following recommendations could be made:

The methodology reported here, for determining the best metering plans for effective and efficient movement of traffic in the corridor could be used by the profession to minimise corridor travel time and reduce opposition to ramp metering.

The benefits and impacts of metering as analyzed, were estimated only for the peak 15 minutes of the peak hour. Further studies are needed to evaluate the impacts of metering for the entire peak period. 
Further studies are seeded in the development of integrated dynamic simulation models, with a view to optimize traffic in a corridor as one system. Such models would be very useful for a comprehensive evaluation of diverted traffic, including dynamic traffic prediction and assignment, and provide accurate corridor analysis.

There is the need to establish a methodology for selecting the type of ramp control strategy under budget constraints, addressing problems such as where to start, when to expand the syster. and the required components for effective operation. Models to determine the best control strategy, given such constraints as available funds, would be very useful to traffic and transportation managers.

Further studies are also needed to determine the criteria to select an integrated control system components (hardware and software components) as well as its cost effectiveness, bearing in mind the rapidly changing technology.

Further studies are needed to quantify the impacts of metering on noise levels, fuel consumption and vehicle emissions in the corridor.

Freeway, arterial and intersection level of service standards determined by the Highway Capacity Manual, although very useful, are not site-specific. More research is required to determine the tolerable level of congestion in the OttawaCarleton Region. Such a study would be used to decide on the threshold level of 
service required at all intersection approaches.

Real time traffic control strategies could be made more responsive to traffic, if the changing O.D. patterns could be accounted for. Rapid advancement in communication, computers and sensor technologies and the increased number of vehicle probes will make it possible to determine real time O.D. patterns. Further studies are required to determine dynamic O.D. patterns to reflect real time traffic.

More research in latent demand, its key factors, and impacts on traffic growth is required.

A number of IVHS technologies, such as sensor technologies currently under development or available, open up more options and innovation for improved traiffic flow. Camera detection devices could be used to identify vehicle types (HOV \& non HOVs). Infrared sensors, relying on infrared heat image technologies will be capable of determining the number of people in a vehicle. These could be used to enforce HOV bypass lane enforcement during priority metering. Development of traffic progression and signal timing plans based on the number of occupants in a vehicle will be made possible to encourage the increased use of HOVs \& HOV lanes. 


\section{References}

Aerde, MV \& Yagar, S 1988a "Dynamic Integrated Freeway/Traffic Signal Networks: A Routing Based Modelling Approach". Transportation Research Part A 1988 Vol. 22a \# 6 page $445-453$

Aerde, MV \& Yagar, S 1988b "Dynamic Integrated Freeway Traffic Signal Network: Proposed Solutions. Transportation Research Part A, 1988 Vol 22a \# 6 Page 435-443

Aerde, MV \& Yagar, S 1987a "Review of Corridor Traffic Simulation Models". Research and development Branch, Ministry of transpsrtation of Ontario (TDS-87-02) September, 1987.

Aerde, MV Yagar, S Ugge, A \& Case, ER 1987b "A Review of Candidate FreewayArterial Corridor Traffic Models" Transportation Research Record 1987 \# 1132 Page 53 64

Ayland, DP Hill, $\mathbf{N}$ et al 1991 "Assessment of Advanced Technologies For Relieving Urban Traffic Congestion" National Cooperative Highway Research Project \# 340 , Transportation Research Board.

Bluementritt, CW Et Al. May 1981 "Guidelines For Ramp Control" National Co-operative Highway Research Program Report \# 232

Brewer, KA Et Al 1969 "Ramp Capacity and Service Volume as Related to Freeway Control" Highway Research Record \#279, Page 70 to 86. 
Chang, E Cohen, SL et al "Maxband 86: A Program For Optimising Left Turn Phase Sequence In A Multi arterial Closed Networks" Transportation Research Record \#1181, 1988

Chen, K \& Ervin, RD 1990 "Intelligent Vehicle Highway Systems: US Activities and Policy Issues" Technological Forecasting and Social Change. Vol 38. Eiselvier Science Publishing Co. Inc.

Clowes, DJ 1982 "Real Time Wide Area Traffic Control-The User's Viewpoint" Traffic Engineering \& Control.

Cocoran, LJ \& Hickman, GA 1991 "Freeway Ramp Metering Effects In Denver" Transportation Research Record \# 1320, Transportation Research Board.

Davies, P \& Ayland, N. 1988 "Urban Traffic Control : The Next Step Forward" Presented At 67th Annual Meeting Transportation Research Board.

Dudek, CL 1961 "Cost Effectiveness Of Freeway Ramp Control" Sponsored By Texas Highways Department \& US Department Of Transportation Research \#2-8-61-24

Dunn, W 1992 "Recent Trends in Freeway Traffic Management" Compendium of Technical Papers, Institute of Transportation Engineers 1992 Joint Annual Conference.

Euler, GW 1990 "IVHS: Definitions and Applications" Institute Of Transportation Engineers.

Ferlis, RA Et Al 1976 "Experimental Applications Of UTCS-1 Network Simulation Model" Transportation Research Record \#567 
Glisksman, AM 1963 "Linear Programming \& Theory of Games" John Wiley \& Sons Inc.

Hawks, JW \& Lomax, T 1989 "Roadway Congestion in Major Urban 1982 to 1987" Texas Transportation Institute,

Hunt, PB et al 1982 "7he SCOOT On Line Traffic Signal Optimisation Technique" Traffic Engineering \& Control.

IBI Group 1993 "Highway 417/17 Preliminary Design Report." Prepared for Ministry Of Transportation Of Ontario, January 1993.

IBI Group, 1991 "Burlington Skyway Freeway Traffic Management System: Preliminary Design" Prepared for Ministry of Transportation of Ontario.

IBI Group 1987 "Ottawa Queensway FTMS: Feasibility and Preliminary Report." A Study Conducted for Ministry of Transportation of Ontario.

Institute of Transportation Engineers, 1992 "Traffic Engineering Handbook." Prentice Hall Englewood Cliffs, New Jersey.

Jacobson. Et Al 1989 "Real Time Metering Algorithms For Centralised Control" Transportation Research Record \# 12321989.

Johnston, RA et al 1990 "Automating Freeways: Policy Research Agenda" Journal of Transportation Engireering Vol. $116 \# 4$.

Kay, Л 1992 "The Los Angeles Smart Corridor: Introduction" Symposium on Integrated Management Traffic Management System, Irvine, California. Presented by Transportation Research Board. 
Kelman, WL 1992 "Gardiner Lakeshore Corridor Traffic Management System" Symposium on Integrated Management Traffic Management System, Irvine, California. Presented by Transportation Research Board.

Leiman, M et. al. 1991 "Integrated System of Freeway Corridor Simulation Mociels" Transportation Research Record 1991 \# 1320 Page 177-188.

Lieberman, EB \& Andrews, BJ 1980 "TRAFLO: A new Tool To Evaluate Transportation System Management Strategies" Transportation Research Record. \#772

Mardsen, B 1981 "Ramp Meters and Travel Quality In Austin Texas" Texas Dept of Highways \& Public Transportation,

Masher, DP Et Al 1975 "Guidelines For Design and Operation Of Ramp Control Systems" National Co-operative Highway Research Program Project \# 3-22 Final Report.

May, Adolf Et Al 1982 "Freeway Simulation And Control" Institute of Transportation Studies, University Of California Research Report.

May, AD 1974 "Optimisation Techniques Applied To Improving Freeway Operations" Transportation Research Record \#495 page 75 to 91.

McCormick Rankin August 1986 "Queen Elizabeth Way Freeway Traffic Management System, Rehabilitation and Expansion" Prepared For Ministry of Transportation of Ontario.

"McShane, WR \& Roess, WP 1990 "Traffic Engineering" Prentice Hall Inc. 
Messer, CJ Whitson, RH et al 1973 "A Variable Phase Multi Progression Optimisation Program" Highway Research Record \#445 Highway Research Board.

Michalopoulos, PG Jacobson RD Et Al February 1993 "Automatic Incident Detection Through Video Image Processing" Traffic Engineering and Control.

Ministry Of Transportation Of Ontario, August 1993. "Highway 401 COMPASS: Annual Report January 1992 to March 1993" Prepared By Freeway Traffic Management Section.

Ministry of Transportation of Ontario, 1991 "Queen Elizabeth Way Burlington Freeway Traffic Management System"

Ministry of Transportation of Ontario, 1991 "Queen Elizabeth Way Mississauga Freeway Traffic Management System"

Ministry of Transportation of Ontario, August 1990 "Highway 17 Ramp Metering Implementation" Information Report.

Morlok, KE 1978 "Introduction to Transportation Engineering and Planning" McGrawhill Publications Inc.

Nsour, SA Clark, JE Cohen, SL Santiago, AL 1992 "An Investigation of The Impacts of Ramp Metering On Tra:fic Flow with \& Without Diversion" Transportation Research Board, $75^{\text {th }}$ Annual Meeting.

Ovaici, K Teal, RF Ray, J \& May, AD 1975 "Developing Freeway Priority Strategies" Highway Research Record, \#533. 
Payne, HJ 1979 "FREFLO: A Macro Simulation Model of Freeway Traffic" Transportation Research Record \#722 Transportation Research Board.

Payne, HJ \& Isaken, L 1973 "Freeway Traffic Surveillance and Control" Proceedings At Institute of Electrical and Electronic Engineers.

Pignataro, LJ 1973 "Traffic Engineering. Theory \& Practice" Prentice Hall Inc, Englewood Cliffs, New Jersey.

Pretty, RL 1984 "Detection Of Congestion On An Urban Freeway For The Purpose Of Access Control." Institute Of Transportation Engineers Journal.

Rathi, AK 1991 "Traffic Metering: An Effectiveness Study" Transportation Quarterly Vol 45 \#3.

Rathi, AK Lieberman, EB Yeldlin, M 1987 "Enhanced FREFLO: Modelling Congested Environments" Transportation Research Record \#1112, Transportation Research Board.

Kay, R 1994 "Booming: Kanata is Growing at an Amazing Pace" The Ottawa Citizen.

Reiss et. al. 1991 "Dynamic Control and Traffic Performance in a Freeway Corridor: A Simulation Study." Transportation Research Part A 1991 Vol 25A \# 2 Page 267-276.

Robinson, J \& Doctor, M 1989 "Ramp Metering Status In North America - Final Report." Federal Highway Administration.

Roos, D 1991 "Roads That Talk" World Highways. 
Sadjeh Et Al 1987 "Comparism Of Arterial Network Software Programs" ITE Journal.

SNCIDELUC/Joint Venture, March 1988. "Feasibility Study On A Freeway Traffic Management For Montreal Region: Final Report."

Spielberg, FZ 1982 "Evaluation Of Freeway Higher Occupancy Vehicle Lanes \& Ramp Metering." Prepared for US Department of Transportation.

Texas Transportation Institute July 1988 "Arterial Signal Timing Optimization Using PASSER II-87: Microcomputer User's Guide" Research Report \# 47-1, Co-operative Research Program.

Thomas, JM 1969 "Simple Ramp Metering Reduces Rear End Collisions" Traffic Engineering \& Control.

Transportation Association Of Canada, November 1993 "IVHS: A. Series Of One Day Seminars" Presented By IVHS Round Table.

Transportation Association Of Canada, June 1992" IVHS: A Synopsis" IVHS Round Table.

Transportation Research Board, 1985. "Highway Capacity Manual" Special Report \# 209

Transportation Research Circular, \# 354 1990. "Research Problem Statements in Freeway Operations".

Transportation Research Circular, \# 251 1983. "Research Problem Statements in Freeway Operations". 
US Army Corps of Engineers, 1992 "Nashua Hudson Circumferential Highway: Revised Draft Environmental Impact Statement." New England Division.

US Department Of Transportation, April 1993 "TRAF User Reference Guide Version 4.0" Federal Highway Administration.

US Department of Transportation Feb. 1993 "Request For Public Comments On Potential Non Technical Constraints To The Implementation and Use Of IVHS" Letters From US Department Of Transportation To State, Local Officials, Academics, Industries \& Private Individuals To Solicit Comments On Non Technical Issues Of IVHS.

US Department of Transportation, 1992 "IVHS Strategic Plan" A Report To Congress From the Secretary Of Transportation.

US Dept Of Transportation, 1988 "A Manual On Uniform Traffic Control Devices For Streets \& Highways" Federal Highway Administration.

US Department of Transportation 1976 "Traffic Control Systems Handbook" Federal Highway Administration.

Wainright, WS \& Rajendra, J. 1972 "Techniques Of Ramp Control" .

Walmsley, J 1982 "The Practical Implementation of SCOOT Traffic Control Systems" Traffic Engineering \& Control.

Wang, CF 1972 "On Ramp Flow Assignment Problem" Transportation Science Vol 6 Wattleworth, JA 1967 "Peak Period Analysis of A Freeway System" Highway Research Record \#157, Highway Research Board. 
Wong, S 1990 "TRAF-NETSIM: How It Works, What It Does." ITE Journal.

Yauch, PJ Gray, JC \& Lewis, WA 1988 "Using NETSIM To Evaluate the effects of

Drawbridge Openings On Adjacent Signalised Intersections". Institute of Transportation Engineers Journal.

Yuan, SL \& Kreer, JB 1971 "Adjustment of Freeway Ramp Metering Queue To Balance Ramp Metering Queues" Transportation Research Vol 5 \#2 
Appendix A

Intersection Count Data

Time: 07:00 to 08:00 Hours

Year: 1992 


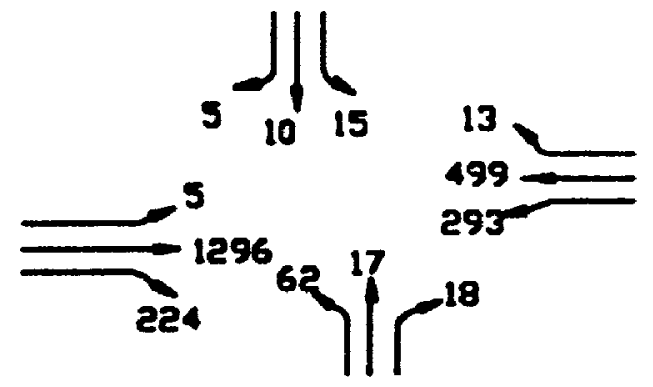

Carling/Pinecrest

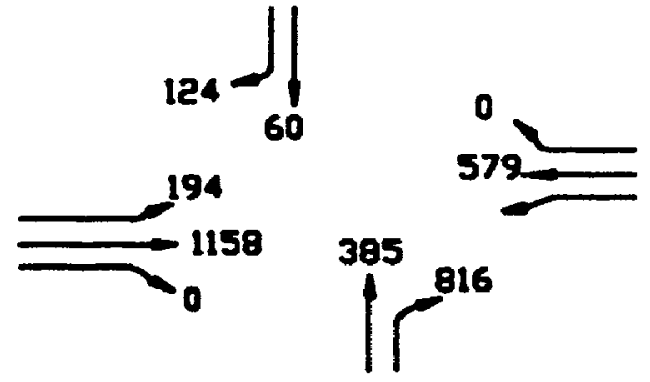

Carling/Richmond
Carling/Alpine
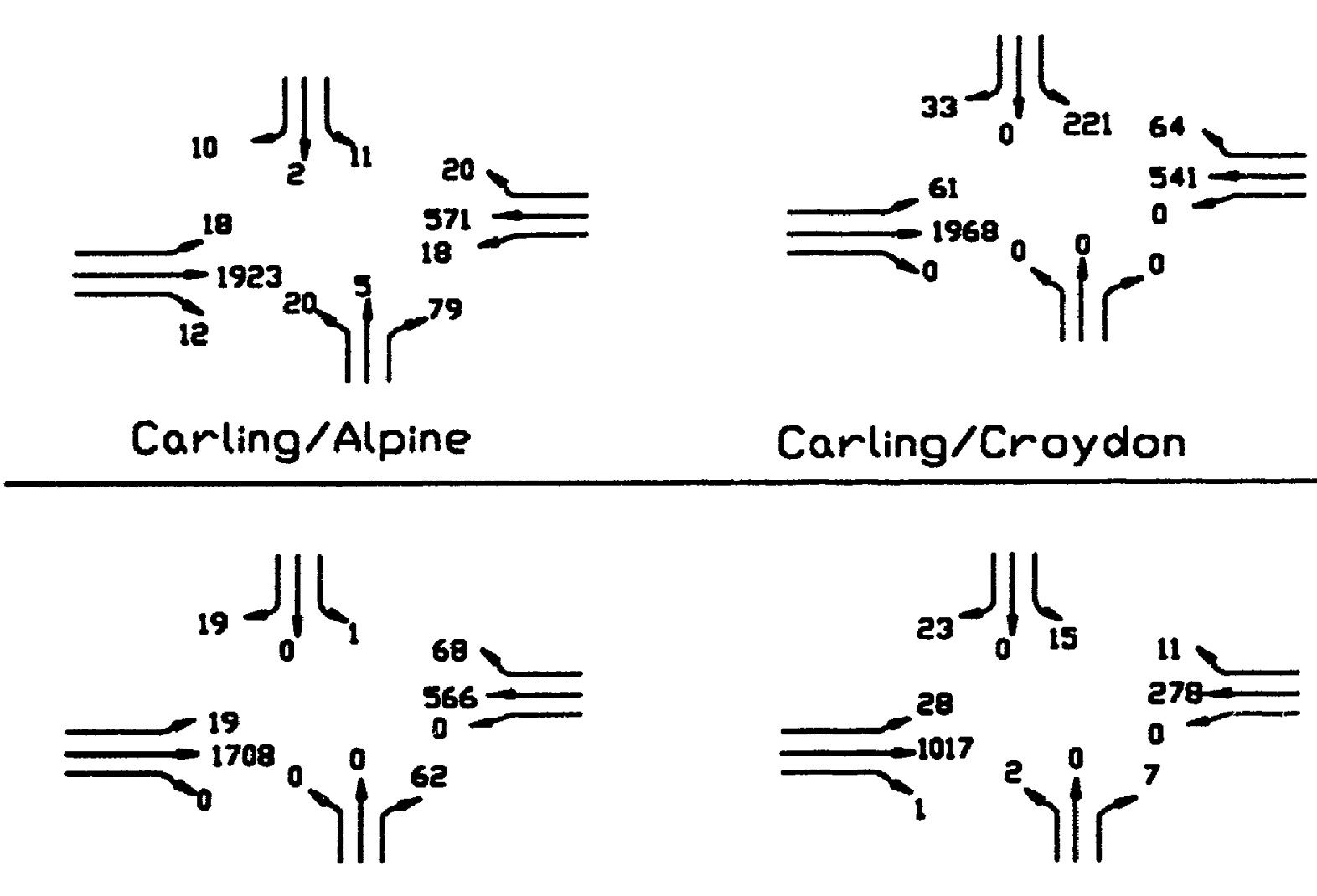

Carling/Croydon

Carling/Connaught

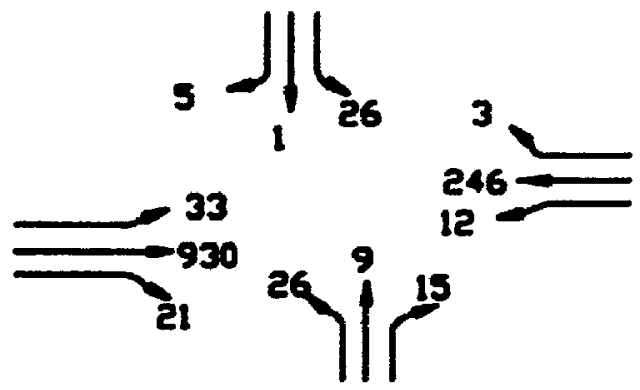

Carling/Edgeworth

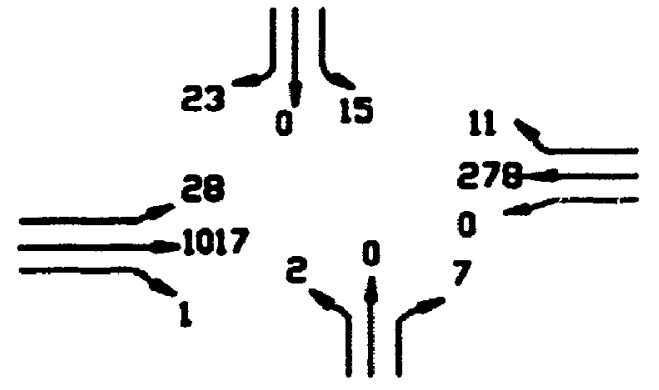

Carling/Lincoln Fields

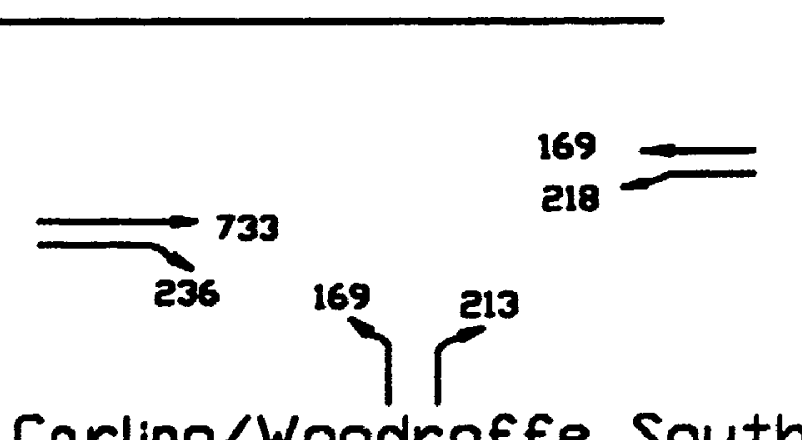

169

218

Carling/Woodroffe South 


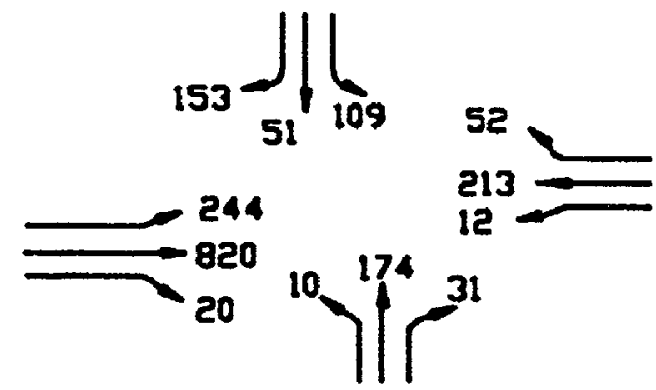

Carling/Fairlawn

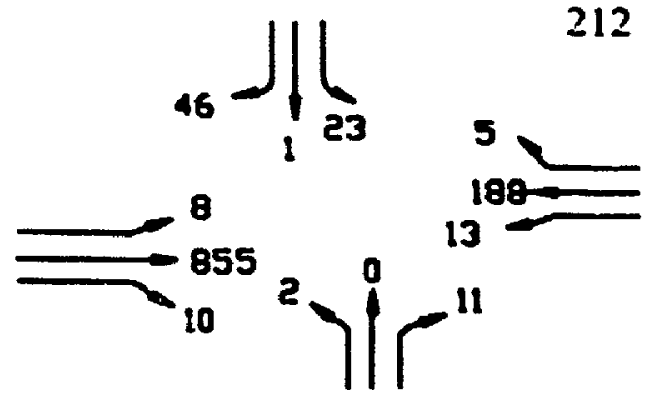

Carlingwood SC
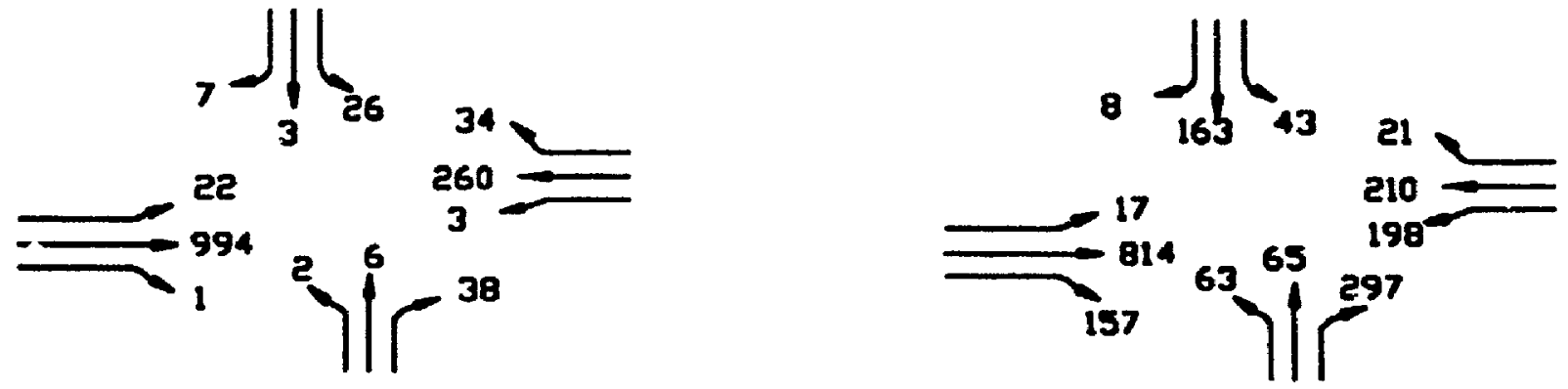

Carling/Iroquous

Carling/Maitland

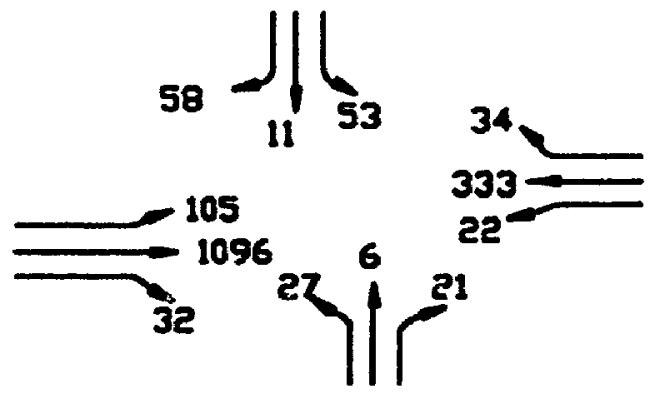

Carling $\backslash$ Broadview

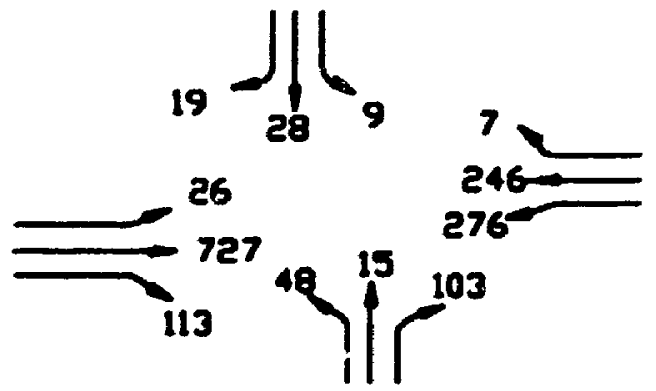

Carling/Clyde

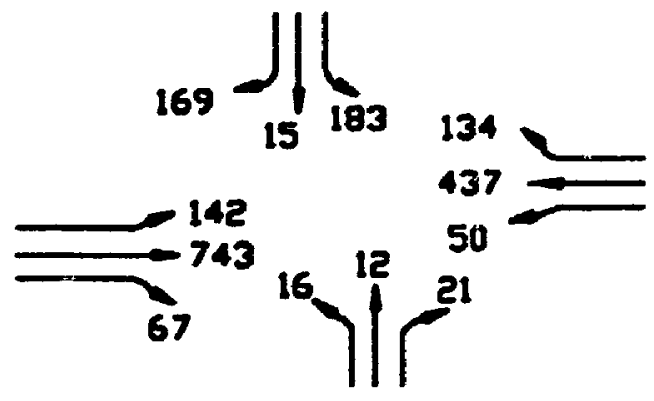

Carling/Churchill

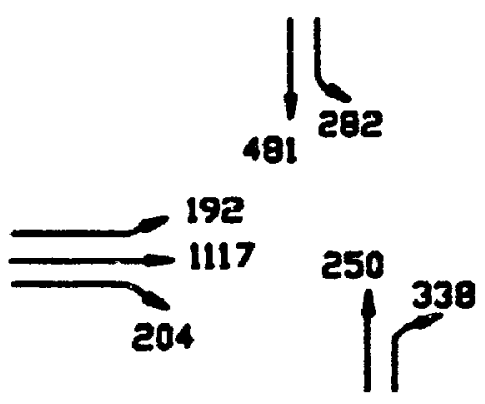

Carling/Kirkwood 
Appendix B

Measures of Effectiveness 


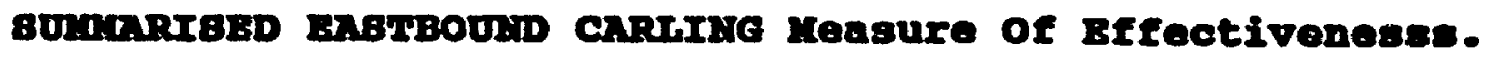

\begin{tabular}{|c|c|c|c|c|c|c|}
\hline \multirow[b]{2}{*}{$\begin{array}{l}\text { LINK } \\
\text { RICH } \\
\text { ALPINE } \\
\text { CROY } \\
\text { COWH } \\
\text { LF } \\
\text { EOGE } \\
\text { U. S } \\
\text { FAIRLAWH } \\
\text { CAL. SC } \\
\text { IROOUOUS } \\
\text { MAIT } \\
\text { BRONDVIEU } \\
\text { CLYOE } \\
\text { CHURCHILL } \\
\text { KIRK } \\
\text { TOTAL }\end{array}$} & \multirow[b]{2}{*}{$\begin{array}{r}\text { VEH } X M^{2} \\
78.94 \\
109.46 \\
65.93 \\
52.06 \\
65.91 \\
177.81 \\
238.26 \\
60.38 \\
46.34 \\
33.85 \\
185.96 \\
91.10 \\
102.07 \\
73.96 \\
174.05 \\
1556.04\end{array}$} & \multirow[b]{2}{*}{$\begin{array}{l}\text { VEH MIH } \\
538.90 \\
176.50 \\
111.70 \\
141.90 \\
115.90 \\
398.40 \\
463.60 \\
233.30 \\
106.50 \\
77.50 \\
319.30 \\
139.10 \\
186.70 \\
240.50 \\
418.70 \\
3668.30\end{array}$} & \multirow[b]{2}{*}{$\begin{array}{r}\text { Tr SECs } \\
124.80 \\
30.60 \\
18.30 \\
21.30 \\
16.90 \\
59.20 \\
70.10 \\
46.30 \\
26.30 \\
19.20 \\
89.50 \\
32.70 \\
45.00 \\
58.40 \\
108.30 \\
766.90\end{array}$} & \multicolumn{3}{|c|}{ HVo.ourt } \\
\hline & & & & $\begin{array}{l}\text { DEL } S / N^{5} \\
31.00 \\
1.70 \\
1.50 \\
3.50 \\
1.50 \\
12.30 \\
6.50 \\
21.10 \\
6.80 \\
5.00 \\
19.50 \\
3.50 \\
10.50 \\
17.80 \\
25.00\end{array}$ & $\begin{array}{l}0 \\
0 \\
0 \\
0 \\
0 \\
0 \\
0 \\
0 \\
0 \\
0 \\
0 \\
0 \\
0 \\
0\end{array}$ & $\begin{array}{l}\text { CUH II NIN } 2.08 \\
2.08 \\
2.59 \\
2.90 \\
3.25 \\
3.53 \\
4.52 \\
5.69 \\
6.46 \\
6.90 \\
7.22 \\
8.71 \\
9.25 \\
10.00 \\
10.98 \\
12.78\end{array}$ \\
\hline 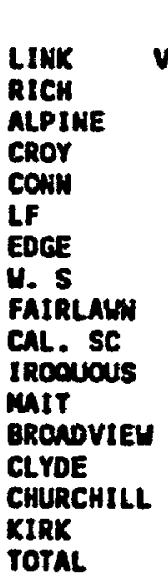 & $\begin{array}{c}\text { VEH KM } \\
67.67 \\
122.75 \\
73.86 \\
57.01 \\
72.47 \\
191.02 \\
249.66 \\
70.80 \\
63.33 \\
46.62 \\
302.62 \\
173.12 \\
168.40 \\
114.13 \\
264.04 \\
2035.58\end{array}$ & $\begin{array}{c}\text { VEH MIN } \\
617.00 \\
203.50 \\
126.00 \\
185.00 \\
136.60 \\
374.50 \\
570.90 \\
103.90 \\
90.40 \\
62.80 \\
663.10 \\
314.40 \\
964.80 \\
365.50 \\
886.30 \\
5666.70\end{array}$ & $\begin{array}{r}T \text { SECS } \\
166.80 \\
31.50 \\
18.40 \\
25.30 \\
18.10 \\
51.80 \\
82.30 \\
17.70 \\
17.10 \\
11.80 \\
113.00 \\
38.80 \\
140.80 \\
57.60 \\
151.40 \\
042.50\end{array}$ & $\begin{array}{c}\text { DEL } \\
56 \\
1 . \\
1 . \\
5 . \\
1 . \\
9 \\
15 \\
0 . \\
1 . \\
1 . \\
30 \\
3 . \\
57 \\
16 \\
42\end{array}$ & $\begin{array}{l}E E D \\
.00 \\
.00 \\
.00 \\
.00 \\
.00 \\
.00 \\
.00 \\
.60 \\
.10 \\
.60 \\
.00 \\
.00 \\
.00 \\
.00 \\
.00\end{array}$ & $\begin{array}{l}414 \pi \\
2.78 \\
3.31 \\
3.61 \\
4.06 \\
4.34 \\
5.20 \\
6.57 \\
6.87 \\
7.15 \\
7.35 \\
9.23 \\
9.88 \\
12.23 \\
13.19 \\
15.71\end{array}$ \\
\hline
\end{tabular}

NVo stands for existing conditions (based on 1992 intersection counts).

NV1 stands for traffic conditions based on optimised metering rates

From NV2 ...NV26, traffic was increased at the rate of 30 vph for Pinecrest, Woodroffe, Maitland, \& Kirkwood interchange.

2 Total Travel in Vehicle Kilometers

3 Total Travel Time in vehicle minutes

4 Travel Time in seconds

5 Average stopped Delay in seconds/Vehicle

6 AII link speeds are in kilometers per hour 


\begin{tabular}{|c|c|c|c|c|c|c|c|}
\hline 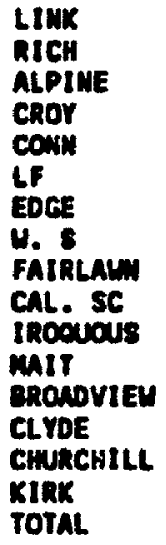 & $\begin{array}{c}\text { VEH } \mathrm{KH} \\
72.26 \\
127.82 \\
75.48 \\
59.87 \\
77.43 \\
209.96 \\
250.26 \\
74.38 \\
70.90 \\
51.48 \\
333.57 \\
179.83 \\
172.99 \\
119.22 \\
223.56 \\
2158.95\end{array}$ & $\begin{array}{l}\text { VEH nIN } \\
650.80 \\
211.40 \\
134.80 \\
199.20 \\
142.90 \\
436.20 \\
617.80 \\
107.60 \\
98.50 \\
69.70 \\
691.70 \\
369.10 \\
924.60 \\
460.40 \\
717.30 \\
5812.00\end{array}$ & $\begin{array}{c}\text { T1 secs } \\
164.80 \\
31.50 \\
19.30 \\
26.00 \\
17.70 \\
54.90 \\
88.90 \\
17.30 \\
16.60 \\
11.40 \\
106.90 \\
61.50 \\
131.50 \\
69.40 \\
113.90 \\
911.60\end{array}$ & $\begin{array}{l}\text { OEL S/N } \\
61.00 \\
1.40 \\
2.00 \\
6.90 \\
1.60 \\
11.10 \\
19.80 \\
0.30 \\
1.00 \\
0.60 \\
26.70 \\
6.70 \\
55.50 \\
22.80 \\
29.30\end{array}$ & $\begin{array}{l}\text { SPEED } \\
7.00 \\
36.30 \\
33.60 \\
18.00 \\
32.85 \\
28.90 \\
24.30 \\
41.50 \\
43.20 \\
44.30 \\
29.00 \\
30.90 \\
11.20 \\
15.50 \\
23.70\end{array}$ & $\begin{array}{l}\text { CuM Tr AIN } \\
2.75 \\
3.27 \\
3.59 \\
4.03 \\
6.32 \\
5.26 \\
6.72 \\
7.01 \\
7.28 \\
7.47 \\
9.26 \\
9.95 \\
12.16 \\
13.30 \\
15.19\end{array}$ & NV2A.OU? \\
\hline 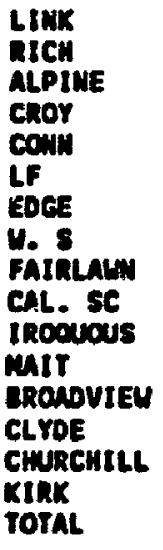 & $\begin{array}{r}\text { VEH } 14 \\
69.19 \\
125.60 \\
74.40 \\
59.48 \\
75.03 \\
189.70 \\
261.67 \\
76.38 \\
68.52 \\
47.98 \\
312.96 \\
175.17 \\
155.36 \\
105.61 \\
264.04 \\
2060.87\end{array}$ & $\begin{array}{l}\text { VEH AII } \\
584.10 \\
205.90 \\
129.70 \\
215.30 \\
165.00 \\
881.70 \\
604.80 \\
108.00 \\
93.90 \\
72.00 \\
611.20 \\
307.20 \\
1094.20 \\
675.10 \\
657.60 \\
6185.70\end{array}$ & $\begin{array}{c}T 1 \text { sEcs } \\
156.60 \\
31.20 \\
18.80 \\
28.30 \\
18.50 \\
122.70 \\
83.20 \\
17.00 \\
16.60 \\
12.60 \\
100.70 \\
37.50 \\
177.20 \\
81.00 \\
112.10 \\
1007.60\end{array}$ & $\begin{array}{l}\text { DEL SN } \\
56.70 \\
1.30 \\
2.10 \\
6.30 \\
2.10 \\
33.70 \\
19.00 \\
0.00 \\
1.00 \\
1.60 \\
22.40 \\
4.40 \\
85.00 \\
29.60 \\
27.80\end{array}$ & $\begin{array}{l}\text { SPEED } \\
7.00 \\
37.00 \\
34.00 \\
17.00 \\
31.00 \\
13.00 \\
26.00 \\
42.40 \\
44.00 \\
40.00 \\
31.00 \\
34.00 \\
9.00 \\
13.30 \\
24.00\end{array}$ & $\begin{array}{l}\text { CUN TT MIU } \\
2.57 \\
3.09 \\
3.41 \\
3.88 \\
6.19 \\
6.23 \\
7.62 \\
7.90 \\
8.18 \\
8.39 \\
10.06 \\
10.69 \\
13.58 \\
16.93 \\
16.79\end{array}$ & NVSA \\
\hline 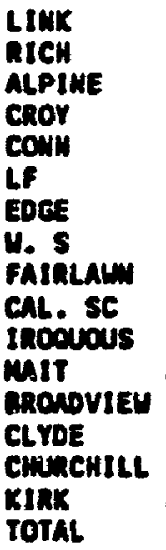 & $\begin{array}{r}\text { VEH M1 } \\
64.31 \\
116.75 \\
69.17 \\
55.70 \\
71.35 \\
190.16 \\
250.26 \\
71.58 \\
61.53 \\
63.51 \\
237.03 \\
154.46 \\
156.95 \\
105.13 \\
251.29 \\
1917.18\end{array}$ & $\begin{array}{l}\text { VEH Mrn } \\
526.10 \\
193.00 \\
133.40 \\
172.20 \\
129.90 \\
367.00 \\
582.80 \\
102.60 \\
85.50 \\
65.70 \\
511.80 \\
284.60 \\
937.50 \\
435.10 \\
658.00 \\
5185.40\end{array}$ & $\begin{array}{l}1 T \text { secs } \\
168.10 \\
31.50 \\
20.80 \\
24.10 \\
17.50 \\
51.00 \\
83.80 \\
17.20 \\
16.60 \\
12.70 \\
102.70 \\
39.40 \\
168.80 \\
76.40 \\
117.90 \\
926.50\end{array}$ & $\begin{array}{l}\text { DEL } S / N \\
54.40 \\
1.30 \\
2.40 \\
4.80 \\
1.80 \\
8.00 \\
13.50 \\
0.20 \\
1.10 \\
1.40 \\
25.60 \\
4.40 \\
61.60 \\
25.80 \\
25.70\end{array}$ & $\begin{array}{l}\text { SPEED } \\
7.00 \\
36.00 \\
31.00 \\
19.00 \\
33.00 \\
31.00 \\
26.00 \\
61.80 \\
43.20 \\
39.70 \\
30.00 \\
33.00 \\
10.00 \\
14.00 \\
22.90\end{array}$ & $\begin{array}{l}\text { CUN TT MIN } \\
2.80 \\
3.33 \\
3.67 \\
4.08 \\
4.37 \\
5.22 \\
6.61 \\
6.90 \\
7.18 \\
7.39 \\
9.10 \\
9.76 \\
12.26 \\
13.48 \\
15.46\end{array}$ & waA \\
\hline
\end{tabular}




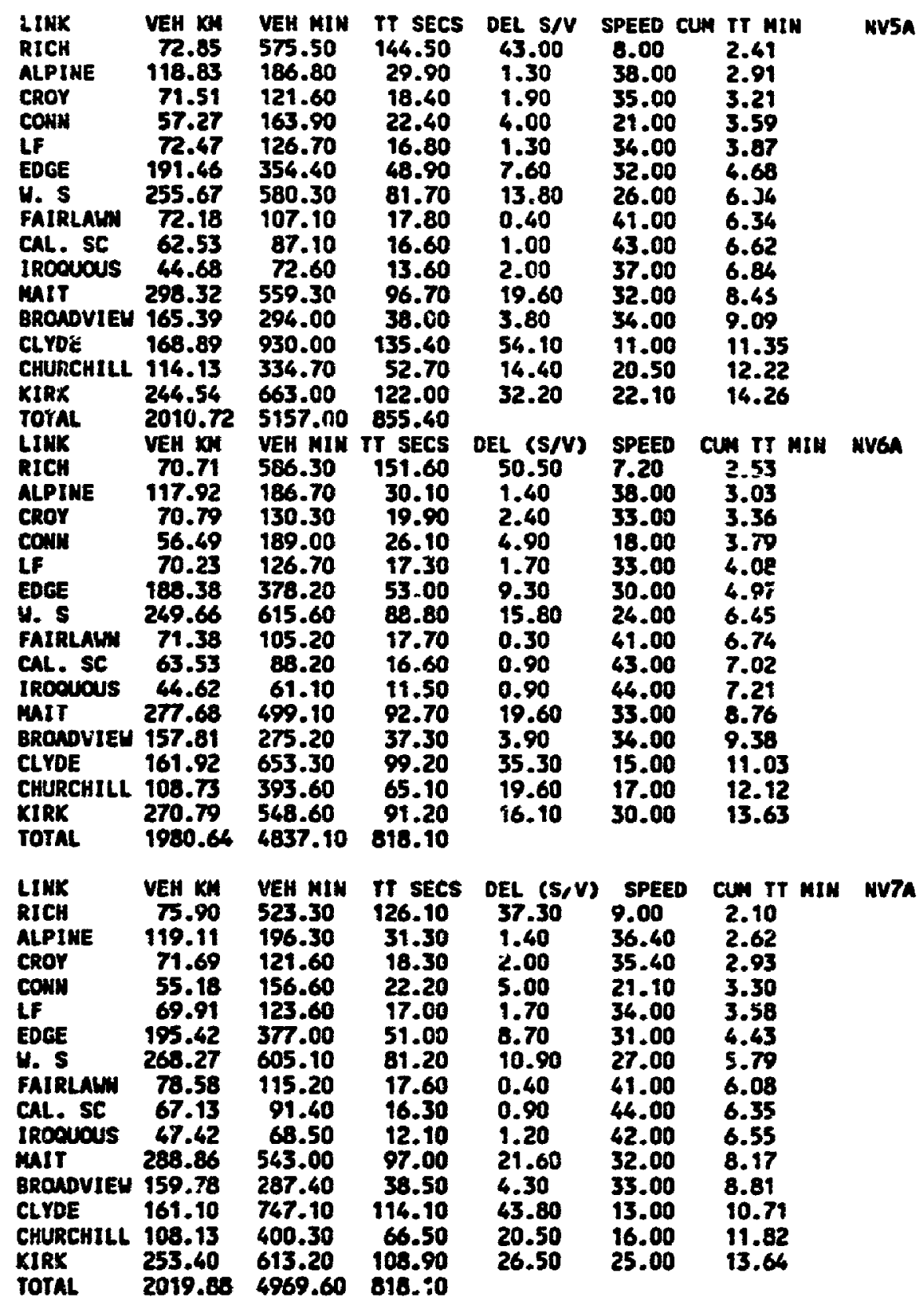




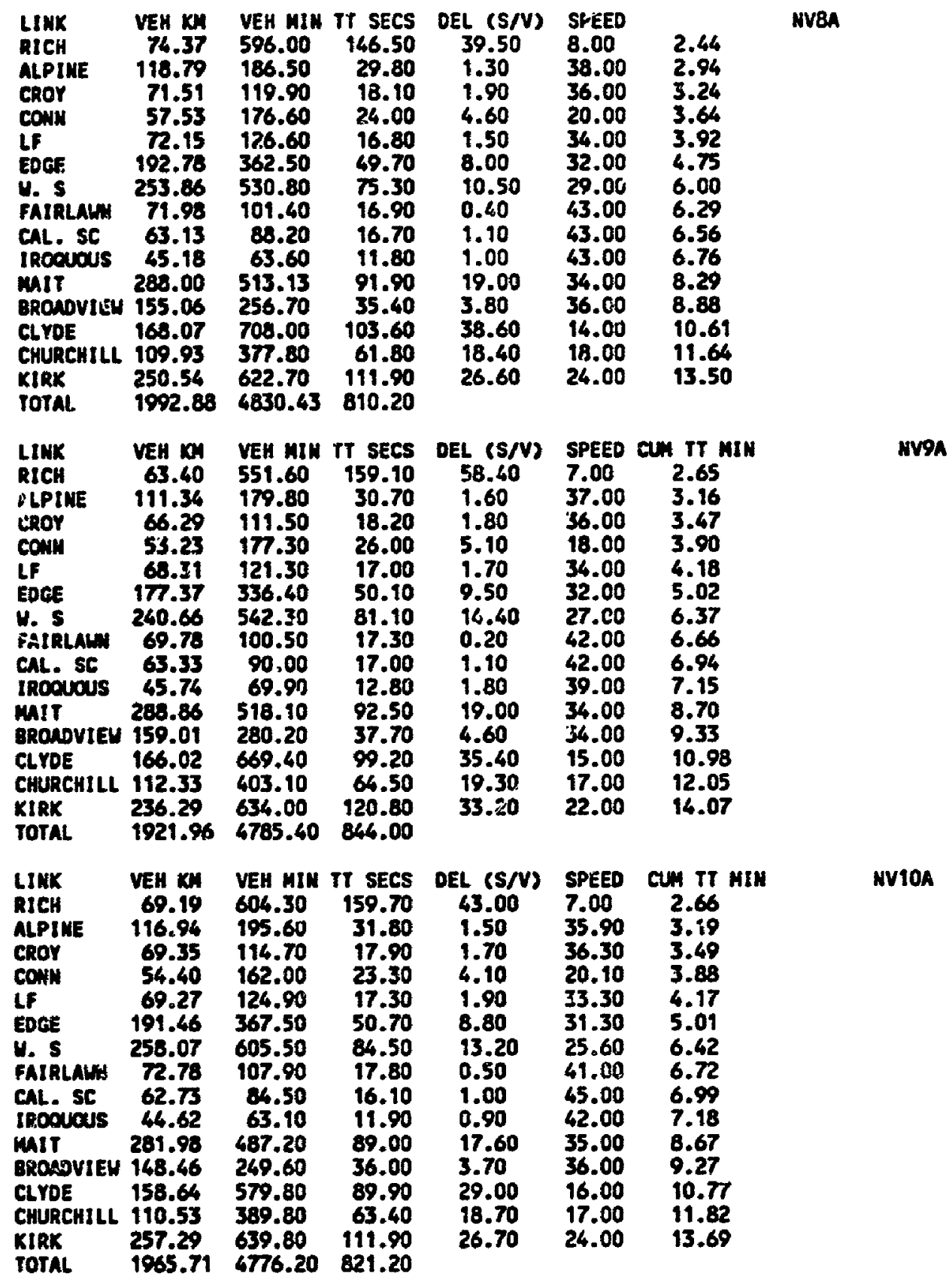




\begin{tabular}{|c|c|c|c|c|c|c|c|}
\hline $\begin{array}{l}\text { LINK } \\
\text { RICH } \\
\text { ALPINE } \\
\text { CROY } \\
\text { COHM } \\
\text { LF } \\
\text { EDEE } \\
\text { H. S } \\
\text { FAIRLAIN } \\
\text { CAL. SC } \\
\text { IROOUOUS } \\
\text { MAIT } \\
\text { BROADVIEY } \\
\text { CLYOE } \\
\text { CHURCHILL } \\
\text { KIRK } \\
\text { TOTAL }\end{array}$ & $\begin{array}{c}\text { VEH KA } \\
70.61 \\
115.37 \\
69.35 \\
55.31 \\
69.75 \\
183.10 \\
240.66 \\
69.78 \\
63.33 \\
44.48 \\
291.46 \\
152.36 \\
161.51 \\
107.83 \\
249.04 \\
1943.72\end{array}$ & $\begin{array}{l}\text { VEH MIN } \\
569.00 \\
179.10 \\
118.30 \\
161.50 \\
124.00 \\
361.00 \\
527.00 \\
98.50 \\
88.70 \\
67.00 \\
520.40 \\
245.00 \\
546.80 \\
394.20 \\
623.40 \\
4621.90\end{array}$ & $\begin{array}{r}T T \text { SECS } \\
147.80 \\
29.50 \\
18.40 \\
22.80 \\
17.10 \\
52.10 \\
78.90 \\
16.90 \\
16.70 \\
12.60 \\
92.10 \\
34.40 \\
83.00 \\
65.70 \\
112.70 \\
800.70\end{array}$ & $\begin{array}{l}\text { DEL }(S / V) \\
45.20 \\
1.40 \\
1.90 \\
3.90 \\
1.60 \\
8.80 \\
13.00 \\
0.30 \\
1.10 \\
1.60 \\
17.50 \\
3.80 \\
27.40 \\
20.20 \\
27.10\end{array}$ & $\begin{array}{l}\text { SPEEO } \\
7.00 \\
39.00 \\
35.00 \\
21.00 \\
34.00 \\
30.00 \\
27.00 \\
43.00 \\
43.00 \\
40.00 \\
34.00 \\
37.00 \\
18.00 \\
16.00 \\
24.00\end{array}$ & $\begin{array}{l}\text { CUA TT MIN } \\
2.46 \\
2.96 \\
3.26 \\
3.64 \\
3.93 \\
4.80 \\
6.11 \\
6.39 \\
6.67 \\
6.88 \\
8.42 \\
8.99 \\
10.37 \\
11.47 \\
13.35\end{array}$ & HVIIA \\
\hline $\begin{array}{l}\text { LINK } \\
\text { RICH } \\
\text { ALPINE } \\
\text { CROY } \\
\text { COWH } \\
\text { LF } \\
\text { EOEE } \\
\text { H. S } \\
\text { FAIRLALH } \\
\text { CAL. SC } \\
\text { IROSUOUS } \\
\text { MIT } \\
\text { BROADUIEU } \\
\text { CLYOE } \\
\text { CHURCHILL } \\
\text { KIRK } \\
\text { TOTAL }\end{array}$ & $\begin{array}{c}\text { VEH KA } \\
72.54 \\
117.55 \\
70.79 \\
56.62 \\
71.99 \\
192.34 \\
252.66 \\
72.38 \\
65.93 \\
46.30 \\
293.16 \\
155.24 \\
158.23 \\
105.13 \\
237.79 \\
1968.65\end{array}$ & $\begin{array}{l}\text { VEH MIN } \\
584.20 \\
188.60 \\
117.60 \\
168.40 \\
130.70 \\
366.60 \\
625.60 \\
105.60 \\
90.60 \\
67.80 \\
496.20 \\
249.80 \\
589.80 \\
403.90 \\
566.30 \\
4751.50\end{array}$ & $\begin{array}{r}T \text { SECS } \\
147.30 \\
30.50 \\
17.90 \\
23.20 \\
17.40 \\
50.30 \\
89.20 \\
17.50 \\
16.60 \\
12.30 \\
87.30 \\
34.50 \\
91.70 \\
69.00 \\
167.20 \\
819.70\end{array}$ & $\begin{array}{l}\text { DEL (S/V) } \\
42.10 \\
1.40 \\
1.90 \\
4.30 \\
1.60 \\
9.10 \\
14.10 \\
0.40 \\
1.00 \\
1.40 \\
16.60 \\
3.50 \\
32.70 \\
22.30 \\
26.00\end{array}$ & $\begin{array}{l}\text { SPEED } \\
8.00 \\
37.40 \\
36.10 \\
20.20 \\
33.00 \\
31.50 \\
24.20 \\
41.00 \\
44.00 \\
41.00 \\
35.00 \\
37.30 \\
16.10 \\
15.60 \\
25.20\end{array}$ & $\begin{array}{c}\text { CUH IT MIM } \\
2.46 \\
2.96 \\
3.26 \\
3.65 \\
3.94 \\
4.78 \\
6.26 \\
6.56 \\
6.83 \\
7.03 \\
8.49 \\
9.06 \\
10.59 \\
11.74 \\
13.53\end{array}$ & MV12A \\
\hline $\begin{array}{l}\text { GIMK } \\
\text { RICH } \\
\text { ALPINE } \\
\text { CROY } \\
\text { COUIU } \\
\text { LF } \\
\text { EDEE } \\
\text { U. S } \\
\text { FAIRLAW } \\
\text { CAL. SC } \\
\text { IROQUOUS } \\
\text { MAIT } \\
\text { BROADVIEH } \\
\text { CLYOE } \\
\text { CHURCHILL } \\
\text { KIRK } \\
\text { TOTAL }\end{array}$ & $\begin{array}{r}\text { VEH KH } \\
71.63 \\
195.28 \\
69.71 \\
55.83 \\
71.03 \\
188.82 \\
246.06 \\
73.58 \\
64.93 \\
45.74 \\
277.68 \\
147.07 \\
158.23 \\
105.43 \\
246.04 \\
1937.06\end{array}$ & $\begin{array}{l}\text { VEH MIH } \\
563.40 \\
179.70 \\
114.70 \\
166.10 \\
127.30 \\
401.00 \\
568.70 \\
105.90 \\
90.10 \\
65.00 \\
459.30 \\
232.70 \\
629.20 \\
271.40 \\
650.00 \\
4624.90\end{array}$ & $\begin{array}{r}\text { TT SECS } \\
144.00 \\
29.50 \\
17.80 \\
23.20 \\
17.20 \\
56.10 \\
83.20 \\
17.50 \\
16.60 \\
11.90 \\
85.30 \\
33.90 \\
97.80 \\
46.30 \\
118.90 \\
799.00\end{array}$ & $\begin{array}{c}\text { DEL (S/V) } \\
46.30 \\
1.30 \\
1.70 \\
4.00 \\
1.60 \\
10.90 \\
16.10 \\
0.40 \\
1.00 \\
1.30 \\
15.10 \\
3.30 \\
34.10 \\
10.50 \\
28.90\end{array}$ & $\begin{array}{l}\text { SPEED } \\
7.60 \\
39.00 \\
37.00 \\
20.00 \\
34.00 \\
28.00 \\
26.00 \\
42.00 \\
43.00 \\
42.00 \\
36.00 \\
37.90 \\
15.00 \\
23.00 \\
23.00\end{array}$ & $\begin{array}{l}\text { CUH IT MIN } \\
2.40 \\
2.89 \\
3.19 \\
3.58 \\
3.86 \\
4.80 \\
6.18 \\
6.47 \\
6.75 \\
6.95 \\
8.37 \\
8.93 \\
10.56 \\
11.36 \\
13.32\end{array}$ & IVI3A \\
\hline
\end{tabular}




\begin{tabular}{|c|c|c|c|c|c|c|c|}
\hline $\begin{array}{l}\text { LINK } \\
\text { RICH } \\
\text { ALPINE } \\
\text { CROY } \\
\text { CONH } \\
\text { LF } \\
\text { EDOE } \\
\text { W. S } \\
\text { FAIRLAWN } \\
\text { CAL. SE } \\
\text { IROOUOUS } \\
\text { MAIT } \\
\text { EROADVIEY } \\
\text { CLYOE } \\
\text { CHURCHILL } \\
\text { KIRK } \\
\text { TOTAL }\end{array}$ & $\begin{array}{r}\text { VEH KY } \\
71.93 \\
118.48 \\
69.89 \\
54.01 \\
68.79 \\
188.38 \\
263.47 \\
74.18 \\
62.53 \\
44.34 \\
273.38 \\
146.48 \\
156.45 \\
107.23 \\
271.54 \\
1969.08\end{array}$ & $\begin{array}{l}\text { VEH MIN } \\
604.80 \\
203.70 \\
123.90 \\
158.40 \\
121.70 \\
362.70 \\
647.70 \\
106.50 \\
84.30 \\
66.60 \\
480.20 \\
236.30 \\
506.30 \\
362.60 \\
686.00 \\
4751.70\end{array}$ & $\begin{array}{r}\text { TT SECS } \\
153.80 \\
32.70 \\
19.20 \\
22.90 \\
17.00 \\
50.80 \\
88.50 \\
17.20 \\
16.10 \\
12.60 \\
90.60 \\
34.60 \\
80.40 \\
60.80 \\
113.70 \\
810.90\end{array}$ & $\begin{array}{c}\text { OEL }(5 / V) \\
44.00 \\
1.50 \\
1.80 \\
3.90 \\
1.70 \\
9.30 \\
13.60 \\
0.60 \\
0.90 \\
1.40 \\
17.10 \\
3.60 \\
26.80 \\
17.30 \\
26.40\end{array}$ & $\begin{array}{l}\text { SPEED } \\
7.00 \\
35.00 \\
34.00 \\
21.00 \\
34.00 \\
31.00 \\
24.00 \\
42.00 \\
45.00 \\
40.00 \\
34.00 \\
37.00 \\
18.00 \\
18.00 \\
24.00\end{array}$ & $\begin{array}{l}\text { CUR TT MIN } \\
2.56 \\
3.11 \\
3.43 \\
3.81 \\
4.09 \\
4.94 \\
6.42 \\
6.70 \\
6.97 \\
7.98 \\
8.69 \\
9.27 \\
10.61 \\
11.62 \\
13.52\end{array}$ & nv14a \\
\hline $\begin{array}{l}\text { LIMK } \\
\text { RICH } \\
\text { ALPIME } \\
\text { CROY } \\
\text { COAN } \\
\text { LF } \\
\text { EDGE } \\
\text { H. } 5 \\
\text { FAIRLAIN } \\
\text { CAL. SC } \\
\text { IROOUOUS } \\
\text { MAIT } \\
\text { GROADVIEY } \\
\text { CLYOE } \\
\text { CHURCHILL } \\
\text { KIRK } \\
\text { TOTAL }\end{array}$ & $\begin{array}{r}\text { VEH KM } \\
68.89 \\
117.27 \\
69.71 \\
52.97 \\
67.35 \\
192.36 \\
262.87 \\
74.18 \\
65.93 \\
46.16 \\
286.28 \\
136.83 \\
154.13 \\
102.13 \\
246.04 \\
1943.08\end{array}$ & $\begin{array}{l}\text { VEH } 1 I M \\
542.30 \\
193.80 \\
122.00 \\
140.10 \\
118.50 \\
389.30 \\
590.80 \\
104.60 \\
89.90 \\
70.20 \\
527.60 \\
208.40 \\
493.70 \\
616.00 \\
756.90 \\
4762.10\end{array}$ & $\begin{array}{r}T T \text { SECS } \\
144.00 \\
31.40 \\
18.90 \\
20.70 \\
16.90 \\
53.40 \\
80.90 \\
16.90 \\
16.30 \\
12.80 \\
95.10 \\
32.70 \\
78.80 \\
72.90 \\
138.50 \\
830.20\end{array}$ & $\begin{array}{l}\text { OEL }(S / V) \\
40.30 \\
1.40 \\
2.00 \\
3.20 \\
1.80 \\
9.40 \\
11.70 \\
0.30 \\
1.00 \\
1.80 \\
20.30 \\
3.10 \\
25.50 \\
24.30 \\
33.30\end{array}$ & $\begin{array}{l}\text { SPEED } \\
8.00 \\
36.30 \\
34.30 \\
23.00 \\
34.00 \\
30.00 \\
27.00 \\
43.00 \\
44.00 \\
39.00 \\
33.00 \\
39.00 \\
19.00 \\
15.00 \\
20.00\end{array}$ & $\begin{array}{l}\text { CUM TT MIH } \\
2.60 \\
2.92 \\
3.26 \\
3.58 \\
3.87 \\
4.76 \\
6.10 \\
6.39 \\
6.66 \\
6.87 \\
8.46 \\
9.00 \\
10.31 \\
11.53 \\
13.84\end{array}$ & V15A \\
\hline $\begin{array}{l}\text { LINK } \\
\text { RICH } \\
\text { ALPINE } \\
\text { CROY } \\
\text { CONH } \\
\text { LF } \\
\text { EDEE } \\
\text { U. } \$ \\
\text { FAIRLAMH } \\
\text { CAL. SC } \\
\text { IROOUOUS } \\
\text { MAIT } \\
\text { BROADVIEU } \\
\text { CLYOE } \\
\text { CHURCHILL } \\
\text { KIRK } \\
\text { TOTAL }\end{array}$ & $\begin{array}{r}\text { VEH KH } \\
71.02 \\
198.17 \\
69.71 \\
54.53 \\
63.15 \\
187.94 \\
232.26 \\
65.58 \\
58.93 \\
42.53 \\
268.23 \\
132.60 \\
167.57 \\
98.53 \\
269.06 \\
1864.79\end{array}$ & $\begin{array}{l}\text { VEA MIN } \\
620.20 \\
204.10 \\
123.20 \\
169.40 \\
123.90 \\
386.10 \\
518.70 \\
96.10 \\
82.50 \\
72.10 \\
472.90 \\
208.80 \\
403.30 \\
324.00 \\
548.80 \\
4354.10\end{array}$ & $\begin{array}{l}\text { IT SECS } \\
159.70 \\
32.80 \\
19.10 \\
24.30 \\
17.50 \\
54.30 \\
80.40 \\
17.60 \\
16.70 \\
14.20 \\
91.10 \\
33.80 \\
67.20 \\
59.10 \\
99.20 \\
787.00\end{array}$ & $\begin{array}{l}\text { DEL }(S / V) \\
46.30 \\
1.40 \\
2.10 \\
5.10 \\
1.90 \\
9.60 \\
11.40 \\
0.90 \\
1.10 \\
2.50 \\
16.90 \\
3.30 \\
19.80 \\
17.00 \\
17.80\end{array}$ & $\begin{array}{l}\text { SPEED } \\
7.00 \\
35.00 \\
34.00 \\
19.00 \\
33.00 \\
29.00 \\
27.00 \\
41.00 \\
63.00 \\
35.00 \\
34.00 \\
38.00 \\
22.00 \\
18.00 \\
27.00\end{array}$ & $\begin{array}{l}\text { CUM IT HIH } \\
2.66 \\
3.21 \\
3.53 \\
3.93 \\
4.22 \\
5.13 \\
3.47 \\
6.76 \\
7.04 \\
7.28 \\
8.79 \\
9.36 \\
10.48 \\
11.46 \\
13.12\end{array}$ & $16 A$ \\
\hline
\end{tabular}




\begin{tabular}{|c|c|c|c|c|c|c|c|}
\hline $\begin{array}{l}\text { LINK } \\
\text { RICH } \\
\text { ALPINE } \\
\text { CROY } \\
\text { CONH } \\
\text { LF } \\
\text { EDGE } \\
\text { U. S } \\
\text { FAIRLALN } \\
\text { CAL. SC } \\
\text { IROOUOUS } \\
\text { MAIT } \\
\text { BRONOWI } \\
\text { CLYDE } \\
\text { CHURCHILL } \\
\text { KIRK } \\
\text { TOTAL }\end{array}$ & $\begin{array}{r}\text { VEH KH } \\
72.54 \\
117.23 \\
70.07 \\
55.96 \\
71.51 \\
191.46 \\
248.46 \\
71.38 \\
64.13 \\
45.46 \\
290.58 \\
139.88 \\
150.85 \\
98.23 \\
228.04 \\
1915.78\end{array}$ & $\begin{array}{l}\text { VEH MIU } \\
593.60 \\
184.60 \\
117.90 \\
155.90 \\
125.80 \\
362.30 \\
551.80 \\
103.50 \\
89.90 \\
66.90 \\
511.60 \\
211.12 \\
431.50 \\
333.80 \\
580.20 \\
4420.42\end{array}$ & $\begin{array}{r}\text { TT SECS } \\
149.70 \\
29.90 \\
18.20 \\
21.80 \\
16.90 \\
50.00 \\
80.00 \\
17.40 \\
16.70 \\
12.30 \\
90.80 \\
32.40 \\
70.40 \\
61.10 \\
114.50 \\
782.10\end{array}$ & $\begin{array}{c}\text { DEL (S/V) } \\
46.00 \\
1.30 \\
2.00 \\
3.50 \\
1.30 \\
8.40 \\
12.00 \\
0.70 \\
1.10 \\
1.30 \\
17.40 \\
2.10 \\
22.80 \\
17.40 \\
32.00\end{array}$ & $\begin{array}{l}\text { SPEED } \\
7.00 \\
38.00 \\
36.00 \\
22.00 \\
34.00 \\
32.00 \\
27.00 \\
41.00 \\
43.00 \\
41.00 \\
36.00 \\
40.00 \\
21.00 \\
18.00 \\
26.00\end{array}$ & $\begin{array}{l}\text { CUN TT MIN } \\
2.50 \\
2.99 \\
3.30 \\
3.66 \\
3.96 \\
4.78 \\
6.11 \\
6.40 \\
6.68 \\
6.88 \\
8.40 \\
8.96 \\
10.11 \\
11.13 \\
13.06\end{array}$ & NV17A \\
\hline $\begin{array}{l}\text { LINK } \\
\text { RICH } \\
\text { ALPINE } \\
\text { CROY } \\
\text { CONH } \\
\text { LF } \\
\text { EDEE } \\
\text { H. S } \\
\text { FAIRLALN } \\
\text { CAL. SE } \\
\text { IROOUOUS } \\
\text { MAIT } \\
\text { BROADVIEH } \\
\text { CLYOE } \\
\text { CHURCHILL } \\
\text { KIRK } \\
\text { TOTAL }\end{array}$ & $\begin{array}{c}\text { VEH KH } \\
72.54 \\
116.27 \\
70.25 \\
56.09 \\
70.39 \\
191.46 \\
261.07 \\
76.38 \\
65.73 \\
45.74 \\
289.72 \\
141.35 \\
155.77 \\
102.13 \\
237.79 \\
1950.68\end{array}$ & $\begin{array}{l}\text { VEH MIU } \\
588.50 \\
184.50 \\
122.00 \\
154.70 \\
125.80 \\
349.20 \\
522.20 \\
109.20 \\
91.50 \\
72.80 \\
482.60 \\
221.20 \\
651.10 \\
361.60 \\
651.70 \\
4488.60\end{array}$ & $\begin{array}{r}\text { TT SECS } \\
148.40 \\
30.20 \\
18.80 \\
21.50 \\
17.20 \\
48.20 \\
72.00 \\
17.60 \\
16.60 \\
13.40 \\
85.80 \\
33.60 \\
71.20 \\
63.60 \\
123.40 \\
781.60\end{array}$ & $\begin{array}{c}\text { DEL }(S / N) \\
46.90 \\
1.30 \\
1.70 \\
3.10 \\
1.30 \\
7.20 \\
9.50 \\
1.00 \\
1.00 \\
2.40 \\
15.20 \\
3.00 \\
22.50 \\
18.30 \\
32.30\end{array}$ & $\begin{array}{l}\text { SPEED } \\
7.00 \\
38.00 \\
35.00 \\
22.00 \\
34.00 \\
33.00 \\
30.00 \\
41.00 \\
43.00 \\
38.00 \\
36.00 \\
38.00 \\
21.00 \\
17.00 \\
22.00\end{array}$ & $\begin{array}{c}\text { CUM TT MIN } \\
2.47 \\
2.98 \\
3.29 \\
3.65 \\
3.94 \\
4.74 \\
5.94 \\
6.23 \\
6.51 \\
6.73 \\
8.16 \\
8.72 \\
9.91 \\
10.97 \\
13.03\end{array}$ & nvisa \\
\hline $\begin{array}{l}\text { LINK } \\
\text { RICH } \\
\text { ALPINE } \\
\text { CROY } \\
\text { CONH } \\
\text { LF } \\
\text { EDGE } \\
\text { H. S } \\
\text { FAIRLAMN } \\
\text { CAL. SC } \\
\text { IROOUOUS } \\
\text { MAIT } \\
\text { BROAOVIEH } \\
\text { CLYOE } \\
\text { CHURCHILL } \\
\text { KIRK } \\
\text { TOTAL }\end{array}$ & $\begin{array}{c}\text { VEH KH } \\
68.58 \\
115.38 \\
68.09 \\
54.14 \\
70.07 \\
181.77 \\
233.46 \\
67.36 \\
60.53 \\
43.09 \\
287.14 \\
138.46 \\
146.36 \\
100.93 \\
220.53 \\
1855.89\end{array}$ & $\begin{array}{l}\text { VEH MIN } \\
595.70 \\
178.40 \\
111.30 \\
158.70 \\
122.20 \\
332.60 \\
672.00 \\
97.00 \\
85.70 \\
69.80 \\
481.30 \\
208.10 \\
353.00 \\
422.00 \\
516.30 \\
4204.10\end{array}$ & $\begin{array}{r}r \text { SECS } \\
158.80 \\
29.40 \\
17.70 \\
22.90 \\
18.70 \\
48.30 \\
72.70 \\
17.30 \\
16.90 \\
13.60 \\
86.50 \\
32.30 \\
59.30 \\
75.10 \\
105.40 \\
772.90\end{array}$ & $\begin{array}{l}\text { OEL (S/V) } \\
47.40 \\
1.20 \\
1.90 \\
4.60 \\
1.30 \\
7.70 \\
10.60 \\
0.60 \\
1.20 \\
2.40 \\
15.10 \\
2.50 \\
17.70 \\
25.70 \\
27.90\end{array}$ & $\begin{array}{l}\text { SPEED } \\
7.00 \\
33.00 \\
37.00 \\
21.00 \\
34.00 \\
33.00 \\
27.00 \\
41.70 \\
42.00 \\
37.00 \\
36.00 \\
40.00 \\
25.00 \\
14.00 \\
26.00\end{array}$ & $\begin{array}{l}\text { C.M TI MIN } \\
2.65 \\
3.14 \\
3.43 \\
3.81 \\
4.09 \\
4.90 \\
6.11 \\
6.40 \\
6.68 \\
6.91 \\
8.35 \\
8.89 \\
9.87 \\
11.13 \\
12.88\end{array}$ & NV19A \\
\hline
\end{tabular}




\begin{tabular}{|c|c|c|c|c|c|c|c|}
\hline $\begin{array}{l}\text { LINK } \\
\text { RICH } \\
\text { ALPINE } \\
\text { CROY } \\
\text { CONN } \\
\text { LF } \\
\text { EDGE } \\
\text { H. S } \\
\text { FAIRLAWH } \\
\text { CAL. SC } \\
\text { IROOUOUS } \\
\text { WIT } \\
\text { BROADUIEU } \\
\text { CLYOE } \\
\text { CHURCHILL } \\
\text { RIRK } \\
\text { TOTAL }\end{array}$ & $\begin{array}{r}\text { VEH IOH } \\
72.54 \\
116.91 \\
70.25 \\
56.09 \\
79.35 \\
191.02 \\
249.06 \\
79.38 \\
62.73 \\
43.93 \\
291.44 \\
131.65 \\
142.65 \\
97.63 \\
236.29 \\
1904.92\end{array}$ & $\begin{array}{l}\text { VEH MIN } \\
574.20 \\
183.60 \\
118.30 \\
168.80 \\
128.40 \\
388.00 \\
542.00 \\
104.80 \\
87.40 \\
69.40 \\
593.40 \\
193.10 \\
299.60 \\
368.90 \\
628.00 \\
4467.90\end{array}$ & $\begin{array}{r}\text { TT SECS } \\
144.80 \\
29.90 \\
18.20 \\
23.50 \\
17.30 \\
53.60 \\
78.50 \\
17.60 \\
16.60 \\
13.30 \\
105.00 \\
31.50 \\
51.70 \\
67.90 \\
119.70 \\
789.10\end{array}$ & $\begin{array}{l}\text { DEL }(S / V) \\
40.40 \\
1.40 \\
1.90 \\
4.10 \\
1.70 \\
9.40 \\
10.60 \\
0.80 \\
1.00 \\
2.30 \\
27.30 \\
1.50 \\
11.80 \\
21.80 \\
31.40\end{array}$ & $\begin{array}{l}\text { SPEED } \\
8.00 \\
38.00 \\
37.00 \\
20.00 \\
33.00 \\
30.00 \\
27.00 \\
41.00 \\
43.00 \\
38.00 \\
30.00 \\
41.00 \\
29.00 \\
16.00 \\
23.00\end{array}$ & $\begin{array}{l}\text { CUM TT MIN } \\
2.41 \\
2.91 \\
3.22 \\
3.61 \\
3.90 \\
4.79 \\
6.10 \\
6.39 \\
6.67 \\
6.89 \\
8.64 \\
9.16 \\
10.03 \\
11.16 \\
13.15\end{array}$ & NV20A \\
\hline $\begin{array}{l}\text { LIMK } \\
\text { RICH } \\
\text { ALPINE } \\
\text { CROY } \\
\text { COWU } \\
\text { LF } \\
\text { EOCE } \\
\text { W. } 5 \\
\text { FAIRLALH } \\
\text { CAL. SC } \\
\text { IROONOUS } \\
\text { MLIT } \\
\text { BROADVIEH } \\
\text { CLYDE } \\
\text { CHURCHILL } \\
\text { KIRK } \\
\text { TOTAL }\end{array}$ & $\begin{array}{r}\text { VEH } x 1 \\
69.90 \\
116.28 \\
68.81 \\
53.62 \\
67.51 \\
188.02 \\
254.47 \\
70.98 \\
63.30 \\
45.32 \\
280.26 \\
135.96 \\
151.67 \\
102.63 \\
258.79 \\
1927.41\end{array}$ & $\begin{array}{l}\text { VEH MIN } \\
598.00 \\
201.10 \\
119.10 \\
152.80 \\
117.80 \\
368.40 \\
549.00 \\
100.80 \\
87.30 \\
68.90 \\
466.60 \\
201.20 \\
411.20 \\
395.10 \\
638.90 \\
4676.20\end{array}$ & $\begin{array}{r}\text { TT SECS } \\
158.10 \\
32.90 \\
18.70 \\
22.30 \\
16.70 \\
51.50 \\
77.70 \\
17.00 \\
16.50 \\
12.80 \\
85.90 \\
31.80 \\
66.70 \\
69.30 \\
111.10 \\
789.00\end{array}$ & $\begin{array}{c}\text { DEL }(S / V) \\
44.80 \\
1.40 \\
1.90 \\
4.20 \\
1.90 \\
8.80 \\
9.90 \\
0.90 \\
1.00 \\
1.80 \\
14.60 \\
2.60 \\
20.70 \\
22.70 \\
25.90\end{array}$ & $\begin{array}{l}\text { SPEED } \\
7.00 \\
35.00 \\
35.00 \\
21.00 \\
34.00 \\
31.00 \\
28.00 \\
42.00 \\
44.00 \\
40.00 \\
36.00 \\
41.00 \\
22.00 \\
16.00 \\
24.00\end{array}$ & $\begin{array}{l}\text { CUH TT MIH } \\
2.64 \\
3.18 \\
3.50 \\
3.87 \\
6.15 \\
5.00 \\
6.30 \\
6.58 \\
6.86 \\
7.07 \\
8.50 \\
9.03 \\
10.14 \\
11.30 \\
13.15\end{array}$ & NV21A \\
\hline $\begin{array}{l}\text { LIMK } \\
\text { RICH } \\
\text { ALPINE } \\
\text { CROY } \\
\text { COWN } \\
\text { LF } \\
\text { EDEE } \\
\text { U. S } \\
\text { FAIRLAM } \\
\text { CAL. SC } \\
\text { IROOUOUS } \\
\text { MIT } \\
\text { BROADVIEU } \\
\text { CLYOE } \\
\text { CHURCHILL } \\
\text { KIRK } \\
\text { TOTAL }\end{array}$ & $\begin{array}{r}\text { VEH } 14 \\
70.71 \\
115.68 \\
69.53 \\
53.75 \\
67.51 \\
180.89 \\
255.07 \\
72.98 \\
64.75 \\
46.30 \\
286.26 \\
136.66 \\
163.47 \\
99.43 \\
234.79 \\
1897.76\end{array}$ & $\begin{array}{l}\text { VEH MIU } \\
565.60 \\
189.20 \\
269.80 \\
165.50 \\
121.30 \\
364.90 \\
511.90 \\
i 06.90 \\
91.10 \\
76.10 \\
522.30 \\
211.70 \\
322.40 \\
363.50 \\
571.60 \\
4613.80\end{array}$ & $\begin{array}{c}\text { TT 6SECS } \\
146.30 \\
31.10 \\
38.80 \\
26.00 \\
17.20 \\
50.30 \\
72.30 \\
17.60 \\
16.80 \\
13.80 \\
94.10 \\
33.30 \\
55.30 \\
65.70 \\
109.60 \\
786.20\end{array}$ & $\begin{array}{l}\text { DEL S/V } \\
47.70 \\
1.60 \\
16.60 \\
4.50 \\
1.60 \\
8.00 \\
9.30 \\
1.30 \\
1.10 \\
2.60 \\
16.60 \\
3.10 \\
15.70 \\
20.70 \\
28.60\end{array}$ & $\begin{array}{c}\text { SPEED } \\
8.00 \\
37.00 \\
17.00 \\
20.00 \\
33.00 \\
32.00 \\
30.00 \\
41.00 \\
43.00 \\
37.00 \\
33.00 \\
39.00 \\
27.00 \\
16.00 \\
25.00\end{array}$ & $\begin{array}{l}\text { CUH TT MIN } \\
2.44 \\
2.96 \\
3.60 \\
6.00 \\
4.29 \\
5.13 \\
6.33 \\
6.63 \\
6.91 \\
7.14 \\
8.71 \\
9.26 \\
10.18 \\
11.28 \\
13.10\end{array}$ & V22A \\
\hline
\end{tabular}




\begin{tabular}{|c|c|c|c|c|c|c|c|}
\hline $\begin{array}{l}\text { LIMK } \\
\text { RICH } \\
\text { ALPINE } \\
\text { CROY } \\
\text { CONH } \\
\text { LF } \\
\text { EDGE } \\
\text { M. S } \\
\text { FAIRLAUH } \\
\text { CAL. SC } \\
\text { IROOUOUS } \\
\text { MAIT } \\
\text { BROADVIEH } \\
\text { CLYDE } \\
\text { CHURCHILL } \\
\text { KIRK } \\
\text { TOTAL }\end{array}$ & $\begin{array}{c}\text { VEH IG } \\
71.63 \\
117.58 \\
69.89 \\
55.96 \\
71.35 \\
189.25 \\
254.47 \\
73.38 \\
66.13 \\
46.30 \\
288.86 \\
138.13 \\
144.70 \\
99.43 \\
231.04 \\
1918.10\end{array}$ & $\begin{array}{l}\text { VEH HIN } \\
547.50 \\
192.70 \\
114.50 \\
159.40 \\
127.60 \\
366.20 \\
549.70 \\
107.10 \\
94.30 \\
75.20 \\
504.20 \\
212.60 \\
325.70 \\
332.00 \\
621.10 \\
4329.80\end{array}$ & $\begin{array}{r}\text { IT SECS } \\
139.80 \\
31.20 \\
17.70 \\
22.20 \\
17.20 \\
51.10 \\
77.80 \\
17.50 \\
17.00 \\
13.70 \\
90.00 \\
33.00 \\
55.40 \\
60.00 \\
121.00 \\
764.60\end{array}$ & $\begin{array}{c}\text { DEL }(S / V) \\
43.20 \\
1.50 \\
1.60 \\
4.10 \\
1.50 \\
8.90 \\
9.90 \\
1.30 \\
1.10 \\
2.50 \\
17.00 \\
2.90 \\
15.60 \\
17.00 \\
28.00\end{array}$ & $\begin{array}{l}\text { SPEED } \\
8.00 \\
37.00 \\
37.00 \\
21.00 \\
34.00 \\
31.00 \\
28.00 \\
41.00 \\
42.00 \\
37.00 \\
34.00 \\
39.00 \\
27.00 \\
18.00 \\
22.00\end{array}$ & $\begin{array}{l}\text { CUM IT MIM } \\
2.33 \\
2.85 \\
3.15 \\
3.52 \\
3.80 \\
4.65 \\
5.95 \\
6.24 \\
6.53 \\
6.75 \\
8.25 \\
8.80 \\
9.73 \\
10.73 \\
12.74\end{array}$ & NV23A \\
\hline $\begin{array}{l}\text { LINK } \\
\text { RICH } \\
\text { ALPINE } \\
\text { CROY } \\
\text { CONH } \\
\text { LF } \\
\text { EDGE } \\
\text { H. S } \\
\text { FA2RLAWN } \\
\text { CAL. SC } \\
\text { IROOUOUS } \\
\text { MAIT } \\
\text { BROADVIEU } \\
\text { CLYOE } \\
\text { CHURCHILL } \\
\text { KIRK } \\
\text { TOTAL }\end{array}$ & $\begin{array}{c}\text { VEH KH } \\
72.54 \\
118.90 \\
70.45 \\
56.49 \\
71.67 \\
195.86 \\
265.27 \\
74.38 \\
64.33 \\
65.60 \\
287.14 \\
132.40 \\
145.52 \\
97.33 \\
221.28 \\
1919.14\end{array}$ & $\begin{array}{l}\text { VEH MIN } \\
578.30 \\
186.40 \\
129.10 \\
163.70 \\
122.80 \\
368.20 \\
535.70 \\
117.20 \\
91.40 \\
77.40 \\
481.80 \\
199.20 \\
369.80 \\
395.10 \\
576.10 \\
4392.20\end{array}$ & $\begin{array}{r}\text { TT SECS } \\
145.80 \\
30.00 \\
19.80 \\
22.60 \\
16.40 \\
49.60 \\
72.70 \\
18.90 \\
17.00 \\
14.20 \\
86.50 \\
32.30 \\
62.30 \\
72.90 \\
117.20 \\
778.20\end{array}$ & $\begin{array}{c}\text { DEL (S/W) } \\
42.20 \\
1.30 \\
2.10 \\
3.30 \\
1.20 \\
7.50 \\
8.10 \\
2.60 \\
1.10 \\
2.90 \\
14.70 \\
2.90 \\
20.20 \\
25.90 \\
31.60\end{array}$ & $\begin{array}{l}\text { SPEED } \\
8.00 \\
38.00 \\
33.00 \\
21.00 \\
35.00 \\
32.00 \\
30.00 \\
38.10 \\
62.20 \\
35.00 \\
36.00 \\
39.90 \\
23.60 \\
14.80 \\
23.00\end{array}$ & $\begin{array}{c}\text { CUA TT HIN } \\
2.43 \\
2.93 \\
3.26 \\
3.64 \\
3.91 \\
4.74 \\
5.95 \\
6.26 \\
6.55 \\
6.78 \\
8.23 \\
8.76 \\
9.80 \\
11.02 \\
12.97\end{array}$ & Y24A \\
\hline $\begin{array}{l}\text { LIMK } \\
\text { RICH } \\
\text { ALPIHE } \\
\text { CROY } \\
\text { CONH } \\
\text { LF } \\
\text { EDEE } \\
\text { H. S } \\
\text { FAIRLAMH } \\
\text { CAL. SC } \\
\text { IROEUOUS } \\
\text { MAIT } \\
\text { BRONDVIEU } \\
\text { CLYOE } \\
\text { CHURCHILL } \\
\text { KIRK } \\
\text { TOTAL }\end{array}$ & $\begin{array}{r}\text { VEH KH } \\
77.11 \\
121.00 \\
71.87 \\
55.83 \\
70.87 \\
189.70 \\
267.07 \\
77.18 \\
65.53 \\
46.30 \\
279.40 \\
129.51 \\
144.29 \\
96.43 \\
240.79 \\
1932.88\end{array}$ & $\begin{array}{l}\text { VEH MIN } \\
565.80 \\
204.20 \\
133.40 \\
167.40 \\
119.60 \\
375.80 \\
555.80 \\
126.30 \\
92.10 \\
72.10 \\
485.10 \\
199.30 \\
403.30 \\
357.80 \\
629.80 \\
4490.80\end{array}$ & $\begin{array}{r}\text { Tr sEcs } \\
134.20 \\
32.10 \\
20.00 \\
23.40 \\
16.20 \\
52.30 \\
74.90 \\
19.60 \\
16.80 \\
13.10 \\
90.00 \\
33.00 \\
68.70 \\
66.70 \\
117.70 \\
778.70\end{array}$ & $\begin{array}{l}\text { DEL (S/V) } \\
38.50 \\
1.50 \\
2.30 \\
4.30 \\
1.50 \\
10.10 \\
8.40 \\
2.80 \\
1.00 \\
2.20 \\
17.30 \\
3.00 \\
20.80 \\
21.40 \\
27.00\end{array}$ & $\begin{array}{l}\text { SPEED } \\
8.00 \\
36.00 \\
32.00 \\
20.00 \\
36.00 \\
30.00 \\
29.00 \\
37.00 \\
43.00 \\
39.00 \\
34.00 \\
39.00 \\
22.00 \\
16.00 \\
23.00\end{array}$ & $\begin{array}{c}\text { CuH TT MIH } \\
2.24 \\
2.77 \\
3.11 \\
3.50 \\
3.77 \\
4.64 \\
5.89 \\
6.21 \\
6.49 \\
6.71 \\
8.21 \\
8.76 \\
9.91 \\
11.02 \\
12.98\end{array}$ & iA \\
\hline
\end{tabular}




\begin{tabular}{|c|c|c|c|c|c|c|c|}
\hline $\begin{array}{l}\text { LIUK } \\
\text { RICH } \\
\text { ALPINE } \\
\text { CROY } \\
\text { COWH } \\
\text { LF } \\
\text { EDGE } \\
\text { W. S } \\
\text { FAIRLALn } \\
\text { CAL. SC } \\
\text { IROOUOUS } \\
\text { MAIT } \\
\text { BROADUIEH } \\
\text { CLYOE } \\
\text { CHURCHILL } \\
\text { KIRK } \\
\text { TOTAL }\end{array}$ & $\begin{array}{r}\text { VEH KU } \\
73.15 \\
117.86 \\
70.97 \\
56.49 \\
71.03 \\
191.90 \\
252.06 \\
71.73 \\
65.53 \\
45.32 \\
289.72 \\
138.16 \\
147.57 \\
103.33 \\
228.04 \\
1922.84\end{array}$ & $\begin{array}{r}\text { VEH } \mu I N \\
593.90 \\
187.80 \\
123.30 \\
177.40 \\
126.40 \\
400.90 \\
505.90 \\
104.70 \\
91.80 \\
67.90 \\
502.50 \\
207.60 \\
428.10 \\
650.10 \\
599.80 \\
4568.10\end{array}$ & $\begin{array}{r}\text { Tr SECS } \\
148.50 \\
30.30 \\
18.80 \\
24.50 \\
17.10 \\
55.20 \\
72.30 \\
17.50 \\
16.70 \\
12.60 \\
89.50 \\
32.30 \\
71.30 \\
78.30 \\
118.40 \\
803.30\end{array}$ & $\begin{array}{c}\text { DEL }(5 / V) \\
43.90 \\
1.30 \\
2.30 \\
4.40 \\
1.60 \\
9.70 \\
8.90 \\
1.30 \\
1.10 \\
1.70 \\
17.20 \\
2.40 \\
25.40 \\
26.80 \\
28.60\end{array}$ & $\begin{array}{r}\text { SPEED } \\
7.00 \\
38.00 \\
35.00 \\
19.00 \\
36.00 \\
29.00 \\
30.00 \\
41.00 \\
43.00 \\
40.00 \\
35.00 \\
40.00 \\
21.00 \\
14.00 \\
23.00\end{array}$ & $\begin{array}{c}\text { CUH IT HIN } \\
2.48 \\
2.98 \\
3.29 \\
3.70 \\
3.99 \\
4.91 \\
6.11 \\
6.40 \\
6.68 \\
6.89 \\
8.38 \\
8.92 \\
10.11 \\
11.42 \\
13.39\end{array}$ & NV26A \\
\hline 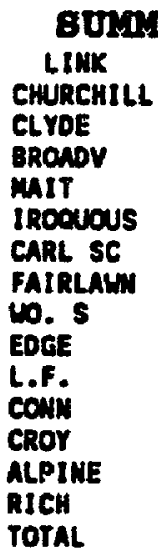 & $\begin{array}{l}\text { RRIBH } \\
\text { VEH } 10 \\
36.53 \\
27.87 \\
27.70 \\
51.57 \\
7.97 \\
12.17 \\
15.40 \\
44.61 \\
34.77 \\
13.28 \\
10.40 \\
13.31 \\
26.88 \\
322.26\end{array}$ & $\begin{array}{c}\text { BD WB } \\
\text { VEH NIN } \\
95.10 \\
84.60 \\
43.50 \\
64.60 \\
10.90 \\
24.80 \\
59.90 \\
64.80 \\
47.50 \\
23.60 \\
27.00 \\
19.50 \\
75.10 \\
640.90\end{array}$ & $\begin{array}{c}\text { CARLI } \\
\text { IT SECS } \\
46.80 \\
74.60 \\
33.90 \\
64.60 \\
11.40 \\
24.40 \\
46.70 \\
52.50 \\
36.10 \\
17.10 \\
20.20 \\
15.80 \\
53.60 \\
497.70\end{array}$ & $\begin{array}{l}\text { MC AVE } \\
\text { STOP S/V } \\
17.70 \\
29.60 \\
4.00 \\
6.40 \\
0.20 \\
7.90 \\
26.10 \\
7.10 \\
2.40 \\
4.00 \\
8.60 \\
1.10 \\
20.20\end{array}$ & $\begin{array}{l}\text { MOES } \\
\text { SPEED } \\
23.00 \\
19.80 \\
38.30 \\
48.00 \\
44.00 \\
30.00 \\
15.00 \\
41.00 \\
44.00 \\
34.00 \\
23.00 \\
41.00 \\
23.00\end{array}$ & NVOA & \\
\hline $\begin{array}{l}\text { LINK } \\
\text { CHuRCHILL } \\
\text { CLYOE } \\
\text { BRONDV } \\
\text { MAIT } \\
\text { IROOUOUS } \\
\text { CARL SC } \\
\text { FAIRLALI } \\
\text { Wo. S } \\
\text { EDGE } \\
\text { L.F. } \\
\text { CONH } \\
\text { CROY } \\
\text { ALPIME } \\
\text { RICH } \\
\text { TOTAL }\end{array}$ & $\begin{array}{l}\text { VEH KH } \\
35.33 \\
23.77 \\
26.62 \\
46.69 \\
6.71 \\
11.57 \\
16.60 \\
48.01 \\
35.65 \\
13.60 \\
10.66 \\
14.57 \\
28.68 \\
314.26\end{array}$ & $\begin{array}{c}\text { VEH MIU } \\
130.60 \\
53.60 \\
58.50 \\
59.50 \\
10.40 \\
33.50 \\
86.10 \\
69.00 \\
47.00 \\
26.20 \\
23.60 \\
20.30 \\
105.20 \\
723.50\end{array}$ & $\begin{array}{l}\text { TT SECS } \\
66.60 \\
55.30 \\
47.40 \\
68.60 \\
13.00 \\
34.70 \\
70.80 \\
51.80 \\
36.80 \\
18.50 \\
17.20 \\
15.00 \\
70.90 \\
564.40\end{array}$ & $\begin{array}{l}\text { STOP S/V } \\
7.20 \\
1.00 \\
16.50 \\
9.30 \\
0.80 \\
17.10 \\
44.90 \\
8.00 \\
3.10 \\
5.40 \\
6.60 \\
9.00 \\
38.10\end{array}$ & $\begin{array}{r}\text { SPEED } \\
16.00 \\
27.00 \\
27.00 \\
45.00 \\
39.00 \\
21.00 \\
10.00 \\
42.00 \\
41.00 \\
31.00 \\
27.00 \\
43.00 \\
16.00\end{array}$ & HV1A & \\
\hline $\begin{array}{l}\text { LIMK } \\
\text { CHURCHILL } \\
\text { CIYOE } \\
\text { BRONDY } \\
\text { MAIT } \\
\text { IROOUOUS } \\
\text { CARL SC } \\
\text { FAIRLALH } \\
\text { W. S } \\
\text { EDEE } \\
\text { L.F. } \\
\text { COUH } \\
\text { CROY } \\
\text { ALPINE } \\
\text { RICH } \\
\text { TOTAL }\end{array}$ & $\begin{array}{r}\text { VEH KU } \\
41.32 \\
28.69 \\
27.70 \\
49.84 \\
7.41 \\
12.97 \\
15.40 \\
48.01 \\
36.09 \\
14.56 \\
12.23 \\
16.74 \\
29.12 \\
340.08\end{array}$ & $\begin{array}{c}\text { VEH MIN } \\
120.90 \\
60.60 \\
67.50 \\
67.10 \\
11.10 \\
38.80 \\
102.60 \\
70.60 \\
67.10 \\
25.70 \\
26.70 \\
22.70 \\
103.20 \\
764.60\end{array}$ & $\begin{array}{c}\text { TT SECS } \\
52.60 \\
51.90 \\
52.60 \\
69.40 \\
13.00 \\
35.80 \\
79.90 \\
53.00 \\
34.50 \\
17.00 \\
17.00 \\
14.60 \\
68.10 \\
559.40\end{array}$ & $\begin{array}{c}\text { sToP } s / V \\
23.10 \\
15.90 \\
22.10 \\
8.60 \\
0.90 \\
16.10 \\
50.90 \\
8.20 \\
2.00 \\
4.00 \\
5.50 \\
0.70 \\
35.70\end{array}$ & $\begin{array}{r}\text { SPEED } \\
21.00 \\
28.00 \\
25.00 \\
45.00 \\
39.00 \\
20.00 \\
9.00 \\
41.00 \\
46.00 \\
34.00 \\
28.00 \\
44.00 \\
17.00\end{array}$ & WV2A & \\
\hline
\end{tabular}




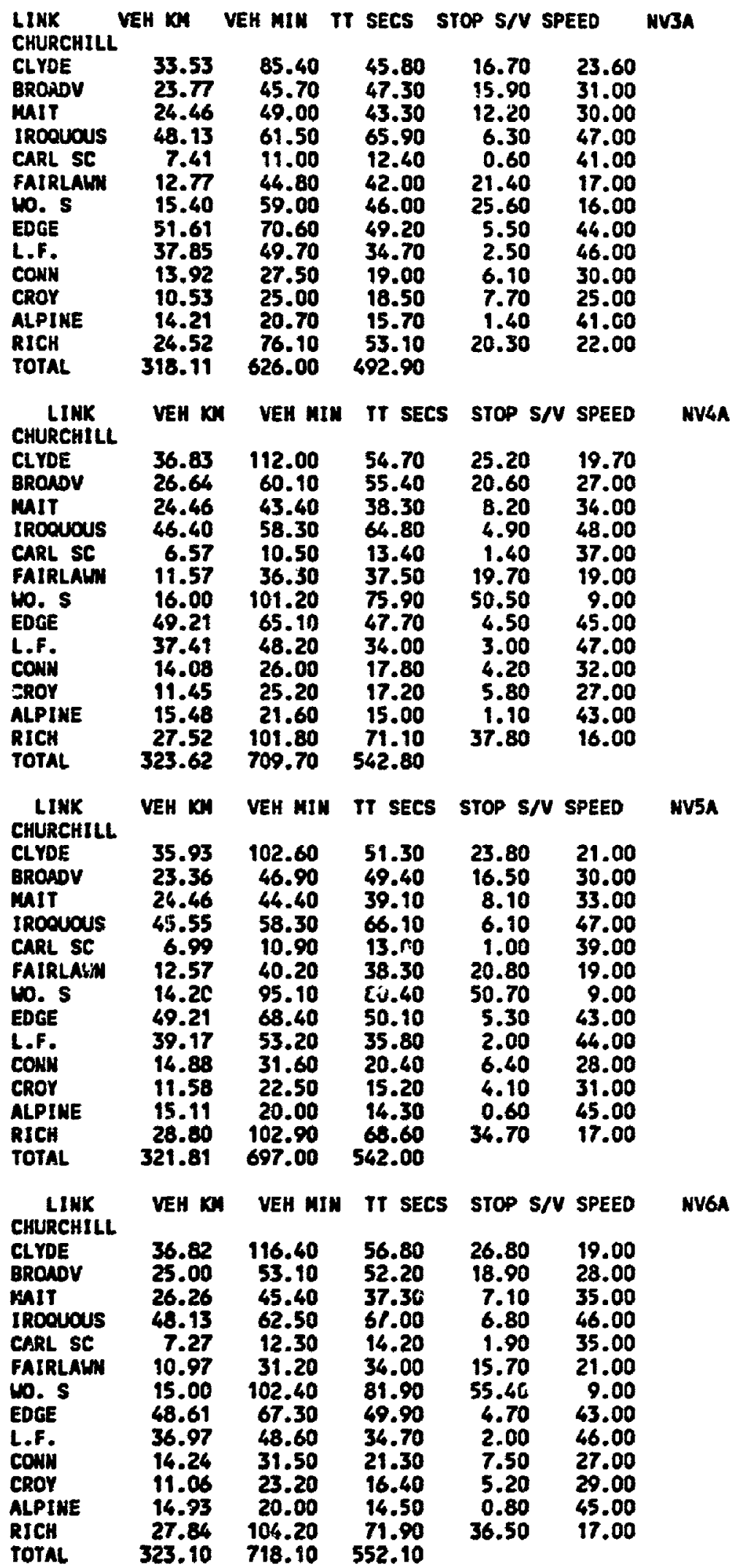




\begin{tabular}{|c|c|c|c|c|c|c|}
\hline 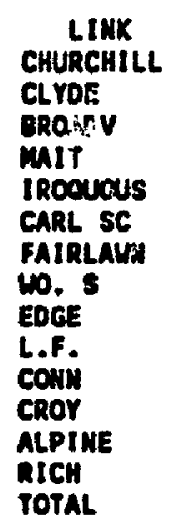 & $\begin{array}{r}\text { VEH KM } \\
35.93 \\
25.82 \\
26.46 \\
44.68 \\
6.71 \\
11.37 \\
16.20 \\
49.21 \\
36.53 \\
13.76 \\
10.79 \\
15.46 \\
28.80 \\
319.74\end{array}$ & $\begin{array}{c}\text { VEH MIN } \\
108.60 \\
65.00 \\
42.60 \\
57.90 \\
10.30 \\
35.50 \\
104.70 \\
68.00 \\
48.50 \\
27.90 \\
22.10 \\
21.30 \\
105.00 \\
717.40\end{array}$ & $\begin{array}{r}56.30 \\
61.90 \\
37.60 \\
66.80 \\
12.90 \\
37.40 \\
77.60 \\
69.80 \\
35.00 \\
19.50 \\
16.00 \\
14.80 \\
70.00 \\
553.60\end{array}$ & $\begin{array}{r}25.20 \\
26.80 \\
7.00 \\
7.10 \\
0.90 \\
19.00 \\
51.80 \\
5.50 \\
2.40 \\
5.00 \\
4.70 \\
1.00 \\
35.60\end{array}$ & $\begin{array}{r}20.00 \\
24.00 \\
34.00 \\
46.00 \\
39.00 \\
19.00 \\
9.30 \\
43.00 \\
45.00 \\
30.00 \\
29.00 \\
44.00 \\
17.00\end{array}$ & NV7A \\
\hline $\begin{array}{l}\text { LIMK } \\
\text { CHURCHILL } \\
\text { CLYDE } \\
\text { EROADY } \\
\text { HIT } \\
\text { IROANOUS } \\
\text { CARL SC } \\
\text { FAIRLAIM } \\
\text { Wo. S } \\
\text { EOGE } \\
\text { L.F. } \\
\text { COWH } \\
\text { ChOY } \\
\text { ALPINE } \\
\text { RICH } \\
\text { TOTAL }\end{array}$ & $\begin{array}{c}\text { VEH KN } \\
36.53 \\
25.00 \\
26.02 \\
47.27 \\
7.41 \\
13.17 \\
14.40 \\
69.21 \\
38.73 \\
16.26 \\
11.84 \\
15.84 \\
27.84 \\
328.10\end{array}$ & $\begin{array}{c}\text { VEH MIM } \\
101.30 \\
51.20 \\
47.20 \\
60.70 \\
10.70 \\
39.50 \\
94.30 \\
67.20 \\
55.40 \\
23.30 \\
24.90 \\
21.70 \\
99.20 \\
696.60\end{array}$ & $\begin{array}{l}\text { TT SECS } \\
49.80 \\
50.40 \\
38.20 \\
66.20 \\
12.90 \\
35.80 \\
78.50 \\
49.10 \\
37.80 \\
15.70 \\
16.40 \\
16.80 \\
68.40 \\
533.30\end{array}$ & $\begin{array}{c}\text { stop s/N } \\
21.60 \\
16.80 \\
7.20 \\
6.50 \\
0.40 \\
18.80 \\
50.30 \\
3.90 \\
3.00 \\
2.10 \\
5.20 \\
0.70 \\
31.90\end{array}$ & $\begin{array}{l}\text { SPEED } \\
22.00 \\
29.00 \\
34.00 \\
47.00 \\
42.00 \\
20.00 \\
9.00 \\
44.00 \\
42.00 \\
37.00 \\
29.00 \\
44.00 \\
17.00\end{array}$ & HV8A \\
\hline 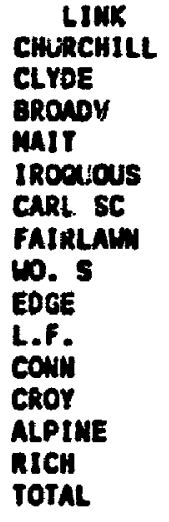 & $\begin{array}{l}\text { VEH XI } \\
39.83 \\
26.18 \\
26.26 \\
46.61 \\
6.85 \\
12.17 \\
14.60 \\
49.21 \\
38.73 \\
14.26 \\
11.19 \\
15.84 \\
29.12 \\
325.63\end{array}$ & $\begin{array}{l}\text { VEH MIN } \\
95.60 \\
51.80 \\
47.60 \\
59.80 \\
10.10 \\
42.40 \\
93.70 \\
70.10 \\
52.70 \\
26.90 \\
22.40 \\
21.20 \\
106.90 \\
701.00\end{array}$ & $\begin{array}{l}\text { TT SECS } \\
46.60 \\
52.70 \\
38.90 \\
66.50 \\
12.30 \\
41.70 \\
77.00 \\
51.30 \\
35.90 \\
18.10 \\
15.60 \\
14.40 \\
70.50 \\
541.50\end{array}$ & $\begin{array}{l}\text { stop s/V } \\
19.60 \\
18.40 \\
7.50 \\
6.40 \\
0.80 \\
23.60 \\
47.90 \\
5.50 \\
2.50 \\
4.80 \\
4.60 \\
0.70 \\
36.00\end{array}$ & $\begin{array}{r}\text { SPEED } \\
23.00 \\
28.00 \\
33.00 \\
47.00 \\
41.00 \\
17.00 \\
9.00 \\
42.00 \\
44.00 \\
32.00 \\
30.00 \\
45.00 \\
16.00\end{array}$ & MV9A \\
\hline 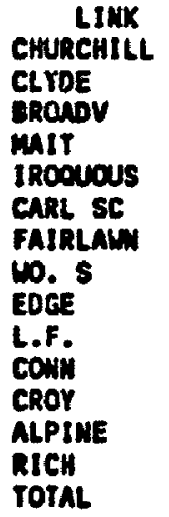 & $\begin{array}{c}\text { VEH KM } \\
38.33 \\
27.87 \\
26.82 \\
46.69 \\
6.85 \\
12.17 \\
15.80 \\
48.01 \\
36.09 \\
13.60 \\
10.92 \\
16.93 \\
27.52 \\
321.60\end{array}$ & $\begin{array}{r}125.30 \\
69.10 \\
44.80 \\
56.80 \\
10.20 \\
38.60 \\
100.40 \\
68.40 \\
67.50 \\
27.60 \\
22.60 \\
20.70 \\
104.60 \\
736.60\end{array}$ & $\begin{array}{l}\text { TI SECS } \\
58.70 \\
61.00 \\
38.90 \\
65.51 \\
12.53 \\
38.00 \\
76.30 \\
51.30 \\
34.80 \\
19.50 \\
16.20 \\
14.90 \\
73.00 \\
560.60\end{array}$ & $\begin{array}{r}27.60 \\
25.00 \\
8.10 \\
5.10 \\
0.90 \\
20.10 \\
48.30 \\
5.80 \\
2.10 \\
4.90 \\
4.40 \\
1.10 \\
37.80\end{array}$ & $\begin{array}{r}1 \text { SPEED } \\
18.00 \\
26.00 \\
33.00 \\
47.00 \\
40.00 \\
19.00 \\
9.00 \\
42.00 \\
46.00 \\
30.00 \\
29.00 \\
43.00 \\
16.00\end{array}$ & NVIOA \\
\hline
\end{tabular}




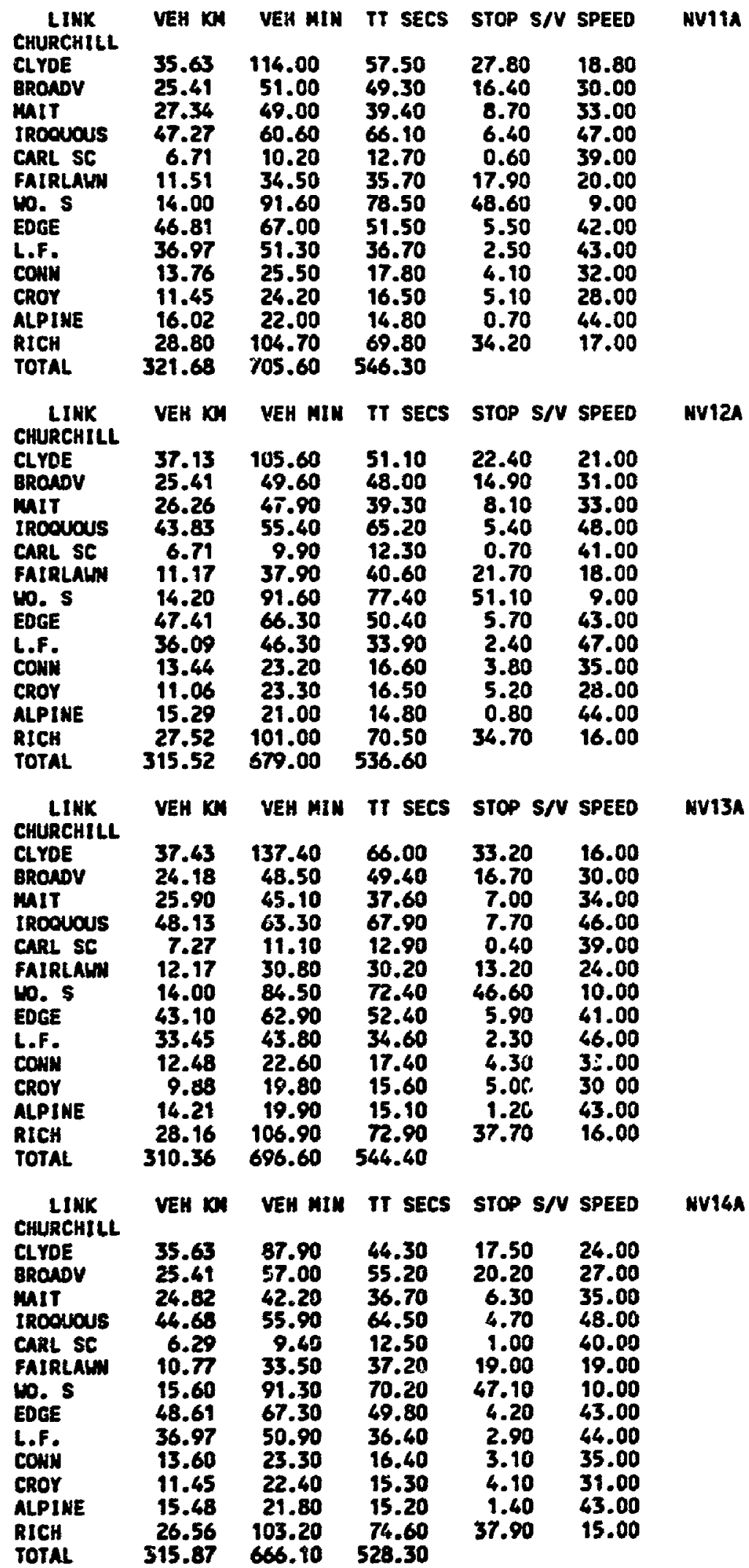




\begin{tabular}{|c|c|c|c|c|c|c|}
\hline 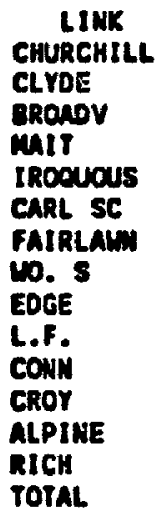 & $\begin{array}{c}\text { VEH KM } \\
39.23 \\
27.46 \\
25.18 \\
67.26 \\
6.71 \\
11.17 \\
15.60 \\
46.21 \\
36.09 \\
13.12 \\
10.92 \\
16.75 \\
27.52 \\
321.22\end{array}$ & $\begin{array}{r}119.10 \\
65.40 \\
44.50 \\
60.80 \\
11.40 \\
34.10 \\
99.50 \\
64.10 \\
48.40 \\
23.00 \\
22.20 \\
20.30 \\
102.90 \\
707.70\end{array}$ & $\begin{array}{r}56.50 \\
58.60 \\
38.20 \\
66.40 \\
16.20 \\
36.50 \\
70.40 \\
69.90 \\
35.40 \\
16.80 \\
15.80 \\
14.80 \\
71.80 \\
543.30\end{array}$ & $\begin{array}{r}24.80 \\
22.30 \\
7.30 \\
6.40 \\
2.00 \\
18.80 \\
48.90 \\
5.30 \\
2.90 \\
4.10 \\
4.30 \\
1.10 \\
36.90\end{array}$ & $\begin{array}{l}20.00 \\
25.00 \\
34.00 \\
47.00 \\
35.00 \\
20.00 \\
10.00 \\
43.00 \\
45.00 \\
34.00 \\
30.00 \\
44.00 \\
16.00\end{array}$ & NV15A \\
\hline $\begin{array}{l}\text { LIUK } \\
\text { CHURCHILL } \\
\text { CLYOE } \\
\text { GRONDY } \\
\text { MIT } \\
\text { IROOUOUS } \\
\text { CARL SE } \\
\text { FAIRLALIN } \\
\text { Wo. } \mathbf{S} \\
\text { EOGE } \\
\text { L.F. } \\
\text { COUI } \\
\text { CROY } \\
\text { ALPINE } \\
\text { RICH } \\
\text { TOTAL }\end{array}$ & $\begin{array}{r}\text { VEH KA } \\
37.43 \\
27.05 \\
24.46 \\
47.26 \\
7.27 \\
11.97 \\
15.00 \\
42.61 \\
33.01 \\
12.16 \\
9.88 \\
14.03 \\
25.60 \\
307.73\end{array}$ & $\begin{array}{c}\text { VEH NIH } \\
100.10 \\
64.20 \\
61.70 \\
59.00 \\
11.00 \\
36.00 \\
91.30 \\
59.10 \\
43.10 \\
21.60 \\
19.60 \\
19.40 \\
93.40 \\
659.50\end{array}$ & $\begin{array}{l}\text { TT SECS } \\
48.00 \\
58.30 \\
36.60 \\
64.10 \\
12.70 \\
36.00 \\
73.00 \\
50.00 \\
34.50 \\
17.00 \\
15.50 \\
14.90 \\
70.10 \\
531.00\end{array}$ & $\begin{array}{l}\text { stop s/V } \\
20.00 \\
22.80 \\
6.60 \\
5.20 \\
0.70 \\
18.10 \\
46.50 \\
4.80 \\
2.10 \\
4.00 \\
4.00 \\
1.10 \\
37.70\end{array}$ & $\begin{array}{l}\text { SPEEO } \\
22.00 \\
25.00 \\
35.00 \\
48.00 \\
40.00 \\
20.00 \\
10.00 \\
43.00 \\
46.00 \\
34.00 \\
30.00 \\
44.00 \\
16.00\end{array}$ & NV16A \\
\hline \begin{tabular}{l}
\multicolumn{1}{c}{ LINK } \\
CHURCHILL \\
CLYOE \\
BROADY \\
WAIT \\
IROOUCOUS \\
CARL SE \\
FAIRLALM \\
WO. S \\
EDGE \\
L.F. \\
CONH \\
CROY \\
ALPINE \\
RICH \\
TOTAL
\end{tabular} & $\begin{array}{c}\text { VEH XY } \\
35.33 \\
25.61 \\
25.90 \\
49.85 \\
7.83 \\
13.17 \\
16.80 \\
47.61 \\
35.65 \\
13.60 \\
10.79 \\
14.03 \\
27.52 \\
323.29\end{array}$ & $\begin{array}{c}\text { VEH MIN } \\
93.30 \\
51.60 \\
46.00 \\
65.40 \\
11.90 \\
43.70 \\
114.20 \\
69.90 \\
47.20 \\
24.00 \\
22.40 \\
19.40 \\
100.00 \\
708.40\end{array}$ & $\begin{array}{l}\text { TT SECS } \\
47.40 \\
49.30 \\
38.30 \\
67.70 \\
12.80 \\
39.70 \\
81.50 \\
53.10 \\
35.00 \\
16.90 \\
16.20 \\
14.90 \\
69.70 \\
542.50\end{array}$ & $\begin{array}{l}\text { stop s/V } \\
20.10 \\
16.40 \\
8.00 \\
8.10 \\
0.90 \\
21.60 \\
52.40 \\
6.60 \\
2.20 \\
3.50 \\
5.00 \\
0.80 \\
34.00\end{array}$ & $\begin{array}{l}\text { SPEEO } \\
22.70 \\
30.00 \\
34.00 \\
46.00 \\
39.00 \\
18.00 \\
9.00 \\
41.00 \\
45.00 \\
36.00 \\
29.00 \\
43.00 \\
17.00\end{array}$ & HV17 \\
\hline $\begin{array}{l}\text { LIHK } \\
\text { CHURCHILL } \\
\text { CLYOE } \\
\text { BROADV } \\
\text { MAIT } \\
\text { IROOUOUS } \\
\text { CARL SC } \\
\text { FAIRLALH } \\
\text { Wo. } 5 \\
\text { EDGE } \\
\text { L.F. } \\
\text { CONH } \\
\text { CROY } \\
\text { ALPINE } \\
\text { RICH } \\
\text { TOTAL }\end{array}$ & $\begin{array}{r}\text { VEH } \mathrm{WI} \\
36.53 \\
23.77 \\
25.90 \\
51.57 \\
7.55 \\
12.57 \\
15.40 \\
61.41 \\
32.13 \\
12.16 \\
9.88 \\
16.21 \\
28.48 \\
311.56\end{array}$ & $\begin{array}{c}\text { VEH NIN } \\
127.70 \\
62.50 \\
46.60 \\
71.70 \\
12.80 \\
36.10 \\
95.10 \\
59.70 \\
43.50 \\
22.90 \\
20.30 \\
19.50 \\
106.50 \\
704.90\end{array}$ & $\begin{array}{l}\text { TT SECS } \\
62.80 \\
43.90 \\
38.80 \\
71.70 \\
16.20 \\
36.30 \\
74.10 \\
51.90 \\
35.80 \\
18.10 \\
16.00 \\
14.80 \\
71.80 \\
548.20\end{array}$ & $\begin{array}{c}\text { STOP } s / Y \\
30.60 \\
12.60 \\
8.00 \\
10.80 \\
1.60 \\
16.00 \\
44.60 \\
6.00 \\
2.80 \\
4.70 \\
5.60 \\
1.10 \\
37.10\end{array}$ & $\begin{array}{l}\text { SPEED } \\
17.20 \\
34.00 \\
33.00 \\
43.00 \\
36.00 \\
21.00 \\
10.00 \\
42.00 \\
44.00 \\
32.00 \\
29.00 \\
44.00 \\
16.00\end{array}$ & NVI8n \\
\hline
\end{tabular}




\begin{tabular}{|c|c|c|c|c|c|c|}
\hline $\begin{array}{l}\quad \text { LINK } \\
\text { CHURCHILL } \\
\text { CLYDE } \\
\text { BROADV } \\
\text { MAIT } \\
\text { IROOUOUS } \\
\text { CARL SC } \\
\text { FAIRLALA } \\
\text { WO. } \mathbf{S} \\
\text { EOGE } \\
\text { L.f. } \\
\text { CONH } \\
\text { CROY } \\
\text { ALPIAE } \\
\text { RICH } \\
\text { TOTAL }\end{array}$ & $\begin{array}{r}\text { VEH KH } \\
36.73 \\
25.82 \\
27.70 \\
54.15 \\
7.97 \\
12.57 \\
16.40 \\
43.21 \\
32.13 \\
12.16 \\
9.75 \\
16.57 \\
28.46 \\
319.64\end{array}$ & $\begin{array}{l}\text { VEH MIM } \\
80.60 \\
49.80 \\
47.80 \\
74.80 \\
13.50 \\
39.30 \\
108.30 \\
63.30 \\
42.90 \\
23.40 \\
19.80 \\
19.80 \\
106.30 \\
689.60\end{array}$ & $\begin{array}{l}\text { TT SECS } \\
41.70 \\
47.40 \\
37.20 \\
71.20 \\
14.20 \\
37.50 \\
79.30 \\
52.80 \\
35.20 \\
18.50 \\
15.80 \\
16.60 \\
71.60 \\
537.00\end{array}$ & $\begin{array}{r}15.30 \\
14.30 \\
6.50 \\
10.00 \\
1.40 \\
18.20 \\
47.90 \\
6.80 \\
3.00 \\
5.10 \\
4.90 \\
0.80 \\
36.60\end{array}$ & $\begin{array}{r}25.80 \\
31.00 \\
35.00 \\
43.00 \\
35.00 \\
19.00 \\
9.00 \\
41.00 \\
45.00 \\
31.00 \\
30.00 \\
44.00 \\
16.00\end{array}$ & WVI9A \\
\hline $\begin{array}{l}\quad \text { LINK } \\
\text { CHURCHILL } \\
\text { CLYDE } \\
\text { BROADV } \\
\text { MAIT } \\
\text { IROOUOUS } \\
\text { CARL SE } \\
\text { FATRLALI } \\
\text { WO. } 5 \\
\text { EDGE } \\
\text { L.F. } \\
\text { COHU } \\
\text { CROY } \\
\text { ALPINE } \\
\text { RICH } \\
\text { TOTAL }\end{array}$ & $\begin{array}{c}\text { VEH XI } \\
35.93 \\
22.13 \\
25.54 \\
45.55 \\
6.99 \\
12.57 \\
15.80 \\
44.41 \\
34.77 \\
13.12 \\
10.27 \\
14.57 \\
27.84 \\
309.49\end{array}$ & $\begin{array}{c}\text { VEH MIU } \\
102.30 \\
42.60 \\
60.40 \\
64.20 \\
11.80 \\
36.40 \\
88.50 \\
64.90 \\
46.90 \\
28.30 \\
21.80 \\
20.60 \\
103.40 \\
692.10\end{array}$ & $\begin{array}{l}\text { IT SECS } \\
51.10 \\
47.40 \\
51.10 \\
72.70 \\
14.20 \\
34.70 \\
67.20 \\
52.60 \\
35.60 \\
20.70 \\
16.60 \\
15.30 \\
71.30 \\
550.50\end{array}$ & $\begin{array}{c}\text { sTop s/V } \\
22.60 \\
14.80 \\
18.80 \\
12.00 \\
1.70 \\
17.20 \\
44.10 \\
7.00 \\
2.10 \\
6.70 \\
5.60 \\
1.10 \\
35.50\end{array}$ & $\begin{array}{l}21.10 \\
31.00 \\
25.00 \\
43.00 \\
36.00 \\
21.00 \\
11.00 \\
41.00 \\
45.00 \\
28.00 \\
28.00 \\
42.00 \\
16.00\end{array}$ & HV20A \\
\hline $\begin{array}{l}\quad \text { LINK } \\
\text { CHURCHILL } \\
\text { CLYDE } \\
\text { BROADY } \\
\text { MAIT } \\
\text { IROOUOUS } \\
\text { CARL SC } \\
\text { FAIRLANA } \\
\text { WO. S } \\
\text { EDGE } \\
\text { L.F. } \\
\text { CONH } \\
\text { CROY } \\
\text { ALPINE } \\
\text { RICH } \\
\text { TOTAL }\end{array}$ & $\begin{array}{r}\text { VEH KH } \\
36.53 \\
27.46 \\
27.70 \\
50.70 \\
7.13 \\
12.17 \\
16.20 \\
42.01 \\
32.13 \\
12.00 \\
9.88 \\
13.67 \\
25.28 \\
312.86\end{array}$ & $\begin{array}{c}\text { VEH KIN } \\
95.50 \\
51.40 \\
49.40 \\
66.70 \\
11.20 \\
39.6 n \\
84.90 \\
57.50 \\
43.20 \\
23.40 \\
19.70 \\
19.30 \\
94.30 \\
656.10\end{array}$ & $\begin{array}{l}\text { IT SECS } \\
47.00 \\
46.00 \\
38.40 \\
67.90 \\
13.20 \\
38.90 \\
62.90 \\
49.30 \\
35.50 \\
18.70 \\
15.50 \\
15.20 \\
71.60 \\
520.10\end{array}$ & $\begin{array}{r}18.70 \\
14.40 \\
8.20 \\
7.50 \\
1.50 \\
20.40 \\
39.80 \\
5.00 \\
3.10 \\
4.90 \\
4.10 \\
1.20 \\
39.10\end{array}$ & $\begin{array}{r}\text { SPEEO } \\
23.00 \\
32.00 \\
36.00 \\
46.00 \\
38.00 \\
19.00 \\
11.00 \\
44.00 \\
45.00 \\
31.00 \\
30.00 \\
43.00 \\
16.00\end{array}$ & wV21A \\
\hline $\begin{array}{l}\quad \text { LIMK } \\
\text { CHURCHILL } \\
\text { CLYOE } \\
\text { BRONOV } \\
\text { MAT } \\
\text { IROOUOUS } \\
\text { CARL SE } \\
\text { FAIRLAIN } \\
\text { W. S } \\
\text { EOCE } \\
\text { L.F. } \\
\text { CONI } \\
\text { CROY } \\
\text { ALPINE } \\
\text { RICH } \\
\text { TOTAL }\end{array}$ & $\begin{array}{r}\text { VEH } 1 \mathrm{r} \\
35.93 \\
26.18 \\
26.26 \\
51.57 \\
7.69 \\
12.97 \\
16.00 \\
45.61 \\
35.65 \\
13.12 \\
10.79 \\
15.48 \\
20.16 \\
323.41\end{array}$ & $\begin{array}{l}\text { VEH MIN } \\
99.10 \\
47.20 \\
45.90 \\
68.30 \\
12.00 \\
40.60 \\
72.70 \\
65.60 \\
48.60 \\
23.90 \\
50.30 \\
30.10 \\
122.70 \\
727.00\end{array}$ & $\begin{array}{r}49.50 \\
48.00 \\
37.70 \\
68.30 \\
17.10 \\
37.50 \\
54.50 \\
51.80 \\
36.00 \\
17.50 \\
36.40 \\
21.00 \\
83.70 \\
555.00\end{array}$ & $\begin{array}{r}21.50 \\
15.10 \\
6.90 \\
8.10 \\
1.10 \\
19.30 \\
32.40 \\
6.00 \\
2.10 \\
3.60 \\
22.00 \\
4.50 \\
47.30\end{array}$ & $\begin{array}{l}22.00 \\
31.00 \\
36.00 \\
45.00 \\
39.00 \\
19.00 \\
13.00 \\
42.00 \\
44.00 \\
33.00 \\
13.00 \\
31.00 \\
14.00\end{array}$ & NV22A \\
\hline
\end{tabular}




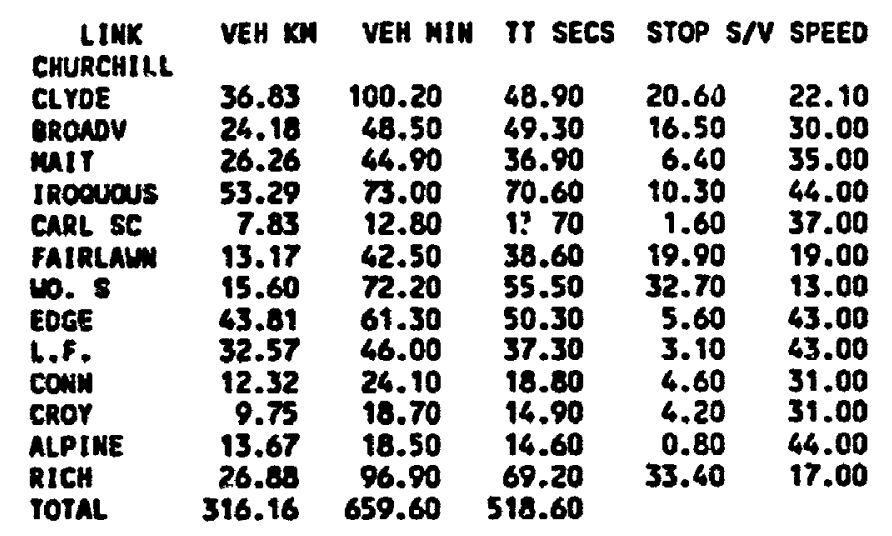

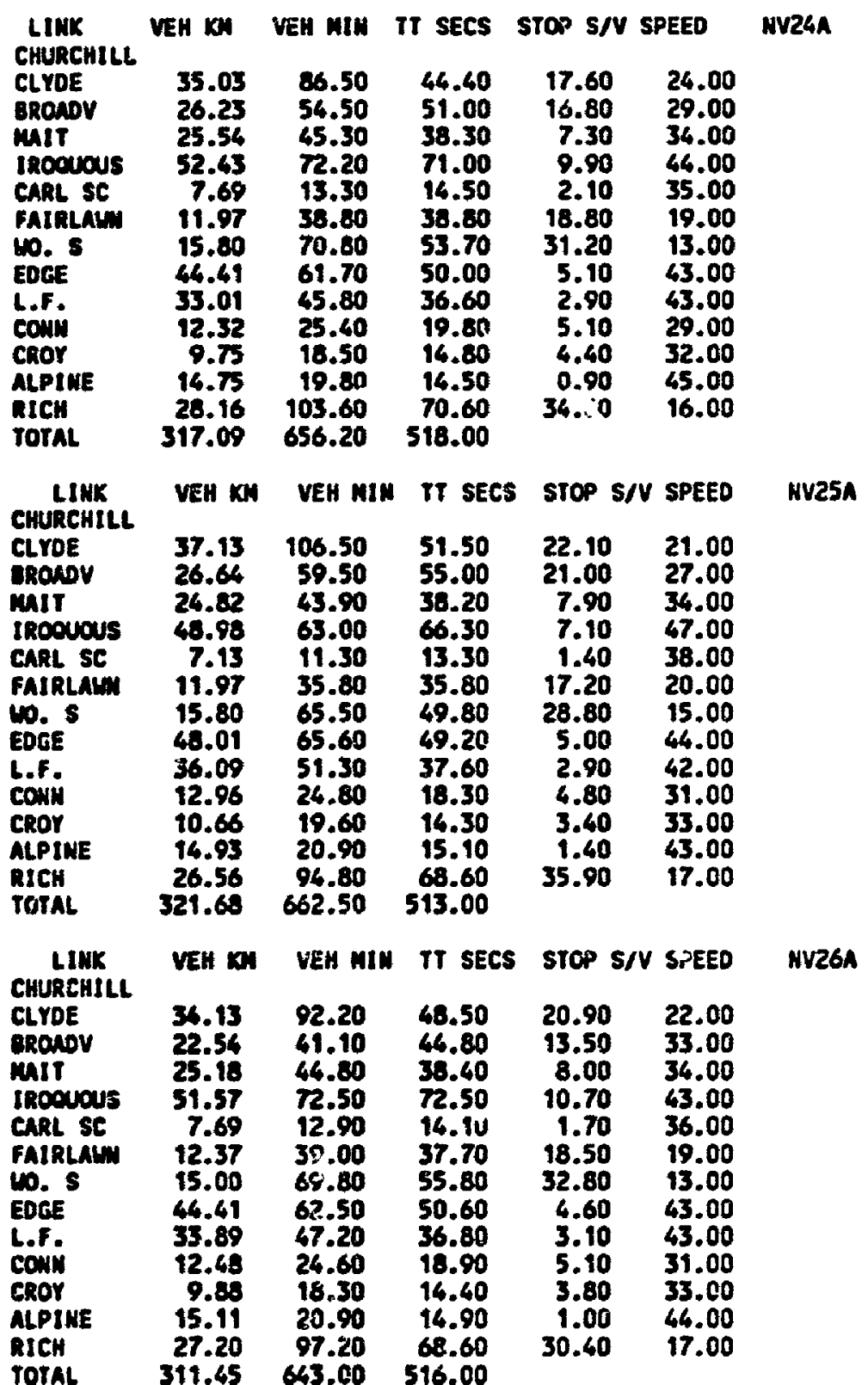




\section{BABTBOUND QUEENGWAY AND EASTBOUND CORRIDOR PERFORLANCE MEABUREB}

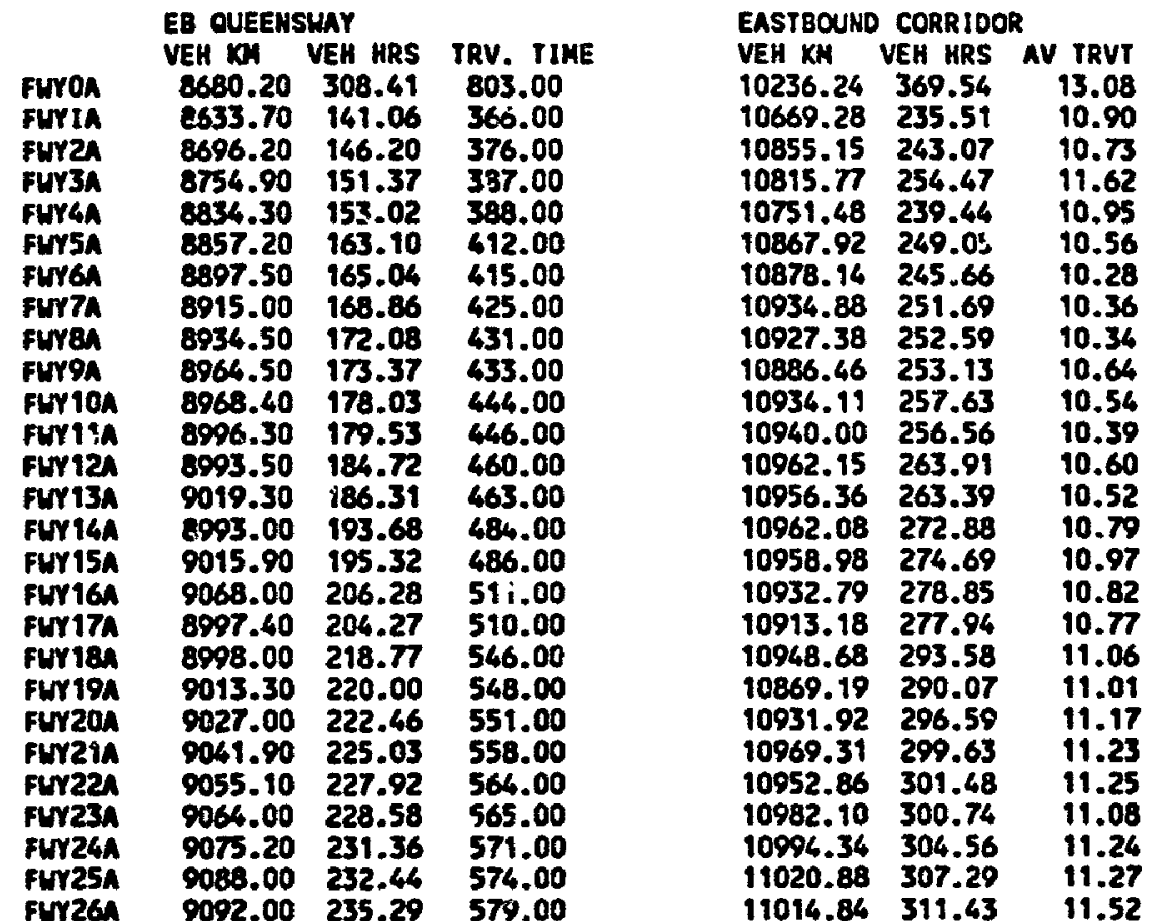

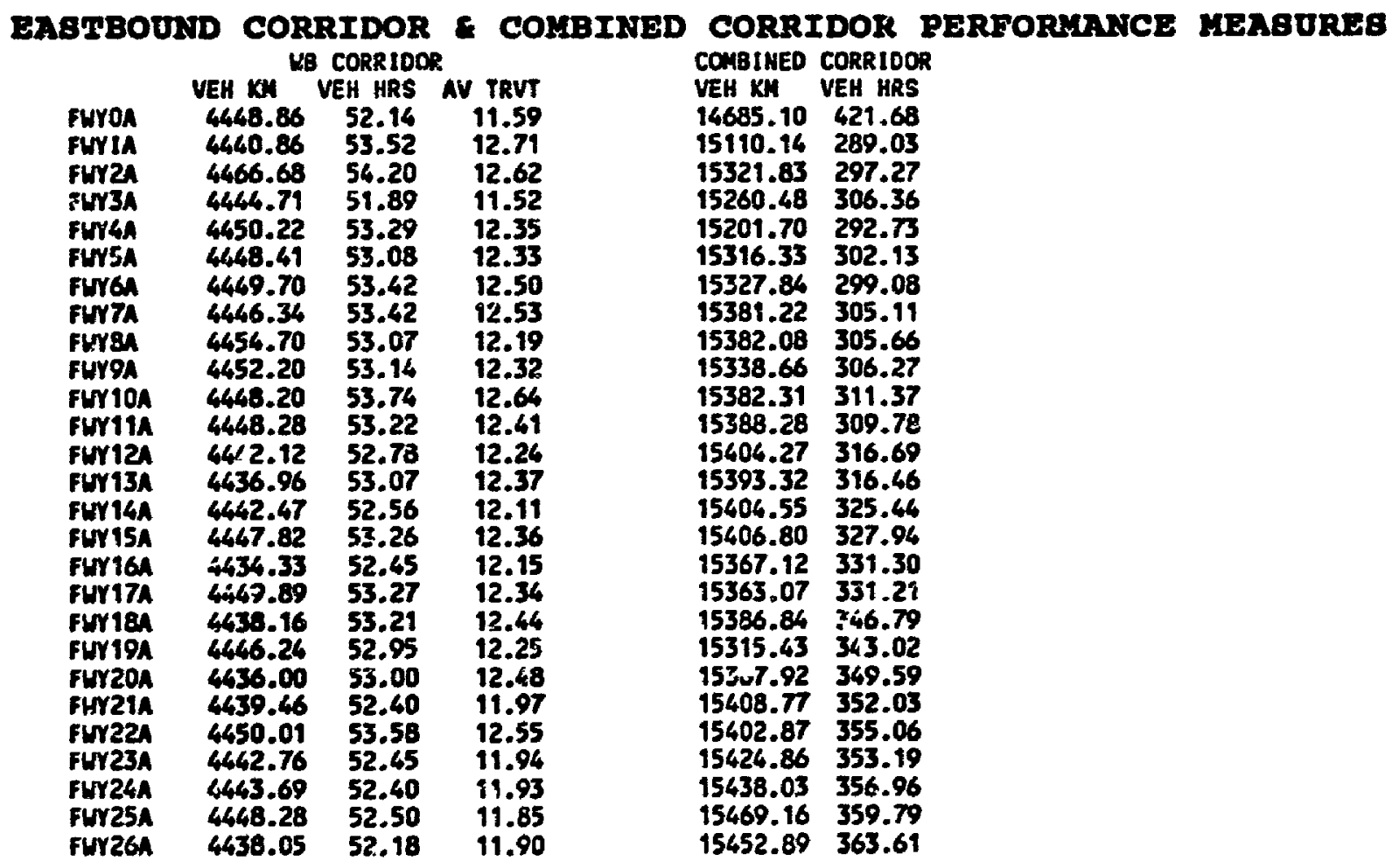




\begin{tabular}{|c|c|c|c|c|c|c|c|c|}
\hline \multicolumn{2}{|c|}{ AVBRRGE } & METgRTSG & \multicolumn{2}{|c|}{ RATHS } & \multicolumn{2}{|c|}{ METERING } & \multicolumn{2}{|c|}{ PTANS } \\
\hline $\begin{array}{c}\text { SImULATION } \\
\text { RUM }\end{array}$ & $\begin{array}{l}\text { PINE } \\
8402 \\
101\end{array}$ & $\begin{array}{c}\text { PINE } \\
\text { 8403 } \\
\text { t02 }\end{array}$ & $\begin{array}{r}10 \\
8405 \\
201\end{array}$ & $\begin{array}{r}10 \\
8406 \\
202\end{array}$ & $\begin{array}{c}\text { MAIT } \\
8408 \\
301\end{array}$ & $\begin{array}{c}\text { KIRK } \\
8410 \\
401\end{array}$ & $\begin{array}{c}\text { KIRK } \\
8411 \\
402\end{array}$ & $\begin{array}{l}\text { AVERACE } \\
\text { METERING } \\
\text { RATE }\end{array}$ \\
\hline 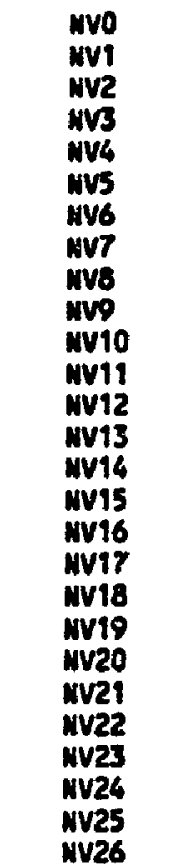 & $\begin{array}{l}345 \\
345 \\
345 \\
345 \\
345 \\
345 \\
345 \\
345 \\
345 \\
345 \\
345 \\
345 \\
345 \\
345 \\
345 \\
345 \\
345 \\
345 \\
345 \\
345 \\
345 \\
345 \\
345 \\
345 \\
345 \\
345 \\
345\end{array}$ & $\begin{array}{r}1148 \\
778 \\
808 \\
\mathbf{0 3 8} \\
868 \\
898 \\
900 \\
900 \\
900 \\
900 \\
900 \\
900 \\
900 \\
900 \\
900 \\
900 \\
900 \\
900 \\
900 \\
900 \\
900 \\
900 \\
900 \\
900 \\
900 \\
900 \\
900\end{array}$ & $\begin{array}{l}220 \\
390 \\
195 \\
200 \\
205 \\
210 \\
215 \\
220 \\
220 \\
220 \\
220 \\
220 \\
220 \\
220 \\
220 \\
220 \\
220 \\
220 \\
220 \\
220 \\
220 \\
220 \\
220 \\
220 \\
220 \\
220 \\
220\end{array}$ & $\begin{array}{r}1092 \\
190 \\
215 \\
240 \\
265 \\
290 \\
315 \\
340 \\
370 \\
400 \\
430 \\
460 \\
490 \\
520 \\
550 \\
580 \\
610 \\
640 \\
670 \\
700 \\
730 \\
760 \\
790 \\
810 \\
840 \\
870 \\
900\end{array}$ & $\begin{array}{l}692 \\
190 \\
220 \\
250 \\
280 \\
310 \\
340 \\
370 \\
400 \\
430 \\
460 \\
490 \\
520 \\
550 \\
580 \\
610 \\
640 \\
670 \\
692 \\
692 \\
692 \\
692 \\
692 \\
692 \\
692 \\
692 \\
692\end{array}$ & $\begin{array}{l}826 \\
800 \\
800 \\
800 \\
800 \\
800 \\
800 \\
800 \\
800 \\
800 \\
800 \\
800 \\
800 \\
800 \\
800 \\
800 \\
800 \\
800 \\
800 \\
800 \\
800 \\
800 \\
800 \\
800 \\
800 \\
800 \\
800\end{array}$ & $\begin{array}{l}244 \\
244 \\
244 \\
2444 \\
244 \\
244 \\
244 \\
244 \\
244 \\
244 \\
244 \\
244 \\
246 \\
244 \\
244 \\
244 \\
244 \\
246 \\
244 \\
264 \\
244 \\
246 \\
244 \\
244 \\
246 \\
244 \\
244\end{array}$ & $\begin{array}{l}430 \\
448 \\
466 \\
484 \\
502 \\
514 \\
526 \\
5388 \\
550 \\
562 \\
574 \\
586 \\
598 \\
610 \\
622 \\
634 \\
646 \\
656 \\
662 \\
668 \\
674 \\
680 \\
684 \\
690 \\
696 \\
702\end{array}$ \\
\hline
\end{tabular}



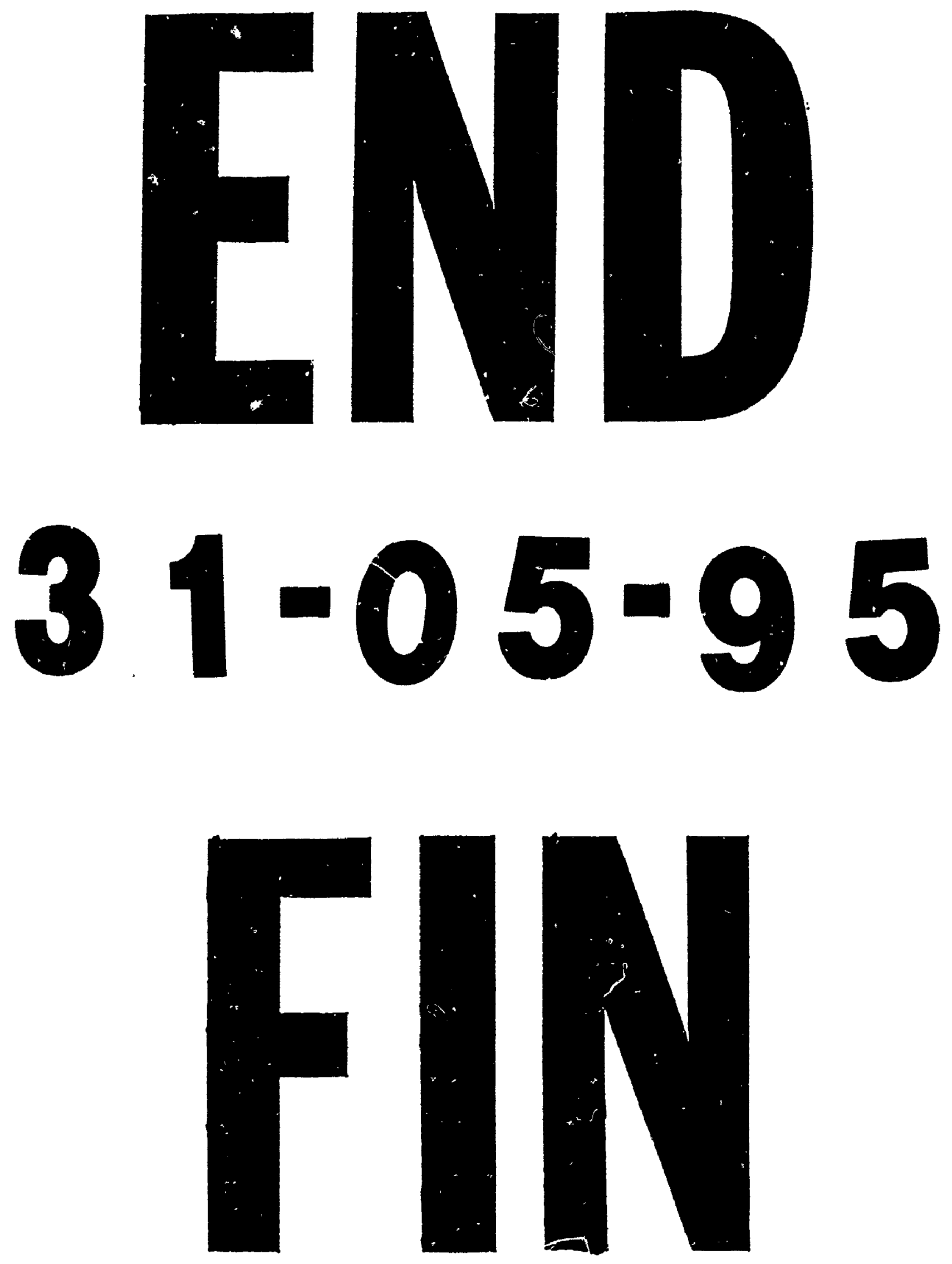